\title{
DER LÜBECKER BÜRGERMEISTER JOHAN WITTENBORCH, HINGERICHTET 1363
}

\author{
ÜBER LEBEN UND TOD, GESCHÄFTSMORAL UND AMTSETHOS EINES \\ HANSISCHEN KAUFMANNS UND RATSHERRN IM ZEITALTER VON \\ SCHWARZEM TOD UND STÄDTISCHEN KRIEGEN GEGEN \\ Waldemar AtTerdag. AuCh EIN Beitrag ZUR GeSCHICHTE DER \\ POLITIK UND DES KREDITS IM „HAUPT DER HANSESTÄDTE“
}

von Gerald Stefke

\section{Zur Einführung}

Das Thema „Johan Wittenborch" hat mich etwa drei Jahrzehnte lang beschäftigt. Herrn Johans „Handlungsbuch“ hatte ich erstmals 1977 durchgearbeitet. Das war zunächst wegen der im „Buch“ enthaltenen geldgeschichtlichen Informationen geschehen. Davon sind viele in eine 1983 erschienene Darstellung der Lübecker Währungsverhältnisse um 1350 eingegangen; damals war auch schon, eher am Rande, über Johan Wittenborchs Geschäftsmoral zu sprechen. Beim Lesen des „Handlungsbuchs“ hatte ich natürlich auch die Texte entdeckt, die es erlauben, über Herrn Johans Amtsethos begründete Aussagen zu machen. Dies Material wäre mit einer Miszelle vergeudet gewesen. Seitdem hätte es zwar wiederholt Gelegenheit gegeben, einen längeren Aufsatz über Johan Wittenborch zu veröffentlichen; aber die Zeit, ihn zu schreiben, hat sich nie finden wollen - das Thema liegt ja am Rande meiner bisherigen Publikationsschwerpunkte. Meinem Nachlass wollte ich die Vorarbeiten aber doch nicht überantworten. Daher bin ich den Organisatoren des „Mittelalterkreises“ der Universität Hamburg, den Herren Nikolaus Henkel und Jürgen Sarnows$k y$, besonders dankbar dafür, dass sie meinem Vorschlag zugestimmt haben, im Wintersemester 2007/08 vor dem Kreis über das Thema zu sprechen. Der Vortrag hat am 19. Dezember 2007 stattgefunden, und aus dem Vortragsmanuskript ist dann das Manuskript des folgenden Beitrags erwachsen. Darin ist ein Sachbereich mit voller Absicht nicht behandelt: Johan Wittenborchs Warenhandel. Das Thema, für dessen Erörterung es 
bisher nicht viele Vorarbeiten gibt, hätte den Rahmen eines Zeitschriftenaufsatzes völlig gesprengt. Es würde wohl überhaupt besser im Zusammenhang einer umfassenden Geschichte des hansischen Handels um die Mitte des 14. Jahrhunderts diskutiert; das Thema harrt schon seit mehr als einem Jahrhundert einer kompetenten Bearbeitung. Ich danke Rolf Hammel-Kiesow als Redakteur und den übrigen Mitgliedern des HGV-Vorstands dafür, dass mein Beitrag trotz seines großen Umfangs so schnell in den Druck kommen konnte. - In der Form der Personennamen bin ich dem Muster gefolgt, das Ahasver VON BRANDT entwickelt und in seinen "Regesten der Lübecker Bürgertestamente" erstmals praktisch angewandt hat. Ich gebrauche also die zeitgenössische niederdeutsche Gestalt von Tauf- und Zweitnamen, wie sie sich den volkssprachlichen Quellen der Zeit um 1350 schon zahlreich entnehmen oder behutsam rekonstruieren lässt, in einer normalisierten Form. Bei den Taufnamen läuft das bisher großenteils nur darauf hinaus, den lateinischen oder latinisierten Formen die Endung zu nehmen. Der weitere Schritt, bei einigen Namen die wirklich belegten volkssprachlichen Formen zu verwenden, also etwa „Bernard" durch „Ber(e)nt" oder „Herman“ durch „Hermen“ zu ersetzen, ist noch nicht getan worden, und da um 1350/60 noch kaum zu ermitteln ist, was allgemein üblich war, konnte ich mich auch nicht dazu entschließen. Der beschriebene Gebrauch hat sich in der Literatur der letzten Jahrzehnte über Lübecker Themen des 13. bis 15. Jahrhunderts weitestgehend durchgesetzt. Er findet sich insbesondere auch in dem neuen Ratmannenverzeichnis von LUTTERBECK (siehe unten Anm. 1). Von dessen Schreibweise bin ich in zwei Punkten abgewichen: Wenn in den Quellen mehrere Formen konkurrieren, habe ich die der heutigen Orthographie nächste gewählt: „Pleskow“, nicht „Plescow(e)“; außerdem lasse ich das „,h“ hinter „g" und „t" immer weg, schreibe also „Segebode“, nicht „Seghebode" und „Tideman“, nicht „Thideman“. - Abkürzungen für Einheiten der Geldrechnung: $\mathrm{ml}$. = Mark lübisch(er Pfennige) zu 16 Schilling à 12 Pfennig. Die Recheneinheit steht in Lübeck um 1350/60 für zwei verschiedene Währungseinheiten: $\mathrm{ml}$. ohne weitere Erläuterung, gelegentlich aber auch ausdrücklich als in auro oder ähnlich bezeichnet, bedeutet das - damals in der Stadt allgemein übliche - Geld (pagimentum Lubicense), dessen Münzbasis der in diesem Kontext 10 Schilling geltende Lübecker Gulden (meist aureus Lubicensis genannt) bildet. Mit ml. argenteorum denariorum oder an sulveren penningen wird die traditionelle Währungseinheit bezeichnet, deren Münzbasis 192 lübische Silberpfennige (und seit 1365 auch 48 silberne „Witten") sind. ma = marca argenti ist eine traditionelle Recheneinheit im Lübecker Wert von $2 \mathrm{ml}$. Mit der (Gewichts-)Mark Silber hat sie um 1350 längst nichts mehr zu tun; es gibt sogar Indizien von 1357 und 
1358 dafür, dass der Ausdruck auch für 2 „Goldmark" verwendet wurde. Andere Geldbezeichnungen werden ausgeschrieben und, wenn nötig, erklärt.

\section{Inhalt}

1. Herr Johan Wittenborch als erfolgloser Heerführer und seine Hinrichtung in der Chronistik, in den hansischen Akten des Jahres 1363 und in der Darstellung von Wilhelm Mantels $(1872 / 1881)$

2. Das Wittenborch'sche „Handlungsbuch“, Carl Mollwos Edition (1901) und die Folgen

3. Der Mann Johan Wittenborch: Vorfahren und Verwandte, Lebensgeschichte, Karriere im Lübecker Rat

4. Johan Wittenborchs „Mentalität“: „Maß“, Geldgier und konventionelle Religiosität

5. Herrn Johan Wittenborchs Amtsethos: Der „Kirchenstiefvater“ von St. Jakobi und seine Hinterbliebenen

6. Herrn Johan Wittenborchs Verfehlungen und die Herrschaftslegitimation des Lübecker oligarchischen Ratsregiments. Die Verwaltung der Kirchenvermögen als Konfliktfeld zwischen Bürgeropposition und Rat

7. „Großzügiger“ Umgang mit fremden und öffentlichen Mitteln in der Sicht der Zeit

8. Die Hinrichtung von diskreditierten Ratmannen durch den Rat als Technik der Herrschaftssicherung?

9. Johan Wittenborch - ein typischer Lübecker Kaufmann und Ratmann seiner Zeit?

10. Herr Johan Wittenborch als Provisor der Jakobikirche in der geschichtswissenschaftlichen Literatur des 20. Jahrhunderts

11. „Parteien“ im Rat? Die Protagonisten der Lübecker „Außen“- und Hansepolitik von 1358 bis zur Kölner Konföderation von 1367

12. Register der Personen- und Ortsnamen

13. Stellenregister zu Mollwos „Handlungsbuch“-Edition 
1. Herr Johan Wittenborch als erfolgloser Heerführer und seine Hinrichtung in der Chronistik, in den hansischen Akten des Jahres 1363 und in der Darstellung von Wilhelm Mantels (1872/1881)

Der Lübecker Bürgermeister Johan Wittenborch,' ein erfolgloser städtischer Kommandeur im ersten Städtekrieg gegen König Waldemar Atterdag von Dänemark, gehört zu den populärsten Gestalten der Hansegeschichte. An Popularität steht er wohl nur hinter „Klaus Störtebeker“ zurück. Dessen Vorsprung ist allerdings gewaltig. Das war freilich nicht immer so. Dass Störtebekers Volkstümlichkeit heute von keiner anderen historischen oder quasihistorischen Gestalt der Hansezeit auch nur annähernd mehr erreicht werden kann, liegt vor allem daran, dass in den letzten 10 bis 15 Jahren aus den zahlreichen kleinen lokalen und regionalen Prielen seiner Legende eine gewaltige, mindestens ganz Norddeutschland unter Wasser setzende Flut geworden ist. Dieser Legendenflut ${ }^{2}$ kann natürlich auch die banale Tatsache nichts anhaben, dass für die Existenz eines führenden Vitalienbruders namens Klaus Störtebeker um 1400 und dessen Hinrichtung in Hamburg keinerlei zeitgenössische Indizien angeführt werden können ${ }^{3}$ - der einzige Gewährsmann für diese Annahmen ist der etwa zwei bis vier Jahrzehnte später, hauptsächlich wohl in Lübeck, schreibende Dominikaner Herman Korner, ${ }^{4}$ der nicht gerade in dem Verdacht steht. durch das Problem des Verhältnisses zwischen der Geschichtsschreibung

\footnotetext{
${ }^{1}$ Nr. 366 (S. 7 und 36) bei E. F. FEHLING, Lübeckische Ratslinie von den Anfängen der Stadt bis auf die Gegenwart (Veröff. zur Geschichte der Freien und Hansestadt Lübeck 7, 1), Lübeck 1925, weiterhin zitiert als FEHLING, und Nr. 301 (S. 437-439) in dem neuen, bis zu den 1396 gewählten Ratmannen reichenden, alphabetisch geordneten Ratsmitglieder-Verzeichnis bei Michael LUTTERBECK, Der Rat der Stadt Lübeck im 13. und 14. Jahrhundert. Politische, personale und wirtschaftliche Zusammenhänge in einer städtischen Führungsgruppe (Veröff. zur Geschichte der Hansestadt Lübeck B 35), Lübeck 2002, weiterhin zitiert als LUTTERBECK. Das Verzeichnis hat. trotz mancher Mängel im Detail. der Beschäftigung mit den behandelten Mitgliedern des Rats eine gänzlich veränderte Grundlage geschaffen. Die Artikel haben die entsprechenden Artikel bei FEHLING (einem Notbehelf von Anfang an) fast überall so völlig überholt. dass diese nicht mehr erwähnt zu werden brauchen. es sei denn aus forschungsgeschichtlichen Gründen oder wegen irgendeiner Detailangabe. Das stelle ich hier um so lieber fest. als meine Freude über LUTTERBECKS auswertenden Teil, in dem pseudostatistische Verfahren eine allzu große Rolle spielen, sich in engen Grenzen hält.

${ }^{2}$ Über die älteren Phasen schon ziemlich ausführlich Matthias PUHLE, Die Vitalienbrüder. Klaus Störtebeker und die Seeräuber der Hansezeit. Frankfurt/New York 1992. S. 159-177 und öfter.

'Gerald STEFKE, Besprechung zu PuHLE, Vitalienbrüder (wie Anm. 2), in ZVHG 81, 1995. S. 241-244, hier S. 243 f.

"Über ihn zuletzt zusammenfassend Katharina KolBERG, „Korner (Corner. Koerner). Hermann OP", in: Die deutsche Literatur des Mittelalters. Verfasserlexikon. 2. Auflage, Bd. 5, Berlin, New York 1985, Sp. 317- 320. und Antjekathrin GrassmanN, „Korner, Hermann", in: Biographisches Lexikon für Schleswig-Holstein und Lübeck Bd. 12, Neumünster 2006. S. 269-271.
} 
und ihren Gegenständen um seinen guten Nachtschlaf gebracht worden zu sein. ${ }^{5}$ Korner hat zwar seine „Chronica novella" ${ }^{\text {"6 }}$ wiederholt überarbeitet; aber die Resultate genießen nicht den Ruf, wachsende Annäherung an die geschichtliche Realität, wie sie aus zeitgenössischen Quellen erschlossen werden kann, auch nur anzustreben. ${ }^{7}$

Herr Johan Wittenborch verdankt seinen „Nachruhm“ zunächst der Tatsache, dass er als Kommandeur der städtischen Streitmacht in der Öresundregion im 1. Waldemarskrieg des Jahres 1362 die Verantwortung für eine schwere Niederlage der Städte zu tragen hatte. Ein erst 1969 bekannt gewordenes Schreiben vom 28. Juni des Jahres, das von dem Ereignis berichtet und versucht, die Verantwortung dafür auf eine Flottille von Schiffen aus Kampen abzuladen, ${ }^{8}$ dürfte als früher Rechtfertigungsversuch aus seinem Umfeld zu werten sein. ${ }^{9}$ Bei dem Vorfall hatte es zwar anscheinend kaum Tote und Verletzte gegeben, aber zwölf coggones waren von den Dänen weggenommen worden, und es waren auch erhebliche Verluste an Kriegsmaterial und Gefangenen eingetreten; unter diesen hatte sich das gesamte, 40 Mann starke Kontingent der Stadt Kiel befunden. Die Aufbringung der Folgekosten und die anteilige Entschädigung der einzelnen Städte hat sich noch über die großen militärischen und politischen Erfolge des 2. Waldemarskriegs und des Stralsunder Friedens hinaus erstreckt. ${ }^{10}$ Irgendwann zwischen dem Spätsommer 1362 und dem Beginn des nächsten Jahres hat der Lübecker Rat dann seinen Bürgermeister in

${ }^{5}$ Diese Sätze waren geschrieben und am 19. Dezember 2007 vorgetragen, als bei mir mit dem nunmehr vorletzten Band dieser Zeitschrift einging: Gregor ROHMANN, Der Kaperfahrer Johann Stortebeker aus Danzig. Beobachtungen zur Geschichte der „Vitalienbrüder“, in: HGBII. 125, 2007, S. 77-1 19. In seinem „Fazit" (S. 117) bemerkt der Verfasser (der, nach seinem Apparat zu urteilen, meine in Anm. 3 zitierte Rezension nie gelesen hat): „Die Namensangabe ,Klaus Störtebeker" ist ... eine arbiträre Zugabe der Chronistik. Ebenso erst Produkt der späteren Geschichtsschreibung ist die Behauptung, .Störtebeker' sei im Jahr 1400 bzw. 1401 in Hamburg hingerichtet worden“. Tandem bona causa triumphat !

${ }^{6}$ Die Chronica Novella des Hermann KoRnER, hg. von Jakob SCHWALM, Göttingen 1895.

${ }^{7}$ Dieser schlechte Ruf ist allerdings anscheinend nicht überall gut begründet, siehe dazu unten mit Anm. 38.

${ }^{8}$ Diplomatarium Danicum (weiterhin: Dipl. Dan.) 3, 6, Nr. 185 (S. 167f.).

${ }^{9}$ Auf das Stück hat Ahasver VON BRANDT in seiner Besprechung des Bandes, HGBll. 88. 1970, S. 344, hingewiesen, und Jochen Götze, Von Greifswald bis Stralsund. Die Auseinandersetzungen der deutschen Seestädte und ihrer Verbündeten mit König Valdemar von Dänemark 1361 - 1370, in: HGB11. 88, 1970, S. 83-122, hier S. 88 mit Anm. 22a, hat es in die Geschichte des Kriegsverlaufs eingeordnet. Beide Autoren haben sich aber nur mit der Bedeutung des Briefs für die Chronologie der Ereignisse befasst. Der Verlust der Schiffe hätte danach etwa in der „Zeit vom 15. bis 20. Juni“" stattgefunden, während Dietrich SCHÄFER. Die Hansestädte und König Waldemar von Dänemark. Hansische Geschichte bis 1376. Jena 1879, S. 313, in seiner grundlegenden Behandlung der Vorgänge „etwa Mitte Juli“ angenommen hatte.

${ }^{11}$ Rezess des Stralsunder Hansetags vom 27. Oktober 1371, Hanserecesse (weiterhin: HR) I, 2, Nr. $18, \S 20$ (S. 32f.), erläutert S. $27 \mathrm{f}$. 
Haft genommen. Diese endete noch 1363 mit Wittenborchs Tod. Von Klaus Störtebeker unterscheidet sich Johan Wittenborch in einem nicht unwesentlichen Punkt: An seiner Historizität ist kein Zweifel möglich; seine Existenz ist durch eine große Zahl von Nachrichten in Urkunden und Akten bezeugt, die praktisch gleichzeitig mit den dokumentierten Sachverhalten niedergeschrieben worden sind. Aber die beiden haben dennoch neben der Popularität ein Zweites gemeinsam: Die Ansicht, dass Johan Wittenborch hingerichtet worden ist, beruht ebenfalls nur auf chronikalischer Überlieferung. Und vor allem, weil er hingerichtet worden sein soll, kommt Johan Wittenborch in so gut wie jeder Darstellung der Hansegeschichte vor, mag sie auch noch so knapp sein. Wie die Erwähnung aussieht, das hängt - jedenfalls seit 1872 und erst recht seit 1901 - auch davon $a b$, wie vertraut der betreffende Autor mit den Quellen und der seriösen Spezialliteratur ist; schon allein darüber ließe sich mancherlei recht Aufschlussreiches berichten, was hier aber entschieden zu weit führen würde.

Auch über Johan Wittenborchs Hinrichtung berichtet Korner, dazu gleich mehr. Außerdem gibt es eine solche Nachricht aber in einer ereignisnah geschriebenen dänischen Chronik und in der Bremer RinesberchSchene-Hemeling-Chronik, einer Kompilation der Zeit um 1400. Diese beiden erzählenden Quellen überbieten Korner noch darin, dass sie Wittenborch auf dem Lübecker Markt sterben lassen, ${ }^{11}$ also mit der größtmöglichen Publizität. Der dänische Bericht steht im jüngsten Abschnitt eines anonym überlieferten Werks, das als „Fortsetzung der Seeländischen Chronik 1308-1363“ bezeichnet wird. ${ }^{12}$ Für die Jahre seit 1340 gilt das

"Siehe dazu bereits Wilhelm MANTELS, Die hansischen Schiffshauptleute Johann Wittenborg. Brun Warendorp und Tidemann Steen (1872), in: DERS., Beiträge zur lübisch-hansischen Geschichte. Ausgewählte historische Arbeiten. [Hg. von K. KOPPMANN], Jena 1881, S. 179-229. hier S. 192f., der das .,Sachentsprechend“ fand und als Kenner der Lübecker Topographiegeschichte noch ergänzte: „wenn das fünf Jahre vorher abgebrannte Rathaus schon wieder stand, vor den offenen Lauben desselben".

${ }^{12}$ Editio princeps für den Schlussteil, ab ,.(1357)“: [Johann Martin] LAPPENBERG, Dänische Annalen, ein Nachtrag zu Langebek Scriptores rerum Danicarum. In: Archiv für Staatsund Kirchengeschichte der Herzogthümer Schleswig. Holstein. Lauenburg und der angrenzenden Länder und Städte Bd. 2. 1834, S. 187-252, hier S. 214-226: ..Annales Danorum et praecipue Sialandorum ab anno 1308 usque ad annum 1363“ (die hier interessierenden Stellen S. 226). Jetzt maßgeblicher Druck: Annales Danici medii aevi, editionem novam curavit Ellen JøRGENSEN, København 1920. S. 188; bei HAMMEL 1982 (wie unten Anm. 69). S. 305. ist die Stelle unter „Quellen“ angeführt. In der älteren deutschen Literatur wird die Quelle zeitweilig „Annalium Ryensium continuatio“ (KOPPMANN in HR I. 1, S. 199) bzw. „Annalen von Ruhekloster“ (MANTEls a.a.O. S. 187 u. 192) genannt. was anscheinend auf ihre Behandlung bei Rudolf USINGER, Die dänischen Annalen und Chroniken des Mittelalters, Hannover 1861, S. 96 zurückgeht. Schon Dietrich SCHÄFER, Dänische Annalen und Chroniken von der Mitte des 13. bis zum Ende des 15. Jahrhunderts, mit Berücksichtigung ihres Verhältnisses zu schwedischen und deutschen Geschichtswerken kritisch untersucht. Hannover 
Werk als die wichtigste berichtende Quelle zur Geschichte des Dänenkönigs Waldemar Atterdag, ${ }^{13}$ die letzte Herausgeberin hat von einem ,gleichzeitigen Bericht von hohem Rang" gesprochen. ${ }^{14}$ Allerdings bezieht sich dies, genau betrachtet, nur auf den Autor, der den Zeitraum ,c. 1343 1358" dargestellt hat; nur ihm sind die besonderen Zeitgeschichtsschreiber-Qualitäten eines „nüchternen, kritischen Beobachters“ mit breitem Interessenspektrum ohne erkennbaren Schwerpunkt in kirchlichen Dingen nachgesagt worden, dessen Latein den Geistlichen nicht erkennen lässt, wenn er denn einer war. ${ }^{15}$ Allgemein wird angenommen, dass mit dem Jahr 1358 ein Verfasserwechsel eingetreten ist ${ }^{16}$. Der neue Autor ist schon durch seine Sprache mit ihren deutlichen Anklängen an Formulierungen der Vulgata zweifelsfrei als Geistlicher erkennbar; die Erzählung hat eher „,zurückschauenden Charakter“"17 und jedenfalls keine Merkmale, die lobend hervorzuheben wären. Die fortlaufende Darstellung reicht gerade bis in Johan Wittenborchs Todesjahr, allerdings nur bis zur Mitte des Jahres, ${ }^{18}$ also nicht bis zum Zeitpunkt seines Todes, der nach dem 15. August und vor dem 21. September eingetreten ist. ${ }^{19}$ Die Todesnachricht steht denn auch nicht unter den Ereignissen des Jahres 1363, wo sie ja die jüngste Nachricht gewesen wäre, sondern in der Berichterstattung über den Krieg des Jahres 1362 und sein vorläufiges Ende. ${ }^{20}$ Diese Berichterstattung ist aber bereits in zwei Punkten als fehlerhaft erwiesen worden: Dass Graf Heinrich von Holstein (von den Städten) zum Hauptmann gemacht wor-

1872, S. 61f. hielt das für nicht begründet: er hat S. 60-71 das Werk unter seinem eingeführten Namen „Continuatio Chronici Danorum et praecipue Sialandiae ab anno 1308 usque ad annum $1363^{\text {" }}$ behandelt.

${ }^{13}$ Dies nach Herluf NIELSEN, „Sjælandske krønike“, Kulturhistorisk Leksikon for Nordisk Middelalder 15 (1970), Sp. 325f. (mit der Forschungsliteratur bis 1969).

't JøRGENSEN, Annales (wie Anm. 12) S. 31.

${ }^{15}$ Ellen JøRGENSEN, Historieforskning og Historieskrivning i Danmark indtil aar 1800. København 1931, S. 16. Die Autorin hat nicht gesagt. warum sie ihn dennoch für einen Geistlichen hielt. Umgekehrt wollte Erik ARUP. Danmarks Historie. 2. Stænderne i Herrevælde 1282-1624. København 1932, S. 106 (vgl. S. 147), in dem Verfasser einen hochadligen Anhänger von König Waldemar sehen. Bo Falk zu Vallø (vgl. S. 103); mit dieser Meinung scheint er allerdings alleingestanden zu haben.

${ }^{16}$ Bereits Dietrich SCHÄFER, Annalen (wie Anm. 12), S. 64, berief sich für diese Ansicht auf die ältere dänische und deutsche Forschung (SUHM; USINGER) und hielt dies auch selbst für "sicher".

${ }^{17}$ JØRGENSEN, Historieforskning (wie Anm. 15), S. 16.

${ }^{18}$ Das letzte Ereignis, von dem die Chronik berichtet. ist der Tod von König Waldemars Sohn Christopher (am 11. Juni, siehe KOPPMANN in HR I, 1, S. 199 mit Anm. 2, und SCHÄFER, Annalen, wie Anm. 12, S. 64) und seine Bestattung im Dom zu Roskilde.

${ }^{19}$ Siehe HAMMEL 1982 (wie unten Anm. 69), S. 303 (zur Quellenbasis unten Anm. 289).

${ }^{20} \mathrm{Da}$ die Stelle, so weit ich sehe, noch nie eingehend diskutiert worden ist (obwohl die Quelle schon seit 1834 an einer für die ältere norddeutsche Forschung gut zugänglichen Stelle gedruckt vorlag, siehe oben Anm. 12), wird eine etwas ausführlichere Behandlung der Sache hier gewiss erlaubt sein. 
den wäre, ist nicht richtig; er gehörte vielmehr zum militärischen Gefolge der Könige von Schweden und Norwegen. ${ }^{21}$ Ebenso falsch ist die Behauptung, der König habe den Städten am Ende alle ihre Schiffe weggenommen; tatsächlich waren es, wie gesagt, nur zwölf. ${ }^{22}$ Die Chronik fährt danach fort: ,Schließlich ist ein Waffenstillstand abgeschlossen worden, und jene große Menge ist in Unordnung in das Vaterland zurückgegangen". Hier hat offenbar eine Übertreibung die nächste nach sich gezogen; denn wenn die städtischen Truppen wirklich gar keine Schiffe mehr gehabt hätten, dann könnte man sich ihren Rückzug (zu Fuß und zu Pferde über die dänischen Inseln und dann durch Jütland!?) wohl wirklich nur als ungeordnet vorstellen. Der Bericht würde mit dem Satz schließen: „Und so hat der Waffenstillstand ein ganzes Jahr und noch länger bestanden“, 23 wenn nicht zwischen den beiden zitierten Sätzen im überlieferten Text noch der Satz stünde: „Aber ihr Hauptmann, der [Bürgermeister] ${ }^{24}$ der Stadt Lübeck Johannes Hvittenburgh [!], ist, weil er weder die Burg [Helsingborg] zerstören noch Dänemark für sie unterwerfen konnte, in der Stadt Lübeck auf dem Marktplatz vor dem Rathaus öffentlich enthauptet worden". Offenkundig haben wir es hier mit einem späteren Einschub zu tun, der allerfrühestens etwa drei bis vier Monate später als der Grundtext entstanden sein kann, aber natürlich auch erst mehrere Jahre oder gar Jahrzehnte später eingefügt worden sein mag. ${ }^{25}$ In der Tendenz passt der

\footnotetext{
${ }^{21}$ KOPPMANN in HR I, 1, S. $199 \mathrm{f}$.

${ }^{22}$ Von „Übertreibung“ sprachen bereits KOPPMANN in HR I, 1, S. 199, und SCHÄFER, Hansestädte (wie Anm. 9), S. 316.

${ }^{23}$ was, wenn es im Hochsommer 1363 geschrieben wurde, mit unserem heutigen Wissensstand übereinstimmen würde. Das oben mit Anm. 8 u. 9 besprochene Schreiben vom 28 . Juni 1362 weiß noch nichts von einem Waffenstillstand. Er wird aber nicht sehr lange danach abgeschlossen werden sein.

${ }_{24}$ "proconsul“" in der Edition von der Herausgeberin ergänzt.

${ }^{25}$ Da es für den Text keine mittelalterliche Handschriftengrundlage mehr gibt (siehe dazu JØRGENSEN, Annales, wie Anm. 12, S. 29f.), könnte prinzipiell nicht einmal ausgeschlossen werden, dass der Zusatz von einem Autor des 16. Jh.s stammt. Die auffällige Schreibung des Zweitnamens mit "Hv" $\mathrm{H}^{* i}$ statt "W", also in dänischer Orthographie, bietet keinen Anhalt für die Datierung der Einfügung, da die Schreibung ,hv" bzw. „hw" für „w" im Anlaut bereits in den ältesten dänischen Texten belegt ist (für die freundliche Auskunft danke ich Herrn Dr. Ludger Zeevaert, Skandinavisten am SFB 538 der Universität Hamburg); so treffen wir etwa in einer seeländischen Urkunde von 1364 die Zweitnamen Hwittensee und Hwit an: Dipl. Dan. 3. 7. Nr. 137 (S. 157). Unabhängig vom Datierungsproblem stellt sich aber die Frage, wie man es sich überhaupt zu denken hat, dass ein niederdeutscher Zweitname in derart veränderter Form in einen latcinischen Text, sei es auch dänischen Ursprungs, gelangt ist. Ich möchte vermuten, dass so etwas in Texten, die für ein gebildetes (begrenzt fremdsprachenkundiges) Publikum gedacht sind, überhaupt schwer erklärbar ist, wenn in der aufnehmenden Sprache dasselbe Alphabet benutzt wird wie in der abgebenden. So steht bei dem um 1600 schreibenden dänischen Adligen Arild HVITFELDT (über ihn etwa JøRGENSEN, Historieforskning, wie Anm. 15, S. 106-116 u. passim) .Johan Wittenborg" (Arrild HuIDTFELD, Den anden Part Chronologiae ..., Kiøbenhaffn 1601, Neudruck unter dem Titel Arild HurTFELDT,
} 
Zusatz allerdings sehr gut zum Grundtext; auch hier geht es offenbar darum, „dick aufzutragen“, um den Misserfolg der Städte als katastrophal erscheinen zu lassen. Unter diesen Umständen versteht es sich fast von selbst, dass ein solcher Text, von dem wir nicht einmal sagen können, ob hinter ihm überhaupt eigenes Wissen eines Zeitgenossen steht, nicht als glaubwürdiges Zeugnis für die genauen Umstände in Betracht kommt, unter denen Herr Johan Wittenborch in Lübeck zu Tode gekommen ist.

In der Bremer Chronik heißt es: Für den Verlust von 11 [so !] ausgerüsteten Koggen machte man verantwortlich hern Johanne Wittenberge [!], borgermestere to Lubeke, darumme houwen se eme aff dat hovet uppe deme markede to Lubeke. Der Ursprung dieser Nachricht ist ebenfalls völlig ungewiss; ${ }^{26}$ wenn wir sie nicht geradezu als stark gekürzte Übersetzung der eben diskutierten dänischen ansprechen wollen, stehen wir

Danmarks Riges Krønike, Chronologia II. Fra Erik Menved til Valdemar Atterdag, 1601, København 1977, S. 558; die Darstellung der Ereignisse von 1362/63 geht letztendlich auf Korner zurück), und dieser Autor hat sogar seinen eigenen Namen in lateinischem Kontext „Arnoldus Wittfelld“ geschrieben (JøRGENSEN a.a.O. S. 110, Anm. 1). Wenn diese Vermutung zutrifft, kann kaum der Däne. der den Chroniktext um den Zusatz erweitert hat, für die dänische Namensform verantwortlich sein, es sei denn. er hätte den Namen nach Gehör geschrieben. Danach möchte ich weiter vermuten, dass die Vorlage dieses Dänen entweder eine mündliche Erzählung oder ein dänischer populär-schriftlicher Text gewesen ist. Um die Reimchronik des späten 15. Jh.s aus dem Kloster Sorø (JøRGENSEN a.a.O. S. 56-59 und Thorkil Damsgaard OLSEN, „Rimkrønike. Den danske“, Kulturhistorisk Leksikon for Nordisk Middelalder 14 (1969), Sp. 299-303) kann es sich aber nicht gehandelt haben, da diese Herrn Johan gar nicht erwähnt. Alles weitere muss ich anderen zu klären überlassen, die sich in der älteren dänischen Sprach- und Literaturgeschichte besser auskennen als ich.

${ }^{26}$ Die Chroniken der niedersächsischen Städte. Bremen (Die Chroniken der deutschen Städte vom 14. bis ins 16. Jahrhundert 37), Bremen 1968, S. 145. Die Behandlung der Waldemarskriege des Jahrzehnts $1361 / 62$ bis $1369 / 70$ (ebd. $\$ 477$, S. 144f.), in deren Mitte der zitierte Satz steht, kennt nur einen Krieg. den ersten, obwohl auch einige wenige „den zweiten Krieg betreffende Informationselemente in die Darstellung hinein(gemengt) " sind (Karl H. SCHWEBEL, Der Stralsunder Friede (1370) im Spiegel der historischen Literatur. Eine Übersicht, Jahrbuch der Wittheit zu Bremen 14. Bremen 1970, S. 50). Die einzige auch uns noch bekannte Quelle für diesen Text (ihr folgt etwas mehr als die Hälfte des Kapitels) ist ein Dokument von 1361 im Bremer Ratsarchiv, dessen Standort in der trezekameren ausdrücklich angegeben wird. Daher hat Hermann MEINERT, der Herausgeber der Chronik. plausibel vermutet, der ganze Komplex stamme erst vom jüngsten der drei Verfasser, dem Bürgermeister Johan Hemeling d. J. (Chroniken a.a.O. S. 145. Anm. 301). Wenn das richtig ist, kann die Passage keinesfalls vor 1382 geschrieben sein. Denn Hemeling ist erst damals als ganz junger Mann? - in den Bremer Rat gewählt worden. Angehört hat er ihm aber bis „etwa 1410", „von 1405 an als Bürgermeister", und gestorben ist er erst 1428 (die biographischen Daten nach ebd. S. XXXf.). Es ist aber sehr wenig wahrscheinlich, dass seine „aktive Beteiligung“ an der Abfassung der Chronik vor den 1390er Jahren begonnen hat (vgl. ebd. S. XXXI), und das Kapitel könnte sehr wohl auch erst im zweiten oder dritten Jahrzehnt des 15. Jh.s entstanden sein. In ihm gibt es auch eine Erzählung, die wahrscheinlich auf freier Erfindung des Verfassers beruht (ebd. S. 145 mit Anm. 307). Damit wäre diese Passage den Hemelingschen Beiträgen zur Chronik zuzurechnen, die nach MEINERTS Auffassung (ebd. S. XXIX) erst nach dem Tod des zweiten Verfassers Herbort Schene ( $\dagger$,um 1414") entstanden sind. 
bereits vor einem unlösbaren Rätsel. Denn wir kennen nur eine einzige weitere Chronik, die den Ereignissen von 1362/1363 zeitlich etwas näher steht, die seit 1385 entstandene des Lübecker Franziskaners Detmar. Die weiß aber nichts von einem solchen Ereignis; der Autor hat sich allerdings bekanntlich „,seiner Aufgabe als Lückenbüßer für die Jahre 1350 bis 1385“ überhaupt ,mehr schlecht als recht entledigt" ${ }^{27}$ Nach dem gesamten Befund könnte man geradezu bezweifeln, dass Johan Wittenborch überhaupt hingerichtet worden ist. Durch zeitgenössische Nachrichten ist nur gesichert, dass am Ende seiner Haft in Lübeck sein Tod gestanden hat; er könnte also auch in der Haft oder bald nach der Haft unter anderen Umständen gestorben sein. Dagegen ist durch zeitgenössisches Schriftgut zweifelsfrei gesichert, dass es andere Sanktionen des Rats gegen Johan Wittenborch schon vor seinem Tod und bald danach gegeben hat; darauf wird später zurückzukommen sein. Unter diesen Umständen wird man alles mit ganz besonderer Vorsicht aufnehmen müssen, was in den Chroniken über den Anlass von Wittenborchs Hinrichtung und über die Details des Vorgangs steht.

Das gilt natürlich auch für Korner und die verschiedenen Bearbeitungsstufen seiner Chronik. Die einschlägigen Angaben sind nicht in allen Fassungen gleich. ${ }^{28}$ Zum einen ist der Bericht zunächst zu 1368 oder 1367 gestellt. Zum andern gibt es Änderungen in der Sachdarstellung. Im ältesten, nach Januar 1417 abgeschlossenen Text ${ }^{29}$ heißt es: Quia Johannes Wittenborg ... perperam egit in commisso, also ,in der ihm aufgetragenen Sache falsch gehandelt hat", fuit capite truncatus et sepultus apud fratres Predicatores in urbe, „begraben bei den Dominikanern im Lübecker Burgkloster"; nur diese letzte Angabe ist quellenkritisch problemlos, als „Insiderwissen“ eines Bruders, der dem Konvent wiederholt angehört hat. Die nächste, nach März 1420 fertig gestellte Fassung ${ }^{310}$ fügt den Vorwurf ungetreuen Handelns hinzu: ... perperam egit in commisso et infideliter, ${ }^{31}$ es ist völlig ungewiss, wodurch der Zusatz veranlasst worden ist. Bei dieser Darstellung ist es, von stilistischen Änderungen abgesehen, auch in der wiederum nächsten, bis Juni 1423 reichenden Fassung ${ }^{32}$ geblieben. Doch tritt hier, und zwar zu 1361-1363, ein weiterer, inhaltlich abwei-

${ }^{27}$ SCHwebel a.a.O. S. 16. Bereits MANTELS, Schiffishauptleute (wie Anm. 11), S. 183. hatte bemerkt, dass Detmar ,diesem Theil seiner Aufgabe minder gewachsen war".

${ }^{28} \mathrm{Vgl}$. zum folgenden bereits Mollwo (wie unten Anm. 55), S. XVIIIf.

${ }^{29}$ SChwalms Fassung $\alpha$ : Korner. Chronica (wie Anm. 6), S. 66. $\$ 567$ mil den textkritischen Fußnoten.

${ }^{30}$ Fassung A: Ebd., als $§,(853 a)^{" 4}$.

"Offenbar deshalb hat KORNER jetzt das Begräbnis im Predigerbruiderkloster als Gnadenakt (des Rats) dargestellt: graciose fuit permissus sepeliri.

${ }^{32}$ Fassung B: Ebd. S. 284. Fußnote (1). 
chender Text hinzu, der dann in Korners letzter lateinischer Fassung ${ }^{33}$ zum einzigen geworden ist. Diese Version lautet - ich zitiere das für uns wesentliche gleich auf Deutsch: „Wegen dieser Nachlässigkeit [der ungenügenden Bewachung der städtischen Schiffe] und wegen gewisser anderer Dinge, die ihm vorgeworfen wurden, ist Herr Johan Wittenburg [!] ... bei seiner Rückkehr in die Stadt gefangen genommen und ... in Fesseln gehalten worden und endlich enthauptet und in der Dominikanerkirche begraben worden ...".34 Diese Darstellung kommt einer Sicht der Vorgänge und ihrer Zeitstellung ziemlich nahe, wie sie sich aus den zeitgenössischen Akten ermitteln lässt. Wenn man die Veränderungen bewerten soll, die Korner - in zwei Schritten - hier an seinem Text vorgenommen hat, dann muss man sagen: Er hat an besser passender Stelle eine inhaltlich bessere Darstellung hinzugefügt und die frühere, chronologisch wie sachlich mangelhafte beseitigt. Das lässt Korners Arbeitsweise in einem konkreten, anhand von zeitgenössischen Archivquellen überprüfbaren Fall in einem sehr viel günstigeren Licht erscheinen, als man nach der herrschenden, von Schwalm und Koppmann begründeten Meinung hätte erwarten können. Danach ist zu fragen, welche neuen Quellen Korner für seine neue Version herangezogen haben mag. Denn aus eigenem hätte er allenfalls Johan Wittenborchs Todesjahr berichtigen können, nach einem Grabmal mit Todesdatum im Burgkloster ${ }^{35}$ oder irgendeinem Schriftstück des Klosters. Alles Übrige kann eigentlich nur aus den Hanserezessen der frühen 1360 er Jahre stammen. ${ }^{36} \mathrm{Da}$ es wenig wahrscheinlich ist, dass die von Korner selbst studiert worden sind, muss er einen Gewährsmann mit Zugang zu den Ratsakten, mindestens zur Ratshandschrift der Hanserezesse, gehabt haben. ${ }^{37}$ Generell wird man nach diesem Befund wohl auch sonst künftig eher, gegen Schwalm und Koppmann, mit der Möglichkeit rechnen wollen, dass Korner bei der wiederholten Überarbeitung seiner

\footnotetext{
${ }^{33}$ Fassung D: Ebd. S. 275f., $\$ 827$.

${ }^{34} \mathrm{Ob}$ quam negligenciam et quedam alia, que sibi obiciebantur, dominus Johannes Wittenburg ... in sua reversione ad urber captus est et ... in vinculis tentus et tandern capite plexus ac in ecclesia fratrum ordinis Predicatorum sepultus.

${ }^{35}$ Das vermutete MANTELS, Schiffshauptleute (wie Anm. 11), S. 193. Erhalten ist anscheinend nichts, auch nicht durch ältere Beschreibung; bei Klaus KRÜGER, Corpus der mittelalterlichen Grabdenkmäler in Lübeck. Schleswig. Holstein und Lauenburg (1100-1600) (Kieler Historische Studien 40), Stuttgart 1999, ist jedenfalls der Zweitname „Wittenborch“ nur durch einen 1489 gestorbenen Domherrn Nicolaus vertreten (S. 639f.).

${ }^{36}$ Dass man mit einer mündlichen Überlieferung in Lübeck, die eine auch nur annähernd zutreffende Darstellung ermöglicht hätte, schon Jahrzehnte vor den $1420 \mathrm{er}$ Jahren nicht rechnen darf, ergibt sich zur Genüge aus den bereits erwähnten Mängeln in der Behandlung der Waldemarskriege durch Detmar.

${ }^{37}$ Und auf dessen Auskunft mag es dann auch irgendwie zurückgehen, dass Korner die Ereignisse im Sund statt zu 1362 zu 1361 behandelt hat.
} 
Chronik das Ziel größerer ,geschichtlicher Richtigkeit“ mindestens auch vor Augen gehabt haben könnte. ${ }^{38}$

Beim Versuch, Johan Wittenborchs Schicksale seit seiner Rückkehr vom Kriegsschauplatz, wohl bald nach Mitte Juli 1362, ${ }^{39}$,aktenmäßig“ darzustellen, fällt zweierlei besonders auf: Die Rezesse der Hansetage dieses Zeitraums, die erst im Oktober einsetzen und zunächst überhaupt nicht sehr redselig sind, erweisen sich als besonders wortkarg, wo es um Herrn Johan geht. ${ }^{4()}$ Und sobald die Protokollführung ausführlicher wird (das geschieht erst im Juli 1363), kommt dem Beobachter auch der Verdacht, dass diese lakonische Kürze mehr als reine Zufallssache gewesen

${ }^{38}$ Die praktischen Grenzen dieses Bemühens zeigen sich dann darin, dass Korner Wittenborchs Gefangenschaft fere per biennium dauern ließ, weil er von seinen Grenzjahren 1361 und 1363 auch das erste für völlig gesichert hielt; siehe dazu bereits MANTELS, Schiffshauptleute (wie Anm. 11), S. 193. Allerdings könnte eine solche kombinatorische Fehlleistung wohl auch einem modernen Historiker passieren, der mit den Problemen einer fragmentarischen Quellenlage zu kïmpfen hat.

${ }^{39}$ Zwischen dem 22. Juli und dem 9. August ist eine erste größere Gruppe von Quittungen ausgestellt worden, mit denen Lübecker Söldner, offenbar aus Dänemark zurück, ihre Ansprüche auf Sold bis zum 29. September und auf Schadenersatz für befriedigt erklärt haben: Urkundenbuch der Stadt Lübeck (weiterhin: UB. Stadt Lüb.) 3, Nr. 424 (S. 432 f.). In den Lübecker Stadtbüchern des Zeitraums kommt Herr Johan, nach den gedruckt vorliegenden Auszügen zu urteilen, nach dem Frühjahr 1362 erst wieder im Sommer 1363 vor, und zwar nur zweimal, am 22. Juli und 15. August: Handlungsbuch (wie unten Anm. 55) S. 74, Nr. IV 26 u. 27.

${ }^{40}$ Von den Beratungen und Beschlüssen der kriegführenden Städte in den ersten neun Monaten des Jahres 1362 ist praktisch nichts überliefert. Einen Rostocker Hansetag vom 24. August kennen wir nur durch eine nachträgliche Erwähnung (HR I, 8, S. 554, versehentlich als „Versammlung zu Lübeck“ bezeichnet). Erst von der Stralsunder Versammlung. die am 8. Oktober begonnen hatte, ist wieder ein Rezess überliefert (HR I, 1, Nr. 267, S. 200)f.): in diesem sind aber weder die Kriegsereignisse des Sommers noch Herr Johan erwähnt. Dasselbe gilt für den Rezess der Rostocker Versammlung vom 6. November (ebd. Nr. 276. S. 205f.). Erst aus dem Rezess des nächsten Hansetags, der am 1. Januar 1363 in Stralsund begonnen hatte, erfahren wir aus der Aufzählung der plures cause, die vorgetragen, aber auf die nächste Versammlung. die am 5. Februar in Rostock beginnen sollte, verschoben worden waren, dass sich darunter auch ein Fall de domino Johanne Wittenborch befand (ebd. Nr. 280. \$ 4, S. 211). Über alle diese „Fälle“ sollte in den Räten der einzelnen Städte beraten und beschlossen werden; der "Wille" der Räte sollte in Rostock eingebracht werden. In Rostock ist dann tatsächlich de causa domini Johannis Wittenborch verhandelt worden; mehr als diese Feststellung enthält der Rezess (ebd. Nr. 287, § 18, S. 218) allerdings nicht. Nicht viel besser sieht es aus im Rezess der nächsten, Wismarer Versammlung vom 17. März (ebd. Nr. 291, \$ 1, S. 222). Aus der Nachricht agebatur negocium domini Johannis Wittenborch lässt sich immerhin herauslesen, dass damals jemand für Herrn Johan „geworben“ hat; sein Anliegen (mndt. „werf") wurde vertreten. Vgl. dazu noch unten mit Anm. 189. Auf den folgenden Tagen, die in Wismar am 23. April und in Nykøbing/Falster am 7. Mai eröffnet wurden, ist, wenn man den Rezessen trauen will, über Herrn Johan nicht einmal gesprochen worden (ebd. Nr. 292, S. 223 f., und Nr. 293, S. 225-230, dazu die Ergänzungen HR I, 3, Nr. 20, S. 19). Was wir aus dem Rezess des großen Lübecker Hansetags vom 24. Juni 1363 über die bisherige Entwicklung und den derzeitigen Stand des „Falls Wittenborch" erfahren (darüber weiter im Text), das ist überhaupt die erste inhaltliche Information, die es in den hansischen Quellen gibt. 
sein könnte. Denn dann wird sehr deutlich: Der Lübecker Rat hat Außenstehende, darunter wohl auch die Räte der anderen Städte, ganz bewusst darüber im unklaren gehalten, weshalb er Johan Wittenborch hat inhaftieren lassen - jedenfalls nicht in erster Linie wegen einer militärischen Fchllcistung des Beschuldigten, die ja alle Städte angegangen wäre, sondern weil ihm die Lübecker etwas zur Last gelegt haben, was ihrer Meinung nach nur sie anging. Diese Politik der Geheimhaltung hat der Lübecker Rat anscheinend mit so gutem Erfolg betrieben, dass noch kurz vor Herrn Johans Tod, auf dem Hansetag, der am 24. Juni 1363 in Lübeck eröffnet wurde und bis zum 2. Juli gedauert hat, ${ }^{4 \mid}$ die amici domini Johannis Wittenborgh ${ }^{42}$ sich darüber zu beklagen hatten, ${ }^{43}$ dass ihnen der Schuldvorwurf nicht bekannt sei; sie baten damals, Herr Johan möge entweder freigelassen werden oder vor die Ratmannen gebracht werden; die Vorwürfe gegen ihn möchten dann gehört und verhandelt werden. „Darauf haben die [auswärtigen] Herren Ratmannen der Städte geantwortet: Dass die Herren Lübecker Ratmannen ihn aus ihrem Rat entfernt und gefangen gesetzt haben, das war ohne ihr Wissen und ihren Rat. Und darüber hinaus [antworteten sie], was vor einiger Zeit in Stralsund in persönlicher Gegenwart von Johan Wittenborch ${ }^{44}$ beschlossen wurde, dass seine Sache nicht straflos sein könne, dass sie ihn [aber] nicht beschuldigten noch irgendeine Klage gegen ihn zu tun vorhätten, sondern es den Herren Lübecker Ratmannen überließen, was mit ihm am besten zu tun sei. ${ }^{45}$ Diese [die

${ }^{41}$ HR 1, 1, Nr. 297 (S. 238f.), eine Urkunde der am Tage Johannis des Täufers im Sommer in Lübeck versammelten Ratssendeboten, berichtet am Ende über eine Handlung der Lübecker Ratmannen, die am Sonntag post octavas sancti Johamnis baptiste predicti in recessu nostro, beim Auseinandergehen der Gesandten, stattfand.

${ }^{12}$ Wir wissen so gut wie nichts darüber, wer diese „Freunde“ waren. Der einzige. den wir kennen, war ein Ratmann aus Anklam (siehe dazu unten mit Anm. 189); wir müssen wohl nicht nur an auswärtige Ratmannen denken. Die Behauptung von Wilhelm BREHMER, Der Lübecker Bürgermeister Jacob Plescow, in: HGBll. Jg. 1882 (1883), S. 49-66, hier S. 55f., "dass zahlreiche und einflussreiche Freunde sich auf das lebhafteste für ihn verwandten", beruht nicht auf irgendeiner Quellennachricht.

${ }^{43}$ Dies und das folgende nach dem Rezess, HR I, 1, Nr. 296, § 12 (S. 235f., rechte Spalte, längere Fassung der Rostocker Handschrift). Soweit es sich um eine Übersetzung des lateinischen Textes handelt, stammt sie von mir, wie fast alle anderen Übersetzungen auch. Eine einwandfreie, aber jetzt doch schon sehr altfränkisch wirkende Übersetzung bot bereits MANTELS, Schiffshauptleute (wie Anm. 11), S. 189.

${ }^{44}$ Dieser Rezessartikel in der Fassung der Rostocker Handschrift ist, so weit ich sehe, die einzige Stelle im hansischen und Lübecker Schriftgut des Jahres 1363, an der ihm das Herren-Prädikat entzogen worden ist.

${ }^{45}$ Die Orts- und (indirekt auch) Zeitangabe ,in Stralsund" gibt Rätsel auf; mit dem, was uns die erhaltenen Hanserezesse sehen lassen (siehe oben Anm. 40), ist sie nicht vereinbar. Ich sehe drei Lösungsmöglichkeiten: 1. Es könnte ein Hansetag im Spätsommer oder Frühherbst 1362 (nach Ende August und vor dem 8. Oktober) gemeint sein, von dem wir sonst nichts wissen. Dann hätte die hansische Diskussion über den „Fall Wittenborch“ viel früher begonnen, als man nach den Rezessen aus den ersten Monaten des Jahres 1363 denken muss. 
Lübecker] Ratmannen berieten sich und antworteten [dann]: Sie hätten wegen des zitierten Stralsunder Beschlusses, nämlich dass [er] nicht straflos sein könne, und wegen anderer Rechtssachen, die sie mit Johan Wittenborch allein hätten, ihn fesseln lassen, und sie wollten dies zu gegebener Zeit in ihrem Rat abschließend behandeln". Diesen zentralen Text finden wir nur in der Version des Rezesses, der in Rostock überliefert ist. Die darin enthaltenen Informationen verdanken wir allein dem Umstand, dass die Lübecker damals durchaus kein Monopol der Rezessformulierung besessen haben, nicht einmal für eine Versammlung, die in ihren eigenen Mauern stattgefunden hatte..$^{\text {th }}$ Mit dem Rostocker Wortlaut verglichen, erinnert die kürzere Lübecker Version an die „Emser Depesche“ in der von Bismarck bearbeiteten Fassung. Wie sich auf dem nächsten Hansetag, der am 25. Juli in Wismar begann, herausstellte, haben die Lübecker die Langfassung bis dahin gar nicht gekannt. Sie wurden damit von den Stralsundern, Wismarern und Rostockern konfrontiert, als die Lübecker Ratssendeboten ihre eigene Version vortrugen, um Schadenersatzansprüche der Kieler gegen Lübeck abzuwehren, die damit begründet wurden, dass Herr Johan Wittenborch die Kieler Bürger auf die Schiffe vor Helsingborg geschickt und damit ihre Gefangennahme verschuldet habe. ${ }^{47}$

Diese Verhältnisse sind in allen Punkten zweifelsfrei und klar erkennbar, seitdem die kritische Zusammenstellung der einschlägigen Akten im ersten Band der „Hanserezesse" vorliegt. Dies Quellenmaterial ist gleich nach dem Erscheinen des Bandes für eine gründliche Untersuchung genutzt worden, die 1872/73 in den „Hansischen Geschichtsblättern" veröffentlicht wurde und 1881 noch einmal in den Druck gekommen ist. Der Verfasser des Aufsatzes über „die hansischen Schiffshauptleute Johann Wittenborg, Brun Warendorp und Tidemann Steen“ war der Lübecker Gymnasiallehrer, Stadtbibliothekar und Gründungsvorsitzende des „Hansischen Geschichtsvereins“ Wilhelm Mantels, ${ }^{48}$ der von 1816 bis 1879

2. Gemeint ist der Hansetag vom 1. Januar 1363: dann müsste man annehmen, dass der Rezess dieses Tages falsch informiert. 3. Statt „Stralsund“ könnte „Rostock“ und der Tag vom 5. Februar 1363 gemeint sein. Das Versehen müsste dann aber schon in der Versammlung passiert sein, ohne dass jemand Einspruch erhoben hätte; denn ,Stralsund“" erscheint in beiden Fassungen des Artikels, in der Rostocker Version sogar zweimal. Ich neige persönlich zur 1. Lösung.

th Auf diese Verhältnisse ist Thomas BehrmanN, Der lange Weg zum Rezess. Das erste Jahrhundert hansischer Versammlungsschriftlichkeit, in: Frühmittelalterliche Studien 36. 2002 [Festschrift für Hagen Keller], S. 433-467, hier S. 466f., nicht eingegangen; die Rezesse des Jahres 1363 sind überhaupt nur noch skizzenhaft erörtert.

${ }^{47}$ HR I, 1, Nr. 299, $\$ 4$ (S. 240f.). Die Lübecker haben sich offenbar bei dieser Gelegenheit die Langfassung abgeschrieben, so dass sie vier Jahrzehnte später auch in die Lübecker Ratshandschrift der Rezesse, die sog. Ledraborger, übertragen werden konnte, siehe ebd. S. 241, Note a.

${ }^{48}$ MANTELS, Schiffshauptleute (wie Anm. 11), S. 179-194 u. 227-229. 
gelebt hat. ${ }^{49}$ Seitdem sind ältere Legenden, die dem Bürgermeister „Verrat" zugunsten des Feindes unterstellt hatten, weitgehend aus dem Bewusstsein der geschichtlich interessierten Öffentlichkeit verschwunden. Seitdem darf aber auch darüber gerätselt werden, was das Besondere war, dessentwegen Herr Johan vom Lübecker Rat belangt worden ist. Damit hat Mantels selbst schon begonnen, indem er darüber spekulierte, ob bei der Behandlung des Falls Wittenborch im Lübecker Rat nicht ,innere Parteiung“ eine Rolle gespielt haben könnte, die er ,sich doch kaum anders auszulegen“ wusste ,als einen Zwist im Rathe selber, der schon auf die 1376 ausbrechenden ständisch-demokratischen Bewegungen [!] hindeutete“. ${ }^{60}$ „Innere Spannungen - vielleicht wirtschaftspolitischer Art ahnen wir" dann auch ein Dreivierteljahrhundert später mit Ahasver von Brandt im Lübecker Rat. ${ }^{51}$ Noch wichtiger ist es, dass Mantels auch schon die allgemeine Richtung, in der meist gerätselt worden ist, vorgegeben hat, indem er seiner Darstellung eine Wertung voranstellte, die sich auf kein noch so schwaches Indiz in den Quellen, nicht einmal in den chronikalischen, berufen kann: Johan Wittenborch und der Lübecker Bürgermeister Tideman Steen, der 1427 wegen einer militärischen Fehlleistung im damaligen Hansekrieg gegen Dänemark beinah hingerichtet worden wäre, hätten, „so weit wir es erfahren oder nach dem Geiste der Zeit sicher voraussetzen können, dem Tode mit Festigkeit ins Antlitz geschaut, den Spruch des Raths als einen gerechten auf sich genommen und wie Männer und wackere Bürger dem Wohl des Ganzen jeden eigenen Wunsch geopfert".52 Damit sollte offenbar jedem Gedanken an politisch motivierte Willkürjustiz des Rats ein Riegel vorgeschoben werden; aber es sollte auch niemand auf den Einfall kommen, die Maßnahmen des Lübecker Rats gegen Johan Wittenborch könnten etwas mit einem Verhalten des ehemaligen Bürgermeisters zu tun gehabt haben, das auch ein wirtschaftsund bildungsbürgerlicher Betrachter des ausgehenden 19. Jahrhunderts als

\$9 Über ihn zuletzt Antjekathrin GRASSMANN in Biographisches Lexikon für SchleswigHolstein und Lübeck Bd. 9, Neumünster 1991, S. 219-222. Am Anfang stand ein Vortrag, den MANTELS am 31. Mai 1871 auf der konstituierenden Versammlung des HGV gehalten hat: „Über den 1363 hingerichteten hansischen Flottenführer, Bürgermeister Johann Wittenborg": Ahasver V. BRANDT, Hundert Jahre Hansischer Geschichtsverein. Ein Stück Sozialund Wissenschaftsgeschichte, in: HGBII. 88, 1970, S. 3-67, hier S. 10 (Abbildung des Programms).

${ }^{50}$ MANTELS, Schiffshauptleute (wie Anm. 11), S. 194. Gemeint ist das Vorgehen, durch das eine breite Koalition von Handwerkern und Kautleuten 1374 (nicht 1376) den Rat zum Verzicht auf die Erhebung von neuen Abgaben gezwungen hat; Näheres dazu unten mit Anm. 436 446.

s1 A. VON BRANDT, Individuum und Gemeinschaft im mittelalterlichen Lübeck, in: DERS., Geist und Politik in der lübeckischen Geschichte. Acht Kapitel von den Grundlagen historischer Größe, Lübeck 1954, S. 53- 68, hier S. 64.

${ }^{52}$ MaNTELS, Schiffshauptleute (wie Anm. 11), S. 180. 
ehrenrührig betrachtet hätte. Was den „Fall Wittenborch“ angeht, ist diese Strategie sehr erfolgreich gewesen: Einerseits ist, so weit ich sehe, das Vorgehen des Rats seitdem niemals kritisch erörtert worden; andererseits ist der „Fall“ selten behandelt worden, ohne das Herr Johan selbst als „unglücklich“ und sein Schicksal als „tragisch“ bezeichnet worden wäre. Seit Mantels könnte die geschichtswissenschaftliche Behandlung des „Falles Wittenborch" denen manchen Stoff bieten, die meinen, dass auch die so genannte „quellenkritische“ Geschichtswissenschaft Geschichte „konstruiert" ${ }^{33}$ statt sich systematisch rekonstruierend um eine möglichst genaue Annäherung an eine vergangene Realität zu bemühen.

\section{Das Wittenborch'sche „Handlungsbuch“, Carl Mollwos Edition (1901) und die Folgen}

In der wissenschaftlichen Öffentlichkeit des Faches „Geschichte“ und einiger „historischer Wissenschaften“54 ist der Bürgermeister aber womöglich noch besser deshalb bekannt, weil von ihm ein Stück Buchführung überwiegend kaufmännischen Inhalts erhalten geblieben ist. Es ist 1901 von Carl Mollwo unter dem Titel „Das Handlungsbuch von Hermann und Johann Wittenborg" im Wortlaut veröffentlicht worden ${ }^{55}$ man findet darin auch, über das „Buch“ verstreut, eine Reihe von Notizen über Zahlungen, die Herr Johan als Inhaber von Ratsämtern entgegengenommen oder geleistet hat. ${ }^{56}$ Als Beilagen wurden zahlreiche Schriftstücke aus dem öffentlichen Schriftgut der Stadt Lübeck mit abgedruckt, die Informationen über Herman, den Vater, und Johan, den Sohn, und ihre wirklichen und angeblichen Verwandten enthalten und vor allem ergänzende Aufschlüsse über ihre Tätigkeit als Geschäftsleute und Geldanleger geben. Die Handschrift des „Buchs“, ein Heft im Quartformat aus zwei Lagen Papier in einem

\footnotetext{
${ }^{53} \mathrm{Vgl}$. dazu etwa Hans-Werner GOETZ, Moderne Mediävistik. Stand und Perspektiven der Mittelalterforschung, Darmstadt 1999, S. 113-117.

${ }^{54}$ Otto BRUNNER, Das Fach „Geschichte“ und die historischen Wissenschaften (Hamburger Universitätsreden 25), Hamburg 1959.

${ }^{55}$ Das Handlungsbuch von Hermann und Johann Wittenborg. Hg. von Carl MoLLwo, Leipzig 1901. Die Quellentexte werden künftig als „Handlungsbuch“ zitiert; mit MoLLwo sind die Beiträge des Herausgebers zur Erschließung der Quelle gemeint.

${ }^{56}$ Darum handelt es sich großenteils bei dem, was MolLwo S. XLI als „Bemerkungen, die ... sein Privatleben angehen“, bezeichnet hat. Beim wirklich „Privaten“ geht es im Wesentlichen um Zahlungen. die Johan Wittenborch $1350 \mathrm{im}$ Zusammenhang mit dem Tod seines Schwiegervaters geleistet hat, und um Ausgaben und Einnahmen für seinen Schwager und reisenden Gesellschafter Arnold Bardewich, wenn dieser nicht zu Hause war. - Außerdem enthält die Handschrift noch zahlreiche „Federproben", die in der Edition großenteils weggelassen worden sind; siehe dazu unten mit Anm. 292-295.
} 
Lederumschlag, ist im Lübecker Archiv überliefert. ${ }^{57}$ Die erste Lage ist vielleicht schon von Herman begonnen worden ${ }^{58}$ Nach dessen Tod, der spätestens Anfang 1338 erfolgt ist, hat die Witwe das Buch bis 1345 geführt oder durch Hilfskräfte führen lassen. Von 1345 bis 1359 (1360) hat es dann Johan Wittenborch selbst weiter benutzt. ${ }^{59}$ Für das Verständnis

${ }^{57}$ Archiv der Hansestadt Lübeck (weiterhin: AHL), Altes Senatsarchiv Interna, Ratsstand 27/1. Die Handschrift ist bei Mollwo S. XXXIV-XXXVI näher beschrieben. Sie war offenbar noch ohne jede Foliierung, als MOLLwO mit ihr gearbeitet hat. Die in der Edition als Marginalien erscheinenden Folio-Angaben sind weder von MoLLwo noch später im Archiv in die Handschrift übertragen worden; es ist aber sinnvoll, sie weiter bei Bedarf zu zitieren, es sei denn, es käme einmal zu einer Neuedition der Handschrift. Im Archiv ist diese später zweimal, beim zweiten Mal mit einem Numeratorstempel, foliiert worden. In dieser 2. Foliierung erscheint das letzte Blatt der ersten Lage, bei Mollwo „Fol. 36“", als f. 37. Da als f. 38-41 die losen Einlagen folgen, die MolLwo auf S. 54 und 66ff. als Handlungsbuch Ila, $1-4$, und III, 1-3 abgedruckt hat, erscheint die zweite Lage des „Handlungsbuchs“ jetzt als $\mathrm{f}$. 42-51; diese Zählung beginnt mit dem Blatt, das MOLLwo zu Recht als letztes gewertet hatte; MOLLwos „Fol. 37a" ist jetzt also f. 51v. - RORIG hat 1928 die Ansicht vertreten, „Johann Wittenborgs Handlungsbuch [könne], wie ein kritischer Vergleich mit Wittenborgs Eintragungen ins Schuldniederstadtbuch zeigt, unmöglich das einzige Buch dieser Art gewesen sein, das er führte": Fritz RöRIG, Wirtschaftskräfte im Mittelalter. Abhandlungen zur Stadt- und Hansegeschichte. Hg. von Paul KaEGBEIN, Weimar 1959, S. 219. Da RörIG dies nie näher ausgeführt hat, ist eine Auseinandersetzung mit dieser Auffassung nicht möglich (er hat hoffentlich nicht nur den Befund für Ende 1359 und 1360 gemeint, der unten in Anm. 59 analysiert ist). Ich sehe allerdings auch nicht, wie sie auf dem angedeuteten Weg bewiesen werden könnte, und halte es demgegenüber für wichtig, dass es im erhaltenen „Buch“ keinen einzigen Verweis auf ein anderes gleichzeitiges „Buch“ gibt. Dagegen hat Johan aber an einer Stelle (Handlungsbuch S. 31, Nr. II 181) auf seine „Elfenbeintafel“ verwiesen, eine Wachstafel aus Elfenbein. Darüber hinaus ist seine Buchführung nur unter der Voraussetzung zu verstehen, dass er seine tagtäglichen Aufzeichnungen auch (hauptsächlich ?) auf Zetteln gemacht hat; von denen ist nur ein einziger erhalten geblieben (MoLLwo S. XXXV). Offenkundig ist nur ein Teil dieser laufenden Notizen ins „Buch“ übertragen worden; vermutlich war Manches (Vieles ?) schon erledigt, wenn Johan Wittenborch das „Buch“ wieder einmal (oft wohl erst nach Ablauf mehrerer Wochen) in die Hand genommen hat. Endlich sind (siehe Mollwo S. XXXIV f.) von den 62 Blättern, aus denen die beiden Lagen ursprünglich bestanden haben, zwei nur ,verstümmelt" erhalten und 15 durch Herausschneiden ganz verloren. Zwar sind auf den überwiegend sehr schmalen Stegen, die stehen geblieben sind, nirgends Schriftreste zu sehen, aber allein das berechtigt natürlich nicht zu der Behauptung. es sei „sehr wahrscheinlich, dass die nicht mehr vorhandenen Blätter überhaupt schon vor dem Beginn der Buchführung gefehlt haben". Obwohl MolLwo diese - an sich erwägenswerte - Aussage schon im nächsten Satz wieder relativiert, hat er das Ganze dann doch als Argument gegen die „Annahme von Lücken in der Buchführung“ zu nutzen versucht. Von diesem Problem (für das es wohl überhaupt keine Lösungsmöglichkeit gibt) abgesehen, halte ich aber die Frage, welche Teile von Johan Wittenborchs Geschäftstätigkeit im „Handlungsbuch" dokumentiert sind, für das noch keineswegs befriedigend gelöste Kernproblem seiner wirtschaftsgeschichtlichen Interpretation: man muss ja sogar - siehe unten mit Anm. $154 \mathrm{u}$. 155 - damit rechnen, dass das „Buch“ zeitweise überhaupt nicht benutzt worden ist.

${ }^{58}$ Soweit die folgenden Angaben über die Führung des „Buchs“ von der bisherigen communis opinio abweichen, komme ich darauf später zurück.

${ }^{54}$ Mollwo S. XXXIX nannte „1360" als Schlussjahr. Tatsächlich gibt es von 1360 aber nur eine einzige, ganz isolierte Eintragung. Sie findet sich, ohne dass die Jahreszahl ausdrücklich genannt würde. Handlungsbuch (wie Anm. 55) S. 53f., Nr. II 351, 2. Absatz mit 
der Formen großkaufmännischer Tätigkeit in einer von nur fünf, allenfalls sechs wirklich bedeutenden Hansestädten des 14. Jh. in Küstennorddeutschland ${ }^{\text {() }}$ bedeutet dieses Buch sehr viel, wie viel, lässt sich schon ahnen, wenn man weiß, dass neben dem Wittenborch-Buch nur noch zwei vergleichbare Geschäftsbücher erhalten geblieben sind: ${ }^{61}$ Die annähernd gleichzeitigen, aber anders aufgebauten Tölner-,,Handlungsbücher“ in Rostock $^{62}$ und das etwa ein Vierteljahrhundert jüngere Buch des Hamburger

Anm. 429; dies ist zugleich die letzte Buchung auf der letzten Seite, ,Fol. 46b“, des „Handlungsbuchs". Zur Datierung hat MOLLwO auf die entsprechende Niederstadtbucheintragung vom 6. Dezember 1360 hingewiesen (Handlungsbuch (wie Anm. 55) S. 84, Nr. V 71), woran es nichts zu deuteln gibt; in der Handschrift findet man sie da, wo sie nach MoLLwoS Angabe zu suchen ist (AHL 1. Niederstadibuch S. 911, 7, letzte Eintragung unter 1360 Nicolai). Alle anderen datierten bzw. durch zugehörige Beurkundung im Lübecker städtischen Schriftgut datierbaren Buchungen reichen aber nur bis Ende 1359. Die jüngste Entsprechung im Niederstadtbuch stammt vom 19. November des Jahres: Handlungsbuch (wie Anm. 55) S. 83, Nr. V 60, zu Handlungsbuch (wie Anm. 55) S. 53, Nr. II 349 mit Anm. 423 (die Jahreszahl ,1369“ ist natürlich Druckfehler). Bereits zwei weitere Niederstadibucheintragungen vom gleichen Tage haben im „Handlungsbuch" keine Entsprechung mehr (Handlungsbuch (wie Anm. 55) S. 83, Nr. V 61. mit unzutreffendem Hinweis auf „II. 335“ in Anm. 5, und 62). Dasselbe gilt für die letzte Eintragung des Jahres 1359, vom 31. Dezember (Handlungsbuch (wie Anm. 55) S. 83f., Nr. V 63, Abrechnung über den Nachlass seines in Preußen gestorbenen reisenden Partners Bertolt Wittenborch), für die Dokumentation einer Forderung von $10 \mathrm{ml}$, an einen gewissen Tiderik Weger, die sich Herr Johan am 16. Dezember 1359 in einem Denkelbrief hat beurkunden lassen (Handlungsbuch (wie Anm. 55) S. 92f., Nr. VI 7), und für alle Niederstadtbucheintragungen von 1360 mit Ausnahme der einen eben genannten (Handlungsbuch (wie Anm. 55) S. 84f., Nr. V 64-70) und 71a). Danach ist es verständlich. dass selbst KOPPMANN, Rezension (wie unten Anm. 67), S. 195, die Geduld verloren und keine Eintragung von 1360 gefunden hat. Bei der Buchung, die nach dem 6. Dezember 1360 geschrieben wurde, handelt sich um den letzten im „Handlungsbuch“ bezeugten Vorgang eines langwierigen und wohl auch schlechten Geschäfts: Die Verwertung von preußischem Malz, das faul geworden war (erste Nachrichten darüber: Handlungsbuch (wie Anm. 55) S. 50-52, Nr. II 336-338). Da es darum auch in der letzten daticrbaren Buchung des Jahres 1359 geht. darf man wohl vermuten, dass Herr Johan das uns erhaltene „Handlungsbuch" uiber den Herbst 1359 hinaus nur noch für Notizen über dies Geschäft verwendet hat. Was sonst noch auf Seite „46b" steht, Aufzeichnungen über den Bezug von Roggen aus Preußen in zwei Schiffsladungen (Handlungsbuch (wie Anm. 55) S. 53. Nr. Il 350 u. 351, I. Absatz, beide undatiert), dürfte ebenfalls nicht über den Herbst 1359 hinausreichen. Denn als Herr Johan es schrieb, wusste er anscheinend noch nicht, dass Bertolt (Wittenborch) tot war (siehe oben); und in diesen beiden Buchungen gibt es außerdem noch keinerlei Nachrichten über den Verkauf des Roggens. Zusammenfassend dürfen wir danach sagen: Das uns überlieferte „Handlungsbuch" ist in der Hauptsache bereits im November 1359 außer Gebrauch gesetzt worden; damals muss Herr Johan also ein ,neues“ Buch angelegt haben. von dem uns aber keinerlei Spuren überliefert sind.

${ }^{(6)}$ Hamburg, Lübeck, Wismar. Rostock. Stralsund und eventuell in der hier interessierenden Zeit auch noch Greifswald.

${ }^{6}$ Einen bequemen Überblick über das gesamte Material des norddeutschen Spätmittelalters, so weit es publiziert ist. bietet jetzt Doris ToPHINKE, Handelstexte. Zur Textualität und Typik kaufmännischer Rechnungsbücher im Hanseraum des 14. und 15. Jahrhunderts (ScriptOralia 114), Tübingen 1999.

62 Johann Tölners Handlungsbuch von 1345-1350. Hg. von Karl KOPPMANN (Geschichtsquellen der Stadt Rostock 1), Rostock 1885. Des Herausgebers Äußerungen zu den Hand- 
Ratmanns Vicke (Frederik) van Geldersen. ${ }^{63}$ Im Lübecker Archiv existiert kein Schriftgut-Umfeld, aus dem sich erkennen ließe, wie das Wittenborch-Buch dahin gekommen ist, und wieso es dort geblieben ist. ${ }^{64} \mathrm{Na}$ türlich konnte man vermuten, dass es einen Zusammenhang mit dem Verfahren vor dem Rat gibt, das zu Johan Wittenborchs Hinrichtung geführt hat. Aber zwingend ist das keineswegs. Immerhin drängt sich die Frage auf, warum dies bereits abgeschlossene Buch und nicht das aktuelle, seit Ende 1359 geführte, an den Rat gekommen ist. Die Vermutung liegt nahe, dass irgendwo im Buch ein auch nach mehreren Jahren noch strafwürdiges Tun dokumentiert ist.

Dieses Tun glaubte der Herausgeber entdeckt zu haben: Johan Wittenborch sollte 1358 ein hansisches Handelsverbot übertreten haben. ${ }^{65}$ Die Behauptung ist sogleich von Karl Koppmann, einem der erfahrensten und scharfsinnigsten Hanseforscher seiner Zeit und Redakteur der „Hansischen Geschichtsblätter" von ihrem ersten Jahrgang bis zu seinem Tod im Jahre $1905,{ }^{66}$ in einer ausführlichen, insgesamt recht kritischen Rezension in „seiner" Zeitschrift furios und bündig widerlegt worden ${ }^{67}$ sie hätte danach nie wieder vertreten werden dürfen. Aber das Unglück hat es gewollt, dass fast ein halbes Jahrhundert später der nächste ebenso scharfsinnige, aber

schriften enden (S. II) mit dem Satz: ..Die in unserer Ausgabe vereinigten Stücke sind ... nicht Bruchstücke oder Theile eines und desselben Buches, sondern zwei verschiedene und inhaltlich vollständige Bücher, die ... für verschiedene Geschäfte geführt wurden“.

${ }^{6.3}$ Das Handlungsbuch Vickos von Geldersen. Bearbeitet von Hans NIRRNHEIM, Hamburg u. Leipzig 1895.

M Als geringen Rest eines solchen Umfelds mag man allenfalls einen Brief an Herrn Johan Wittenborch aus der Zeit kurz vor seinem Tod ansprechen; siche dazu unten mit Anm. $187 \mathrm{u}$. 188. Selbst das würde aber nur gelten, wenn der Brief nicht schon im Zusammenhang mit den Ratsmaßnahmen gegen Herrn Johan dahin gelegt worden ist, wo bereits Mol.Lwo ihn vorgefunden hat: In der ..Handlungsbuch"-Handschrift. Wie es damit steht. ist wahrscheinlich überhaupt nicht mehr zu klären. Nach seinen Angaben auf S. XXXIl u. XXXIVf. zu urteilen, hat MOLLwo in der Handschrift nicht nur diesen Brief, sondern alle vier losen Beilagen angetroffen, die sich auch heute noch darin befinden (siehe oben Anm. 57), dazu anscheinend auch Herrn Johans Testament von 1362, das es dort heute nicht mehr gibt. Aber ob dies alles schon so war, als „1895“ das ..Handlungsbuch“ vom „Staatsarchivar Professor Dr. P. Hasse im lübecker Staatsarchiv ... gefunden" wurde (MOLLwo S. [1] des unpaginierten ..Vorworts"), und wenn ja, seit wann. muss dahingestellt bleiben. Mindestens der Handlungsbuch (wie Anm. 55) S. 66f., Nr. III 2 abgedruckte Pergamentbrief des Kolberger Rats an Herrn Johan dürte (noch ?) im 18. Jh. anderswo gelegen haben, trägt er doch auf der Aulsenseite eine kurze Inhaltsangabe aus dieser Zeit.

${ }^{6.5}$ MOLlWO S. XV-XVII.

${ }^{66}$ VON BRANDT. Hundert Jahre (wie Anm. 49), S. 55f;; vgl. Hugo WECZERKA. Die Vorstandsmitglieder des Hansischen Geschichtsvereins 1871-1969. in: HGBll. 88, 1970, S. 72-80, hier S. 78.

${ }^{67}$ Karl Koppmann in HGBll. Jg. 1900 (1901), S. 187-208, hier S. 191f. Auf S. 188 heiBt es etwa: „Der Text leidet an häufigen Druckfehlern; die Lesart ist deswegen und bei dem bösen Latein und der willkürlichen Schreibwei[s]e der Schreiber vielfach unsicher; zuweilen liegt auch wohl ein Versehen des Herausgebers vor". 
noch nicht ganz so erfahrene Hanseforscher, der sich etwas ausführlicher mit Johan Wittenborch befasst und das Ergebnis 1954 in einem Band mit eigenen Aufsätzen veröffentlicht hat, allem Anschein nach Koppmanns Rezension nicht gelesen hatte. Daher hob der damalige Lübecker Archivdirektor Ahasver von Brandt zwar einerseits zutreffend hervor, dass der Grund für Johan Wittenborchs Hinrichtung nicht bekannt ist, fand aber andererseits doch „Mollwos Annahme, dass Wittenborg, obwohl lübeckischer Bürgermeister, das damalige Handelsverbot mit Flandern übertreten habe, und dass dieser Umstand bei seiner Verurteilung eine Rolle gespielt habe, ... recht einleuchtend" ${ }^{68}$ Danach hat sich lange Zeit niemand mehr eingehend mit Johan Wittenborch und seinem Geschäftsbuch befasst. Daher ist es weiter nicht auffallend, dass Rolf Hammel(-Kiesow), als er zu Beginn der 1980er Jahre für das „Biographische Lexikon für SchleswigHolstein und Lübeck" einen Artikel über den Bürgermeister schrieb, in erster Linie den Aufsatz des hoch angesehenen Ahasver von Brandt zum Ausgangspunkt seiner eigenen Verfasserschaft genommen hat; und Hammel hat dann auch in diesem Punkt auf die Worte des Meisters geschworen. ${ }^{6 y}$ Der Artikel ist später von anderen zugrunde gelegt worden, wenn sie Johan Wittenborch zu behandeln hatten. Das gilt für den Hochund Spätmittelalter-Beitrag, den der damalige Kieler Ordinarius für Schleswig-holsteinische Landesgeschichte Erich Hoffmann für die von der Direktorin des Lübecker Archivs herausgegebene, erstmals 1988 erschienene große Stadtgeschichte beigesteuert hat, ${ }^{70}$ und es gilt auch für den Artikel über Herman und Johan Wittenborch und ihr „Handlungsbuch“, der 1999 in der 2. Auflage des „Verfasserlexikons“ zur deutschen Literatur des Mittelalters erschienen ist. ${ }^{71}$ Eigenständiger ist dagegen die Behand-

${ }^{68}$ VON BRANDT, Individuum (wie Anm. 51), S. 203, Anm. 26 zu S. 64.

${ }^{69}$ Rolf HAMMEL, „Wittenborg, Johann", Biographisches Lexikon für Schleswig-Holstein und Lübeck Bd. 6. Neumünster 1982, S. 303-305. Unveränderter Nachdruck in: Lübecker Lebensläufe aus neun Jahrhunderten, hg. von Alken BRUNS, Neumünster 1993, S. 421-423. Ich zitiere weiterhin nur den ursprünglichen Druck, und zwar als HAMMEL 1982.

${ }^{70}$ Erich HoffMANN, Lübeck im Hoch- und Spätmittelalter: Die große Zeit Lübecks. In: Lübeckische Geschichte Hg. von Antjekathrin GraSSMANN, 3. verbesserte und ergänzte Auflage Lübeck 1997, S. 79-339, hier S. 149; dazu auf S. 810 der Hinweis auf HAMMELS Artikel. Auch dessen Verfasser ist übrigens gelegentlich auf das Thema zurückgekommen, so in seiner ausführlichen Besprechung des 1995 erschienenen Hanse-Buchs von Heinz STOOB: Rolf HAMMEL-KIESOW. Die Hanse in der wechselnden Betrachtung der Generationen. Überlegungen zur jüngsten Gesamtdarstellung ihrer Geschichte, in: ZVLGA 77, 1997, S. 209-225. hier S. 218 mit Anm. 20. In der auf wenige Zeilen begrenzten Äußerung zum Fall verdrängt das ,ignoramus“ alle Mutmaßungen. Die 1982 vertretene Position wollte der Verfasser damit offenbar nicht revidieren, wie der Verweis auf den Artikel und auf HoFFMANNS eben zitierte Darstellung zeigt.

"Helgard UlmSCHNEIDER, „Wittenborg, Hermann und Johann“, In: Die deutsche Literatur des Mittelalters. Verfasserlexikon. 2. Auflage, Bd. 10, Berlin u. New York 1999. Sp. 
lung des „Falls Wittenborch“ in der Freiburger Habilitationsschrift über spätmittelalterlichen Gesellschaftshandel im Hanseraum, die der Rechtshistoriker Albrecht Cordes 1998 der Öffentlichkeit vorgelegt hat: ${ }^{72}$ im besonderen Abschnitt „Der Bürgermeister auf dem Schafott: Die Hinrichtung des Johann Wittenborch" ist auch Koppmanns Rezension berücksichtigt; sie hat den Verfasser allerdings - überraschenderweise, wie ich finde - nicht völlig überzeugt, so dass er zwar ,einen dritten, unbekannten Vorwurf" für den entscheidenden erklärte, aber dennoch meinte, „Mollwos Hypothese [sei] wohl nicht mit Sicherheit auszuschließen“. ${ }^{73}$ Eine verwandte Position ist dann ein Jahr später von Georg Asmussen, der sich mit Herrn Johan als „Flandernfahrer" beschäftigt hat, in geradezu beklemmender Weise auf die Spitze getrieben worden: Der Verfasser widerlegt, ohne Koppmanns Besprechung zu kennen, Mollwos These mit denselben Argumenten wie Koppmann, schließt seine Ausführungen aber mit dem Satz: „Dennoch ist die Behauptung, dass Wittenborch verbotenen Flandernhandel betrieben habe, als eine sinnvolle Erklärung für seine Anklage nicht von der Hand zu weisen, wenn auch der Beweis fehlt ". ${ }^{74}$ Damit verglichen, ist das Beispiel von Zitate häufender Autoritätenhörigkeit, das in dieser Frage zuletzt Lutterbeck geboten hat, ${ }^{75}$ beinahe erholsam.

Vor Ahasver von Brandt hatte sich noch ein bayrischer (allerdings aus Bremen gebürtiger) Gelehrter mit Johan Wittenborch beschäftigt oder vielmehr mit dem „Handlungsbuch“: Der Wirtschaftshistoriker Franz Bastian (1881-1944) hat einen großen Teil seiner wissenschaftlichen Lebensarbeit der angemessenen Publikation eines Regensburger Zwei-Generationen-,,Handlungsbuchs“ aus den Jahren 1383 bis 1407 gewidmet; es ist

1278-1280. Für das Biographische ist außerdem die ziemlich ausführliche Darstellung bei Philippe Dollinger, Die Hanse, Stuttgart 1966 (und öfter), S. 223-225, stark benutzt worden. VON BRANDTS Aufsatz ist in den Literaturangaben gar nicht mehr erwähnt. Dass sich neuerdings nicht nur die Literaturwissenschaft, sondern auch die Linguistik für das kaufmännische Geschäftsschriftgut des norddeutschen Spätmittelalters interessiert, bezeugt die 1999 veröffentlichte Freiburger Habilitationsschrift von Doris TOPHINKE, Handelstexte (wie oben Anm. 61), die alles berücksichtigt, was gedruckt vorliegt, darunter auch das Wittenborch-.,Handlungsbuch"; in ihren knappen biographischen Angaben zu Johan Wittenborch (S. 139) folgt sie ihrem Gewährsmann DOLLINGER (ebd.) auch darin, dass sie Mollwos Erklärungsversuch für Herrn Johans Tod nicht erwähnt. Vgl. auch DiES., Das kaufmännische Rechnungsbuch im Kontext städtisch-amtlicher Schriftlichkeit, in: JbVNddtSpr. 122, 1999, S. $25-43$.

${ }^{72}$ Albrecht CORDES, Spätmittelalterlicher Gesellschaftshandel im Hanseraum (Quellen und Darstellungen zur hansischen Geschichte NF. 45), Köln, Weimar, Wien 1998, S. 214-216.

${ }^{73}$ Ebd. S. 216 mit Anm. 43 (.,So zuletzt Hammel 1982 ...").

${ }^{74}$ Georg ASMUSSEN, Die Lübecker Flandernfahrer in der zweiten Hälfte des 14. Jahrhunderts (1358-1408) (Hansekaufleute in Brügge 2 = Kieler Werkstücke D. 9), Frankfurt am Main usw. 1999. S. 893, Anm. 51 am Ende, ohne ausdrücklichen Hinweis auf Literatur.

${ }^{75}$ LUTTERBECK S. 36 mit Anm. 151; hier, sortiert im Verfasseralphabet, die besprochenen Stellungnahmen von HAMMEL, HOFFMANN und CORDES. 
dann unter dem Namen „Runtingerbuch“ in einem Textband und zwei ergänzenden Bänden zwischen 1935 und 1944 veröffentlicht worden. ${ }^{76}$ Bastian $^{77}$ hat u. a. das Ziel verfolgt, die Technik der Buchführung von deutschen Kaufleuten des Spätmittelalters so genau wie möglich vergleichend zu rekonstruieren; zu diesem Zweck hat er auch die meisten norddeutschen „Handlungsbücher" des 14. Jahrhunderts in seine Analyse einbezogen und sich dabei nicht mit den Drucken begnügt, sondern auch die Handschriften untersucht. Da sich seit den Herausgebern niemand mehr unter schriftgutkundlichen Gesichtspunkten mit diesen „Büchern“ befasst hatte, ${ }^{78}$ stellen Bastians Untersuchungsergebnisse die letzten fachkundigen Äußerungen zu ihrer Entstehungsgeschichte dar. Bastians Äußerungen müssen natürlich - noch bis heute - von jedem beachtet und erwogen werden, der sich mit einem dieser Bücher beschäftigen will, selbst wenn es „nur" um inhaltliche Auswertung gehen soll. Darauf hatte vor mehr als einem halben Jahrhundert Wilhelm Koppe aufmerksam gemacht. als er

\footnotetext{
${ }^{76}$ Franz BASTIAN, Das Runtingerbuch 1383-1407 und verwandtes Material zum Regensburger-südostdeutschen Handel und Münzwesen 1-3 (Deutsche Handelsakten des Mittelalters und der Neuzeit 6, 1-3), Regensburg 1944. 1935, 1943, weiterhin zitiert BASTIAN I usf.

${ }^{77}$ Obwohl sein Werk unübersehbar ist und bleibt, fällt es heute nicht leicht. Informationen über die Person dieses originellen und scharfsinnigen Gelehrten zusammenzutragen. Im Deutschen Biographischen Index, 2. kumulierte und erweiterte Ausgabe München 1998, Bd. 1, S. 176, kommt der Name nicht vor; auch „Bosls Bayerische Biographie“, von einem zu seiner Zeit sehr einflussreichen Münchner Mittelalterhistoriker herausgegeben und 1983 bei einem Regensburger Verlag erschienen, enthält keinen Artikel. Eben so wenig führen die zeitgenössischen Nachschlagewerke weiter. In „Kürschners Deutschem Gelehrten-Kalender“ fehlt BASTIAN, weil der Mitarbeiter der Historischen Kommission bei der Bayerischen Akademic der Wissenschaften nie einen Professorentitel bekommen hat; sich um die Aufnahme in das ,Wer ist wer ?" oder gar in das ,.Reichshandbuch der deutschen Gesellschaft" zu bemühen, war er sicherlich nicht eitel genug. Auch bei Wiltrud EIKENBERG, Das Handelshaus der Runtinger zu Regensburg. Ein Spiegel süddeutschen Rechts-. Handels- und Wirtschaftslebens im ausgehenden 14. Jahrhundert. Mit einem Beitrag von Walter BoLL (Veröffentlichungen des Max-Planck-Instituts für Geschichte 43), Göttingen 1976. die Bastıans Publikation eingehend (S. 3-8) gewürdigt hat. gibt es weder biographische Details noch einen Hinweis auf eine Stelle, an der man sie finden könnte. Dasselbe gilt für das "Geleitwort", das der geborene Bayer und Freund BASTIANS Hermann HFiMPEL dem Buch mitgegeben hat (S. XVII). Relativ eingehend ist Bastians dienstliche Tätigkeit immerhin behandelt von Hermann AUBIN. Deutsche Handelsakten des Mittelalters und der Neuzeit. in: Die Historische Kommission bei der Bayerischen Akademie der Wissenschaften, Göttingen 1958. S. 158-165, hier S. 160-163. Vgl, auch noch BASTIAN I. S. VII-IX (,Vorwort” mit autobiographischen Elementen) und Hermann HEIMPEL, Aspekte. Alte und neue Texte, hg. von Sabine KRÜGER, Göttingen 1995, S. 173f. Birgit NOODT, Fritz Rörig ( I882-1952): Lübeck. Hanse und Volksgeschichte. in: ZVLGA 87, 2007, S. 155-180, hier S. 179, hat neuerdings zwar, anhand des Rörig-Nachlasses, von Rörigs Reaktion „auf Kritik des Herausgebers des Runtinger-Buches an ihm“ in ,einem empörten, vierseitigen Brief an den Förderer des Projektes, Hermann Heimpel“ berichtet, BASTIANS Namen aber nicht erwähnt.

${ }^{7 \mathrm{~K}}$ Ausnahme: KOPPMANN als Rezensent des Wittenborchbuchs, der aber wahrscheinlich die Handschrift nicht gesehen hat.
} 
das Werk in dieser Zeitschrift besprach. ${ }^{79}$ Aber diese Rezension scheint in der neueren deutschen Hanseforschung ebenso gründlich in Vergessenheit geraten zu sein wie das Werk selbst. ${ }^{80}$ Auf Einzelnes aus Bastians Arbeit wird hier immer wieder zurückzukommen sein.

\section{Der Mann Johan Wittenborch: Vorfahren und Verwandte, Lebensgeschichte, Karriere im Lübecker Rat}

Was wissen wir über den Mann Johan Wittenborch? Die gesicherten äuBeren Lebensdaten könnten zwar in wenigen Sätzen dargestellt werden. Wenn man aber über diese ebenso unstrittigen wie banalen Fakten hinauskommen will, bedarf es sorgfältigster Analyse aller Quellen, die entgegen dem ersten Anschein alles andere als reichhaltig und lückenlos sind. Johan war der Sohn und anscheinend das einzige Kind eines Lübecker Kaufmanns namens Herman Wittenborch ${ }^{81}$ und seiner Frau Margarete Grope. ${ }^{82}$ Über die Vorfahren von Johans Vater hat auch Mollwo nichts herausfinden können. Wenn Herman selbst erst nach Lübeck eingewandert und dort Bürger geworden ist, dann ist das in einer Zeit geschehen, aus der keine Bürgeraufnahmelisten erhalten geblieben sind; denn er hat bereits 1310 in der Stadt Grundeigentum erworben. ${ }^{83}$ Über seine Seitenverwandten ist nicht viel mehr bekannt. ${ }^{84}$ Auch Margarete ist bisher als eine Frau ohne

${ }^{74}$ HGBll 70, 1951, S. 114-116. Die Besprechung enthält aber auch deutliche Kritik an BASTIANS Neigung, über die ihm eigentlich ziemlich fremden Verhältnisse der Lübecker Kaufmannschaft apodiktische Urteile abzugeben. So weit sich KoPPES Bemerkungen auf die Geschäfte von Lübeckern mit Frankfurt am Main beziehen, ist neuerdings die schon 1951 angekündigte Studic von Wilhelm KOPPE über ,.Die Lübecker Frankfurt-Händler des 14. Jahrhunderts" zu vergleichen, die kürzlich aus dem Nachlass des 1986 verstorbenen Verfassers von seinem Sohn Gert KOPPE in überarbeiteter Fassung zum Druck gebracht worden ist (Veröffentlichungen zur Geschichte der Hansestadt Lübeck B, 42, Lübeck 2006). Auch sonst ist es natürlich nicht angezeigt. BASTIANS Aussagen zu einzelnen Sachfragen einfach ohne Nachprüfung für bare Münze zu nehmen.

${ }^{80}$ Für Benutzer, die an den norddeutschen Aspekten interessiert sind, handelt es sich natürlich vor allem um den zuletzt erschienenen Band 1. den ,Darstellungs“-Band. Bei KOPPE u. KOPPE a.a.O. ist das Buch selbstverständlich - auf S. 277 - verzeichnet. Sonst ist mir die jüngste Erwähnung begegnet bei Ahasver VON BRANDT, Mittelalterliche Bürgertestamente. Neuerschlossene Quellen zur Geschichte der materiellen und geistigen Kultur (Sitzungsberichte der Heidelberger Akademie der Wissenschaften. Philosophisch-historische Klasse Jg. 1973. 3), Heidelberg 1973. S. 21 mit Anm. 32.

${ }^{81}$ Das ist erst seit MoLı.wo bekannt. Die älteren Lübecker Genealogen hatten Johan zum Sohn des Bürgermeisters Hinrik Wittenborch (LUTTERBECK Nr. 300) und Urenkel eines anderen gleichnamigen Bürgermeisters des 13. Jh.s (LUTTERBECK Nr. 299) erklärt: MANTELS, Schiffshauptleute (wie Anm. 11), S. 187f., kommentarloses Referat.

${ }^{82}$ Das wissen wir zunächst einfach deshalb, weil sie sich als Witwe zweimal selbst so genannt hat, siehe unten mit Anm. 135.

${ }^{83}$ Mollwo S. IV mit Anm. I.

${ }^{84}$ Einem avunculus (Neffen ?) namens Kopeke Hoykendorp hatte Herman, anscheinend 
bekannte Vorfahren erschienen; ${ }^{85}$ sehr wahrscheinlich war sie aber eine Tochter des Herrn Alvin ${ }^{86}$ Grope, ${ }^{87}$ der zwischen 1301 und 1325 im Lübecker Rat gesessen hat ${ }^{88}$ und einen nur schwach bezeugten, vielleicht relativ

aus Gefälligkeit, cin Darlehen von $10 \mathrm{ml}$. gewährt (Handlungsbuch (wie Anm. 55) S. 3, Nr. I 17), keine Kleinigkeit, wenn man bedenkı, dass dies etwa dem Halbjahresertrag einer auskömmlich ausgestatteten Messpriesterpfründe (Vikarie) entsprach. Ein nicht namentlich genannter (1vunculus (derselbe ?), hat sich, wohl zu einem früheren Zeitpunkt, mit 10 ma, also $20 \mathrm{ml}$., an einer vera societas beteiligt, die Herman mit einem Johan Holt abgeschlossen hatte (Handlungsbuch (wie Anm. 55) S. 1, Nr. I 4; dazu CORDES, Gesellschaftshandel, wie Anm. 72, S. 208). Die 21 Druckseiten umfassende „Zusammenstellung der Nachweise über die Familie Wittenborgs“ bei MolLwo S. XX-XXX, die nach der Fußnote auf S. XX ,alle Mitglieder der Familie Wittenborg" enthalten soll, ist tatsächlich eine Liste aller (?) Lübecker Träger des Zweitnamens „Wittenborch“ zwischen dem ausgehenden 13. und dem frühen 15. Jh. Wer es nicht schon wusste, erfährt hier, dass dieser Zweitname im spätmittelalterlichen Lübeck sehr häufig war - kein Wunder, da die namengebende Stadt in der Grafschaft Schwerin ja nur eine Tagereise von Lübeck entfernt ist. Keine Verwandten „unseres" Herman waren vor allem mit an Sicherheit grenzender Wahrscheinlichkeit alle vier Personen, die MOLLwo S. III und XXXI (,Stammbaum der Familie Wittenborg“) für Hermans Geschwister erklärt hat; dazu bereits KoppMANN, Rezension (wie oben Anm. 67), S. 190. Daher kennen wir auch keine Nachkommen von Seitenverwandten Hermans. Darum hätte es sich nur handeln können bei Johan Wittenborchs 1359 gestorbenem Mitarbeiter Bertolt Wittenborch, wenn MOLLwos Behauptung (S. LVIII), es habe sich um einen „entfernten jüngeren Verwandten“ gehandelt. begründet wäre. Über eine alleinstehende ältere Verwandte unbekannten Verwandtschaftsgrads namens Alheid van Wittenborch, die $1331 \mathrm{ihr}$ Testament gemacht hat, siehe unten mit Anm. 316.

${ }^{85}$ MOLLwo S. III: „Margarethe Grope“; HAMMEL 1982, S. 303: „Margarethe geb. Grope“. Nur ASMUSSEN, Flandernfahrer (wie Anm. 74), S. 885, hat ohne Begründung einen „Lübecker Bürger Alwin Grope“ als Johan Wittenborchs Großvater namhaft gemacht.

${ }^{86}$ Der Name kommt, so weit ich sehe, nur in der lateinischen Form „Alvinus“" o. ä. vor und steht vielleicht einfach für „Alf“, die Kontraktionsform von „Adolf“. Dafür scheint jedenfalls die Geschichte des Straßennamens „Alfstraße“ zu sprechen (Datenbasis für das folgende ist Thomas KRÜGER, Die Straßennamen der Lübecker Innenstadt unter Berücksichtigung der Überlieferung bis 1600, [masch.| Zulassungsarbeit für die Prüfung für das Lehramt an Höheren Schulen Kiel 1983, S. 40-42; für den Hinweis auf den Titel danke ich meiner Hamburger Kollegin Dagmar HEMMIE). Die Straße hieß in den bis ins 15. Jh. hinein fast ausschließlich lateinischen Quellen zunächst, erstmals schon 1227 belegt, „platea Adolfi““. Der volkstümliche deutsche Name begegnet als „Alvesstrate“ zuerst 1419, schon 1347 aber, ganz vereinzelt, als "platea Alfi“. Aus der Sicht eines lateinisch gebildeten Ratsnotars war dies gewiss eine sehr unelegante Form der Latinisierung von „Alf“; andere Versuche reichen von „Alfei“ über „Alevi“" und „Alvini“ (mit 1287 sehr früh und danach relativ häufig belegt) bis zu geradezu komischem „Alvelini“ (nur um 1400, vermutlich der Einfall eines bestimmten Notars). Krügers eigene Versuche, mit diesen verwirrenden Befunden umzugehen, bezeugen nur, dass auch er keine rechte Vorstellung davon hatte, wie es im Spätmittelalter zuging, wenn Leute, deren ganzer Alltag volkssprachlich verlief, in bestimmten traditionellen Teilbereichen ihrer Berufstätigkeit Latein schreiben mussten. KRÜGER wollte hinter „Alvini“ usw. ,einen anderen [deutschen] Personennamen“ als Adolf/Alf sehen, konnte aber keinen nennen.

${ }^{87}$ Latinisiert kommt der Name gelegentlich als „Olla“" (= der Grapen) vor.

${ }^{88}$ LUTTERBECK Nr. 108 (S. 264f.); hierher alle weiteren Angaben über den Ratmann, wenn nicht andere Literatur oder eine Quellennachricht genannt wird. Der Artikel nennt als Herrn Alvins Kinder nur, zu 1332, zwei Söhne Alvin und Hinrik; der Verf. hat also Herrn Alvin nicht als Vater der Margarete Grope-Wittenborch und ihrer im Wittenborch-Material namentlich erwähnten beiden Brüder Goswin und Hinrik Grope (über sie weiter unten) angesehen. 
jung verstorbenen Ratmann Werner Grope zum Vater hatte. ${ }^{89}$ Dann hätte Margarete Grope-Wittenborch also aus einer (spätestens) im 3. Viertel des 13. Jahrhunderts begründeten Lübecker Ratsfamilie gestammt. Obwohl der Name „Grope“ im Lübeck der ersten Jahrzehnte des 14. Jahrhunderts nicht häufig vorkommt, ${ }^{90}$ ist cs unter den Quellenbedingungen der Zeit nicht leicht, es wenigstens hochwahrscheinlich zu machen, dass Herr Alvin der Vater von Margarete Grope-Wittenborch war. Denn nicht genug, dass diese Margarete nie als jemandes Tochter erscheint, gibt es auch allem Anschein nach keine Quelle, in der Herrn Alvins Kinder namentlich genannt sind. Außerdem hat es damals auch einen ,einfachen“ Bürger Alvin Grope gegeben, dessen Lebenszeit als Erwachsener sich mit der des Ratmanns überschnitten haben könnte. Es lässt sich nicht von vornherein auf Anhieb entscheiden, wer von den beiden gemeint ist, wenn in einer Quelle ein „Alvinus Grope“ auftaucht. Denn damals wurden noch durchaus nicht alle Ratmannen bei jedem Auftreten mit dem Titel „dominus" geehrt oder als „consul" bezeichnet. Dieser Gebrauch scheint sich in Lübeck, nach den „Societates“-Einträgen des ersten erhaltenen Niederstadtbuchs zu urteilen, erst im Laufe der 1330er Jahre durchgesetzt zu haben. ${ }^{91}$ Und der Ratmann Alvin Grope ist offenbar in den Lübecker Quel-

${ }^{89}$ LUTTERBECK Nr. 109 (S. 265). Danach käme er überhaupt nur zweimal in den Quellen vor, 1275 als Ratmann und 1290 (wohl bereits tot, siehe unten mit Anm. 98) mit seinem Sohn Alvin, einer Tochter und deren Mann Henneke Wullenpunt.

${ }^{* 0}$ Außer den im Folgenden zu besprechenden Namensträgern kenne ich aus der hier interessierenden Zeit nur noch den Tideman Grope, mit dem Herman Wittenborch, vermutlich um 1330, ein Gesellschaftsverhältnis eingegangen ist: Handlungsbuch (wie Anm. 55) S. I, Nr. I 2 (mit Übertragungstehler "Thidemanus"; die Handschrift hat richtig Thidemanno); inm bin ich nicht nachgegangen. Zur Sache vgl. CORDES, Gesellschaftshandel (wie Anm. 72), S. 206-209.

"I Societates. Das Verzeichnis der Handelsgesellschaften im Lübecker Niederstadtbuch 1311 - 1361, hg. von Albrecht CORDES, Klaus FRIEDLAND und Rolf SPRANDEL unter Mitarbeit von Holger GROPP und Ulrich SIMON (Quellen und Darstellungen zur hansischen Geschichte N.F. 54), Köln usw. 2003. Ich beziehe mich auf diese Quelle, weil sie die einzige Lübecker serielle dieses Zeitraums ist, die im Druck vorliegt. In der oft so redseligen Darstellung von LUTTERBECK gibt es über das Problem der Unterscheidung von Ratmannen und ihren nicht ratsangehörigen gleichzeitigen Namensvettern, das für weit mehr als die Hälfte seines Untersuchungszeitraums von Belang ist, nicht einen einzigen Satz. Stattdessen findet man auf S. 32f. nach Ausführungen über Fälle, in denen stadtsässige, nichtritterliche Laien als ..dominus" bezeichnet wurden, obwohl sie keine Ratsmitglieder waren, die Aussage, ,die Titulierung als dominus (erfolge) in den Quellen doch insgesamt recht präzise" - mit Beispielen aus den 1380er Jahren. Ergänzt wird dies durch die (hier) beleglose Behauptung: „zumindest im innerstädtischen Gebrauch gehörte die Titulatur dominus bzw. her für Ratsherren schon in der zweiten Hälfte des 13. Jh.s zu den üblichen Umgangsformen“. Vermutlich handelt es sich um Paraphrasierung von Wilhelm EBEL, Lübisches Recht. Bd. I, Lübeck 1971, S. 238: „im innerstädtischen Verkehr wird (die Titulatur) in der Mitte des 13. Jh.s gebräuchlich" (in Anm. 1 Hinweis auf die Stadtbücher von Wismar und Rostock); die Stelle ist bei LUTTERBECK zitiert S. 31, Anm. 131. 
len der Zeit oft nicht als Ratmann charakterisiert worden." ${ }^{92}$ Die Unterscheidung zwischen den beiden Gleichnamigen muss also nach anderen Kriterien getroffen werden.

Dass die Oldenborchsche Ratslinie das Todesjahr des Ratmanns mit 1325 richtig angegeben hat, kann kaum zweifelhaft sein; ${ }^{93}$ da er sein Wohnhaus Breite Straße 1/3 schon 1290 besessen hat, wird er bei seinem Tod mindestens etwa 60 Jahre alt gewesen sein. Der gleichnamige Bürger ist sehr wahrscheinlich ein erwachsener Sohn des Ratmanns gewesen, der aber relativ jung, bald nach der Heirat und der Erwerbung eines eigenen Wohnhauses, gestorben ist. Das ergibt sich aus der Besitzgeschichte des Hauses Königstr. 42 (Jakobi-Quartier 662 in der Nummernfolge von 1820), soweit in ihr Träger des Namens Grope vorkommen: ${ }^{94} 1301$ hat

${ }^{92}$ Nur in den Urkunden, in denen er als einer der Provisoren des Johannisklosters genannt wird, sieht es meist anders aus; siehe dazu unten mit Anm. 459.

${ }^{43}$ Am 19. Februar 1324 ist er letztmalig als Ratszeuge bei einer Testamentserrichtung belegt: Regesten der Lübecker Bürgertestamente. Bearb. u. hg. von A. vON BRANDT. Bd. 1: 1278-1350 (Veröffentlichungen zur Geschichte der Hansestadt Lübeck 18), Lübeck 1964, Nr. 79 (S. 52). Dieser Band und Bd. 2: 1351-1363 (Veröffentlichungen ... 24), Lübeck 1973, werden weiterhin als Reg. Test. 1 und 2 zitiert.

${ }^{94}$ Das Folgende nach AHL Hs. 900a, S. 550. Bei dieser 1846 fertiggestellten Handschrift handelt es sich um den Jakobi-Quartier-Teil der sogenannten Schroederschen Topographischen Regesten, ausführlichen, größtenteils wortwörtlichen Auszügen aus den chronologisch geführten Oberstadtbuchbänden des Zeitraums 1284-1600. die vom Bearbeiter H. Schroeder „Zu Grundbuchblättern für die einzelnen Grundstücke zusammengestellt worden“ sind. Über die mit dieser abgeleiteten Quelle verbundenen quellenkundlichen und quellenkritischen Probleme hat zuletzt eingehend gehandelt Rolf HAMMEL[-KIESOW], Hauseigentum im spätmittelalterlichen Lübeck. Methoden zur sozial- und wirtschaftsgeschichtlichen Auswertung der Lübecker Oberstadtbuchregesten, in: Lübecker Schriften zur Archäologie und Kulturgeschichte 10, 1987. S. 85-300, hier S. 98-116 (das wörtliche Zitat von S. 98). Neben diesen für die wissenschaftliche Nutzung grundlegenden .Regesten“ (die „Exzerpte“ sind nach Mollwo, „Vorwort“ S. [2], schon von ihm, aber noch auf dem Lübecker Hypothekenamt, benutzt worden) gibt es von Schroeder im Archiv der Hansestadt Lübeck nach Rep. 81 Hss. zwei weitere Handschriftengruppen, die das gleiche Sachgebiet betreffen: Erstens sind unter der Signatur „Hs. 850e-m“ vorhanden „8 Bände Vorarbeiten zum Top[ographischen] Replertorium] 14.-19. Jahrhundert", die frühestens 1899 ins Archiv gelangt sein können; ich habe sie nicht benutzt. Zweitens kamen 1899 mit einer Handschriften-,,Ablieferung des Vereins für Lübeckische Geschichte“, die als Hs. 843-850d verzeichnet wurde, auch vier Bände, Hs. 850 a. b. c. d, ins Archiv, die dort als ,Schroeder: Lübeck im 14ten, 15ten, 16ten und 17ten Jahrhundert, Topographisches" beschrieben sind. Es handelt sich um eine deutschsprachige Bearbeitung des Oberstadtbuchmaterials, die vermutlich auf den „Vorarbeiten“, nicht auf den "Regesten" beruht (dort ist ja das 17. Jh. gar nicht berücksichtigt). Über den Zweck dieser Bearbeitung scheint bisher nichts bekannt zu sein. Sie ist, nach Stichproben zu urteilen. knapper, bietet aber hier und da auch eine Interpretation der Quellennachrichten (vgl. dazu unten mit Anm. 95, 98 und 102). Auch sie hat, wie die "Regesten“ (s. HAMMEL a.a.O. S. 99 mit Anm. 13), alle Angaben des Oberstadtbuchs weggelassen, die Hausrenten betreffen. Von dieser Bearbeitung habe ich Hs. 850a, Lübeck im 14. Jh., mitbenutzt; die Angaben zur Königstraße 42 stehen auf S. 171. Vgl. auch LuTTERBECK S. 264, der die im folgenden zu nennenden Daten von 1301, 1303 und 1305 richtig auf den Ratmann Alvin Grope bezogen hat, obwohl es in den "Regesten" nirgends den geringsten Hinweis darauf gibt, dass der dort 
Alvin Grope beurkunden lassen, dass Johan Wullenpund [sein Schwager ?] bekannt hat, ihm ,vor mehreren Jahren“ die Hälfte des Hauses verkauft zu haben, 1303 besaß er $3 / 4$ davon, 1305 kaufte er auch noch das letzte Viertel ,des Hauses, in dem er wohnt". 1332 hat „Alvin Grope von seiner Mutter und seinen übrigen Brüdern und Schwestern das Haus ... gekauft" - vor diesem Jahr ist also der Alvin Grope der Jahre 1301-1305, doch wohl der Ratmann, gestorben; seine Witwe und die - mindestens fünf gemeinsamen Kinder haben das Haus geerbt. Der gleichnamige (älteste ?) Sohn erwarb jetzt das Haus, ${ }^{95}$ sicherlich für das Geschäft und die Familie, die er begründet hatte. Im gleichen Jahr 1332 hat (derselbe) Alvin Grope „das Haus Königstr. 664, das seine Frau ihm zugebracht hatte“, verkauft; die Frau war „Margareta, Witwe des Rodolfus de Dulmen“. Der Start eines neuen Unternehmens und einer jungen Familie hat offenbar schnell ein trauriges Ende genommen: Bereits 1333 wurde das Haus Königstraße 42 ,von Margareta, Witwe des Alvin Grope“, verkauft ${ }^{96}$. Bis zum Beweis des Gegenteils wird man unterstellen dürfen, dass aus dieser kurzen Ehe keine Kinder hervorgegangen sind. Nach all dem können „unsere“ Margarete Grope und ihre später zu besprechenden Geschwister, wenn sie denn zu dieser Familie gehört haben, keinesfalls Kinder des ,jüngeren“ Alvin Grope gewesen sein. Dann muss auch der Henricus filius Alvini Gropen, dem unter dem Datum des 15. Juli 1332 eine am 8. September 1333 fällige Forderung von $50 \mathrm{ml}$. beurkundet wurde, ein Sohn des Ratmanns gewesen sein; ${ }^{97}$ wie wir sehen werden, hatte ,unsere“ Margarete einen kaufmännisch tätigen Bruder Hinrik, der um 1340 im Wittenborch-

genannte Alvinus Grope dem Rat angehört hat. Offenbar hat LUTTERBECK hier mit anderen Verfahren zur Ermittlung von Ratmannen gearbeitet als den von ihm selbst erklärten.

${ }^{95}$ In Schroeders deutscher Bearbeitung ist der oben von mir übersetzte und kommentierte lateinische Text so wiedergegeben: „1332 kaufte Alfwin [!?] Grope junior die Antheile seiner Mutter und seiner Geschwister". Schroeder hat hier also einerseits zutreffend interpretiert (,junior"), andererseits aber unzulässig vereinfacht: Wenn man sich auf seinen Ausdruck "Geschwister" verlassen würde, dürfte man die Zahl der Kinder nur mit „mindestens drei“ veranschlagen. - LUTTERBECK S. 264 mit Anm. 1738 hat aus dieser Nachricht zwar ebenfalls geschlossen, dass der Ratmann Alvin Grope einen gleichnamigen Sohn gehabt hat; dessen mindestens vier Geschwister hat er aber "unterschlagen“.

96 AHL Personenkartei. Aus den Schroederschen Topographischen Regesten, AHL Hs.900a/2. S. 552. zum Haus Königstraße Jakobi-Quartier Nr. 664 = Königstraße 38 erfahren wir außerdem noch. dass Margareta bereits 1331 als Witwe des Rodolf van Dulmen erwähnt wird: damals hat sie von ihren Kindern (pueris) alle vom verstorbenen Vater geerbten Anteile an dem Haus gekauft. Ein paar Jahre später treffen wir diese Kinder auch im WittenborchMaterial an: Zusammen mit den filiis Rodolphi de Dulmen hat Herman eine Rente besessen: Handlungsbuch (wie Anm. 55) S. 5, Nr. I 31. Die Nachricht vom frühen Tod des jüngeren Alvin Grope steht wieder in AHL Hs. 900a/2, S. 550.

"7 AHL Niederstadtbuch 1, S. 243, 3 (nicht gelöscht). So ist die Nachricht auch von LUTTERBECK S. 264 mit Anm. 1738 gedeutet worden; er gewann damit dem Ratmann Alvin Grope ein zweites und - s. oben Anm. 95 - letztes Kind. 
Schriftgut belegt ist. Andererseits taucht dort niemals ein Bruder Alvin auf; wenn der 1332/33 gestorbene Alvin Grope Margaretes Bruder war, braucht man sich darüber nicht zu wundern.

Schon die recht hohe Personenzahl, um die es sich sowohl bei den Kindern des Ratmanns Alvin Grope wie bei Margarete Grope-Wittenborch und ihren - gleich zu besprechenden - Geschwistern gehandelt hat, stellt ein nicht zu verachtendes Indiz dafür da, dass diese beiden kurz nacheinander bezeugten Geschwister-Gruppen mit dem Familiennamen "Grope“ miteinander identisch gewesen sind. Eine zweite Hausgeschichte soll es mehr als nur wahrscheinlich machen, dass Margarete und ihre Geschwister Kinder des Herrn Alvin gewesen sind. Es handelt sich um das bereits erwähnte Doppelhaus Breite Straße 1/3 (1820: Jakobi-Quartier 770/771). ${ }^{98}$ 1290 haben Henneke Wullenpunt und seine Frau, die Tochter des Werner Grope, ihre Einwilligung dazu erteilt, dass Alvin Grope, der Sohn des Werner Grope, diese seine beiden Häuser beim Jakobikirchhof ganz wie seine Kaufmannsgüter gebrauchen dürfe; daraus hat schon der Topograph Schroeder in der deutschen Bearbeitung seiner Regesten gefolgert, wahrscheinlich zu Recht, dass „Alfwin [!] Grope [diese] zwei Häuser ... von seinem Vater Werner Grope geerbt hatte"; dieser wäre also 1290 schon tot gewesen. 1315 hat Johan Smale die beiden Häuser von Alvin Grope gekauft. Näheres über dies Geschäft, das am 1. August beurkundet wurde, erfahren wir aus einer Position im letzten Jahrgang von Fritz Rörigs Oberstadtbuchregesten: ${ }^{99}$ Vermutlich, weil der Käufer das Objekt nicht bar bezahlen konnte, wurde ihm der Kaufpreis oder ein größerer Teil davon gestundet; er verpflichtete sich, dem Verkäufer künftig eine Rente von jährlich $16 \mathrm{ml}$. zu zahlen, von der jede $\mathrm{ml}$. mit $16 \mathrm{ml}$. abgelöst werden konnte; bei einem Zinsfuß von 6,25\%, dem damals normalen, ${ }^{100}$ betrug der Kapitalwert der Rente also $256 \mathrm{ml}$. Der Rückkauf hätte auch in zwei Raten geschehen dürfen; dabei wären $6 \mathrm{ml}$. und $10 \mathrm{ml}$. Rente abzulösen gewesen. ${ }^{101}$ Die beiden Häuser wurden 1336 dem Everhard van der A, dem Ehemann der Elizabet Smale, durch die Vormünder der Gertrud Smale aufgelassen; nach dem Topographen Schroeder waren „Elisabeth Smale" und Gertrud Smale Schwestern. ${ }^{102}$ Eine der zugrundeliegenden Ober-

${ }^{98}$ Das Folgende wieder nach den Schroederschen Topographischen Regesten, AHL Hs. 900a/2, S. 637, und nach Schroeders deutscher Bearbeitung derselben Materie, Hs. 850a, S. 79 .

${ }^{49}$ AHL Hs. 1053, „Register zum [richtig: Regesten der Eintragungen im] ältesten Oberstadtbuche (1284-1315)“", Heft 41, B1. 849/850, Nr. 218.

${ }^{100}$ Ahasver VON BRANDT, Der Lübecker Rentenmarkt von 1320-1350, Diss. phil. Kiel 1935, S. 19.

${ }^{101}$ Aus dieser Bestimmung ergibt sich, dass RöRIGS Angabe über die Gesamthöhe der Rente, „18 M“. auf einem Schreibversehen beruht.

${ }_{102}$ Wie oben Anm. 98. 
stadtbucheintragung unmittelbar folgende, den Vorgang abschließend dokumentierende findet man im Wortlaut in der Edition des „Handlungsbuchs“. Danach wurde unter dem Datum des 3. März 1336 auch festgestellt, dass in diesen beiden Häusern Herman Wittenborch schon seit langem (dudum) eine Weichbildrente von $16 \mathrm{ml}$. jährlich habe, deren ursprünglicher Zinsfuß nicht mehr festzustellen ist, weil die Beträge irgendwann durch Radieren und Überschreiben geändert worden sind. Zuletzt betrug der Zinsfuß $5 \%,{ }^{103}$ so dass die Rente einen Rückkaufwert von 320 ml. hatte. ${ }^{104}$ Mit diesen Konditionen treffen wir die Rente nach Hermans Tod im Besitz seiner Witwe und ihres Sohnes Johan, ego ... Grete et Johannes filius meus, im „Handlungsbuch“ an. ${ }^{105}$ Es fiele sehr schwer, zu erklären, wie diese Rente aus dem Besitz von Herrn Alvin Grope an Herman Wittenborch und seine Erben gekommen sein könnte, wenn man nicht annehmen will, dass sie mit Margarete Grope an ihn gekommen ist; vermutlich hatte Herr Alvin sie seiner Tochter als Mitgift mitgegeben. Für enge verwandtschaftliche Beziehungen zwischen Herrn Alvin und Herman Wittenborch gibt es dann noch ein zweites Indiz: Herman hat 1333 von (mindestens) zwei namentlich nicht genannten Töchtern des Herrn Alvin Grope, die Nonnen waren, ein Darlehen empfangen, und der Vorgang muss nach den ganzen Umständen wohl als eine Transaktion unter nahen Verwandten gewertet werden. ${ }^{106}$

Herman Wittenborch, der sich, wie bereits angedeutet, etwa 1310 als selbständiger Kaufmann und vermutlich auch Ehemann etabliert haben dürfte, ist vor dem 29. März 1338 gestorben. Dass er in der Marienkirche begraben wurde, erfahren wir aus Herrn Johans Testament von 1362; denn der wollte dort ebenfalls, unter dem Grabstein seines Vaters, bestattet wer-

${ }^{103}$ Nach den Daten bei von BrandT. Rentenmarkt (wie Anm. 100), S. 20, und im Hinblick auf die nächste Erwähnung der Rente (unten mit Anm. 105) dürfte die Veränderung des Zinsfußes bald nach 1336 und vor 1342 stattgefunden haben.

${ }^{10}$ Handlungsbuch (wie Anm. 55) S. 69, Nr. IV 8 mit Anm. 9 und 10; in der 1. Zeile des lateinischen Textes ist unverständliches ,Everhardus“ zu Everhardo zu emendieren. In Anm. 10 hat Mollwo bereits hingewiesen auf Carl Wilhelm PAULI, Die s. g. Wieboldsrenten oder die Rentenkäufe des Lübischen Rechts. Größtentheils aus ungedruckten Quellen (DERS., Abhandlungen aus dem Lübischen Rechte 4), Lübeck 1865, S. 78f., wo derartige Veränderungen an älteren Renten in der Zeit behandelt sind, als der fünfprozentige Rentenzins allgemein üblich wurde.

${ }^{105}$ Handlungsbuch (wie Anm. 55) S. 6, Nr. I 44. Die Rente ist dann noch mehr als ein Jahrzehnt lang gezahlt worden. 1353 sind die Häuser aber an Herrn Johan gefallen, weil dies nicht mehr geschehen war. Sie sind dann so lange in seinem und seiner Erben Eigentum geblieben, bis sie 1380 ein gewisser Godeke Vrese „als Mitgift mit seiner Frau Taleke, Herrn Johann Wittenborchs Tochter" erwarb: AHL Hs. 900a/2, S. 637 (vgl. oben Anm. 98). Vgl. Handlungsbuch (wie Anm. 55) S. 21, Nr. II 91 mit S. 72, Nr. IV 19 und S. 40. Nr. II 262. Nach Mollwo S. VII mit Anm. 8 und X mit Anm. 1 ist diese Ehe schon 1374 geschlossen worden.

${ }^{116}$ Siehe dazu unten mit Anm. 118-120. 
den. ${ }^{107}$ Unter dem Datum „Judica 1338“ begegnen uns „Witwe und Knabe (puer) des Herman Wittenborch" im Oberstadtbuch mit einem Rentenkauf, ${ }^{\prime 118}$ der in ausführlicherer Formulierung auch im „Handlungsbuch“ dokumentiert ist, ${ }^{109}$ die Erwerber erscheinen hier als „,ich Margareta und Johan mein Sohn“. Unter dem Datum des darauffolgenden Palmsonntags wurde der Witwe und ihrem filius eine weitere Rente zugeschrieben. "II Damit wurde die bereits besprochene $16 \mathrm{ml}$.-Rente um $14 \mathrm{ml}$. jährlich im Kapitalwert von $280 \mathrm{ml}$. vermehrt. Das zeigt schon, dass Herman seine Familie nicht als arme Leute zurückgelassen hat. Bei den Rentenkäufen des Frühjahrs 1338 hat es sich aber beileibe noch nicht darum gehandelt, dass hier bereits ein großer Teil vom Geschäftskapital des verstorbenen Vaters angelegt worden wäre.

Denn über den Vater lässt sich begründet sagen, dass er zwar nicht zu den reichsten Lübeckern seiner Zeit gehört hat, dass er aber dennoch ein erfolgreicher Kaufmann gewesen ist. Das ergibt sich quantitativ aus den Buchungen am Anfang des überlieferten „Buchs“."11 Diese stellen nicht Hermans „Handlungsbuch“ dar, wie Mollwo diesen Komplex genannt hat. Dank Bastian wissen wir, dass der Grundtext dieser Folge von inhaltlich ganz unterschiedlichen Buchungen in einem Zuge niedergeschrieben, also abgeschrieben worden ist; vermutlich handelt es sich nur um die Sachverhalte, die zum Zeitpunkt der Niederschrift noch nicht erledigt waren. ${ }^{112}$ Wir dürfen den Komplex also wohl als eine Vermögensaufstellung werten und die Beträge addieren. ${ }^{113}$ Damit kommen wir für den unbaren, in For-

${ }^{107}$ Handlungsbuch (wie Anm. 55) S. 89, Nr. VI 3.
${ }^{108}$ Handlungsbuch (wie Anm. 55) S. 69. Nr. IV 9.
${ }^{109}$ Handlungsbuch (wie Anm. 55) S. 8 . Nr. I 72.
${ }^{10}$ Handlungsbuch (wie Anm. 55) S. 69 f., Nr. IV 10, 2. Teil, mit falscher Datumsauflösung „März 29" statt April 5; nach der entsprechenden Buchung im „Handlungsbuch" selbst. Handlungsbuch (wie Anm. 55) S. 8, Nr. I 73, hat die Zuschreibung tatsächlich erst am 8. April stattgefunden.

11 Handlungsbuch (wie Anm. 55) S. 1-6.

112 BASTIAN 1, S. 217 u. 261. BASTIAN sprach zutreffend einerseits von den „42 ersten Hauptbuchungen“, andererseits von der „Hauptfeder [d. h., dem ununterbrochenen Schreibvorgang] von I I - I 43"; Handlungsbuch (wie Anm. 55) S. I, Nr. I 6 ist ein Nachtrag von anderer Hand. Wer hier abgeschrieben hat, und wann das geschehen ist (doch wohl irgendwann um Hermans Todestag herum). ist ungewiss: die jüngste genau datierbare Eintragung, Handlungsbuch (wie Anm. 55) S. 5f., Nr. I 35, nimmt Bezug auf eine Beurkundung im Niederstadtbuch vom 29. Juni 1336 (vgl. BASTIAN 1. S. 261). Mol.Lwo hat behauptet. die $\$ \$$ 1-43 seien von Herman geschrieben. Dafür könnte es sprechen, dass diese Hand, so weit ich sehe, später nie mehr vorkommt. Auch der Besitzvermerk auf der Vorderseite des Umschlags (Mollwo S. XXXIV, Anm. I: Ista sibi pertinent Hermanno Wittenborch) lässt sich als weiteres Argument anführen; allerdings habe ich auch diese Hand anderswo nicht wiederfinden können, auch nicht in den Händen, von denen die $\$ \$ 1-43$ stammen. KOPPMANN, Rezension (wie Anm. 67) S. 193 hat seine Zweifel nicht begründet. Die Frage wird sich wahrscheinlich überhaupt nicht klären lassen. 
derungen bestehenden Teil von Hermans Geldvermögen auf eine Summe von über $3000 \mathrm{ml}$. Dieser Teil bestand hauptsächlich aus Gesellschaftsanteilen, Rententiteln und Forderungen aus Warengeschäften. Der Kapitalwert der Rentenbezugsrechte von mehr als $80 \mathrm{ml}$. jährlich betrug etwa $1000 \mathrm{ml} .{ }^{1 / 4}$ Die Durchschnittsrendite war also erheblich höher als die der Stadtlübecker Fünfprozenter. Dieser Typ war in Hermans Portefeuille denn auch nur ein einziges Mal vertreten; ${ }^{115}$ das übrige Geld war außerhalb der Stadt Lübeck angelegt. Die Außenstände aus der Gewährung von Kredit im Warenhandel betrugen über $770 \mathrm{ml} .{ }^{116}$ diese Forderungen waren natürlich nicht alle gleich gut. Aber selbst wenn sich die eine oder andere als faul erwiesen haben sollte, ${ }^{117}$ konnte die Witwe mit ihrem Sohn doch schon von den Zinsen des Rentenvermögens, maximal etwa $110 \mathrm{ml}$. jährlich, sehr gut leben. Eine einzige Schuldposition von $80 \mathrm{ml}$. ist 1333 wohl im beiderseitigen Interesse unter nahe Verwandten begründet worden. Der Kredit kostete Herman jährlich $4 \mathrm{ml}$. Zinsen, also nicht mehr als den derzeit ,absolut herrschend[en]“ Rentenmarktsatz von $5 \%,{ }^{118}$ mit dem er sich selbst, wie gesagt, normalerweise nicht begnügt hat. Das Kapital war durch einen Schuldeintrag im Niederstadtbuch gesichert. Es gehörte den

\footnotetext{
${ }^{113}$ Mit der gebotenen Vorsicht: So betreffen einzelne Buchungen offenbar ein späteres Stadium eines bereits vorher verbuchten Geschäftsvorgangs. Das gilt zweifelsfrei für das Verhältnis zwischen Handlungsbuch (wie Anm. 55) I 25 und I 15; dazu ausführlich CORDES, Gesellschaftshandel (wie Anm. 72), S. 209-212.

${ }^{114}$ Handlungsbuch (wie Anm. 55) S. 1-5, Nr. I 9, 12, 21, 26-28 und 31. Nur bei drei Titeln ist sowohl die Rente wie ihr Kapitalwert überliefert. Ich habe das Landgut als Zehnprozenter bewertet. - Verglichen mit den Beträgen, die von wirklich reichen Leuten in den ersten Jahrzehnten des 14. Jh.s allein auf dem städtischen Hausrentenmarkt angelegt worden sind (siehe VON BRANDT, Rentenmarkt, wie uben Anm. 100, S. 22-34), sind $1000 \mathrm{ml}$, ein eher bescheidener Betrag, selbst wenn man im Auge behält, dass bekanntlich mancher Hausrentenkauf in der Stadt nur der Wiederanlage von Geldern gedient haben dürfte, die von den bisherigen Schuldnern gekündigt worden waren.

${ }^{115}$ Handlungsbuch (wie Anm. 55) S. 5, Nr. I 28, 7 ml. Rente; der Hinweis auf „I 19“" in Anm. 21 ist unbegründet. MOLLwo hat keine Oberstadtbuch-Eintragung nachgewiesen, in der dieser Rentenkauf beurkundet worden wäre. - Die oben mit Anm. 99-105 erörterte 16 ml.-Rente im Kapitalwert von zuletzt $320 \mathrm{ml}$. aus Breite Str. 1/3, die im „Handlungsbuch“ erst bei Hermans Witwe sichtbar wird, ist in diesem Überblick nicht enthalten.

${ }^{116}$ Handlungsbuch (wie Anm. 55) S. 3-6, Nr. I 16, 24 (vgl. 32), 29, 33, 35 und 37. Die Aufstellung enthält nichts über noch unverkaufte Waren; diese oder wenigstens einen Teil davon erfassen wir dann möglicherweise in den Aufzeichnungen von Hermans Witwe, siehe unten mit Anm. 136.

${ }^{117}$ Das könnte insbesondere für einige Forderungen an Adlige getten. Einem Herrn Johan Bulowe (Bülow) gegenüber hatten Herman und seine Mitgläubiger bereits zum letzten Mittel gegriffen und den Rektor der Jakobischule beauftragt. gegen einen Drittelanteil die - hier gar nicht mehr bezifferte - Forderung mit den Mitteln der geistlichen Gerichtsbarkeit einzuklagen (cum spirituali iudicio postula[re]): Handlungsbuch (wie Anm. 55) S. 6, Nr. I 42. Die Darstellung des Vorgangs bei CoRDES, Gesellschaftshandel (wie oben Anm. 72), S. 213, Anm. 32, verkennt die Verhältnisse.

${ }^{118}$ VON BRANDT, Rentenmarkt (wie Anm. 100), S. 20.
} 
Töchtern des Herrn Alvin Grope, die Klosterfrauen waren; ${ }^{119}$ diese halte ich für (mindestens) zwei unverheiratete Schwägerinnen von Herman Wittenborch. Für die Nonnen dürfte der Hauptvorteil dieses Arrangements darin gelegen haben, dass sie sicher sein konnten, ihre Rente von einem solventen, ihnen gut bekannten Schuldner immer pünktlich ausgezahlt zu bekommen. ${ }^{120}$ Bei seinem Tode hatte Herman mindestens $100 \mathrm{ml}$. Bargeld im Haus, ${ }^{121}$ einen Betrag, von dem damals mehrere Messpriester ein Jahr lang hätten auskömmlich leben können. Hermans städtischer Immobilienbesitz scheint sich auf ein Haus in der früheren Johannisstraße $\mathrm{e}^{122}$ beschränkt zu haben, ${ }^{123}$ das er 1310 zur Hälfte und 1318 ganz erworben hatte. Es ist anscheinend auch für den Sohn und seine Familie das Wohnhaus geblieben, bis es 1369 an den späteren Ratmann Peter van Hereke überging. ${ }^{124}$

Margaretes Geschwistern begegnet man hin und wieder auch sonst noch im Wittenborch-Material. Sie sind sicherlich alle nicht reich gewesen. $\mathrm{Zu}$ -

${ }^{119}$ Handlungsbuch (wie Anm. 55) S. 3, Nr. 113 (ohne die Angabe, dass die Eintragung gestrichen ist, und mit teilweise irriger Anm. 11), und S. 77, Nr. V 13. aus dem Niederstadtbuch, hier ohne Erwähnung der Verzinsung (sonst hätte die Buchung als Rentenkauf sicherlich ins Oberstadtbuch gehört): der Betrag als ,40 ma" formuliert (die Wahl der einen oder anderen Recheneinheit war damals offenbar völlig ins Belieben des jeweiligen Schreibers gestellt). Im „Handlungsbuch“ ist aus dem domini Alvini Gropen des Stadtbuchs übrigens Alvine Gropen geworden. Als Rechtsvertreter der Nonnen trat neben einem für mich nicht näher bestimmbaren Gotschalk van Warendorpe Albert Wullenpunt auf, vermutlich derselbe. der seit 1345 wiederholt als Geschäftsfreund von Johan Wittenborch belegt ist (siehe über ihn noch unten mit Anm. 324). Das Geschäft ist bei BASTIAN I. S. 220. Anm. 58 erwähnt und S. 261 unter buchhaltungstechnischen Gesichtspunkten behandelt: die fünf Zeilen zeigen besonders konzentriert, wie wenig sich der Verfasser mit den - ihn offenbar überhaupt nicht interessierenden - Lübecker Lokalverhältnissen vertraut gemacht hat. Ebenso wie dieser Kredit ist wahrscheinlich zu beurteilen das Darlehen von $64 \mathrm{ml}$., das Herman schon lange vor 1331 bei seiner Verwandten Alheid van Wittenborch aufgenommen hatte, siehe dazu unten mit Anm. 316-318.

${ }^{120} \mathrm{Ob}$ es für sie auch eine Rolle gespielt hat, dass sic bei Bedarf jederzeit ihr Geld zurückfordern konnten, lässt sich schwer beurteilen.

${ }^{121}$ Handlungsbuch (wie Anm. 55) S. 7, Nr. I 58.

${ }^{122}$ Sie heißt heute Dr.-Julius-Leber-Straße: HAMMEL, Hauseigentum (wie Anm. 94), S. 98. Anm. 7, und LUTTERBECK S. 7 mit Anm. 32.

${ }^{123}$ Zum folgenden MOLLwo S. IV, soweit es dort um dieses Haus (Johannisstr. 9) geht, und LUTTERBECK S. $438 \mathrm{f}$.

${ }^{124}$ MOLlwo a.a.O. hat Peter für Herrn Johans Schwiegersohn gehalten. Diese Meinung wird von ASMUSSEN, Flandernfahrer (wie Anm. 74), S. 378-380, und LUTTERBECK Nr. 123 (S. 276-278) offensichtlich nicht geteilt. - Handlungsbuch (wie Anm. 55) S. 7. Nr. 160 erwähnt Margarete Grope-Wittenborch einen Everhard Smale, der in mea hereditate apud sanctum Jacobum wohnt. Sollte sie dort etwa noch ein - anderweitig nicht fassbares - Haus aus dem Grundbesitz der Familie Grope besessen haben ? Oder ist nur - in äußerst verkürzter Ausdrucksweise - das oben mit Anm. 98-105 behandelte Doppelhaus Breite Str. 1/3 gemeint, das vor langer Zeit Margaretes Vater gehört hatte, aus dem sie aber immer noch eine hohe Rente bezog? Dessen Eigentümer war ja Everhard van der A mit seiner Frau Elisabeth Smale, die das Objekt in die Ehe gebracht hatte. 
gunsten einer namentlich nicht genannten Schwester hatte Margarete 100 $\mathrm{ml}$. in $5 \mathrm{ml}$. Rente angelegt; es handelte sich um einen Anteil von einem Siebentel an einer Rente von $35 \mathrm{ml}$. für $700 \mathrm{ml}$., die Margarete, wohl 1339, auf ihren eigenen Namen erworben hatte; ${ }^{125}$ ob die Schwester mit einer der eben erwähnten Nonnen von 1333 identisch war, muss offen bleiben. Vom Geld ihres Bruders Hinrik, der sich vielleicht auswärts als Kaufgeselle aufgehalten hat, ${ }^{126}$ gewährte Margarete zwei Darlehen von insgesamt $45 \mathrm{ml} .{ }^{127} 1362$ wird Hinrik wohl nicht mehr am Leben gewesen sein. Denn damals hat Herr Johan in seinem Testament ${ }^{128}$ verfügt, seine Testamentsvollstrecker sollten dem Herrn Goswin Grope, Bischof von Aulon, auf Lebenszeit jährlich $3 \mathrm{ml}$. zahlen, die er ihm ex parte Hinric[i] Gropen fratris s[ui] schulde, ${ }^{129}$ weitere Nachweise für diesen Dominikaner, der 1353 Prior des Lübecker Konvents war, Anfang 1359 Bischof wurde und zuletzt 1368 als in Norddeutschland tätiger Weihbischof belegt ist, hat 1976 Jürgen Reetz. zusammengestellt. ${ }^{130}$ Dass Herrn Alvin Gropes

${ }^{125}$ Handlungsbuch (wie Anm. 55) S. 6. Nr. I 46. Zum Zeitpunkt der Niederschrift hat Margarete die Rente in casu surori [!], also in den Schusterbuden, schon besessen. Im Oberstadtbuch hat MOLLwo keinen diese hohe Rente begründenden oder feststellenden Eintrag gefunden. Die Rente ist offenbar relativ schnell in Raten abgelöst worden. Nach Handlungsbuch (wie Anm. 55) S.7. Nr. I 53, hat Johan Wittenborch 1351 nur noch $12 \mathrm{ml}$. bezogen. Diese ganze Eintragung, in der als Rentner ego Margareta ... cum filii mei [nicht „mio“, wie im Druck] Johamni erscheinen. könnte übrigens ein Nachtrag von Johans Hand sein. MOLLwOS Textwiedergabe ist auch sonst mangelhaft: In der 2. Zeile ist statt ,prescriptam“ reddituum (geschrieben einfach als Majuskel-R mit Kürzungsstrich !) zu lesen, und in der 3. wäre zu erwähnen gewesen, dass die Datierung ursprünglich anno 39 gelautet hat (vermutlich ist die Rente in diesem Jahr begründet worden).

${ }^{126}$ Handlungsbuch (wie Anm. 55) S. 8, Nr. I 68 u. 69.

${ }^{127}$ Handlungsbuch (wie Anm. 55) S. 7, Nr. I 47 (Empfänger: Nicolaus Grabowe) u. 49 (Empfänger: Margaretes avunkulus Wedcke Clingenberch; vgl. dazu auch noch Handlungsbuch (wie Anm. 55) S. 8, I 68 (derselbe Empfänger, doch wohl ein neuer Vorgang ?). Vermutlich hat es sich um diesen "Onkel“ (doch wohl eher einen Neffen) auch bei dem Wedeke Clingenberch gehandelt, dessen Knecht vor 134524 Schilde an Johan nach Flandern überbracht hat. Handlungsbuch (wie Anm. 55) S.9, Nr. I 84. Weiter spricht nichts gegen Identität mit dem Ratmann der Jahre 1344-1350 (LUTTERBECK Nr. 66, S. 231 f.), über den weiterhin RöRIG, Wirtschaftskräfte (wie Anm. 57), S. 175f. u. 179-181 zu beachten ist. Der Ratmann ist auch zweimal in Verbindung mit Johan Wittenborch belegt (Handlungsbuch (wie Anm. 55) S. 16f., Nr. II 50 u. 51, vgl. unten mit Anm. 153); darüber hinaus sind mehr oder minder enge Kontakte zwischen den Kindern des Ratmanns, besonders einem Sohn namens Johan bzw. Henneke, und Herrn Johan zwischen 1357 und 1362 bezeugt: Handlungsbuch (wie Anm. 55) S. 38, Nr. II 242, S. 85, Nr. V 74, S. 86, Nr. V 79, u. S. 90, Nr. VI 3). Der ,avunculus“ war jedenfalls ein Verwandter von Margaretes Mutterseite, über die wir so gut wie nichts wissen: Nach LUTTERBECK S. 264 ist von Herrn Alvin Gropes Frau nur der Taufname (in der Kurzform Hille) bekannt (von seiner Mutter nicht einmal dieser).

${ }^{128}$ Handlungsbuch (wie Anm. 55) S. 89f., Nr. VI 3; Reg. Test. (wie Anm. 93) 2, Nr. 925 (S. 294).

${ }^{129}$ In den eckigen Klammern habe ich die offensichtlichen Druckfehler in MoLLwos Druck (wie vorige Anm.) korrigiert.

${ }^{130}$ Jürgen REETZ, Zwei bemerkenswerte Lübecker Geistliche des 14. Jahrhunderts: Hinricus de Culmine und Goswinus Grope, in: ZVLGA 56, 1976, S. 107-111. hier 110f. 
Sohn Alvin, in der hier vertretenen Auffassung ein dritter Bruder der Margarete, im Wittenborch-Material überhaupt nicht vorkommt, lässt sich ungezwungen erklären: Er war ja schon seit 1332 oder 1333 tot. ${ }^{131}$ Von den vier Kindern des Ratmanns Alvin Grope, die um 1340 sicher oder wahrscheinlich noch am Leben waren, haben also anscheinend nur Margarete und Goswin eine Stellung erreicht, die ihnen in der Lübecker Kaufmannsgesellschaft des mittleren 14. Jahrhunderts ein gewisses Gewicht gab. Abschließend ist noch eine völlig freie Erfindung von Mollwo als solche zu kennzeichnen: Margarete habe „mit Hülfe ihrer Brüder, der Gropes, die Geschäfte ihres verstorbenen Mannes zu Ende“ geführt. ${ }^{1 \hat{2} 2}$ Denn dies hat in der neuesten Literatur einen Widerhall gefunden. ${ }^{133}$

Margarete ${ }^{134}$ hat anscheinend von 1338 bis 1345 dem Haus und der Kleinstfamilie vorgestanden. Jedenfalls lassen sich alle Buchungen des „Handlungsbuchs“ aus diesen Jahren mehr oder minder sicher auf sie zurückführen. An zwei Stellen hat sie sich selbst „Margarete Grope“ genannt. ${ }^{135} \mathrm{Ob}$ sie während dieser Jahre als Kauffrau auch eigenständig Warenhandel getrieben hat, ist ungewiss. ${ }^{136}$ Sie ist aber schon zu Lebzeiten ihres Mannes in den Geschäftsbetrieb einbezogen gewesen, denn als einmal Herman mit seinen beiden Partnern über seine wichtigste Gesellschaft

\footnotetext{
${ }^{131}$ Oben bei Anm. 95 u. 96.

132 Mollwo S. V. Eine Variante dazu gibt es auf S. XXXVII mit Anm. 2: „Hände von Testamentsvollstreckern Hermann Wittenborgs" (was in der langen Anmerkung über die verschiedenen Hände gesagt ist, die in diesem Übergangsbereich vorkommen, verdient aber Überprüfung; das gilt natürlich nicht für die Zuweisung von zwei Händen an Margaretes „Brüder" „Alwin und Nicolaus“).

${ }^{133}$ CORDES, Gesellschaftshandel (wie Anm. 72), S. 213: „führte sie abwechselnd mit ihren Brüdern sein Handlungsbuch weiter".

${ }^{134}$ Zum folgenden vgl. CORDES a.a.O. S. $213 \mathrm{f}$.

${ }^{135}$ Handlungsbuch (wie Anm. 55) S. 8. Nr. I 68 u. 69. Ob das dadurch veranlasst ist, dass es in beiden Buchungen um finanzielle Verpflichtungen gegenüber ihrem Bruder Hinrik Grope ging ?

${ }^{136}$ Dafür würde sprechen, dass in Handlungsbuch (wie Anm. 55) S. 7, Nr. I 52, wo es um eine Forderung der Witwe aus dem Verkauf von Schönwerk geht, als Zeuge Hinricus Volmensteyne meum [!] socium [!] erwähnt wird. Auch gibt es weitere Belege dafür, dass Margarete an Geschäften mit Pelzwerk beteiligt war (ebd. S. 7f., Nr I 55. 56, 59, 63 und 67, das hier als „Scevemsten“ gedruckte Wort ist nach der Handschrift als sceveniscen zu lesen). Aber es scheint mir ungewiss, ob es dabei um mehr als die Abwicklung von Hermans Geschäften gegangen ist; in diesem Bereich stehen auch Notizen über Ausgaben für die Bestattung bzw. das rituelle Gedächtnis ihres Mannes (ebd. Nr. 61 u. 65), und Hinrik Volmestene war bereits mit diesem für den Nowgorod-Handel in vera societate verbunden: Handlungsbuch (wie Anm. 55) S. 1, Nr. 17 u. 8. Vgl. CORDES a.a.O. S. 213. Im Niederstadtbuch hat MOLLwo keine Eintragungen aus den Jahren 1338-1345 ermitteln können, die sich wirklich auf Margareta und/oder ihren Sohn Johan beziehen; die Buchung Handlungsbuch (wie Anm. 55) S. 79, Nr. V 34 von 1343, die einen Johannes Wittenborch ohne jede weitere Angabe zu seiner Person nennt, bezieht sich mit Sicherheit auf einen Johan, dessen Vater Hinrik hieß, vgl. dazu Reg. Test. (wie Anm. 93) I, Nr. 146 (S. 81).
} 
abrechnete, war auch Margarete dabei. ${ }^{137}$ In den veröffentlichten Quellen kommt Margarete nach 1345 nicht mehr vor. ${ }^{138}$

„Unser“ Johan war wohl im März 1338 noch nicht mündig, wenn man es ernst nehmen will, dass er damals als puer bezeichnet wurde. ${ }^{139}$ Wann er das Mündigkeitsalter von $18 \mathrm{Jahren}^{140}$ erreicht hat, lässt sich nach den verfügbaren Daten nicht genau sagen. Aber weit davon entfernt kann er 1338 nicht mehr gewesen sein, wenn er im Spätsommer 1345 bereits verheiratet war (siehe unten), und daher wird man von den Grenzdaten „1320“ und „1325“, die Hammel für Johans Geburtsjahr genannt hat, ${ }^{141}$ das erste vorzuziehen haben. ${ }^{142}$ Dass Johan nach 1338 noch öfter zusammen mit seiner Mutter vorkommt, besagt sicherlich nur, dass die beiden weiterhin im ungeteilten Besitz ihres gesamten Vermögens gesessen haben; ob der Sohn noch nicht alt genug war, um Abteilung verlangen zu können, oder ob er sie einfach nicht verlangt hat, kann nicht entschieden werden; jedenfalls ist er im gedruckt vorliegenden Quellenmaterial auch nie mit einem Vormund belegt. Der größte Teil einer ganzen, durchgängig deutsch geschriebenen Seite im „Handlungsbuch“, der Seite „6a“, ${ }^{143}$ zeigt ihn auf Geschäftsreise in Flandern; ${ }^{144}$ der Text stammt zweifellos von Margarete, die sich hier also von der Konvention des Lateinschreibens freigemacht hat, wenn auch nur auf Zetteln, ${ }^{145}$ deren Abschrift hier offen-

${ }^{137}$ Handlungsbuch (wie Anm. 55) S. 4f., Nr. I 25; Abdruck des Textes bei CoRdES a.a.O., S. 210 .

${ }^{138}$ Der Grund dafür, dass sie Handlungsbuch (wie Anm. 55) S. 7, Nr. I 53 zu „1351“ erwähnt scheint, ist oben Anm. 125 dargelegt. Unter diesen Umständen erscheint es nicht unmöglich, dass die unbelegte Angabe, ,Seine Witwe Margarethe heiratete in 2. Ehe Arnold Premzslaw" bei ASMUSSEN, Flandernfahrer (wie Anm. 74) S. 885, Anm. 2, sich auf „unsere“ Margarete beziehen könnte; ich habe es nicht nachgeprüft.

${ }^{139}$ Siehe oben mit Anm. 108.

${ }^{140}$ A. VON BRANDT. Die Lübecker Knochenhaueraufstände von 1380/84 und ihre Voraussetzungen. Studien zur Sozialgeschichte Lübecks in der zweiten Hälfte des 14. Jahrhunderts, in: ZVLGA 39, 1959, S. 123-202, hier S. 155.

${ }^{141}$ HAMMEL 1982, S. 303.

${ }^{142}$ Für diese Auffassung ist es ohne Bedeutung, dass Mollwo S. V glaubte „1321“" als Geburtsjahr erschließen zu können; KOPPMANN, Rezension (wie Anm. 67), S. 190 hat dargelegt, dass der Weg dahin unzulässig war. Belangvoll ist aber der Hinweis bei vON BRANDT a.a.O. S. 155 mit Anm. 28, dass seit dem Ende des 13. Jh.s, römischrechtlich fundiert, das „25. Lebensjahr“ als Zeitpunkt für den Beginn der unbeschränkten Geschäftsfähigkeit „Eingang in die lübischen Rechtskodifikationen gefunden" hat.

${ }^{143}$ Handlungsbuch (wie Anm. 55) S. 9, Nr. I 82-87.

${ }^{1+4}$ Ebd. Nr. 83-87.

145 Auf „Zettelaufzeichnungen“ (dazu bereits oben Anm. 57) hat MoLLwo S. XLIV beiläufig hingewiesen. Erst dank BASTIANS Untersuchungen ist dann deutlich geworden, wie wichtig die Annahme einer umfangreichen „Zettelwirtschaft“ für das Verständnis von spätmittelalterlicher Buchführung ist; unter „Zettel“ sind im Einzelfall auch mehrseitige Stücke zu verstehen. Dass dies nicht nur für die kaufmännische Buchführung gilt, hat exemplarisch dargestellt Antje SANDER-BERKE, Zettelwirtschaft. Vorrechnungen, Quittungen und Liefer- 
bar vorliegt. ${ }^{146}$ Johans Flandern-Aufenthalt wird wohl kaum länger als eine Saison, vom Frühling bis zum Herbst, gedauert haben. ${ }^{147}$ Leider enthält der Komplex keinerlei Datierung und auch nur einen Anhalt, aus dem eine Datierung erschlossen werden kann. Als Johan erstmals selbständig auftrat, war er nicht nur wieder in Lübeck zurück, sondern auch bereits mit der Tochter eines Lübecker Ratmanns verheiratet; unter dem Datum des 1. September 1345 wurde dem Johannes Wittenborch, gener domini Arnoldi Bardewik, im Oberstadtbuch eine Rente von $12 \frac{1}{2} \mathrm{ml}$. im Kapitalwert von $200 \mathrm{ml}$. zugeschrieben, die er, so die Eintragung, von den Brüdern Herrn Wedeke und Herman van Warendorpe in ihren Wechsler- und Schusterbuden am Markt gekauft hatte (emit). ${ }^{148}$ Johan muss also spätestens im

scheine in der spätmittelalterlichen Rechnungslegung norddeutscher Städte. in: Vestigia Monasteriensia. Westfalen - Rheinland - Niederlande. Hg. von Ellen WIDDER. Mark MERSIOWSKY u. Peter JOHANEK (Studien zur Regionalgeschichte 5), Bielefeld 1995, S. 351-364.

${ }^{1+6}$ Die ganze Seite ist von einer Hand und wahrscheinlich auch in einem Zuge geschrieben. ..mit einer Feder" in BASTIANS Terminologie; für Abschrift spricht auch, dass in Nr. 82 offenbar ein Posten ausgefallen ist. Bei der Schrift handelt es sich - im ganzen Buch singulär - um eine schmucklose Buchminuskel. Wohl deshalb wollte MolLwo S. VI hier eine ..Schreiberhand" sehen (vgl. S. XXXVII). Was KoppMAnN. Rezension (wie Anm. 67), S. 193 dagegen eingewendet hat, bezieht sich auf die Sprache. nicht auf die Schrift, die er wahrscheinlich gar nicht gesehen hat. Nach Peter GERLACH, Ein Lüneburger Wachstafelbuch aus dem 14. Jahrhundert. in: LünebBll. 15/16, 1965. S. 21-70. hier S. 40. kommt ,auf den Lübecker Schülertafeln“. die Gerlach im Original angesehen hatte, ,,auch Buchschrift" vor; in der Publikation dieser Wachstafeln (J. WARNCKE, Mittelalterliche Schulgeräte im Museum zu Lübeck. Ein Kloakenfund vom Grundstück der alten Lübecker Stadtschule, in: Zeitschrift für Geschichte der Erziehung und des Unterrichts 2, 1912, S. 227-250 und Tafel I-III. hier S. 238-250) ist davon aber nichts zu sehen, es sei denn, GERLACH hätte nur die auf S. 249 nachgezeichneten Majuskel-Initialen gemeint. Übrigens ist nach GERLACH S. 25, Anm. II .Warnckes Abschrift der Texte ... nicht immer zuverlässig".

${ }^{147}$ Mollwo S. VI sprach von ,.längere[r] Zeit" und dachte offenbar an mehrere Jahre.

${ }^{148}$ Handlungsbuch (wie Anm. 55) S. 70f., Nr. IV 13, von Johan selbst verbucht S. 12. Nr. II 2 (ego ... habemus cum domino Wedekino de Warendorpe in 3 casu camsori et cum omni casu sutori...). Das darüber von Johan auf eigener Zeile nachgetragene Datum des 21 . Septembers 1347, das Mollwo als Nr. la gedruckt hat, ist identisch mit dem Datum, unter dem die Fortexistenz der Rente im Oberstadtbuch beurkundet wurde: Handlungsbuch (wie Anm. 55) S. 71, Nr. IV 14 mit Anm. 1. Als Eigentümer der Buden und Rentschuldner erscheint hier, wie in Johans eigener Noti\%, nur Herr Wedeke, dem die Buden als Kaufmannsgut zugeschrieben worden waren, als die Brider - noch 1345 oder erst 1.347 (so LUTTERBECK S. 425f.) ? - ihren Besitz geteilt hatten. Zur Interpretation dieser Erwerbung als Mitgift von Johans Frau siehe unten mit Anm. 213. Über die weitere Geschichte der Rente ist nichts bekannt; in Herrn Wedekes Testament vom 4. Oktober 1350 (Reg. Test. (wie Anm. 93) 1, Nr. 406. S. 209f.) kommen auch die Buden nicht vor. - Dem ersten Anschein nach gibt es an der Spitze derselben Seite ,7a“ der Handschrift eine um ganze zwei Jahre ältere Eintragung (Nr. II 1), in der Johan, ohne seine Mutter zu erwähnen, erklärt, er habe bei der Stadt Lübeck eine Rente von $5 \mathrm{ml}$. jährlich, die 1343 (ohne Tagesangabe) im Buch der Stadt Lübeck geschrieben sei. Mollwos Folgerung. der auf Hermans Witwe zurückzuführende Teil des Buchs reiche nur bis zu diesem Jahr, ist auch von KoPPMANN, Rezension (wie Anm. 67) S. 19l akzeptiert worden. Aber BASTIAN 1, S. 263, hat nach „Heranziehung des Originals“ ausgeführt, dass diese Eintragung ,sicher nicht schon gleichzeitig mit dem Kauf der ... Rente, d. h. 
Sommer 1345 zurückgekehrt sein. Tatsächlich hat er aber Flandern wohl schon einige Zeit vor dem Ende des Vorjahres wieder verlassen. Denn für insgesamt 32 Schilde, eine französisch-niederländische Goldmünzensorte, die Margarete in Lübeck angekauft und ihrem Sohn nach Flandern nachgeschickt hat, bezahlte sie 11 Schilling 9 Pfennig und 12 Schilling pro Stück. ${ }^{149}$ Das passt gut zu dem Betrag, den niederländische Preußenreisende im März 1344 in Lübeck erhielten, als sie Schilde gegen gängiges Geld einwechselten: 11 Schilling lübisch. Die Teilnehmer einer weiteren Adelsreise, die Lübeck ein dreiviertel Jahr später berührt haben, erhielten dort nur noch 10 Schilling lübisch für den Schild. ${ }^{150}$

Ein paar Jahre später ist Johan Wittenborch auch in England gewesen; davon erfahren wir nur deshalb, weil er einen Gefälligkeitskredit von 5 Schilling Sterling, den er durch Brun Warendorp - wir wissen nicht, welchen $^{151}$ - bei Herrn Wedeke Clingenberch ${ }^{152}$ aufgenommen hatte, vor seiner Abreise nicht mehr völlig hatte tilgen können. ${ }^{153}$ Im Anschluss an die Beobachtung von Albrecht Cordes, dass das „Handlungsbuch" Ende der 1340 er Jahre längere Zeit nicht benutzt worden ist, ${ }^{154}$ könnte man den

im Jahre 1343" geschrieben worden ist. Insoweit stimme ich ihm $\mathrm{zu}$, obwohl ich seinen weiteren Ausführungen nicht folgen kann, vielmehr meine, dass Nr. I, m. E. von derselben „Feder" wie Nr. 2 und also frühestens von 1345, sehr wohl als erste auf dieser Seite geschrieben sein kann. Jedenfalls ist die Seite nicht vor 1345 in Benutzung genommen worden. Übrigens hat schon MoLLwo selbst, allerdings an eher versteckter Stelle (S. LXVI unten), Johans selbständige kaufmännische Tätigkeit „1345“ beginnen lassen. Die von Johan erwähnte Beurkundung des Erwerbs der Stadtrente im Stadtbuch hat MOLLwo nicht ausfindig machen können: man müsste sie wohl im Kämmereibuch der Zeit suchen; es handelt sich aber offenbar nicht um einen Anteil an der großen Anleihe, die der Rat 1342 zur Finanzierung der Anpfändung von Segeberg aufgenommen hat. UB. Stadı Lüb. 3, Nr. 592, S. 624-628.

${ }^{149}$ Handlungsbuch (wie Anm. 55) S. 9, Nr. 184 u. 85.

${ }^{150}$ Gerald STEFKE, „Goldwährung" und ,lübisches" Silbergeld in Lübeck um die Mitte des 14. Jahrhunderts, in: ZVLGA 63, 1983, S. 25-81, hier S. 55.

151 Über die Schwierigkeit. (mindestens) zwei gleichzeitig lebende Träger dieses Namens zu unterscheiden. s. unten mit Anm. 172.

152 Über ihn oben Anm. 127.

${ }^{153}$ Handlungsbuch (wie Anm. 55) S. 17, Nr. II 51, dazu Mollwo S. XI mit Anm. 10. Die hier genannte Datierung „vor 1348“ ist unbegründet; es gibt nur Termini ad quem: Formell ist dies Herrn Wedekes Todestag, der 31. August 1350, tatsächlich aber wohl das Frühjahr 1350. in dem Johan in den Rat kam (unten mit Anm. 174) oder sogar der Herbst 1349. Denn vermutlich ist er am 22. Februar gewählt worden, und sicherlich nicht in seiner Abwesenheit; die Rückreise aus Westeuropa wird aber eher im Herbst 1349 als im Winter 1349/50) stattgefunden haben. Zwischen dem 26. Mai und dem 4. Oktober 1350 war Herr Johan dann schon so häufig als Testamentszeuge beansprucht, dass er Lübeck nie für länger als etwa zwei Wochen verlassen haben kann.

${ }^{154}$ CORDES, Gesellschaftshandel (wie Anm. 72), S. 218 mit Anm. 48. Um eine „Pause von drei Jahren" hat es sich allerdings nicht gehandelt. Ausgangspunkt aller weiteren Überlegungen ist die Tatsache, dass es aus den Jahren 1349 und 1350 keine datierten oder sicher in diese beiden Jahre datierbaren Eintragungen gibt. Handlungsbuch (wie Anm. 55) S. 17, Nr. II 
England-Aufenthalt plausibel ins Jahr 1349 setzen. ${ }^{155}$ Seine letzte sicher bezeugte ,private“ Reise, in der man eine Geschäftsreise sehen darf, hat Johan Wittenborch 1354 vor Juni 24 angetreten; es war eine Schiffsreise, von der wir aber nicht wissen, wohin sie ihn geführt hat, ${ }^{156}$ sie kann nicht sehr lange gedauert haben, da er am 11. August schon wieder als Testamentszeuge belegt ist. ${ }^{157}$ Trotzdem müssen wir dieser Reise eine weitere, ziemlich pathetisch klingende, leider nicht genauer datierte Eintragung im „Handlungsbuch“ zuordnen, in der er festgehalten hat, was er an Geld zurückließ, in seiner Kiste und für seine Frau, als er in eine Reise auszog, über deren Ziel auch an dieser Stelle nichts gesagt ist. ${ }^{158}$ Über einen Ritt nach Aachen, den Herr Johan 1356 unternommen hat, wird später zu reden sein. ${ }^{159}$

Bevor Johan Wittenborch seine erste Flandernreise antrat, hat er sicherlich mindestens zwei andere Ausbildungsstufen durchlaufen. Zunächst

56 von 1348 ist durch die dazugehörige Niederstadtbucheintragung auf den 4. Dezember datiert (entstanden ist die Schuld allerdings schon Mitte des Jahres, siehe Handlungsbuch (wie Anm. 55) S. 23, Nr. II 110). Handlungsbuch (wie Anm. 55) Nr. II 57, „1351“ ohne genauere Datumsangabe datiert, ist, wie bereits MoLLwo in Anm. 64 festgehalten hatte, ein bloßer Nachtrag zu Nr. 56. Er ist, in für Johan Wittenborch sehr kleiner Schrift, hineingezwängt in eine schmale Lücke zwischen Nr. 56 und den ganz undatierten Eintragungen $\mathrm{Nr}$. 58-60, die also auch schon vor dem Nachtrag da waren und mit einer „Feder“ geschrieben sind. Eine Datierungsmöglichkeit ergibt sich nur daraus, dass von derselben „Feder“ höchstwahrscheinlich auch die Nummern 50 und 51 stammen, die allerdings ebenfalls undatiert sind. Da wir wissen, dass Nr. 51 nach Johan Wittenborchs Rückkehr aus England geschrieben ist, können wir danach immerhin sagen, dass alle diese Eintragungen höchstwahrscheinlich nach Ende 1348 und nicht vor Ende 1349/Anfang 1350 geschrieben sind. Da Handlungsbuch (wie Anm. 55) S. 18, Nr. II 61, von zweifelsfrei neuer „Feder“, „1351“" datiert ist und in den Hochsommer gehört (Bertolt Wittenborch war nach Schonen abgereist), ergibt sich für Nr. 50/51 und 58-60 auch ein Terminus ad quem: Nr. 60 hält fest, dass Bertolt nach Flandern gereist ist; da er von dort ja erst wieder zurückkommen musste, bevor er im Sommer 1351 nach Schonen aufbrechen konnte, kann die Flandernreise keinesfalls später als im Frühling 1351 stattgefunden haben. Aber damit ist natürlich nicht ausgeschlossen, dass sie schon irgendwann im Laufe des Jahres 1350 stattgefunden hat; dasselbe gilt für die Vorfälle. die in den übrigen Einträgen der Gruppe dokumentiert sind. Der Eindruck, dass das „Handlungsbuch" auch 1350 nicht benutzt worden ist, könnte also trügen.

${ }^{155}$ Natürlich muss Johan nicht das ganze Jahr in England verbracht haben; es könnte sich zum Teil auch um einen weiteren Flandernaufenthalt gehandelt haben.

${ }^{156}$ Handlungsbuch (wie Anm. 55) S. 27, Nr. II 134. Auch Mollwo S. XI hat zu „1354“ von „einer Reise über See“ gesprochen, in Anm. II aber nicht diese Stelle erwähnt, sondern „II. 118“, und zwar mit der für diese Eintragung offensichtlich falschen Datumsangabe „1354 vor Juni 24"*; in dieser Quelle (siehe auch Nr. 119) ist überdies nur von Herrn Johans Mitarbeiter Bertolt [Wittenborch] die Rede; es ging um die Begleitung einer Sendung eingeführten Weins, die schon längere Zeit vor dem 6. Dezember 1353 in Lübeck angekommen ist. Höchstwahrscheinlich hat sich MOL.Lwo einfach beim Schreiben des Belegs vergriffen.

${ }^{157}$ Reg. Test. (wie Anm. 93) 2, Nr. 541 (S. 79).

${ }^{158}$ Handlungsbuch (wie Anm. 55) S. 23, Nr. II 114. Wie bereits BASTIAN I, S. 247 mit Anm. 152 u. S. 265 (vgl. S. 274) festgestellt hat, ist die Jahreszahl „1354“ von MoLLwo als „1353“verlesen worden.

${ }^{159}$ Unten mit Anm. 359 u. 360. 
hat er gewiss die städtische Lateinschule für die Bürgerkinder besucht, die keine geistliche Laufbahn einschlagen sollten, die Schule bei der JakobiPfarrkirche. Die überwiegend mageren Lernresultate können wir an Johans und seiner Standesgenossen mehr oder minder mangelhaftem Latein ablesen; nach der angewandten Lehrmethode - man ließ die Schüler u. a. Latein nach Diktat schreiben ${ }^{160}$ - konnte ein besserer Erfolg nur bei sehr sprachbegabten Zöglingen erwartet werden. Nach dem Wittenborch'schen „Handlungsbuch" in allen seinen Teilen zu urteilen, müssen die Schüler neben dem allgemeinen Anfänger-Stoff ${ }^{|t|}$ auch die wichtigeren Wörter und Floskeln der Kaufmannssprache auswendig gepaukt und sich die hier gängigen Abkürzungen sorgfältig eingeprägt haben; denn in diesem Bereich "klappt“ gewöhnlich alles. Wirkliche Schwierigkeiten traten aber immer auf, wenn es galt, auch ungewöhnliche Sachverhalte lateinisch darzustellen. ${ }^{162}$ Und eben das verlangte die überkommene Konvention. Herman Wittenborch scheint sich ihr noch ganz gefügt zu haben, und er hat die damit gestellten Aufgaben wohl auch einigermaßen angemessen bewältigt; ${ }^{16.3}$ allerdings ist zu bedenken, dass von ihm ja nur ein kleiner Teil der Buchführung überliefert ist, und der auch noch in einer Abschrift, die vielleicht gar nicht von seiner Hand stammt. Einzelne lateinische Buchungen aus der Zeit, in der Hermans Witwe Firma und Haus geleitet hat,

${ }^{160}$ Darüber jüngst Albrecht CORDES, Juristische Bildung für Kaufmannskinder. Die städtische Schule in Lübeck und ihr Lehrplan im 13./14. Jahrhundert, in: ZVLGA 87, 2007, S. 41-53. Der Verfasser beschäftigt sich vor allem mit dem Inhalt des bekannten Wachstafelfundes bei der Jakobischule von 1866. Wenn die Transskriptionen der Tafeltexte (siehe oben Anm. 146) zuverlässig sind, war das Latein. das die Schüler nach Diktat geschrieben haben, oft nicht sehr viel besser als das Handlungsbuchlatein der Kaufleute, wenn sie mehr oder minder frei formulieren mussten. Als bloßer Beleg dafür, dass um 1370 in der Jakobischule Latein gelehrt wurde, ist der Quellenkomplex auch erwähnt bei Birgit NOODT, Religion und Familie in der Hansestadt Lübeck anhand der Bürgertestamente des 14. Jahrhunderts (Veröffentlichungen zur Geschichte der Hansestadt Lübeck B. 33), Lübeck 2000. S. 37 mit Anm. 238 (S. 422), im Anschluss an Fritz RöRIG, Mittelalter und Schriftlichkeit, in: Die Welt als Geschichte 13, 1953, S. 29-41, hier S. 38f. Seit es auch die ,einfache [d. h., muttersprachliche] Lese- und Schreibschule" gab, die in Lübeck 1418 sicher bezeugt ist (NOODT a.a.O. mit Anm. 237), ist sicherlich die Kenntnis des Lateinischen, auch die mangelhafte, noch weiter zurückgegangen.

${ }^{161}$ Wozu auch die Abkürzungen der nomina sacra gehörten; so schreibt Johan Wittenborch für "Christi" richtig xpi.

${ }^{162}$ Auch Johan Wittenborchs Latein weist die Merkmale auf, die RöRIG, Wirtschaftskräfte (wie Anm. 57), S. 168, für Herman Warendorp ,minor", Ratmann 1334-1350 (LUTTERBECK Nr. 282, S. 422f.) beschrieben hat. - Als Ahasver VON BRANDT in der Einleitung zum 1. Band seiner Testamentsregesten (Reg. Test. (wie Anm. 93) 1, S. 8) von einem „,bemerkenswerte[n] Ausmaß der Lateinkenntnis mindestens in der bürgerlichen Oberschicht" sprach, meinte er damit nur die Fähigkeit, geschriebenes Latein zu verstehen. Die weitschweifigen Erörterungen von NOODT, Religion und Familie (wie Anm. 160), S. 36-53, führen kaum weiter.

${ }^{163}$ Nahezu unverständlich ist allerdings Handlungsbuch (wie Anm. 55) S. 5, Nr. I 30. 
gehören zum Schlimmsten an ungrammatischem Latein, was das Handlungsbuch überhaupt zu bieten hat. ${ }^{164}$ Aber die Routinetexte fallen auch hier nicht besonders aus dem Rahmen. Sollte das alles oder wenigstens zum großen Teil von Margarete stammen, so wäre immerhin bemerkenswert, dass sie es wagen konnte, auch mit dem Lateinschreiben die Arbeit ihres Mannes fortzusetzen. ${ }^{165}$ Gesichert ist freilich nur, dass sie auf Deutsch klare Geschäftsaufzeichnungen verfassen konnte. ${ }^{166} \mathrm{Ihr}$ Sohn hat sich schnell von der Konvention des Lateinschreibens um jeden Preis gelöst. Denn er hat von Anfang an auch in seinem „Buch“ überwiegend deutsch geschrieben, nicht nur auf Zetteln oder in Kladden; vermutlich hat er seine Buchführung schon in der klaren Erkenntnis begonnen, dass es mit seiner Fähigkeit, lateinisch zu formulieren, nicht weit her war, wenn es um mehr als die einfachen Grundformeln der kaufmännischen Buchführung und die Aufzeichnungen über Renten- und Immobilienbesitz ging, bei denen man sich an das Muster der Stadtbucheinträge halten konnte. ${ }^{167}$

${ }^{164}$ Besonders hervorzuheben ist Handlungsbuch (wie Anm. 55) S. 8. Nr. 1 64: der Eintrag ist nur in Verbindung mit Nr. 4la (S. 6) dahin zu verstehen, dass Margarete eine (silberne) Schale und 5 goldene Ringe, die Herman für eine Schuld des Herrn Herman Cremon (wohl eines Priesters) in Höhe von $12 \mathrm{ml}$. als Pfand bekommen hatte, dem Marquard Wesler übergeben hat, wofür ihr dieser die $12 \mathrm{ml}$. geliehen hat.

165 Ich meine hier vorerst zwei Hände unterscheiden zu können, von denen eine entschieden häufiger vorkommt. Aber es gibt natürlich keine Möglichkeit zu beweisen, dass Margarete im .,Buch“ überhaupt selbst geschrieben hat. Und wenn hier Hilfskräfte tätig waren. liegt es nahe zu vermuten, dass diese auch für die Umsetzung von Margaretes Angaben in das dilettantische Latein der Buchungen verantwortlich gewesen sind.

${ }^{166}$ Siehe oben mit Anm. 143-146.

${ }^{167} \mathrm{Vgl}$. TOPHINKE, Handelstexte (wie Anm. 61), die S. 146 durchaus gesehen hat, dass von Johan Wittenborch ,früh ... komplexe Geschäftsvorgänge, die nicht nach einem (lateinischen) Muster notiert werden können, in mittelniederdeutscher Sprache verbucht (werden)"; allerdings hat sie diesen Gesichtspunkt nicht systematisch durchgeführt. Ihre Aussage (S. 147), erst ,ab 1358“ sei das Deutsche ,zur dominierenden Buchungssprache“ geworden, trifft nicht zu; schon Johans erste Niederschriften über komplizierte geschäftliche Sachverhalte. von 1345/46, Handlungsbuch (wie Anm. 55) S. 13f., Nr. II 7-16, sind rein deutsche Texte, abgesehen von einfachsten Elementen wie caur. Lub. oder recepi. Dass daneben immer wieder, auch noch später, lateinische Buchungen in kleinen Folgen oder einzelnen Stücken auftreten, wenn es um Standardsachverhalte, insbesondere Aufzeichnungen über Forderungen, ging, so gleich anschließend Handlungsbuch (wie Anm. 55) S. 14, Nr. II 17-20, braucht deshalb nicht bestritten zu werden. Auch trifft natürlich zu, dass „das Lateinische bei Johann Wittenborg ... noch nicht (ganz verdrängt wird)“. TOPHINKES Überlegung, dass „dies für die Generation. deren Schrifterwerb ganz wesentlich [?] an das Lateinische gekoppelt ist, nicht möglich (ist)", sollte noch durch die Frage ergänzt werden, weshalb die Generation denn auf die vertrauten und bequemen lateinischen Wörter und Floskeln, für die es großenteils Standard-Abkürzungen gab, hätte verzichten sollen. Mit den Abkürzungen konnte man überdies, auch noch viel später, ebenso gut in deutschsprachigen Texten operieren; s. dazu unten mit Anm. 323. Sprachlich im Wesentlichen einwandfreie lateinische Aufzeichnungen über die Erwerbung von Immobilien und Renten bezeugen wahrscheinlich überhaupt nur die Fähigkeit, eine professionell verfasste lateinische Vorlage korrekt abzuschreiben. Denn man darf sicherlich mit Paul REHME, Das Lübecker Ober-Stadtbuch. Ein Beitrag zur Geschichte der 
Übrigens könnte er es, vielleicht vorzeitig aus der Schule genommen, bedauert haben, dass seine Lateinkenntnisse nicht besser waren. ${ }^{168}$ Auch seine Buchführungstechnik, die von Bastian detailliert rekonstruiert worden ist, ${ }^{169}$ würde der Jakobischule kein gutes Zeugnis ausstellen, falls Johan das Buchhalten dort gelernt haben sollte. Denn auch wenn man versteht, wie das Resultat zustande gekommen ist, bleibt doch vor allem der Eindruck, dass Johan ein ziemliches Durcheinander angerichtet hat, in dem er sich selbst nur deshalb nicht „verlaufen“ hat, weil sein „Handlungsbuch" nur ein dünnes Heft gewesen ist.

Vermutlich hat Johan in der Lateinschule auch schon die Grundzüge des Rechnens gelernt. ${ }^{170}$ Eine praktische kaufmännische Ausbildung wird sich angeschlossen haben. Außerdem wird er wohl nicht nur reiten gelernt haben, wie jeder andere gesunde Junge aus stadtbürgerlicher Oberschicht im 14. Jahrhundert auch. ${ }^{171}$ Johan wird darüber hinaus vielleicht eine militärische Grundausbildung bekommen haben, die dann der eines Jungen aus dem Niederadel des flachen Landes nicht nachgestanden haben dürfte. Dies ist ja die unabdingbare Voraussetzung dafür, dass Angehörige dieser „großbürgerlichen“ Kreise, etwa ein Brun Warendorp im Jahre 1362, gegen Sold Kriegsdienste leisten konnten, bevor sie in den Rat aufgenommen wurden, ${ }^{172}$ und als Ratmannen militärische Leitungsfunktionen aus-

Rechtsquellen und des Liegenschaftsrechtes. Mit einem Urkundenbuche, Hannover 1895, S. 250f., vermuten, dass sich die erst seit der Mitte des 16. Jh.s bezeugte Praxis, den an derartigen Geschäften und ihrer Beurkundung im Oberstadtbuch Beteiligten von den Eintragungen Abschriften auszuhändigen, ,viel früher ausgebildet hat".

${ }^{158}$ Siehe unten Anm. 295.

169 BASTIAN 1. S. 262-275.

${ }^{170}$ Mindestens Übungen im Schreiben von römischen Zahlen sind im Wachstafelfund aus der Jakobikirchenschule belegt: WARNCKE. Schulgeräte (wie oben Anm. 146), S. 238.

${ }^{171}$ Dass er es konnte, ist überdies ausdrücklich bezeugt. hat er doch seine erste Flandernreise zu Pferde mit einem berittenen Knecht gemacht: Handlungsbuch (wie Anm. 55) S.9, Nr. I 86 u. 87.

172 UB. Stadt Lüb. 3, Nr. 425 (S. 434): Brun Warendorp. Gozwin vamme Kerkhove und Arnold Lange quittieren am 6. August über das sallarium von je $30 \mathrm{ml}$. für den Dienst, den sie der Stadt Lübeck ,in diesem Jahr" geleistet haben. Es wird sich wohl um Reiterdienst mit berittenem Knecht und 3. Pferd (Gleve) gehandelt haben. Dieser Brun ist entweder mit dem Ratmann und Bürgermeister zu identifizieren, der, 1366 in den Rat gekommen, bereits 1369 in Schonen als Lübecker Flotten- und Heerführer gestorben ist (LUTTERBECK Nr. 277 , S. 414f.) oder mit seinem Namensvetter, dem Sohn des Wilhelm Warendorp. der von 1367 bis 1411 dem Rat angehört hat (LUTTERBECK Nr. 278, S. 415-417). Dies gilt natürlich unter der Voraussetzung, dass es 1362 nicht etwa noch einen dritten Gleichnamigen gegeben hat, der nie in den Rat gekommen ist. MANTELS, Schiffshauptleute (wie Anm. 11), S. 202 hat sich ohne weiteres für den erstgenannten entschieden. Dafür könnte beim derzeitigen Forschungsstand wohl nur sprechen, dass er nicht annähernd so reich gewesen zu sein scheint wie der andere und also am Solddienst auch ein finanzielles Interesse hätte haben können. Auch hat MANTELS die drei Aussteller der Quittung ohne jeden erkennbaren Grund als „Hauptleute“ und „Führer einer Söldnercompagnie“ angesprochen. Die systematische Auswertung aller 
üben konnten. Das wird niemand bezweifeln, der weiß, wie gering der Abstand zwischen Landadel und städtischen Oberschichten im 14. Jahrhundert gewesen ist; speziell für Lübeck hat das vor einem Dutzend Jahren in ziemlicher Breite Rainer Demski dargestellt. ${ }^{173}$ Allerdings habe ich bisher noch nirgends Untersuchungen über das hier interessierende Spezialthema „militärische Ausbildung von norddeutschen Bürgersöhnen“" gefunden.

Dies sind die persönlichen Voraussetzungen, unter denen Johan Wittenborch im Frühjahr 1350 in den Rat berufen worden ist; als Ratszeuge bei der Errichtung eines Testaments ist er erstmals am 26. Mai belegt. ${ }^{174}$ Er hat sicherlich noch nicht davon profitiert, ${ }^{175}$ dass der Rat 1350 durch den Schwarzen Tod „stark dezimiert" worden ist, denn mit einer möglichen Ausnahme sind die Pestopfer des Jahres aus dem Rat erst zwischen dem 11. August und dem 1. November gestorben; ${ }^{176}$ dass Johan auch ganz

erhaltenen Soldquittungen von Männern, die im Feldzug von 1362 Solddienst für Lübeck geleistet haben, durch Rainer DEMSK1, Adel und Lübeck. Studien zum Verhältnis zwischen adliger und bürgerlicher Kultur im 13. und 14. Jahrhundert (Kieler Werkstücke D 6), Frankfurt am Main usw. 1996, S. 149f., hat allerdings ergeben, dass sich unter 215 Soldempfängern „,nur 16 Lübecker Bürger“ „Zweifelsfrei“ erkennen lassen. Davon sind acht ausdrücklich als Handwerker - Gerber und „Schlachter" - bezeichnet. Der hier gemeinten Gruppe dürften also, abgesehen von Ratmannen, die als Kommandeure mitwirkten und aus Soldquittungen nicht zu erfassen sind, nur insgesamt sechs bis acht Personen angehört haben. Danach wird man sich davor hüten müssen, den Anteil dieser Gruppe an der Lübecker Bevölkerung zu überschätzen.

${ }^{173}$ Siehe die vorige Anm.

${ }^{174}$ Reg. Test. (wie Anm. 93) 1, Nr. 322 (S. 163). Das Datum und die Quelle bereits bei MolLwo S. VI mit Anm. 3.

${ }^{175}$ Das folgende gegen Mol.Lwo S. VI, dem auch noch HAMMEL 1982, S. 304 gefolgt ist.

${ }^{176}$ Nach der grundlegenden Behandlung des Gegenstands bei Elisabeth PETERS, Das große Sterben des Jahres 1350 in Lübeck und seine Auswirkungen auf die wirtschaftliche und soziale Struktur der Stadt, in: ZVLGA 30.1, 1939, S. 15-148, hier S. 9l f., sind zwar wirklich in den ersten Monaten des Jahres drei Ratsmitglieder gestorben, am 10. Januar, 7. März und 5. Mai, aber es ist zunächst ganz ungewiss, ob wenigstens schon der 2. und/oder 3. Todesfall etwas mit der Pest zu tun hatte. Denn die zusammenhängende Reihe der acht weiteren Sterbefälle des Jahres beginnt erst am 11. August. Auch die Zahl der erhaltenen Bürgertestamente (Überblick bei PETERS a.a.O. S. 32f.) erreicht Spitzenwerte erst in den Monaten Juli bis September, ist allerdings schon im März und Mai mit 12 bzw. 10 Stück ungewöhnlich hoch. Vgl. zu all dem auch zusammenfassend Jürgen Hartwig IBS, Die Pest in SchleswigHolstein von 1350 bis $1547 / 48$. Eine sozialgeschichtliche Studie über eine wiederkehrende Katastrophe, Frankfurt am Main 1994 (= Kieler Werkstücke A 12), S. 87 u. 89 (Grafik). Ein Blick auf die Testamente des Frühjahrs (Reg. Test. (wie Anm. 93) 1, S. 152-164, Nr. 300-323/324) führt aber weiter. Danach waren von den neun Personen, die zwischen dem 5. Mai und dem 6. Juni ihr Testament gemacht haben, sechs krank, und man darf dann wohl vermuten, dass die Pest damals in Lübeck zuerst aufgetreten ist. Falls der Ratsherrentod vom 5. Mai ebenfalls in diesen Zusammenhang gehört, und falls die beiden anderen neuen Ratsherren des Frühjahrs 1350, Herman van Dulmen und Johan van Schepenstede, die bereits am 9. April erstmals als Testamentszeugen belegt sind (Reg. Test. (wie Anm. 93) 1, Nr. 312. S. 159), auch vor Johan Wittenborch gewählt worden sind, dann könnte dieser immerhin an die Stelle des ersten Pesttoten aus dem Lübecker Rat getreten sein. 
gewiss nicht seinen verstorbenen Schwiegervater Arnold Bardewik im Rat ersetzt hat, weil Herrn Arnolds Todestag der 21. September war, ist bereits von Lutterbeck dargelegt worden. ${ }^{177}$ Von den allgemeinen Bedingungen, die normalerweise diskutiert werden, wenn man fragt, warum im Spätmittelalter ein Lübecker oder sonstwie küstennorddcutsch-hansestädtischer Kaufmann in den Rat seiner Stadt aufgenommen wurde, waren zwei erfüllt: Er war sicherlich wohlhabend, vielleicht sehr wohlhabend, wenn auch ebenso wenig wie sein Vater wirklich reich, und er gehörte nach Abstammung und Eheverbindung zu dem Kreis der Familien, die bereits in den Generationen der Eltern und Großeltern Mitglieder des Lübecker Rats gestellt hatten.

Danach bleibt nur noch zu erwägen, inwieweit für die Anfänge von Herrn Johans „Karriere“ seine Beziehungen zu einflussreichen, im Lübecker Rat vertretenen Verwandtschaftskreisen tatsächlich eine Rolle gespielt haben könnten. Dass dabei Verwandte seiner Eltern nicht in Betracht gekommen sind, ist bereits dargelegt worden. ${ }^{178}$ Es bleiben also nur noch die angeheirateten Verwandten zu behandeln, die Johan durch die Ehe mit einer Tochter des Ratmanns Arnold Bardewich erworben hat. Der Schwiegervater ist, wie gesagt, am 21. September 1350 gestorben, nachdem er fast ein Vierteljahrhundert lang dem Rat angehört hatte. Bereits Mantels wusste, dass er ,verschuldet gestorben“ ist. ${ }^{179}$ Mollwo meinte, er sei „kurz vor seinem ... Tod in Vermögensverfall geraten", und stellte die Indizien dafür aus der Zeit bald nach seinem Tode zusammen. ${ }^{180}$ Insbesondere war Herr Arnold dem Ratmann Wedeke van Warendorp, ${ }^{181}$ der drei Wochen nach ihm, am 11 . Oktober 1350, gestorben ist, $454 \mathrm{ml}$. schuldig geblieben. Dafür mussten seine Kinder autkommen, Elisabeth (Telse), Herrn Johan Wittenborchs Frau, ${ }^{182}$ und Arnold Bardewich, ,den Wittenborg ... immer

\footnotetext{
${ }^{177}$ LUTTERBECK S. 88 mit Anm. 399.

${ }^{178}$ Siehe oben mit Anm. 84 u. 125-132.

${ }^{179}$ MANTELS. Schiffshauptleute (wie Anm. 11), S. 190.

${ }^{180}$ Mollwo S. VII. Vgl. Fehling Nr. 332, S. 30; hier heißt es: "Sein Nachlaß war überschuldet". Allerdings steht da auch die unsinnige Angabe, , seine drei Söhne“ seien ,ins Ausland" gegangen.

${ }^{181}$ LUTTERBECK Nr. 284 (S. 424-426). Der Taufname ist hier als „Wedekin“ angegeben, vermutlich, weil man es so auch bei vON BRANDT (Reg. Test. (wie Anm. 93) 1, S. 209. Nr. 406) findet. Die volkssprachliche Form ist aber zweifellos "Wedeke", siehe nur Handlungsbuch (wie Anm. 55) S. 21, Nr. II 89, S. 24, Nr. II 117 und öfter.

${ }^{182}$ In der - auch sonst nicht weiterführenden - Verwandtschaftstafel Johan Wittenborch bei ASMUSSEN, Flandernfahrer (wie Anm. 74) S. 160 findet sich als ihre Schwester eine „Ghertrud van Bardewik", die mit dem 1340 gestorbenen Bürgermeister Hinrik Pleskow verheiratet war; tatsächlich handelt es sich um eine Schwester ihres Vaters, s. LUTTERBECK Nr. 184, hier S. 338, und Nr. 16 (Albrecht van Bardewich). hier S. 198. Bereits Jürgen WIEGANDT, Die Plescows. Ein Beitrag zur Auswanderung Wisbyer Kaufmannsfamilien nach Lübeck im 13. und 14. Jahrhundert (Quellen und Darstellungen zur hansischen Geschichte N.F. 28), Köln.
} 
in seinem Geschäft verwandte“. ${ }^{183}$ Es ist fraglich, ob danach noch etwas für die beiden übrig geblieben ist; anscheinend hat darüber hinaus auch Herr Johan Wittenborch für seinen Schwager einspringen müssen. Wahrscheinlich ist Herr Arnold aber schon einige Jahre vor seinem Tod in finanziell bedrängter Lage gewesen, hat er doch 1347 das Haus in der Königstraße verkauft, in dem er bisher und vor ihm schon sein Vater, Herr Albrecht van Bardewich, seit 1289 gewohnt hatten. ${ }^{184}$ Im weiteren Verlauf der 1350er Jahre tauchen Herr Arnold, eine - wohl ebenfalls 1350 verstorbene - weibliche Verwandte namens Agnete und einmal auch der schon 1310 gestorbene Herr Albrecht im „Handlungsbuch“ nur noch auf, wenn Herr Johan es übernommen hatte, kleine Beträge für das liturgische Gedächtnis der Toten auszulegen bzw. an die richtige Stelle zu befördern. ${ }^{185}$ Es ist klar, dass Johan Wittenborchs „Karriere“ auch von diesen Verwandten nicht hat gefördert werden können. Doch hat es weitere angeheiratete Verwandte gegeben, die nicht den Namen Bardewich tragen. ${ }^{186}$ So taucht kurz vor der Zeit, in die Herrn Johans Tod fällt, der Anklamer Ratmann Marquard van Zagentze erstmals als ein solcher angeheirateter Verwandter auf. Er hat nämlich am 11. August 1363 einen lateinischen Brief an ,seinen lieben swagerus Herrn Johan Wyttenborch, Bürgermeister in Lübeck“, geschrieben; ${ }^{187}$ der Absender nennt sich „Euer aufrichtiger swagerus". Der Brief ist im Lübecker Archiv überliefert und wurde also vom Rat beschlagnahmt; ${ }^{188}$ wir können nicht sagen, ob Herr Johan den Wortlaut wenigstens noch vorgelesen bekommen hat. Durch den Brief wird einerseits wenigstens einer von seinen Freunden sichtbar, die sich auf

Wien 1988, S. 35, hatte aus Herrn Hinrik den Schwiegersohn von Herrn Arnold gemacht und von diesem dann behauptet, er habe „zweifellos zu den einflussreichsten Lübecker Persönlichkeiten seiner Zeit" gehört.

${ }^{183}$ Mollwo S. VII. „Immer“ heißt, dass Arnold seit 1353 als Kaufgeselle für Herrn Johan gereist ist, fast immer nach Osten. Der früheste Beleg betrifft eine solche Reise, zu der Arnold nach dem 12. Mai (Pfingsten) 1353 aufgebrochen ist: Handlungsbuch (wie Anm. 55) S. 19. Nr. II 78.

${ }^{184}$ LUTTERBECK S. 200 und 199.

${ }^{185}$ Mollwo S. 95 (Personenverzeichnis) hat aus diesen Nachrichten .Agnete van Bardewic, Frau des Ratsherrn Arnold van Bardewic" konstruiert; vgl. auch ebd. S. 94 „Agnes“. Mich stört an der Gleichsetzung von „Agnete“ mit „Arnolds Mutter" vor allem, dass .Agnete" nur ein einziges Mal „Frau" genannt ist (Handlungsbuch (wie Anm. 55) S. 21. Nr. II 90). .Agnete“ war aber zweifellos eine nahe Verwandte der Bardewich-Geschwister: vielleicht ist moder als "modder" = "Tante" oder "Base" zu verstehen. Herr Albrecht fehlt in Mollwos Register: Handlungsbuch (wie Anm. 55) S. 37, Nr. II 238.

${ }^{186}$ Ohne besondere Bedeutung für Herrn Johans Karriere war wohl die oben Anm. 182 erwähnte Verschwägerung der Bardewich mit Herrn Hinrik Pleskow dem Alten; jedenfalls treffen wir nie einen Pleskow in seiner näheren Umgebung an.

${ }^{187}$ Handlungsbuch (wie Anm. 55) S. 67. Nr. III 3.

${ }^{188}$ Siehe dazu bereits oben Anm. 64. 
den Hansetagen des Jahres 1363 für ihn eingesetzt haben. ${ }^{189}$ Andererseits kommt ein sonst gar nicht auffallender Kreis von angeheirateten Verwandten in Lübeck zum Vorschein, die noch Beziehungen nach Vorpommern haben. Denn Herr Marquard bezeichnet den Bürgermeister Tideman Warendorp als seinen avunculus. Herr Tideman hat von 1340 bis zu scincm Tode im Jahre 1366 dem Rat angehört, spätestens seit dem Frühjahr 1356 als Bürgermeister. ${ }^{190}$ Er ist u. a. am 4. Oktober 1350 von dem eben erwähnten Herrn Wedeke Warendorp zum zweiten von fünf Testamentsvollstreckern bestimmt worden; Herr Johan Wittenborch war der vierte. ${ }^{191}$ In diesem Testament erscheint weiter ein Marquard van Zagense als - offenbar auswärtiger - Schuldner des Testators und seines Bruders Herman; es handelt sich doch wohl um denselben Marquard, den wir eben als Anklamer Ratmann kennen gelernt haben. ${ }^{192}$ Herr Tideman, der vielleicht ein Vetter der beiden Brüder war, sollte ein Vermächtnis an arme Verwandte des Testators in Anklam auszahlen. Unter den sonst noch Bedachten war auch ein Arnold Bardewich, der u. a. $10 \mathrm{ml}$. Rente in einem Lübecker Haus bekommen sollte. Da diese Rente auch auf einem Zettel vom 25. Dezember 1350 erwähnt wird, der als Einlage in Herrn Johans „Handlungsbuch“ überliefert ist, ${ }^{193}$ ist die Identität dieses Arnold mit Herrn Johans Schwager gesichert. Herr Wedeke wollte ihm außerdem eine noch zu begründende, mit $500 \mathrm{ml}$. Kapital auszustattende Vikarie zuwenden. Dafür hätte er eine andere Vikarie, die er bereits innehatte, abtreten sollen. Von dem ziemlich mäßigen Ertrag dieser Vikarie, knapp $11 \mathrm{ml}$., ist auf demselben Zettel die Rede. ${ }^{194}$ Der Betrag stellt wohl nur den Rest dar, der nach der Bezahlung eines Mietpriesters übrig geblieben war; denn Amold ist 1350 offenkundig nicht Priester gewesen und es auch niemals geworden. ${ }^{195}$ Als Besitzer eines Altars, an dem er nicht selbst zelebriert hat, ist er aber noch 1353 belegt. ${ }^{196} \mathrm{Da}$ Arnold seit diesem Jahr aber auch als kaufmän-

${ }^{189}$ Als Vertreter seiner Stadt ist Herr Marquard in der hier interessierenden Zeit - seit Herbst 1362 - allerdings nur auf der Wismarer Tagung vom 17. März belegt (HR I, 1, Nr. 291, S. 222); vgl. dazu oben Anm. 40. Danach erscheint er erst wieder am 22. September in Greifswald auf einem Hansetag (ebd. Nr. 300, S. 247. \$1, linke Spalte); da war Herr Johan schon tot. Vgl. dazu bereits MOLLwo S. XXXIII.

${ }^{190}$ LUTTERBECK Nr. 283 (S. 423f.).

${ }^{191}$ Reg. Test. (wie Anm. 93) 1, Nr. 406 (S. 209f.).

${ }^{192}$ Auf Vorpommern weist der Schuldbetrag von 300 Mark Stralsunder Pfennige hin.

${ }^{193}$ Handlungsbuch (wie Anm. 55) S. 54, Nr. II a 2 (über den Zettel Mollwo S. XXXV).

${ }^{194}$ Ebd. 1.

${ }^{195}$ Im Testament von Herrn Johans Witwe wird er 1367 einfach als „Arnold Bardewick, mein Bruder" mit einem goldenen Saphirring bedacht und zum dritten von fünf Testamentsvollstreckern bestimmt: Handlungsbuch (wie Anm. 55) S. 90 f., Nr. VI 4.

${ }^{196}$ Handlungsbuch (wie Anm. 55) Nr. II 126 am Ende (S. 26), niedergeschrieben wohl Anfang 1354: Herr Johan hat ,für Arnold ausgegeben dem Priester, der Messe las an seinem Altar, $2 \frac{1}{2} \mathrm{ml} . “$. 
nischer Mitarbeiter von Herrn Johan bezeugt ist, ${ }^{197}$ wird er nach einigen Jahren des Zögerns überhaupt darauf verzichtet haben, geistlich zu werden; vielleicht sind ja die guten materiellen Aussichten im geistlichen Stand, die ihm 1350 durch Herrn Wedekes Testament eröffnet worden waren, bereits durch Arnolds Zahlungsverpflichtungen gegenüber Herrn Wedekes Nachlass hinfällig geworden. Arnold Bardewich taucht auch in Herrn Johans Testament von 1362 unter den Testamentsvollstreckern auf, die ausdrücklich als Bürger bezeichnet sind. ${ }^{198}$ Warum hat Herr Wedeke Warendorp den Arnold Bardewich so reichlich bedenken wollen? Und weshalb hat er außerdem den Ehemann der Elisabeth Bardewich zu einem seiner Testamentsvollstrecker bestimmt? Die Antwort findet man in dem Testament, das Herrn Wedekes Vater, der 1333 gestorbene Bürgermeister Herman Warendorp (senior), ${ }^{199}$ am 16. Mai dieses Jahres errichtet hat: ${ }^{200}$ Die - bisher unbekannte - Ehefrau des Herrn Arnold Bardewich, die Mutter seiner beiden Kinder, muss eine Warendorp gewesen sein. Sehr wahrscheinlich war sie eine namentlich nicht bekannte Schwester von Herrn Herman, die schon in jungen Jahren verstorben ist. Denn Herr Herman hat den Kindern des Herrn Arnold Bardewich ${ }^{201}$ (der selbst an zweiter Stelle unter den Testamentsvollstreckern genannt ist), mit $200 \mathrm{ml}$. ebenso viel vermacht wie „den Kindern seiner Schwester Elisabeth". ${ }^{202} \mathrm{Zu}$ dieser

\footnotetext{
${ }^{197}$ Siehe oben Anm. 183.

${ }^{198}$ Handlungsbuch (wie Anm. 55) S. 90, Nr. VI 3 am Ende.

${ }^{199}$ LUTTERBECK Nr. 281 (S. 420-422).
}

${ }^{201}$ Reg. Test. (wie Anm. 93) 1, Nr. 121 (S. 71). Wenn man die Beziehungen der Familie nach Vorpommern aus Herrn Wedekes Testament kennt, fält einem sofort auf, dass davon im Testament seines Vaters nicht das geringste zu sehen ist. Vermutlich sind diese Beziehungen hier systematisch herausgehalten worden; damit wäre es auch zu erklären, dass unter den „Söhne[n] des Erblassers“ Herman fehlt. Wenn er damals noch nicht in Lübeck war, könnte er identisch sein mit dem Hermannus de Warendorp, der im Frühjahr 1344 als Lübecker Neubürger verzeichnet wurde, leider ohne Nennung eines Bürgen: Olof AHLERS (Hg.), Civilitates. Lübecker Neubürgerlisten 1317 - 1356 (Veröff. zur Geschichte der Hansestadt Luibeck 19), Lübeck 1967, 1344, 27 (S. 95).

${ }^{201}$ Sie werden im Regest „Albert und Elisabeth“ genannt. „Albert” ist offensichtlich Schreib- oder Übertragungsfehler für „Arnold“, den wir hier ja sonst vermissen müssten; der Name „Albert" ist also auch bei LUTTERBECK S. 199 (wo er neben Arnold aufgeführt ist !) zu streichen.

${ }^{202}$ Deren - offenbar auch schon verstorbener - Mann hier ebenso wenig namentlich genannt ist wie Herrn Arnolds Frau. Nach RöRIG, Wirtschaftskräfte (wie Anm. 57), S. 170 mit Anm. 6, wäre diese Elisabeth mit einem „vor 1285“ gestorbenen „Reinfried de Warendorp“ aus ,blutmäßig“" verschiedener Warendorp-Familie verheiratet gewesen (vgl. auch PETERS, Sterben, wie Anm. 176, S. 90, „Warendorp I"); ihre Kinder hätten dann 1333 mindestens um die 50 Jahre alt sein müssen; darunter wäre auch der Ratmann und Bürgermeister Brun Warendorp gewesen. der offenbar als Sohn des Reinfried belegt ist und von 1289 bis zu seinem Tod im Jahre 1341 im Rat saß (LUTTERBECK Nr. 276, S. 412-414). All das ist äußerst unwahrscheinlich; es scheint nicht einmal sicher, dass die Frau des Reinfried eine andere. eine Generation ältere Elisabeth war (LUTTERBECK a.a.O. S. 413 nennt Herrn Bruns Mutter nicht). 
Einsicht passt dann auch eine weitere, bisher nicht zitierte Bestimmung zugunsten von Arnold Bardewich (junior) in Herrn Wedekes Testament von 1350: Arnold solle „den ganzen, ihm von seiner Mutter zukommenden Anteil an der Salinenpfanne“" erhalten. ${ }^{203}$ Dass dieser Anteil bisher von Herrn Wedeke besessen worden war, ist ein wcitercs Indiz dafür, dass Arnolds Mutter derselben - offenbar am Anfang des 14. Jahrhunderts aus Vorpommern nach Lübeck eingewanderten ${ }^{204}$ - Warendorp-Familie angehört hat wie Herr Hermann, seine Söhne und Herr Tideman. Aus noch nicht allzu lange zurückliegender Einwanderung erklärt es sich dann gewiss auch, dass bisher weder Herrn Hermans noch Herrn Tidemans Eltern bekannt geworden sind, ${ }^{205}$ Herr Tideman, der wahrscheinlich erst im Frühjahr 1337 Lübecker Bürger geworden ist, ${ }^{206}$ mag einen Bruder von Herrn Herman zum Vater gehabt haben. Für die weitere Rekonstruktion dieser Familie verdient es Beachtung, dass im Verwandtenkreis wiederholt der in Lübeck an sich nicht häufige Taufname Lub(b)ert oder Lutbert auftaucht. Ein Lutbertus de Warendorpe, für den „Herr Herman, sein Bruder" gebürgt hat, ist 1331 Lübecker Bürger geworden; ${ }^{207}$ zwei Jahre später begegnen wir ihm erneut, in Herrn Hermans Testament als erstgenanntem Testamentsvollstrecker. ${ }^{208}$ Auch ein Sohn von Herrn Herman und ein Bruder von Herrn Tideman hießen so. Andererseits erscheint Herr Johan Wittenborch noch 1356 unter den Vormündern der Kinder der verstorbenen Brüder [Herr] Wedeke und Herman Warendorp. ${ }^{2019}$ Diese Waren-

\footnotetext{
${ }^{203}$ Reg. Test. (wie Anm. 93) I, Nr. 406, Satz 15 auf S. 210.

${ }^{2(4)}$ Beziehungsweise zurückgewanderten, wenn man annimmt, dass auch diese Warendorp ursprünglich über Lübeck aus Westfalen gekommen sind.

${ }^{20.5}$ Siehe LUTTERBECK S. 420 u. 423.

${ }^{206}$ AHLERS, Civilitates (wie Anm. 200), 1337, 22 (S. 77; Thidemannus de Warendorpe civis, kein Bürge genannt, der einzige Neubürger dieses Namens im Erfassungszeitraum). Für die Identität spricht weiter, dass auch die Lübecker Nachrichten über den Ratmann bei LUTTERBECK S. 423f. erst 1337 einsetzen, und zwar gleich mit zwei Hauskäufen, in der Breiten Straße (wo er dann gewohnt hat) und in der Johannisstraße.

${ }^{207}$ A HLERS, Civilitates, 1331, 203 (S. 63) ; für die ebd. S. 9 geäußerte Vermulung. Lutbert sei „wahrscheinlich“ Lübecker Bürgersohn gewesen, spricht nichts. Zwei weitere Träger des Namens Lub(b)ertus Warendorp(e) haben 1340 (ebd. 140, S. 89) und 1350 (ebd. 98, S. 111) das Lübecker Bürgerrecht erworben; leider sind hier keine Bürgen genannt.

${ }^{208} \mathrm{Vgl}$. zu den meisten der hier genannten Warendorp auch PETERS, Sterben (wie Anm. 176), S. 90f., genealogische Übersicht .Warendorp III“, wo Herr „Tidemann“" ohne weiteres als Sohn von Herrn Hermans Bruder Lubbert aufgeführt ist. Da die Angaben nicht belegt sind (für die Warendorp hat sich PETERS ebd. S. 88, Anm. 132, u. a. auf eine .,ungedruckte Stammtafel der Warendorp" von RÖRIG berufen), muss offen bleiben, ob PETERS dafür eine Quelle gehabt hat, die LUTTERBECK entgangen ist, oder ob hier einfach eine nicht unplausible, aber natülich nicht zwingende Vermutung zur Gewissheit erhoben worden ist.

${ }^{2019}$ UB. Stadt Lüb. 3, Nr. 260 (S. 254f.), eine Urkunde des Lüneburger Rats, in der alle fünf namentlich erwähnten Lübecker Ratsmitglieder ohne den Titel „Herr“ vorkommen. Unter den Vormündern der Elisabeth, Tochter des Herrn Wedeke Warendorp. begegnet uns Herr Johan noch einmal am 12. März 1357: UB. Stadı Lüb. 4, Nr. 64, hier S. 67. - Herrn Wedekes
} 
dorp $^{210}$ waren offenbar eine Sippe, die über lange Zeit sehr fest zusammengehalten hat; das schloss offensichtlich sowohl die in Anklam zurückgebliebenen Verwandten ein wie die in Lübeck durch Heiraten Hinzugekommenen und deren Kinder. Wenn verwandtschaftliche Beziehungen zu Johan Wittenborchs Wahl in den Rat und zu seiner Erhebung zum Bürgermeister beigetragen haben sollten, dann hat es sich gewiss um die durch seine Ehe mit Elisabeth Bardewich geschaffenen - Beziehungen zu dieser Sippe gehandelt, die im Frühjahr 1350 durch zwei Angehörige im Lübecker Rat vertreten war; 1359 hat sie zwar nur noch ein Ratsmitglied gestellt, aber eines, das drei Jahre zuvor selbst zum Bürgermeister aufgestiegen war. Unter den geschilderten Voraussetzungen erscheint es dann sinnvoll, einen Blick ins Jahr 1345 zurückzuwerfen, in dem Johan Wittenborch als Schwiegersohn des Herrn Arnold Bardewich $12 \frac{1}{2} \mathrm{ml}$. Rente im Marktbudenbesitz der Brüder Herr Wedeke und Herman Wittenborch erworben - angeblich gekauft - hatte. ${ }^{211}$ Die Brüder dürften es höchstens kurzfristig nötig gehabt haben, sich Geld durch Belastung ihres Grundbesitzes $z u$ beschaffen. ${ }^{212}$ Ich zögere daher nicht mit der Vermutung, dass es sich bei dieser Rente um Elisabeths Mitgift gehandelt hat, von der anderweitig nichts verlautet. ${ }^{213}$ Für die hätten dann Elisabeths mütterliche Verwandte gesorgt; wenn das Geld nicht geradezu gestiftet war, so könnte es im Rahmen irgendeines Tauschgeschäfts zur Verfügung gestellt worden

Bruder Herman ist schon vor ihm gestorben; er war bereits am 27. Mai 1350 tot: PETERS a.a.O. S. 65. Also kann es sich bei dem Herman Warendorp, Sohn des Herrn Herman, der am 29. Juni 1361 gemeinsam mit Herrn Johan Wittenborch im Niederstadtbuch als Gläubiger auftrat (Handlungsbuch (wie Anm. 55) S. 85, Nr. V 76), nur um den Sohn des Anfang 1350 gestorbenen Ratmanns Herman ,iunior“ (s. LUTTERBECK Nr. 282, hier S. 422) gehandelt haben (der Schuldner war übrigens „Herman van Warendorp, Bruder der Frau Elisabeth Vundengudes"“). Dieser Herman Warendorp war dann vermutlich auch der Namensträger, der 1362 unter Herrn Johans nicht ratsangehörigen Testamentsvollstreckern an erster Stelle genannt ist (Handlungsbuch (wie Anm. 55) S. 90, Nr. VI 3).

${ }^{210}$ Für die hier erörterten Beziehungen unergiebig ist Uta WEBBELER, Die Warendorp im Ostseeraum. Ein Überblick, in: Warendorfer Schriften 28-29, 1999, S. 263-286; Anklam ist gar nicht berücksichtigt.

${ }^{211}$ Siehe oben mit Anm. 148.

${ }^{212}$ Es muss hier dahingestellt bleiben, was VON BRANDT, Rentenmarkt (wie Anm. 100), S. 25 veranlasst hat, sich ausgerechnet die beiden Brüder als einziges Exempel für RörIgS Behauptung auszusuchen, dass ,für Leute, die als Rentner in Behaglichkeit oder gar im Wohlleben einer jeunesse dorée ihr Leben verbringen wollten, einfach kein Platz" im Lübeck der Zeit gewesen sei. Ob VON BRANDT wohl zur Kenntnis genommen hat, dass Wedeke 1343 in den Rat gewählt worden ist ? So viel ich sche, ist Herrn Wedekes Testament von 1350 das letzte einigermaßen aussagekräftige (aber den Immobilienbesitz nicht erwähnende) Zeugnis über die wirtschaftliche Lage von einem der vier Söhne des Bürgermeisters Herman Warendorp senior, von denen keiner das Jahr 1350 überlebt hat; es lässt keine Schwierigkeiten erkennen.

${ }^{213}$ Vgl. HAMMEL 1982, S. 303. 
sein. ${ }^{214}$ Wegen der schlechten Vermögensverhältnisse von Herrn Arnold Bardewich hat Rolf Hammel darüber spekuliert, ob man nicht Johan Wittenborchs Ehe als „Fall der Einheirat eines (reichen) ,homo novus' in eine (wirtschaftlich bedrängte) altangesehene Ratsfamilie" deuten könne. ${ }^{215}$ Dieser Überlegung, bei der noch nicht berücksichtigt werden konnte, dass Johan Wittenborch als Sohn einer Ratsherrentochter gar kein ,homo novus" gewesen ist, möchte ich eine andere Spekulation an die Seite stellen: Ob wohl Elisabeth, deren Vater vermutlich kaum in der Lage war, für ihre Mitgift zu sorgen, eine „standesgemäße“ Ehe hätte schließen können, wenn sich nicht die Warendorp-Brüder um die Sache gekümmert hätten ? Die hier erörterten Zusammenhänge ${ }^{216}$ stellen auch einen kleinen empirischen Beitrag zu der Frage dar, die Lutterbeck aufgeworfen hat: Inwieweit auch ,weniger enge [verwandtschaftliche] Verbindungen" „soweit als verbindend empfunden wurde[n], dass [sie] das Denken und Handeln beeinflusste[n] $[217$

Es wäre natürlich interessant zu wissen, wie viele jüngere Männer es gleichzeitig noch in Lübeck gegeben hat, die vergleichbare Voraussetzungen mitbrachten. Aber diese Frage lässt sich beim gegenwärtigen Forschungsstand wohl noch nicht beantworten, zumal es dafür ja nicht genügen würde, sich diejenigen näher anzusehen, die sonst noch um 1350 in den Rat berufen worden sind; man müsste auch die unter die Lupe nehmen, die den Ruf nicht bekommen haben. Man wüsste gern, ob es außerdem noch persönliche Merkmale gab, die Johan Wittenborch im Alter von ungefähr 30 Jahren als besonders qualifizierten Ratmannen-Nachwuchs erscheinen ließen. Aber es gibt so gut wie keine Quellen, die man unter diesem Gesichtspunkt sinnvoll befragen könnte. ${ }^{218}$

Die Frage nach Herrn Johans besonderer persönlicher Qualifikation für die Mitwirkung an der Arbeit des Lübecker Rats muss zu 1359 erneut gestellt werden, denn in diesem Jahr ist er in den Kreis der führenden Mitglieder aufgerückt; am 25. Mai ist er zum ersten Mal als Bürgermeister belegt. ${ }^{219}$ Die Quellenlage erlaubt es zwar nicht, sich ein völlig klares oder

\footnotetext{
${ }^{214}$ Als Tauschobjekt könnte man sich Elisabeths Anteil an der Salzpfanne aus dem Besitz ihrer Mutter vorstellen, von der wir 1350 erstmals erfahren (oben mit Anm. 203).

${ }^{215}$ HAMMEL 1982, S. 303.

${ }^{216}$ Die bis in ihre letzten Verästelungen zu verfolgen hier natürlich weder möglich noch geboten war.

${ }^{217}$ LUTTERBECK S. 68.

${ }^{218}$ Allenfalls könnte man versuchen, seinen weiteren Bekanntenkreis zu rekonstruieren. Auch hier käme man aber sicherlich nur zu Resultaten. die für zahlreiche Altersgenossen ebenso gegolten haben müssen.

${ }^{219}$ HAMMEL 1982, S. 304, hat erstmals das Jahr 1359 (mit genauer Bezeichnung seiner Quelle, aber ohne Angabe über das Datum) genannt; bis dahin galt „1360“. Die Quelle ist AHL, Niederstadtbuch 1312-1363, S. 800; es handelt sich um einen Quittungsvermerk vom
} 
gar lückenloses Bild davon zu machen, was Johan Wittenborch in neun Jahren als „einfaches" Ratsmitglied geleistet hat. Aber immerhin lassen sich Beiträge zu einer Antwort erarbeiten. Fragen wir zunächst, wie es an dieser Stelle nahe liegt, nach Herrn Johans Beitrag zur hansischen Politik des Rats: Die Rezesse der Hansetage, aus denen wir seit dem späteren 14. Jahrhundert dank dem obligatorischen Rezesselement der Ratssendebotenverzeichnisse jedenfalls in erheblichem Umfang ersehen können, ob und in welchem Ausmaß bestimmte Ratmannen in diesem Aufgabenbereich eingesetzt worden sind, hat es, soweit die zunächst ganz fragmentarische und formal disparate Überlieferung ein begründetes Urteil erlaubt, überhaupt erst seit 1358 gegeben, ${ }^{220}$ und vor dem Herbst 1362 enthält sie viel mehr Lücken als Stücke. Aus den gut vier Jahren bis zu dem - unbekannten - Zeitpunkt im Frühjahr 1362, als Herr Johan sich auf den Kriegsschauplatz begeben hat, sind nur vier Rezesse oder rezessähnliche Aufzeichnungen erhalten geblieben. Davon haben zwar drei ein Verzeichnis der an der Versammlung beteiligten Ratssendeboten. Aber gleich der erste Text, das als settinghe bezeichnete Beschlussprotokoll der Lübecker Versammlung vom 20. Januar 1358, in der es vor allem um den Boykott der flandrischen Wirtschaft gegangen ist, behandelt, wie später (erstmals 1396) so oft, den gesamten Lübecker Rat als Teilnehmer und nennt daher nicht einen einzigen Lübecker Namen. Für unsere Fragestellung nach Johan Wittenborchs amtlichen Leistungen vor dem Frühjahr 1359 kommt deshalb nur ein Schriftstück in Betracht. Der Rezess der Rostocker Versammlung vom 6. Dezember $1358,{ }^{221}$ der erste erhaltene ,richtige“ Hanserezess, ${ }^{222}$ nennt drei Lübecker Gesandte. Auf Herman van Wickede, Bürgermeister seit 1351, ${ }^{223}$ folgen, nach Anciennität sortiert, Bertram Vorrad, seit 1332 im Rat, ${ }^{224}$ und Johan Wittenborch. ${ }^{225}$ Die Versammlung hat

genannten Tag: Ein Gläubiger des Hamburger Ratmanns Hinrik Witzekendorp hat vor den Bürgermeistern Tideman Warendorp und Johan Wittenborch bekannt, dass ihm der am 21 . April 1359 fällig gewesene Schuldbetrag von dem Bürgen des Schuldners bezahlt worden ist. Neuerdings hat LUTTERBECK S. 438 mit Anm. 3568 unter Berufung auf dieselbe Eintragung behauptet, dass Herr Johan „bereits 1358 “ (Juni 24) als Bürgermeister belegt sei. Dies ist das Kopfdatum der Seite.

${ }^{220}$ Dies ganz klar ausgesprochen zu haben, ist das hauptsächliche Verdienst von BEHRMANN. Rezess (wie Anm. 46).

${ }^{221}$ HR I, 1. Nr. 223 (S. 149f.); ich werte die einzige - in Rostock selbst - erhaltene Handschrift, ein einseitig beschriebenes Blatt Papier, als Konzept. Die Datierung ist nur, allerdings völlig plausibel, erschlossen.

${ }^{222}$ Daran ist gegen die schlecht begründeten Einwände von BEHRMANN a.a.O., S. 459f., unbedingt festzuhalten.

${ }^{22.3}$ Über ihn unten mit Anm. 266.

224 Über ihn unten mit Anm. 267.

${ }^{225}$ Dass er, der am 25. Mai 1359 erstmals als Bürgermeister bezeugt ist, hier noch an letzter Stelle aufgeführt wird, bietet einen bestätigenden terminus ante quem für die Datierung des 
vor allem ein dreijähriges Bündnis der Seestädte zwischen Hamburg und Vorpommern gegen Verunrechtungen durch „Fürsten oder Landesherren“ entworfen, aber auch über mindestens vier verschiedene weitere Themen Beschlüsse gefasst. Danach kann man nur, aber doch immerhin sagen: Herr Johan Wittenborch hat bereits als ,einfacher" Ratmann an der hansischen Politik des Lübecker Rats mitgewirkt. ${ }^{226}$

Auch das Nachrichtenangebot des Urkundenbuchs der Stadt Lübeck ist für die 135()er Jahre wahrlich noch nicht üppig. Hervorzuheben ist eine Nachricht vom 18. Juli 1353: Damals hat der Lauenburger Herzog Erich „der Jüngere“ ${ }^{6227}$ sich damit einverstanden erklärt, dass Herr Johan neben seinem älteren Kollegen Johan Woltvoge ${ }^{228}$ „,das Schloss zu Dömitz" bis zum kommenden 15. August holden würde. ${ }^{229}$ Die beiden Ratmannen sollten also, natürlich in ihrer Eigenschaft als Vertreter der Stadt Lübeck, die Burg innehaben, bis über deren weiteres Schicksal entschieden war. ${ }^{230}$ Dömitz ist offenbar vorher im Rahmen einer großen Militäraktion gegen die rofhuse (Detmar) ${ }^{231}$ von den Landfriedenstruppen eingenommen wor-

Rezesses. - Über Ratsvertreter auf Hansetagen zwischen 1358 und dem Anfang des 15. Jh.s am Beispiel von Wismar. Lübeck und Greifswald vgl. die prosopographische Studie von Dietrich W. POECK, Hansische Ratssendboten, in: Vergleichende Ansätze in der hansischen Geschichtsforschung, hg. von Rolf HAMMEL-KIESOW (Hansische Studien 13). Trier 2002. S. 97-142. Im Lübeck-Kapitel (S. 120-131) sind allerdings sowohl Johan Wittenborch wie der wichtige, hier auch weiterhin noch oft zu nennende Herman van Wickede nur beiläufig erwähnt (S. 120f. u. 131). Von solchen Mängeln im Detail (vgl. auch noch unten Anm. 278 zu Johan Pleskow) abgesehen. hege ich crhebliche methodische Bedenken gegen die vom Verfasser betriebene ,statistische“ Behandlung von Personenkreisen, die nach einem einzigen Kriterium aus erheblich größeren Populationen herausgegriffen sind: schließlich waren auch die Hansepolitiker der Räte keine "Fachidioten". Aber ich verkenne natürlich nicht. dass eine vergleichende Untersuchung aller Lübecker Ratmannen der 2. Hälfte des 14. Jh.s nach allen wesentlichen Kriterien durch Quellenmangel sehr erschwert und vielleicht geradezu unmöglich gemacht würde. vgl. unten Anm. 444.

${ }^{226}$ BASTIAN 1, S. 227, sah hier schon „die erste Nachricht über eine hervorragende außenpolitische Betätigung Wittenborgs ..., die ihm in kurzem die Bürgermeisterwürde seiner Vaterstadt eintrug, ihn freilich weiterhin auch auf das Schaffott brachte". BASTIAN meinte allerdings auch, dass Herr Johan , schon damals seine kaufmännische Tätigkeit ,ab(gebaut) ${ }^{\text {.. }}$ habe. Dagegen würde ich, was BASTIAN so gedeutet hat, eher als Zeugnisse für eine schwierige Absatzlage in den Jahren des hansischen Flandernboykotts interpretieren.

${ }^{227}$ Näheres über ihn unten mit Anm. 263-265.

228 Im Rat 1338-1354: LUTTERBECK Nr. 303 (S. 441 f.).

${ }_{229}$ UB. Stadt Lüb. 3, Nr. 179 (S. 182), danach Mecklenburgisches Urkundenbuch 13, Nr. 7799 (S. 352), vgl. dazu ebd. S. 349 f.

${ }^{230}$ Die Nachricht ist schon bei FEHLING S. 33 erwähnt, wo aber schief von „Nutzung" die Rede ist. Bereits bei Mol..wo S. XI mit Anm. 6 gibt es den zutreffenden Hinweis „Die Lübecker brachen dann Dömitz".

${ }^{231}$ Die Chroniken der niedersächsischen Städte. Lübeck Bd. I [Bearbeitet von Karl KoPPMANN] (Die Chroniken der deutschen Städte vom 14. bis ins 16. Jahrhundert Bd. 19), Leipzig 1884. S. 523f., \$ 685. mit den Anm. 3-4 u. 1-5, besonders 3. über Dömitz), und Die Chroniken der niedersächsischen Städte. Lübeck Bd. 2 [Bearbeitet von Karl KOPPMANN| (Die Chroniken der deutschen Städte vom 14. bis ins 16. Jahrhundert Bd. 26), Leipzig 1899. S. 245, \$ 685. Die Edition wird weiterhin als Chron. Lüb. 1 und 2 zitiert. 
den, und es ist also gut vorstellbar, dass Woltvogel und Wittenborch die Kommandeure des Lübecker Kontingents gewesen sind. ${ }^{232}$ Wie das Kontingent ausgesehen haben könnte, zeigt die Nachricht über eine ähnliche Abteilung, die der Lübecker Rat 1377 dem Kaiser für die Belagerung der Schlösser Lüchow und Dannenberg zur Verfügung gestellt hatte, in der so genannten Rufus-Chronik: ${ }^{233}$ „Der Rat ... sandte ihm zwei aus dem Rate, Herrn Simon Swerting, Bürgermeister, Herrn Gerd van Ateldorn, Ratmann, mit 60 Mannen wohl gewaffnet und zwei Bliden mit allem Gerät“". Eine im Rostocker Archiv überlieferte, am 25. Oktober 1353 in Lübeck ausgefertigte Abrechnung ${ }^{234}$ lässt dann erkennen. wie es in Dömitz weitergegangen ist, nachdem die Burg erobert und den Räten von Rostock, Wismar und Lübeck übergeben war. Denn in der Rechnung ist zusammengetragen, was die genannten Räte gemeinschaftlich zu bezahlen pflichtig waren, weil es in Dömitz verbraucht und ausgegeben worden ist. Die Rostocker und Wismarer Ratsdiener (familiares dominorum consulum) hatten Dömitz bald nach der Übergabe verlassen, und es blieben nur noch ipsi [domini consules Lubicenses] cum familiaribus Lubicensibus übrig. Die Hauptaufgabe bestand darin, den turris Domenitze abzubrechen. Als dies in Angriff genommen werden sollte, übergaben die Herren advocato nostro, also dem Hauptmann der Lübecker Reitenden Diener, dem so genannten Ausreitervogt, ${ }^{235} 50 \mathrm{ml}$. Aus der Rechnung ist leider nicht ersichtlich, ob damit der Vogt und seine Mannschaft bereits auf den Heimweg geschickt wurden, oder ob sie (oder wenigstens ein Teil von ihnen) noch bis zum Ende der Arbeiten in Dömitz geblieben sind. An den Abbrucharbeiten nahmen Steinmetze und Träger. ${ }^{236}$ Maurer und Zimmerleute teil; sie stammten offenbar alle aus Lübeck. Als die Arbeiten abgeschlossen waren, wurden die unberittenen Lübecker (pedestres Lubicenses) auf zwanzig Wagen nach Lübeck nach Hause gebracht (domi Lubeke ducebantur). Wenn die Vermutung richtig ist, dass die beiden am 18. Juli

\footnotetext{
${ }^{232}$ Man hätte gern eine nicht näher datierte Eintragung von „1353“ in Herrn Johans „Handlungsbuch“ (Handlungsbuch (wie Anm. 55) S. 23, Nr. II 114) über seinen „Auszug“ in eine nicht weiter erläuterte reyse hierher gestellt, wäre nicht die Jahreszahl nach der Handschrift $\mathrm{zu}, 1354^{\prime \prime} \mathrm{zu}$ berichtigen. Es ging also nicht um einen Kriegszug, sondern um etwas, was man auch heute noch als Reise bezeichnen würde; siehe dazu oben mit Anm. 158.

${ }^{233}$ Chron. Lüb. 2 (wie Anm. 231), S. 254, Nr. 785. Bei Detmar (ebd. 1, S. 560, Nr. 789, 2. Absatz) fehlen alle hier interessierenden Details.

${ }^{234}$ UB. Stadt Lüb. 4, Nr. 47 (S. 49f.), danach auch Mecklenburgisches Urkundenbuch 13. Nr. 7822 (S. 37 I f.).

${ }^{235} \mathrm{Zu}$ Organisation und Personal dieser Truppe vom Ende des 13. bis zum 16. Jh. siehe Georg FINK, Die Entwicklung des Lübecker Marstall-Offiziums, in ZVLGA 25, I, 1929. S. 199-226, hier S. 204-210. Vgl. auch EBEL, Lübisches Recht (wie Anm. 91), S. 261 f.

${ }^{236}$ fertores im Mecklenburgischen Urkundenbuch, irriges fartores (= Küter oder Fleischer) im Lübecker Urkundenbuch berichtigend.
} 
genannten Lübecker Ratmannen nicht nur den Abbruch der Burg geleitet haben, sondern schon, zum Lübecker Teil, ihre Belagerung und Eroberung, dann hätten wir hier einen ersten Beleg dafür, dass Johan Wittenborch als ein Mann gegolten hat, der für militärische Verwendung geeignet war. Dazu passt es, dass er, nach Notizen in seinem „Handlungsbuch“ zu urteilen, 1354 zusammen mit Herrn Johan Wesler ${ }^{237}$ einer der Marstallherren gewesen ist. ${ }^{238}$ Daraus würde man zunächst nur schließen, dass Wittenborch Pferdeverstand gehabt haben dürfte. ${ }^{239}$ Aber tatsächlich ergänzt die Information das auf das Beste, was zum Vorjahr gesagt worden ist. Denn den Marstallherren unterstand die Truppe der Reitenden Diener. ${ }^{2+1}$ Auch dies wird dann in zwei Notizen des „Handlungsbuchs" sichtbar: Ebenfalls 1354 hat Wittenborch, offenbar als Marstallherr, einmal allein und einmal mit Herrn Johan Wesseler gemeinsam, reitenden Dienern kleine Darlehen gewährt. ${ }^{241}$ Und wenn man den Zusammenhang kennt, dann wundert man sich auch nicht darüber, dass Herr Johan Wesler in seinem Testament vom 18. August 1367 den Wert seines Wohnhauses in der Königstraße, $600 \mathrm{ml}$., „,der Stadt für den Marstall vermacht“ hat, „mit der ausdrücklichen Bestimmung, dass davon Knechte oder Pferde zum Zweck der Verteidigung der Stadt gehalten werden sollen“. ${ }^{242} \mathrm{Zu}$ den Aufgaben des Marstalls gehörte außerdem die Verwaltung der städtischen Waffen und Rüstungen, also der Bereich, der später „Zeughaus“ hieß. ${ }^{243}$ In

\footnotetext{
${ }^{237}$ Im Rat 1351-1367: LUTTERBECK Nr. 289 (S. 428f.).

${ }^{238}$ Nach MoLlwo S. XI mit Anm. 3 soll er das Amt „1354 und 1358“ bekleidet haben; weder an den hier nachgewiesenen Stellen, Handlungsbuch (wie Anm. 55) S. 23f.. Nr. II 115 u. 116, noch sonstwo kann ich von „1358" etwas sehen.

${ }^{2.39}$ In Nr. 116 sind zahlreiche Pferdeverkäufe verbucht.

${ }^{2+1)}$ Fink (wie Anm. 235). Die Zugehörigkeit des (Ausreiter-) Vogts zum ..Ressort" Marstall ist im 2. Kämmereibuch (seit 1338) ausdrücklich festgehalten: UB. Stadt Lüb. 2. S. 1078 mit Anm. 85 am Ende.

${ }^{2+1}$ Handlungsbuch (wie Anm. 55) S. 23, Nr. II 111: Witten Deteleve, eme utrider (so ist das letzte Wort mit BaStian 1, S. 275 zu lesen) 10 Schilling [in Gold]. Handlungsbuch S. 27, Nr. II 130: Her Johan Wesseler unde ic ... Mowen deme utrider 3 lübische Gulden I= 30 Schilling in Gold].

${ }^{242}$ FINK a.a.O. S. 203 mit Anm. 8; der lateinische Wortlaut in UB. Stadt Lüb. 4, S. 100, Anm. I zu Nr. 106, und bei FEHLING S. 37. Fink kommentiert: „Abermals erscheint hier der Marstall als Vertreter der Wehrorganisation, der nicht nur die Pferde, sondern auch die Söldner stellt". NOODT, Religion und Familie (wie Anm. 160) hat dieser Stiftung eine eigene Rubrik (,5.4 Ein Geschenk an die Stadt“, S. 216f.) gewidmet, aber die Erwähnung des Marstalls unterdrückt und stattdessen als ,augenscheinliches" Stiftungsmotiv den „dänischhansische[n] Krieg" eingeführt. LUTTERBECK S. 429 mit Anm. 3462 erwähnt das Vermächtnis, ohne irgendetwas über dessen Zweckbestimmung zu sagen.

${ }^{243}$ FINK a.a.O. S. 201 (1298: dieselben zwei Ratmannen bewareden der stades armborste unde dat schot; en wart och bevolen de martstall) und S. 203: Der "Futtermarschall", ein gehobener Marstall-Bediensteter "für den inneren Dienst“, hatte nach seiner Instruktion vom Jahre 1400 auch „die alten Waffen und Harnische" zu verkaufen, „verwaltete also die Zeugkammer". Zu den Marstallherren vgl, auch Ernst PITZ, Schrift- und Aktenwesen der städti-
} 
diesem Kontext des Militärischen, das sich als ein Tätigkeitsschwerpunkt des jungen Ratmanns Johan Wittenborch herausgeschält hat, könnten dann auch zwei weitere Nachrichten aus den mittleren 1350er Jahren, die auf den ersten Blick belanglos erscheinen, eine gewisse Bedeutung gewinnen: An 13. Dezember $1354^{244}$ bezeugte in Lübeck der Knappe Herman Rint, Vogt desselben Herzogs Erich, dass er, der wegen eines Raubes in der Stadt Lübeck verfestet war, sich mit ihr verglichen habe, und verpflichtete sich, ihr Gönner und Diener zu sein, ausgenommen nur den Fall einer Fehde zwischen seinem rechten Herrn und dem Lübecker Rat. Die Lübecker Ratmannen Bertram Vorrad ${ }^{245}$ und Johan Wittenborch und der [Ausreiter-] Vogt des Rats Hinrik Luchow nahmen das Versprechen entgegen. Am 27. April $1356^{246}$ beurkundete der Knappe Tiderik Dunker, Herman Dunkers Sohn, dass er sich mit der Stadt Lübeck so gesühnt habe, dass er den Ratmannen in ihrem Kriege dienen solle und wolle sullef teynde wapent gegen alle ihre Feinde ${ }^{247}$ ein Vierteljahr lang, wenn sie ihn sechs Wochen vorher auffordern, auf seinen eigenen Gewinn und Verlust und der Stadt Kost. Das Gelöbnis nahmen diesmal für den Rat entgegen Herr Johan Wittenborch und Herr Johan Pertzeval, im Rat 1352 - 1399 und am 28. Mai 1365 erstmals als Bürgermeister belegt, ${ }^{248}$ nach dem ausdrücklichen Zeugnis der Urkunde hatten die Herren die Vereinbarung auch ausgehandelt.

Weiter lässt sich aus zwei Eintragungen im „Handlungsbuch“ die Vermutung ableiten, dass Johan Wittenborch 1356/57 einer der beiden Richteherren war, möglicherweise der geschäftsführende. ${ }^{249}$ da er größere Zahlungen für das Gericht entgegengenommen hat. ${ }^{250}$

schen Verwaltung im Spätmittelalter. Köln - Nürnberg - Lübeck. Beitrag zur vergleichenden Städteforschung und zur spätmittelalterlichen Aktenkunde (Mitteilungen aus dem Stadtarchiv von Köln 45), Köln 1959, S. 388-391. Das alles hat EBEL, Lübisches Recht (wie Anm. 91), S. 236f,, ganz knapp zusammengefasst: „Die Marstallherren, ... mit der Aufsicht über den städtischen Marstall sowie über Waffen, Kriegsgerät und reitende Söldner betraut".

${ }^{244}$ Schleswig-Holsteinische Regesten und Urkunden 4, Nr. 6.33 (S. 411: in Zeile 24 ist statt „efficeret“ natürlich efficerenur zu lesen). Ein Regest dieser Urkunde auch bei DEMSKI. Adel (wie Anm. 172), S. 325, Nr. 4, ohne Erwähnung des Drucks.

245 Über ihn unten mit Anm. 267.

${ }^{246}$ UB. Stadt Lüb. 3, Nr. 256 (S. 252f.).

${ }^{247}$ Erstaunlicherweise gibt es hier keinen Vorbehalt zugunsten eines Herrn.

${ }^{248}$ Über ihn unten mit Anm. 555, 556 u. 579.

${ }^{249}$ Es ist, so weit ich sehe, in der Literatur bisher nicht üblich gewesen. bei den Inhabern der Lübecker kollegialen Ratsämter des 14. Jh.s zwischen geschäftsführenden und nicht geschäftsführenden Herren zu unterscheiden. Dass es sinnvoll ist, dies zu tun, ergibt sich aus den Verhältnissen in der von 1365 bis 1377 reichenden Rechnung der Silbermünzherren (AHL Altes Senatsarchiv Interna Münzwesen 30/7). Es hat immer nur ein Münzherr zur Zeit das Buch geführt, und zwar eigenhändig. Der andere tritt erst nach dessen Ausscheiden aus dem Amt auf, als der Nachfolger. Es gibt dann auch genügend Indizien dafür, dass der buchführende Herr zugleich der geschäftsführende gewesen ist. 
Endlich erfahren wir noch aus dem „Handlungsbuch“, dass Herr Johan spätestens seit 1352 auch Provisor der Pfarrkirche St. Jakobi war, ${ }^{251} \mathrm{zu}$ nächst gemeinsam mit Herrn Johan Woltvogel, der uns schon als Wittenborchs Kollege im zeitweiligen Kommando in Dömitz begegnet ist. Woltvogel wird bereits am 16. Mai 1350 anderweitig in diesem Amt bezeugt, ist aber schon am 25. April 1354 gestorben. ${ }^{252}$ Da Johan Wittenborch nach dem 29. September 1354 begonnen hat, seine Ausgaben für die Jakobikirche in Sachkontoform aufzuzeichnen, ${ }^{253}$ ist er wahrscheinlich nach dem Tod des Kollegen in die Stellung des geschäftsführenden Provisors eingerückt. ${ }^{254}$ Die finanzielle Seite der Wittenborchschen Amtsführung ist auch sonst im „Handlungsbuch“ relativ breit dokumentiert; das wird uns noch eingehend zu beschäftigen haben. So fügt sich aus nicht gerade zahlreichen, nicht immer sehr aussagekräftigen Einzelnachrichten doch das einigermaßen anschauliche Bild eines Nachwuchs-Ratmanns zusammen, der auf vielen Feldern der Lübecker Ratsverwaltung - offenbar erfolgreich tätig gewesen ist.

Mit diesem nicht eben sensationellen Ergebnis des Zusammentragens und Analysierens von verstreuten Zeugnissen verglichen, mutet es nun schon fast komisch an, mit wie bescheidenem Aufwand, nämlich dem simplen Auszählen von Vorkommensbelegen in einer einzigen Quellengattung, wir genaue und fast quantitative Kenntnis darüber erlangen können, in welchem Umfang Herr Johan an der Erfüllung einer Routineaufgabe teilgenommen hat: Bei der Errichtung von Bürgertestamenten als Ratszeuge anwesend zu sein. ${ }^{255}$ Ahasver von Brandt hatte darauf hinge-

\footnotetext{
${ }^{250}$ Handlungsbuch (wie Anm. 55) S. 29, Nr. II 161, und S. 35, Nr. Il 214. Da er von der an dieser Stelle gebuchten Einnahme gleich 20 Lübecker Gulden wieder an Bischop den Kölner für Wein ausgegeben hat, könnte er 1357 auch einer der Weinherren gewesen sein.

${ }^{251}$ Handlungsbuch (wie Anm. 55) S. 18, Nr. Il 69, anno 52, ohne nähere Datierung: Herr Johan hat jemandem vier Schilling de pecunia ad sanctum Jacobum geliehen. Ebd. S. 22, Nr. II 105, undatiert, aber nach der Datierung des vorangehenden Eintrags, der auch sachlich in denselben Geschäftsbereich gehört, mit an Sicherheit grenzender Wahrscheinlichkeit ebenfalls ins Frühjahr (um Ostern = April 8) oder in den Frühsommer 1352 zu setzen.

${ }^{252}$ LUTTERBECK S. 441 mit Anm. 3603 und 3598. Auffälligerweise erscheint er 1350 ohne einen Kollegen (allerdings zusammen mit dem Werkmeister): AHL Niederstadtbuch I, S. 566. 2. Vermutlich war dies situationsbedingt, oder der Vorgang fiel in eine kurze Zeit, als ein neuer Kollege vom Rat noch nicht ernannt war.

${ }^{253}$ Handlungsbuch (wie Anm. 55) S. 19. Nr. Il 82 auf „Fol. 15a", das bereits mit Nr. 80a beginnt, nicht erst mit Nr. 81. Nach den „Feder“-Verhältnissen zu urteilen, ist auch Nr. 80 (Einnahmen für St. Jakobi für Glockenläuten) auf der links gegenüberliegenden Seite, ,Fol. 14b“. die bereits mit den ,.Federproben“ hinter Nr. 79 beginnt, im Herbst 1354 geschrieben.

${ }^{254}$ Aus den mir bisher bekannten Quellen erhellt nichts über seinen Nachfolger als zweiten Provisor. Dass es keinen gegeben hat, sollte man daraus doch wohl nicht einfach (c silentio) ableiten, obwohl es das zweite Mal ist. dass wir innerhalb weniger Jahre einen zweiten Provisor der Jakobikirche vermissen (siehe oben Anm. 252 zu 1350).

${ }^{255}$ Obwohl die Testamentsüberlieferung sicherlich nicht lückenlos ist, besitzt sie in der uns
} 
wiesen, dass Johan Wittenborch einer von nur vier Ratmannen des Zeitraums 1351-1363 ist, die in dieser Tätigkeit besonders häufig belegt sind. ${ }^{256}$ Die Tätigkeit hat sicherlich ziemlich viel Zeit gekostet. Sie setzte regelmäßige Anwesenheit in Lübeck und ein nicht unerhebliches Maß an Abkömmlichkeit von den Berufsgeschäften voraus. ${ }^{257}$ Wer so oft eingesetzt wurde, eine sicherlich nicht immer angenehme Aufgabe zu erfüllen, hat vermutlich ausdrücklich seine Bereitschaft dazu erklärt. Gehörte auch das zu den Dingen, durch die jemand für die Wahl zum Bürgermeister qualifiziert wurde? Die Antwort muss allem Anschein nach „nein“ lauten. Denn von den drei Ratmannen, die von Brandt in diesem Zusammenhang noch genannt hat, ${ }^{258}$ ist keiner Bürgermeister geworden. Dabei hatten sie alle ähnlich lange Amtszeiträume wie Johan Wittenborch, und zwei von ihnen, Bernard Paal (1349-1363) ${ }^{259}$ und Bernard Oldenborch (13521367), ${ }^{260}$ waren, nach ihrer sonstigen Amtstätigkeit zu urteilen, hochqualifizierte und sehr geschätzte Mitglieder des Rats. Nur der dritte, Everhard Swarte (1352-1367), ${ }^{261}$ erscheint als ein in dieser Hinsicht völlig unbeschriebenes Blatt. Auch die Einbeziehung weiterer, durch von Brandt nicht erwähnter Ratmannen in die Untersuchung würde am Bild nichts ändern. ${ }^{262}$ Der hauptsächliche Nutzen derart dichter Nachrichtenfolgen

interessierenden Zeit doch offenkundig eine so große Dichte, dass das Auszählen von Standard-Sachverhalten eine sinnvolle Form der Nutzung ist. Quantitative Aussagen über das Ausmaß der Verluste schon vor 1945 liegen von Ahasver VON BRANDT allerdings nur an zwei Stellen vor; sie sind überdies miteinander nicht vergleichbar: Nach Reg. Test. (wie Anm. 93) 1, S. 5, waren aus dem letzten Drittel des 13. Jh.s 12 Stück erhalten, ,denen noch die doppelte Anzahl von anderweitig erwähnten, aber nicht erhaltenen Testamenten zuzurechnen ist“, dazu die Übersicht auf S. 219-221, mit 23 Nummern aus der Zeit zwischen „vor 1230 Apr. 15“ und „vor 1299 März 22“. Reg. Test. (wie Anm. 93) 2, S. 7 ist von ,mindestens sieben Fällen" die Rede, in denen ,nicht bewahrte Testamente“" in den erhaltenen des Zeitraums 1351-1363 erwähnt werden; die ganze übrige Überlieferung ist also bisher nicht überprüft worden.

${ }^{256}$ Reg. Test. (wie Anm. 93) 2, S. 7, mit dem Hinweis, dass Entsprechendes auch schon "in Bd. I" zu beobachten ist. VON BRANDT nennt für Herrn Johan 75 Fälle; für 1350 siehe oben Anm. 153 am Ende.

${ }^{257}$ Eine weitere, ähnliche Aufgabe bestand darin, als Ratszeuge für private Denkelbriefe tätig zu werden. Da wir überhaupt nicht wissen, welchen Anteil an den ehemals vorhandenen "litterae memoriales" die erhaltenen darstellen, und welcher Teil der erhaltenen gedruckt ist, können wir auch nicht beurteilen, wie stark einzelne Ratmannen durch diese Tätigkeit in Anspruch genommen worden sind. Im gedruckten Material ist Herr Johan nur zweimal, 1354 und 1356, als Denkelbriefzeuge belegt: UB. Stadt Lüb. 3, Nr. 209 (S. 205f.) und 263 (S. 257). Außerdem hat Mollwo drei Denkelbriefe zu Herrn Johans bzw. seiner Erben Gunsten gedruckt, die im Urkundenbuch der Stadt Lübeck übergangen worden waren: Handlungsbuch (wie Anm. 55) S. 92f., Nr. VI 6-8. Zum Quellentyp s. auch noch unten Anm. 358.

${ }^{258}$ Mit 114, 85 und 78 Vorkommen.

${ }^{259}$ LUTTERBECK Nr. 173 (S. 323f.).

261) LUTTERBECK Nr. 171 (S. 319-321), ermordet am 3. oder 4. Juni 1367.

${ }^{261}$ LUTTERBECK Nr. 238 (S. 384f.).

${ }^{262}$ Im Zeitraum 1351-1363 hat es auch der eben als passionierter Marstallherr besprochene 
dürfte darin bestehen, dass sie eine Art negatives Itinerar der betreffenden Ratmannen darstellen: Wenn sie als Testamentszeugen belegt sind, können sie nicht weit weg von Lübeck gewesen sein. Zur Erklärung von Johan Wittenborchs Karriere im Rat bleibt also weiterhin nur die - nicht gerade breit fundierte - Möglichkeit, dass er als Militärspezialist zur Bürgermeisterwürde aufgerückt sein könnte. Das wäre dann vielleicht schon ,auf Verdacht" geschehen, ungefähr ein Jahr, bevor sich abgezeichnet hat, dass die Stadt Lübeck demnächst in einen ,richtigen“ Krieg verwickelt sein könnte.

Aus Herrn Johans kurzer Bürgermeisterzeit sind zunächst zwei weitere Begegnungen mit Herzog Erich dem Jüngeren zu besprechen; sie führen uns in den Kernbereich der Lübecker ,großen Politik“. Die Regierungszeit dieses Erich „II.“” von der Ratzeburg-Lauenburger Linie des Hauses Sachsen-Lauenburg wird zwar von der Lauenburger Landesgeschichtsschreibung überwiegend mit ,1361 (oder 1360) - 1368“ angegeben. ${ }^{263}$ Der Fürst war aber bereits 1340 nicht nur erwachsen, sondern auch ein selbständiger Akteur in der norddeutsch-dänischen Politik; ${ }^{264}$ er ist bis zu seinem Tode vor allem ein wichtiger und zuverlässiger, auch militärisch

Johan Wesler auf 66 Fälle von Testamentszeugenschaft gebracht, und 63 Fälle zählt man im Register des Bandes für Herrn Jacob Pleskow (1352-1381), der im Frühjahr 1364, ganz gewiss nicht deshalb, Bürgermeister wurde und sich seitdem zum führenden Hansepolitiker des Lübecker Rats entwickelt hat (Näheres unten mit Anm. 576). An diesem Punkt habe ich das Auszählen abgebrochen.

${ }^{26.3}$ Ehrhard SCHULzE, Das Herzogtum Sachsen-Lauenburg und die lübische Territorialpolitik (Quellen und Forschungen zur Geschichte Schleswig-Holsteins 33), Neumünster 1957, nach S. 220): „Stammtafel der regierenden Herzöge ... nach ihren Regierungsjahren"; danach Erich HoffMANN. Das Herzogtum Sachsen-Lauenburg im Spätmittelalter, in: DERS., Spätmittelalter und Reformationszeit (Geschichte Schleswig-Holsteins 4, 2), Neumünster 1990. S. 345-352 und 500f. (Anmerkungen), hier S. 346f.

${ }^{264}$ Siehe Sven TÄGIL, Valdemar Atterdag och Europa (Bibliotheca historica Lundensis 9), Lund 1962, S. 37, nach Dipl. Dan. 3, 1, Nr. 31 (S. 34f.), vorher u. a. gedruckt SchleswigHolsteinische Regesten und Urkunden 3, Nr. 1068 (S. 627f.). Vielleicht deshalb ist in der Stammtafel, die als Beilage zu Eckardt OPITZ (Hg.), Herzogtum Lauenburg. Das Land und seine Geschichte. Ein Handbuch, Neumünster 2003, veröffentlicht wurde, zu Erich (II.) angegeben: ,reg. seit 1340"; es bleibt dem Benutzer überlassen, sich darüber Gedanken zu machen, wie dies zu der Mitteilung passen könnte, dass sein Vater Erich (I.) 1360 gestorben ist. Der Beitrag von Jürgen MEYN, Sachsen-Lauenburg im Hohen und Späten Mittelalter, S. 55-147, bietet keine Hilfe, da man dort weder für den Vater noch für den Sohn Regierungsoder Lebensdaten findet. Völlige Konfusion herrscht dann in dieser Hinsicht bei Cordula BORNEFELD, Die Herzöge von Sachsen-Lauenburg, in: Carsten Porskrog RaSMUSSEN, Elke IMBERGER, Dieter LOHMEIER, Ingwer MOMSEN (Hgg.), Die Fürsten des Landes. Herzöge und Grafen von Schleswig, Holstein und Lauenburg, Neumünster 2008, S. 372-389: Nach S. 377 hätte Erich II. 1340-1368, ,reg[iert]"; aber in der Stammtafel auf S. 388 (die nicht von der Verfasserin stammt, s. S. 449) steht bei Erich I. ,1275-1360“ und bei Erich II. „+ 1368“, und zum Überfluss gibt es auf S. 389 noch eine - ebenfalls redaktionell erstellte? - Regentenliste mit den Regierungsjahren „1308-1360“ und „1360-1368“. 
oft tätiger Verbündeter des Dänenkönigs Waldemar Atterdag gewesen. ${ }^{265}$ Mit Herzog Erich haben 1360 und 1361 drei Mitglieder des Lübecker Rats für die Stadt zwei wichtige Verträge abgeschlossen und doch wohl auch ausgehandelt: Johan Wittenborch, sein bereits erwähnter älterer Bürgermeister-Kollege Herman van Wickede ${ }^{266}$ und der uns ebenfalls schon bekannte Bertram Vorrad, ein sehr erfahrener Ratmann, der dann Anfang 1363 Herrn Johans Nachfolger im Kreis der Bürgermeister geworden ist. ${ }^{267}$ Diese Verträge, die in den Kopfregesten des Lübecker Urkundenbuchs und danach auch gelegentlich in der Literatur als „Friedensvertrag“ bzw. „Freundschaftsvertrag“ bezeichnet werden, ${ }^{268}$ sind weder das eine noch das andere. Es handelt sich vielmehr um regional begrenzte Nichtangriffspakte zwischen den Parteien für den Fall eines Krieges zwischen der Stadt Lübeck und dem König von Dänemark. In einem solchen Fall war der Herzog dem König zu Kriegsdienst in Dänemark verpflichtet, und durch die Verträge wurde sichergestellt, dass daraus keine militärische Ausein-

${ }^{265}$ Über diesen Fürsten scheint es keine neuere monographische Darstellung zu geben; auch in der letzten Bearbeitung des ..Dansk Biografisk Leksikon“ und im „Biographischen Lexikon für Schleswig-Holstein und Lübeck" sucht man vergeblich nach einem Artikel. Daher kann hier nur auf seine zahlreichen weiteren Erwähnungen bei TÄGIL a.a.O. verwiesen werden (dort S. 136f. auch über die Reise ins Heilige Land, die König Waldemar und Herzog Erich 1346/47 unternommen haben; in dieser hat die ältere Literatur, sicherlich zu Unrecht, den Ursprung des Zusammenhalts zwischen den beiden gesehen). Vgl. auch SCHULZE. Herzogtum (wie Anm. 263), S. 76 mit Anm. 212, wo einschlägige Stellen bei SCHÄFER, Hansestädte (wie Anm. 9) nachgewiesen sind, und HofFMANN (wie Anm. 263), S. 347 (in enger, aber nicht erklärter Anlehnung an SCHÄFER a.a.O. S. 291). Noch weniger bietet die neueste deutsche Lauenburg-Literatur: MEYN, Mittelalter (wie Anm. 264), S. 78 mit Anm. 114, sagt der Lauenburg-Ratzeburger Linie nach, dass sie "die Nähe Dänemarks suchte"; in der Anmerkung (S. 135) heißt es dann, unter Berufung auf HOFFMANN a.a.O.: „Das gilt vor allem für Herzog Erich II., der mütterlicherseits mit dem dänischen König Waldemar IV. verwandt war und Inhaber mehrerer dänischer Lehen war". In der neuesten. für das Mittelalter vor allem auf MEYN a.a.O. gestützten Darstellung der Geschichte des Fürstenhauses von BoRNEFELD (wie Anm. 264) gibt es nicht mehr den geringsten Hinweis darauf, dass um 1350/60 einmal ein Angehöriger dieses Duodezherzogshauses zu den wichtigen Personen der nordmitteleuropäischen Geschichte gehört hat.

${ }^{266}$ LUTTERBECK Nr. 291 (S. 431-433): Im Rat 1327-1367, am 2. Juni 1351 erstmals als Bürgermeister belegt (Reg. Test. (wie Anm. 93) 2, Nr. 447, S. 28). Bei FEHLING Nr. 331 (S. 29) ist Herrn Hermans Bürgermeisterzeit grob fehlerhaft mit ,1365-1367“ angegeben. was noch bei ASMUSSEN, Flandernfahrer (wie Anm. 74), S. 892, zu der nun überflüssigen Anm. 47 geführt hat.

${ }^{267}$ LUTTERBECK Nr. 263 (S. 403-405): Im Rat 1332-1379. Noch am 11. Januar 1.363 als einer von sechs ,einfachen“ Ratmannen erwähnt (UB. Stadt Lüb. 3, Nr. 449, S. 458f.), wird er erstmals am 29. April 1363 in einer 23 Namen umfassenden Ratsliste als letzter unter den vier Bürgermeistern genannt (UB. Stadt Lüb. 3, Nr. 459, hier S. 481). Er stand aber schon am 6. November 1362 an der Spitze der dreiköpfigen Lübecker Delegation zum Hansetag in Rostock (HR I, 1, Nr. 276, S. 205f.), in der es also überhaupt keinen Bürgermeister gegeben hat.

${ }^{268}$ Besonders hüibsch Mollwo S. XI mit Anm. 8 zu 1360: „er führte die Friedensunterhandlungen mit dem Herzog zu glücklichem Ende". 
andersetzung zwischen den Vertragspartnern in ihrer „Heimat" werden konnte. Diese Pakte ${ }^{269}$ gehören zu den Lübecker Vorbereitungen für einen Krieg gegen Dänemark. Der erste Vertrag, vom 6. Mai 1360, ${ }^{270}$ war auf ein Jahr abgeschlossen. Er stellt, soweit ich sehe, das früheste eindeutige Zeugnis dafür dar, dass Lübeck Krieg im Schilde führte oder mindestens fest mit Krieg in nächster Zukunft rechnete. ${ }^{271}$ König Waldemar wird von diesem Vertrag gewiss sehr bald Kenntnis bekommen haben, und das wird auf sein Verhalten gegenüber Lübeck und den mit Lübeck verbundenen Seestädten sicherlich nicht ohne Auswirkungen geblieben sein. Am Vertrag vom 6. Mai 1360 wird erstmals deutlich, dass Herr Johan, damals schon nicht mehr der jüngste Bürgermeister, ${ }^{272}$ an der Implementierung (und vermutlich auch schon an der Formulierung) von wichtigen Zielen der Lübecker „Außenpolitik“ beteiligt war. Der Anschlussvertrag für die nächsten drei Jahre wurde bereits am 6. März 1361 von denselben Lübecker Verhandlungsführern abgeschlossen; ${ }^{273}$ er sollte bis zum 12. Mai (Pfingsten) 1364 gelten. ${ }^{274}$ Im Februar 1362 ist diese Regelung dann in

\footnotetext{
${ }^{269} \mathrm{Vgl}$. dazu ganz. kurz. aber treffend KOPPMANN in Chron. Lüb. I (wie Anm. 231), S. 533. Anm. 5; er kommentierte damit in aller Nüchternheit das Märchen von dem herzlichen Verhältnis zwischen Herzog Erich und dem Lübecker Rat, das Detmar zu 1363 erzählt hat. Beide Verträge sind dann neuerdings auch von ASMUSSEN. Flandernfahrer (wie Anm. 74), S. 892 mit Anm. 46 u. 47, erwähnt worden; es wird allerdings nicht klar, dass sie dieselbe Materie regeln.

${ }^{270}$ In diesem Vertrag ist Herr Johan an erster Stelle genannt; man darf also vermuten, dass er die kleine Ratsdelegation geleitet hat. Urkunde des Herzogs: UB. Stadt Lüb. 3, Nr. 358 (S. 373f.). Gegenurkunde: Schleswig-Holsteinische Regesten und Urkunden 4. Nr. 863 (S. 553); einen Auszug daraus gibt es Dipl. Dan. 3, 5, Nr. 308 (S. 278f.).

${ }^{271} \mathrm{Vgl}$. dazu bereits ASMUSSEN, Flandernfahrer (wie Anm. 74), S. 892, Anm. 46; ob die Lübecker dabei aber wirklich schon an eine „bevorstehende Auseinandersetzung ... um Schonen" gedacht haben (das war damals ja noch in schwedischer Hand), muss wohl ohne weitere Indizien dahingestellt bleiben.

${ }^{272}$ Dies ist er nur etwa ein Jahr lang geblicben, da bereits am 9. April 1360 Herman Gallin (LU'TTERBECK Nr. 99, S. 259f.) als weiterer Bürgermeister belegt ist: UB. Stadt Lüb. 3, Nr. 351, hier S. 362. Herr Johan, Herr Herman und der Ratsmarschall Eghard Schiphorst erscheinen am 18. Juli 1360 gemeinsam bei der Entgegennahme der Urfehde des Knappen Sifrid van Bocwolde: UB. Stadt Lüb. 3, Nr. 367 (S. 381 ).

${ }^{273}$ Nur dieser zweite Vertrag ist besprochen bei SCHÄFER, Hansestädte (wie Anm. 9), S. 291, Götze, Greifswald (wie Anm. 9), S. 88, und HoffmanN, Sachsen-Lauenburg (wie Anm. 263), S. 348. Auch bei TäGIL, Valdemar (wie Anm. 264) ist der Vertrag von 1360 nicht erwähnt, was sich aber schon daraus erklärt, dass der Autor die hansisch-dänischen Auseinandersetzungen der Jahre 1360-1362 überhaupt nur in äußerster Kürze behandelt hat; auch den Vertrag von 1361 hat TÄGIL (S.236f. mit Anm. 22) nur, im Anschluss an SCHÄFER a.a.O.. als Zeugnis für Herzog Erichs „gute Kontakte" zu Lübeck angeführt. Dagegen hat LUTTERBECK S. 403, 432 und 437f. den zweiten Vertrag ganz übersehen.

${ }^{274}$ Hier steht Johan Wittenborch hinter Herman van Wickede. Urkunde des Herzogs: UB. Stadt Lüb. 3, Nr. 389 (S. 401 f.). Auszug: Dipl. Dan. 3, 6, Nr. 15 (S. 19); zur Gegenurkunde siehe ebd. Nr. 16 (S. 20). Im Diplomatarium Danicum sind alle diese Urkunden als „Waffenstillstand" bezeichnet. und die Namen der Lübecker Verhandlungsführer sind immer ausgelassen.
} 
Verhandlungen zwischen den Räten von Lübeck und Hamburg und den Vögten und Lehnsmannen des Herzogs für unbestimmte Zeit auf die „gemeinen Städte" ausgedehnt worden. Es ist nicht bekannt, wer damals für die Städte verhandelt hat; die Sache ist nur in einem Brief des Lübecker Rats überliefert. ${ }^{275}$

Ein halbes Jahr nach dem Abschluss des zweiten Vertrags mit dem Lauenburger begegnen wir Herrn Johan erneut als wichtigem Teilnehmer an den Vorbereitungen für eine militärische Auseinandersetzung mit Dänemark. Diese haben inzwischen eine neue Stufe erreicht: Der Greifswalder Hansetag, der für den 31. August 1361 anberaumt war, hat vor allem über die Maßnahmen beraten und beschlossen, die für die Kriegführung gegen König Waldemar Atterdag erforderlich waren. Der Rezess ${ }^{276}$ weist das Datum des 7. Septembers auf; damit ist wohl - ausnahmsweise - der letzte Tag der Städteversammlung gemeint; anschließend haben offenbar noch erste Bündnisverhandlungen mit Gesandten der Könige von Schweden und Norwegen stattgefunden. ${ }^{277}$ Die Stadt Lübeck war auf dem Han-

${ }^{275}$ HR I, 1, Nr. $443 / 444$ (S. 402), zu „1368“, was, wie bereits SCHÄFER, Hansestädte (wie Anm. 9), S. 292 in der exkursartigen Anm. I gezeigt hat, falsch ist. Letzter Druck: Dipl. Dan. 3. 6, Nr. 156 (S. 142f.). Doch ist auch im Vorfeld des 2. Waldemarskrieges ein ähnlicher Vertrag mit Herzog Erich auf dem Lübecker Hansetag vom 2. Februar 1368 erörtert worden (HR I, 1, Nr. 427. § 7, S. 387; der Verweis in Anm. I2 zu streichen). Am 25. Februar 1368 ist dann der Vertragsabschluss zwischen dem Herzog (der sich jetzt de olde nannte) mit seinem Sohn Erich (IV.) und der Stadt Lübeck auf zwei Jahre erfolgt (UB. Stadt Lüb. 3, Nr. 642 , S. 687f.); im Vertragstext ist allerdings nicht ausdrücklich gesagt, dass der Herzog das Recht behielt, in Dänemark gegen Lübeck und Lübecks Verbündete zu kämpfen. Siehe zu all dem auch SCHÄFER a.a.O. S. 473f. und TÄGIL, Valdemar (wie Anm. 264), S. 312f,, wo aber wieder die Verweise auf HR 1, I, Nr. 443 bzw. S. 402 in Anm. 21 und 22 zu streichen sind. ${ }^{276}$ HR I, I, Nr. 259 (S. 186f.). Am Ende des Rezess-Kontextes steht noch ein Beschluss über die unnachsichtige Verfolgung von Leuten, „die auf der See geraubt hatte[n]“, der höchstens mittelbar mit dem Thema .Kampf gegen Dänemark“ zu tun hat.

${ }^{277}$ Die Verträge, HR I, 1, Nr. 260-263 (S. 187-192), sind auf den 8. und 9. September datiert; siehe dazu und zum folgenden bereits grundlegend KOPPMANN, ebd. S. 186. So weit es sich um den Zeitpunkt der Ausfertigung der Urkunden handelt, sind diese Daten natürlich in jedem Fall fiktiv (vgl. neuerdings etwa Dipl. Dan. 3, 6, S. 76). Aber auch die Verhandlungen sind damals noch nicht abgeschlossen worden; den damals erreichten Stand geben vermutlich die in Lübeck und Bremen überlieferten Entwürfe wieder. Einen etwas näheren Einblick in die Chronologie der Verhandlungen erlaubt der einzige dieser Verträge, in dem die Städtevertreter namentlich erwähnt sind: Nr. 263, hier S. 191, zuletzt nach den Handschriften gedruckt Dipl. Dan. 3, 6, Nr. 82, S. 82f. Als Hamburger Ratssendeboten sind in den Ausfertigungen zwei Bürgermeister genannt, die ihre Stadt noch nicht auf der Greifswalder Tagung Anfang September vertreten haben, sondern erst auf den nächsten Hansetagen. Da in den Vertragsentwürfen Hamburg überhaupt fehlt, ist der Hamburger Vertreter auf dem Greifswalder Hansetag entweder gleich nach dessen Ende abgereist, oder er hat sich für nicht befugt gehalten, den noch in Greifswald ausgehandelten Ergebnissen zuzustimmen. Nach HR I, 1, Nr. 264, hier S. 193, sind dann die „vielen Verhandlungen“, die in Deutschland mit den Gesandten der Könige geführt worden waren, einige Zeit vor dem 19. November zum Abschluss gekommen, vermutlich im Oktober. Die hier besonders interessierenden Lübecker Vertreter sind in den Ausfertigungen des Vertrags dieselben wie in den Entwürfen. 
setag vertreten durch Johan Wittenborch als Bürgermeister, Herrn Johan van Pleskow, der dem Rat seit 1348 angehört hat, ${ }^{278}$ und den bereits erwähnten Herrn Bernard Oldenborch. ${ }^{279}$ Diese drei haben dann wahrscheinlich auch am Abschluss der Verhandlungen mit den Gesandten der beiden Könige bis zum Oktober 1361 mitgewirkt. ${ }^{280}$

Fasst man diese Nachrichten aus den Jahren 1360 und 1361 zu einer begründeten Vermutung über die Rolle zusammen, die Johan Wittenborch damals in der Politik des Lübecker Rats gespielt hat, dann darf man wohl die Aussage wagen, dass Herr Johan (spätestens) seit 1360 der führende Lübecker Vertreter einer aktiven (um nicht zu sagen, aggressiven) Städtepolitik gegen König Waldemar von Dänemark gewesen ist. Im Spätsommer 1361 und vermutlich auch in dem halben Jahr vom Herbst 1361 bis zum Frühjahr 1362 war Herr Johan maßgeblich an der organisatorischen Vorbereitung des Krieges beteiligt. ${ }^{281}$ Wenn er außerdem praktische mili-

${ }^{278}$ LUTTERBECK Nr. 187 (S. 343-346), gestorben 1367 nach dem 25. August. Seine Tätigkeit als Ratmann ist auch ausführlicher behandelt bei WIEGANDT, Plescows (wie Anm. 182), S. 157f., der es bemerkenswert fand, dass diese Tätigkeit durch ,seinen wirtschaftlichen Zusammenbruch" (darüber S. 153-155) nicht beendet worden ist; möglicherweise war der „Zusammenbruch“ doch weniger dramatisch? Nach ebd. S. 179 hat seine Witwe eine 1366 begründete Schuld von $400 \mathrm{ml}$. bis 1369 auf ein Viertel reduzieren können. - Nach POECK. Ratssendboten (wie Anm. 225), soll Herr Johan Pleskow Lübeck bis „1376“ auf Hansetagen vertreten haben, also noch neun Jahre über sein Todesjahr hinaus (S. 120, „Schwerpunkt in den 60er Jahren“; vgl. S. 124 zum 23. März 1376). Der Verfasser ist hier einem unkorrigierten (aber von der sonstigen Literatur, auch schon von FEHLING, stillschweigend berichtigten) Übertragungsfehler in HR I, 2, Nr. 115 (S. 123) zum Opfer gefallen; an dieser Stelle ist "Johannes Plescowe" natürlich zu Jacobus Plescowe zu emendieren. Man fragt sich, in welchem Maße dieser Irrtum zu POECKS Meinung (S. 128) beigetragen hat, ,die beiden Zweige der Plescows mit den ihnen verwandtschaftlich und freundschaftlich [!??] verbundenen Familien" hätten „fraglos" ,in entscheidendem Maße die Lübecker Hansepolitik [in der zweiten Hälfte] des 14. Jahrhunderts" bestimmt. Tatsächlich war nur in den Jahren 1348-1367 und 1393-1408 mehr als ein einziger Pleskow im Rat. Den Höchststand, gleichzeitig vier Träger des Namens, gab es 1352 bis 1363, als mit den „Hansepolitikern“ Johan und Jacob drei weitere - von POECK nicht erwähnte - Pleskow im Rat saßen: Bernard (1344-1367; LUTTERBECK Nr. 182, S. 334-336, keine Teilnahme an hansischen Versammlungen nachgewiesen) und der jüngere Hinrik Pleskow (1348-1358; LUTTERBECK Nr. 185. S. 339f.; vgl. dazu noch unten Anm. 377). Herr Hinrik, der zum 16. April 1357 als Bürgermeister belegt ist. kann unbedenklich als Hansepolitiker angesprochen werden, hat er doch 1356 Lübeck in Brügge bei der Ordnung des „Kontors“ vertreten. Wer sonst zwischen 1352 und 1358 die Lübecker Hansepolitik gestaltet hat, ist aus den oben mit Anm. 220 und 221 dargestellten Quellengründen unbekannt. Über die amtliche Tätigkeit von Herrn Hinriks Halbbruder Arnold Pleskow, der 1359 in den Rat kam, aber schon 1363 gestorben ist (LUTTERBECK Nr. 181, S. 333f.) scheint bisher gar nichts bekannt geworden zu sein. Zwischen 1381, als Herr Jacob gestorben war. und 1389, als Herrn Arnolds Sohn Jordan in den Rat kam (LUTTERBECK Nr. 188, S. 346-348), war der Name Pleskow im Lübecker Rat überhaupt nicht vertreten.

${ }^{279}$ Oben mit Anm. 260.

${ }^{280}$ Siehe oben Anm. 277 am Ende.

281 Über diesen Zeitraum, in dem nach dem Zeugnis der Hamburger Kämmereirechnungen 
tärische Erfahrungen aufweisen konnte, wie begrenzt die auch im Vergleich mit denen eines „Berufsmilitärs“ wie des Dänenkönigs gewesen sein mögen, ${ }^{282}$ muss es nahe gelegen haben, ihm auch den Oberbefehl im Krieg gegen Dänemark zu übertragen. Das gilt jedenfalls unter der Voraussetzung, dass diese Position unstrittig nur von einem Lübecker Bürgermeister bekleidet werden konnte. Vielleicht stand dann damals sogar überhaupt niemand anders zur Wahl. Denn von den vier Bürgermeistern, die es Ende 136I/Anfang 1362 in Lübeck gegeben hat, wäre nach den geschilderten Lübecker personengeschichtlichen Aspekten der Vorgeschichte des Krieges wohl statt Herrn Johan nur Herman van Wickede ${ }^{283}$ in Frage gekommen; der war aber wenigstens zwei Jahrzehnte älter als Herr Johan und daher vielleicht schon physisch gar nicht mehr imstande, ein militärisches Kommando wahrzunehmen. Die beiden anderen Bürgermeister der Zeit, Tideman Warendorp ${ }^{28-4}$ und Herman Gallin, ${ }^{285}$ dürften ebenfalls schon ältere Herren gewesen sein. Sie kamen für das Kommando im Krieg gegen Dänemark aber wohl auch deswegen von vornherein nicht in Betracht, weil sie im Kontext der Lübecker Dänemark- und Hansepolitik niemals aufgetreten sind. Wir wissen nicht, wieso das so war. Es kann

bis zum 22. Februar 1362 noch drei Hansetage stattgefunden haben (HR I, 1, S. 186) wissen wir überhaupt sehr wenig, weil aus der Zeit zwischen dem September 1361 und dem 8. Oktober 1362 keine Hanserezess-Überlieferung erhalten geblieben ist. Nach dem. was oben Anm. 277 über den Fortgang der Verhandlungen mit den Gesandten der Könige von Schweden und Norwegen nach dem 8. und 9. September gesagt ist, dürfen wir daraus, dass in den Ausfertigungen der Bündnisurkunde HR I, I, Nr. 26.3 dieselben Lübecker Vertreter genannt sind wie im Rezess vom 7. September, mindestens schließen, dass sie die Verhandlungen für Lübeck auch zum Abschluss gebracht haben. In der Überlieferung des Jahres 1363 gibt es dann noch einen Nachrichtensplitter (HR I, I, Nr. 299, § 2, S. 240; vgl. Nr. 325. \$ 7. S. 281), nach dem Herr Johan und Herr Segebode Crispin (unten mit Anm. 413) mit dem Hamburger Rat über Einzelheiten der Hamburger Beteiligung am bevorstehenden Krieg verhandelt haben.

${ }^{282}$ Vgl. ARUP, Danmarks Historie 2 (wie Anm. 15), S. 146, der bemerkte: „Man kann sich da nicht wundern, dass es in dieser ersten großen militärischen Kraftprobe Lübecks mit König Waldemar noch dieser erfahrene Feldherr gewesen ist, der militärisch den Sieg davontrug". ARUP hat ohne weiteres angenommen, dass Johan Wittenborch allein deshalb zum „Admiral der Flotte“ gemacht worden sei, weil er Lübecker Bürgermeister war. Dass er damit der Wahrheit ziemlich nahe gekommen sein könnte, wird gleich zu zeigen sein.

28.3 Über ihn oben mit Anm. 266.

284 Über ihn oben mit Anm. 190.

${ }^{285}$ Ratmann seit 1351, damals vermutlich schon kein junger Mann mehr: LUTTERBECK Nr. 99 (S. 259f.). Als Bürgermeister ist er erstmals am 9. April 1360 belegt (siehe oben Anm. 272). Als seinen Todestag gibt LUTTERBECK den 17. Dezember 1365 an, offenbar nach der sog. „Oldenborchschen Ratslinie“" (Eintrag gedruckt bei LUTTERBECK S. 454, Nr. 342). Doch ist Herr Herman noch am 6. Januar 1366 belegt: UB. Stadt Lüb. 3, Nr. 547. Auf die Diskrepanz zwischen dieser Urkunde und der ,Rathsmatrikel“ ist bereits ebd. Anm. 3 zu Nr. 634 (S. 679) hingewiesen. Auch hat LUTTERBECK die Urkunde vom 6. Januar 1366 auf S. 55 selbst zitiert, als Beleg dafür, dass „1.366 sechs Bürgermeister nebeneinander genannt werden". 
jedenfalls nicht daran gelegen haben, dass sie durch Herrn Johan Wittenborch verdrängt worden wären. Denn an diesen Verhältnissen hat sich offenbar auch durch Herrn Johans Ausscheiden aus dem Rat nichts geändert. Unsere Nachrichten über die Zusammensetzung der Lübecker Delegationen zu den Hansetagen der Jahre 1362 und 1363 setzen freilich erst mit dem Rostocker Tag vom 6. November 1362 ein. Damals kamen die Lübecker ohne einen Bürgermeister; an der Spitze ihrer dreiköpfigen Gesandtschaft stand der damalige Doyen der „,einfachen“ Ratmannen, Herr Bertram Vorrad, der dann ein paar Monate später zum Bürgermeister erhoben wurde, mehr als dreißig Jahre nach seinem Eintritt in den Rat; ${ }^{286}$ auch wenn er 1363 vielleicht als Kompromisskandidat gewählt worden ist, muss er sich doch nicht nur als erfahrener und tüchtiger Mann empfohlen haben, sondern auch als körperlich und geistig belastbar, trotz seines Alters. Andererseits kann man aus den dargestellten Befunden doch wohl nur schließen, dass Tideman Warendorp und Herman Gallin jederzeit als für derartige Aufgaben völlig ungeeignet gegolten haben, aus welchen Gründen auch immer. ${ }^{287}$ Auch die zu Anfang 1362 geäußerte Vermutung, dass der am 29. Januar 1367 gestorbene Herr Herman van Wickede wegen seines Alters größeren körperlichen Strapazen nicht mehr gewachsen gewesen sein könnte, wird durch die Daten der Jahre 1363 bis 1366 bestätigt: Seit Ende 1362 kommt er nicht mehr als Lübecker Ratssendebote auf auswärtigen Hansetagen vor; auf den frühsommerlichen Hansetagen in Lübeck ist er aber zwischen 1363 und 1366 stets als einer der Lübecker Vertreter erwähnt. ${ }^{288}$

\footnotetext{
${ }^{286}$ Dazu oben mit Anm. 267. Die Tatsache ist auch bei LUTTERBECK S. 55 erwähnt; mit der Zahlenhuberei. mit der der Verfasser den Sachverhalt angeht, ist er natürlich überhaupt nicht zu erklären. Der einfache Gedanke, dass neue Bürgermeister in der Regel erst gewählt wurden. wenn Vakanzen eingetreten waren, scheint LUTTERBECK nicht recht zu Bewusstsein gekommen zu sein. obwohl sich daraus fast alles weitere in seiner großen Vielfalt erklären lässt. Das Unverständnis für die grundlegenden Mechanismen bringt dann so unsinnige Begriffe wie „Dienstalter" und „Anzahl der abgesessenen Jahre“ ins Spiel.

${ }^{287}$ Dass sie deshalb nicht zu solchen Aufgaben herangezogen worden sein könnten, weil sie als Förderer von Johan Wittenborch (Herr Tideman) bzw, als seine Kreatur (Herr Herman, nach dem Zeitpunkt seiner Erhebung zum Bürgermeister) galten, lässt sich ohne weiteres ausschließen, da die beiden ja bereits vor Herrn Johans Sturz in diesem Bereich nicht aufgetreten sind. Unter diesen Umständen fragt man sich natürlich, wie BREHMER, Jacob Plescow (wie Anm. 42), S. 55, auf den Gedanken gekommen sein mag, neben und noch vor Johan Wittenborch auch .Tidemann Warendorf" zum Leiter der bis 1362 „,maßgebende[n]“ Ratspartei zu erklären. Daraus hat WIEGANDT. Plescows (wie Anm. 182), S. 229, dann sogar den „von den Bürgermeistern Tideman Warendorp und Johann Wittenborg geleiteten Krieg gegen Dänemark" gemacht, woran der in Anm. 805 angerufene Dietrich SCHÄFER völlig unschuldig ist.

${ }^{288}$ Es kann hier darauf verzichtet werden, Einzelbelege aus HR I, I anzuhäufen. Bei LUTTERBECK S. 432 fehlt „1366“.
} 
Dies also waren die personellen Voraussetzungen, unter denen Herr Johan in die militärische Spitzenposition gelangt ist, in der er dann wenige Monate später scheiterte. Die ihn betreffenden Vorgänge zwischen seiner Rückkehr aus Dänemark und seinem Tod sind bereits einleitend dargestellt worden. Herrn Johans Tod ist 1363 nach dem 15. August und vor dem 21. September eingetreten. ${ }^{289}$

Johan Wittenborch hat mit seiner Frau Elisabeth (Telse) mindestens sechs Kinder gehabt; so viele - zwei Jungen und vier Mädchen - waren am Leben, als seine Witwe am 22. Juli 1367 körperlich schwach ihr Testament machte. ${ }^{290}$ Mit den weiteren - jedenfalls nicht aufsehenerregenden - Schicksalen der Kinder hat sich bisher nur Mollwo beschäftigt und dabei teilweise die Stadtbucheintragungen, auf die er sich berief, nicht einmal abgedruckt. Bei dem „Geschick“, mit dem er sonst Verwandte „identifiziert" hat, ${ }^{291}$ müsste man alles wohl von neuem sorgfältig untersuchen; dazu besteht hier keine Veranlassung.

\section{Johan Wittenborchs „Mentalität": „Maß“, Geldgier und konventionelle Religiosität}

Was lässt sich über Johan Wittenborchs „Mentalität“ sagen ? Wenn man der Literatur des 20. Jahrhunderts glauben wollte, wäre er ein entschiedener Verfechter des Maßhaltens in jeder Beziehung gewesen. Diese Ansicht stützt sich nicht etwa auf Zeugnisse für maßvolles Handeln oder wenigstens entsprechende Äußerungen in konkreten Entscheidungssituationen. Vielmehr handelt es sich um die inhaltliche Interpretation von kurzen lateinischen Wortfolgen, Prosa wie Versen, die sich in dem von ihm geschriebenen Teil des „Handlungsbuchs“ finden, und zwar als „Fe-

\footnotetext{
${ }^{289}$ Handlungsbuch (wie Anm. 55) S. 74. Nr. IV 27 (im Oberstadtbuch wird unter diesem Datum beurkundet, dass Herr Johan Wittenborch per procuratores suos eine Rente vor dem Gericht verfolgt hat) und S. 86, Nr. V 83 (Anfang einer Niederstadtbucheintragung, in der drei provisores quondam domini Johannis Wittenborch als Mitglieder einer Gläubigergemeinschaft erwähnt sind. Diese Eintragung liegt jetzt auch vollständig gedruckt vor in Das Lübecker Niederstadtbuch (1363-1399). Bearbeitet von Ulrich SIMON (Quellen und Darstellungen zur hansischen Geschichte N.F. 56), Teil 1 u. 2, Köln usw. 2006 (weiterhin: NStB 1363-1399), T. 1, S. 13, 3 (Schluss auf S. 14). Hier ist der Zweitname des Schuldners als Birzst gelesen, was nach KOPPE u. KOPPE, Frankfurt-Händler (wie Anm. 79), S. 88, richtig ist; MOLLwo hatte den im „Handlungsbuch" und seinen Beilagen ziemlich häufig vorkommenden Namen immer als Busc bzw. Buzsc wiedergegeben. Andererseits sind die Namen der ersten beiden Provisoren an einer anscheinend unsauberen Stelle der Handschrift offenbar verlesen: Statt des doch wohl sinnlosen „Bruno Warendorp filius domini Gherhardi de Allen..." ist sicherlich mit Mollwo zu lesen Bruno Warendorp filius domini God/scalci] [der spätere Bürgermeister !], Gherard[us] de Allen et Johannes Luturencii.

${ }^{290}$ Handlungsbuch (wie Anm. 55) S. 90f., Nr. VI 4.

${ }^{291}$ Oben Anm. 84.
} 
derproben““. ${ }^{292}$ Das fängt bereits beim Herausgeber Carl Mollwo an. ${ }^{29 i \mathfrak{z}}$ Der hat „zwei Verse, offenbar seine Wahlsprüche“, herausgestellt: Omnibus adde modum, modus est pulcherrima virtus ${ }^{294}$ und Omnia dat dominus, non habet ergo minus. Dazu gab er gleich die Deutung: „Man sieht, ein verständiger Mann, der der überschäumenden Thatkraft die Zügel weiser Mäßigung aufzuerlegen wünscht und dabei ganz im Geiste seiner Zeit die Größe des Gebers aller Gaben anerkennt". Dabei hat Mollwo aber nicht verhehlt, dass es im Buch weitere lateinische Wortfolgen als „Federproben“ gibt, die sich einer inhaltlichen Interpretation verschließen. „Seltsam berührt" hat ihn als ,immer wiederkehrende Federprobe“ ein Satz aus dem Prolog des Johannesevangeliums: fuit homo missus a deo, cui nomen erat Johannes, und es hat ihn auch irritiert, dass in gleicher Funktion „oft" auch „feierliche Urkundenanfänge“" vorkommen. ${ }^{205}$ Wenn das Material in dieser Breite vorgeführt wird, ist der Weg zu der Einsicht nicht weit, dass es sich hier um weitere Elemente aus dem oben bereits skizzierten Einpaukbetrieb der Lateinschule für die Laien-Kinder handeln dürfte. Aber bei dieser Form der Präsentation ist es nicht geblieben. Fritz Rörig hat sich

${ }^{292}$ Für das Thema nach wie vor grundlegend Bernhard BISCHOFF, Elementarunterricht und Probationes Pennae in der ersten Hälfte des Mittelalters, in: DERS., Mittelalterliche Studien. Ausgewählte Aufsätze zur Schriftkunde und Literaturgeschichte. Bd. I, Stuttgart 1966, S. 74-87. Die Studie greift aber nur ausnahmsweise über das 12./13. Jh. hinaus. Bei Johan Wittenborchs „Federproben" handelt es sich zum Teil, vielleicht überwiegend, eher um Schönschreibübungen. Das gilt ganz sicher von den zahlreichen Initialen, die sich etwa als ein wesentlicher Teil auf der in der Edition überhaupt nicht berücksichtigten ersten Seite des ..Buchs" (siehe dazu Mollwo S. XXXIV, Anm. 2), aber auch später noch finden. Eine

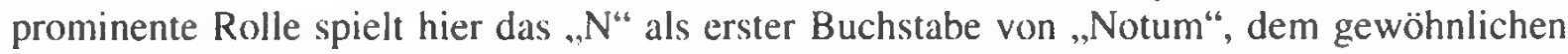
Einleitungswort der lateinischen Buchungen im ,Handlungsbuch"; daneben kommen auch ..No" und selbst vollständiges „Notum“ vor. Der Zusammenhang mit dem Schreibunterricht der Lateinschule ist hier ganz deutlich. Einzelne Versalien gibt es auch auf einer der Wachstafeln aus der Kloake der Jakobischule: WARNCKE, Schulgeräte (wie Anm. 146), S. 249, Nr. 21a. 1. Seite.

${ }^{29.3}$ MolLwo S. XLf.

${ }^{294}$ Das gibt es auch ausnahmsweise, offenbar als wirkliche Federprobe, unvollständig nach Handlungsbuch (wie Anm. 55) S. 18, Nr. II 70 (nicht abgedruckt): Omnibus ad.

${ }^{295}$ Die mit Omnibus beginnenden Urkundenanfänge stellen tatsächlich die häufigste Gruppe dar. Sie treten in ganz unterschiedlicher Länge auf. Die längste Version, auf der von MoLLwo als „Fol. 27b" bezeichneten Seite (S. 34 der Edition), belegt zum Überfluss, das es sich bei Johan Wittenborchs Latein wirklich nur um Eingepauktes handelt: Omnibus presens scriptum cernentibus visuris et audituris nos konsules[!], advocates[!] et commune civitatis Lubice. Angesichts aller dieser Versuche im Latein- und Schönschreiben fragt man sich, ob Johan es vielleicht bedauert hat, auf der Schule nicht weitergekommen zu sein, ob er womöglich gar lieber „Klerk“ geworden wäre ? Zu vergleichen ist auch das Handlungsbuch (wie Anm. 55) S. 54 als „Ilb“ mit abgedruckte, aber, so viel ich sehe, noch nie von jemandem kommentierte Eschatokoll eines Notariatsinstruments auf der Innenseite des Heftumschlags, das beginnt mit Et ego Johannes Wittenborch dericus[!?]... - Es erscheint immerhin erwähnenswert, dass von Johans vier Zeilen drei mit dem Wort „omnis“ beginnen und damit eine früh- und hochmittelalterliche Gruppe ergänzen, auf die BISCHOFF, Elementarunterricht (wie Anm. 292), S. 77-79, hingewiesen hat. 
1928 den modus-Vers herausgegriffen; er entdeckte darin „das beruhigende Motiv der Spätzeit" der Lübecker Kaufmannschaft des Mittelalters. ${ }^{296}$ Tausend und einige Jahre später, in einem programmatischen Vortrag, der 1947 gehalten und 1950 gedruckt wurde, hatte der Vers dann den Rang einer „ewige[n] menschliche[n] Grundweisheit“" errungen. ${ }^{297}$ Der Vers stammt aus einer im Spätmittelalter äußerst beliebten Sammlung von gereimten „Regeln für die praktische Lebensführung“ namens „Facetus“, die, um sie von einer anderen, auch andersartigen Sammlung mit demselben Namen zu unterscheiden, nach ihrem ersten Vers als „Facetus Cum nihil utilius" bezeichnet wird. ${ }^{298}$ Die Sammlung ist seit dem 13. Jahrhundert überliefert und wurde bis ins 16. als Schultext verwendet; der Hamburger Germanist Nikolaus Henkel hat sie in seinem Buch über „Deutsche Übersetzungen lateinischer Schultexte" zuletzt eingehend behandelt. ${ }^{299}$ Ihre Grundtendenz wird im „Verfasserlexikon“ mit dem Satz beschrieben: „Bescheidenheit und Dienstwilligkeit sind die für alle Lebenslagen empfohlenen Tugenden“. ${ }^{300}$ Aus der Zeit zwischen dem 14. und dem frühen 16. Jahrhundert gibt es zahlreiche Übersetzungen ins Deutsche, darunter eine von Sebastian Brant und übrigens auch mehrere ins Mittelniederdeutsche. Das Rörig'sche Verfahren, von Johan Wittenborchs diversen „Federproben"-Sprüchen nur diesen zu beachten und ihn dann je nach Lust und Konjunktur mehr oder minder phantasievoll zu deuten, hat auch andere Autoren zur Nachfolge angeregt. Am Anfang stand, wenn ich nichts Wesentliches übersehen habe, Erich Maschke mit seinem bekannten Aufsatz über das „Berufsbewusstsein des mittelalterlichen Fernkaufmanns“ von 1964. Obwohl Maschke Wittenborchs Umgang mit dem Vers als „,belanglose Federproben“ wertete, weil statt modum, modus auch notum, not-

\footnotetext{
${ }^{296}$ RÖRIG, Wirtschaftskräfte (wie oben Anm. 57), S. 146.

${ }^{297}$ Fritz RÖRIG, Stand und Aufgaben der Hansischen Geschichtsforschung, in HGBll. 69, 1950, S. 1-13, hier S. 12.

${ }^{298}$ Nachgewiesen im Thesaurus Proverbiorum Medii Aevi. Lexikon der Sprichwörter des romanisch-germanischen Mittelalters. Begründet von Samuel SiNGER, Bd. 8, Berlin, New York 1999, S. 128, gedruckt bei Carl Schroeder, Der deutsche Facetus (Palaestra 86), Berlin 1911, S. 26. Verspaar 175. 1. Zeile. Die Herkunft war auch schon zu ermitteln aus Jakob WERNER, Lateinische Sprichwörter und Sinnsprïche des Mittelalters aus Handschriften gesammelt, 2. überarbeitete Auflage von Peter FLuRY, Heidelberg 1966, S. 87, Spruch 63, aber noch nicht aus der ersten Auflage: Jakob WERNER, Lateinische Sprichwörter und Sinnsprüche des Mittelalters aus Handschriften gesammelt (Sammlung mittellateinischer Texte 3). Heidelberg 1912, S. 66. Spruch 59.

${ }^{299}$ Nikolaus HENKEL, Deutsche Übersetzungen lateinischer Schultexte. Ihre Verbreitung und Funktion im Mittelalter und in der frühen Neuzeit. Mit einem Verzeichnis der Texte (Münchener Texte und Untersuchungen zur deutschen Literatur des Mittelalters 90), München 1988, besonders S. 245-248.

${ }^{30()}$ Rüdiger SCHNELL, ,Facetus', in: Die deutsche Literatur des Mittelalters, Verfasserlexikon 2. Auflage, Band 2. Berlin, New York 1980, Sp. 700-703, hier Sp. 701.
} 
um vorkomme, ${ }^{301}$ hat er nicht darauf verzichten mögen, den Spruch zu zitieren und gleich anschließend Johan Wittenborch zum Repräsentanten eines ,anderen Kaufmannstyp[s]“ zu erklären, ,nicht den des unbegrenzten Gewinnstrebens, sondern des maßhaltenden Kaufmanns, den es auch sonst gab". ${ }^{302}$ Wir werden hoffentlich gleich sehen, was es damit auf sich hat.

Es ist natürlich nicht leicht, unter den Quellenbedingungen des norddeutschen 14. Jahrhunderts zu entscheiden, ob einer der ganz wenigen Kaufleute, von denen einigermaßen umfangreiches Datenmaterial erhalten ist, nach „unbegrenztem Gewinn“ gestrebt hat oder nicht. Allenfalls kann man seine Geschäfte daraufhin untersuchen, ob er in dem Bemühen, möglichst hohe Gewinne zu erzielen, allgemein anerkannte Schranken beachtet hat oder nicht. Das ist beim Warenhandel sehr schwer zu überprüfen. Es müsste schon ein Zeitgenosse den Kaufmann beschuldigt haben, mit Kollegen überhöhte Verkaufspreise verabredet, die Ware verfälscht oder falsches Gewicht benutzt zu haben, damit man ihn heute überführen könnte, die Voraussetzungen willentlich missachtet zu haben, unter denen ein „gerechter Preis“ zustande kommen sollte; das könnte wohl nur in Gerichtsakten überliefert sein. Ich wüsste nicht, dass Derartiges aus dem Lübeck des 14. Jahrhunderts erhalten geblieben ist. Bessere Chancen könnte der Geldhandel bieten, die Gewährung von verzinslichen Darlehen. Es geht um „Wucher“, lateinisch „usura“. Damit kommen Rechts- und Wertbegriffe ins Spiel, ${ }^{303}$ und es wird nach der geschäftlichen Moral des

\footnotetext{
${ }^{301} \mathrm{Vgl}$. dazu oben in Anm. 292 die Nachweise für alleinstehendes notum.

302 Erich MASCHKE, Das Berufsbewusstsein des mittelalterlichen Fernkaufmanns, in: Beiträge zum Berufsbewusstsein des mittelalterlichen Menschen. Hg. von Paul WILPERT unter Mitarbeit von Willehad Paul ECKERT (Miscellanea mediaevalia. Veröffentlichungen des Thomas-Instituts an der Universität Köln 3), Berlin 1964, S. 306-335, hier S. 310 . Man vermisst von vornherein weitere Belege für den Nachweis dieses Kaufmannstyps. Gut zwanzig Jahre später hat dann Franz IRSIGLER, Kaufmannsmentalität im Mittelalter, in: Mentalität und Alltag im Spätmittelalter. Hg. von Cord MECKSEPER u. Elisabeth SCHRAUT (Kleine Vandenhoeck-Reihe 1511), Göttingen 1985, S. 53-75, hier S. 62f., Wittenborchs „Ma13“-Sprüche (,längst Gemeingut der Forschung geworden“) unter ausdrücklicher Bezugnahme auf MASCHKES Aufsatz erneut zum Anlass genommen zu versichern: „Es gab den Typ des maßhaltenden ... Kaufmanns". Allerdings hat IRSIGLER der Sache dadurch eine etwas andere Wendung gegeben, dass er Maßhalten mit der Vermeidung von ,unnötigen Risiken und geführlichen Spekulationsgeschäften" gleichsetzte. - Birgit NOODT hat ihre Studic über Fritz Rörig (wie Anm. 77) mit der Bemerkung eröffnet (S. 155), sie sei seit dem „Beginn der 1990er Jahre" „immer mehr ins Staunen (geraten) über seine Bereitschaft. weitgehende Schlussfolgerungen auf schmalster Quellenbasis zu ziehen“. Damit ist gewiss ein zentrales Merkmal von RÖRIGS Arbeitsweise getroffen. Und doch zeigt sich an der hier vorgeführten Folge von Aussagen. die, genau besehen, überhaupt keine „Quellenbasis“ haben, exemplarisch, dass RÖRIG als Person durch das Urteil Unrecht erfährt. Denn er knüpfte in diesem Punkt an einen Vorgänger an, und er hat renommiertc Nachfolger gefunden.

${ }^{303}$ Wie Gerhard RÖCH, Wucher in Deutschland 1200-1350. Überlegungen zur Normdi-
} 
Kaufmanns Johan Wittenborch gefragt. Einschlägige Informationen muss man selbstverständlich in seinem „Handlungsbuch“ suchen. Im öffentlichen Wirtschaftsschriftgut, das im Lübeck des 14. Jahrhunderts vor allem aus den Eintragungen der beiden großen Beurkundungsbücher Ober- und Niederstadtbuch besteht, ${ }^{304}$ findet man natürlich so gut wie nichts, was Anstoß hätte erregen können, ${ }^{305}$ damals oder später. In Johans Buchführung aber gibt es tatsächlich Belege dafür, dass er sich als wucherischer Geldverleiher betätigt hat. Und zwar handelt es sich um Wucher im heutigen Sinn, um das Nehmen von unanständig hohen Zinsen. In der spätmittelalterlichen Literatur zum Thema „Zinsen“, die sich mit der Interpretation der Lehrquellen des Christentums und der Normen des kanonischen Rechts befasste und ausschließlich Moraltheologen und Kirchenrechtler zu Verfassern hatte, geht es zwar um ein Verständnis von „Wucher“, dem grundsätzlich jedes Zinsnehmen unerlaubte ,usuraria pravitas“ war, den „Extremisten“ unter ihnen selbst der ,normale“ Rentenkauf. ${ }^{306}$

daxe und Normrezeption, in: HZ 259, 1994, S. 593-636, hier S. 599-602, dargelegt hat. deckt sich der Inhalt der beiden Begriffe nicht. Während „usura“ (Grundbedeutung: „Zinsen") der Fachbegriff des lateinisch geschriebenen theologischen und kanonistischen Schrifttums ist, hat „Wucher“ im spätmittelalterlichen Deutsch eine sehr breite. stark emotionsgeladene Bedeutung, die weit über das bloße "Zinsen nehmen" hinausreicht. RösCH hat (S. 601) „Wucher“ geradezu als „Sammelbegriff für unsoziales Verhalten allgemein“ charakterisiert. Das dürfte gelegentlich auch Rückwirkungen auf den Gebrauch von ,usura“ gehabt haben, s. etwa RösCH S. 604 (Trierer Provinzialstatuten 1227-1310). Vor allem dürfte der sprachliche Sachverhalt aber ein ernsthaftes Hindernis für die Popularisierung des Zinsverbots im Sinne von Theologie und Kanonistik dargestellt haben. RösCH (S. 609) konstatiert: .Mit den Wucherbestimmungen des kanonischen Rechts hatten auch Seelsorger Mühe, wenn sie nicht Rechtsgelehrte waren"; die Probleme, die sich daraus für Predigt und Beichte ergaben, hat er anschließend (S. 609-621) detailliert erörtert.

${ }^{304}$ Neuester Überblick über die Bestände: Antjekathrin GRASSMANN, Zu den Lübecker Stadtbüchern. In: Verwaltung und Schriftlichkeit in den Hansestädten, hg. von Jürgen SARNOWSKY (Hansische Studien 16), Trier 2006, S. 71-80. Der treffende Begriff „Beurkundungsbücher" stammt von Jürgen REETZ, Hamburgs mittelalterliche Stadtbücher, in: ZVHG 44, 1958, S. 95-139, hier S. 99 mit Anm. 19; vgl. auch noch S. 112 mit Anm. 70.

${ }^{305}$ Vgl. C. W. PAuli, Das Creditwesen und der Handelsverkehr, in: DERs., Lübeckische Zustände zu Anfang des 14. Jahrhunderts [= Lübeckische Zustände im Mittelalter 1], Lübeck 1847, S. 121-147, hier S. 130 mit Anm. 19: ,mir (sind) ... manche Urkunden aufgestoßen ..., welche zeigen, dass das kirchliche Verbot (bedungene|r] Zinsen) hier nicht immer streng beachtet ward". PAULI hat bekanntlich vor allem mit den Stadtbüchern gearbeitet; der einzige Quellennachweis zum zitierten Satz führt auf ein Stück von 1336 aus dem Niederstadtbuch (ebd. S. 224f., Nr. 100), in dem jemand, der für eine Schuld von $40 \mathrm{ml}$. sein Haus zum Pfand setzt, außerdem verpflichtet wird. dem Gläubiger jährlich $2 \mathrm{ml}$. zu zahlen.

${ }^{306}$ Vgl. oben mit Anm. 303. Ein Beispiel aus der Praxis der regionalen kirchlichen Gerichtsbarkeit in „Wucher"-Fällen bietet eine Urkunde des Abts des Klosters St. Marien bei Stade vom 22. August 1362. Der Abt wollte damit als päpstlich delegierter Richter zugunsten von drei Brüdern aus der Adelsfamilie Wensin ein Verfahren gegen sechs genannte Lübecker auf Beendigung der Zinserhebung und Rückerstattung der bereits erhobenen Zinsen einleiten: UB. Stadt Lüb. 3, Nr. 426 (S. 434f.). Das päpstliche Mandat ist der Urkunde inseriert. Wir wissen leider nicht, ob es nur um einen Rentenkauf oder um Schlimmeres ging. Zu einer 
Das schlägt sich auch in der sehr umfangreichen modernen Literatur nieder. Diese spricht, wenn sie ihren Gegenstand ehrlich beschreibt, vom „wirtschaftlichen Denken der Scholastiker", ${ }^{307}$ scheut sich aber oft auch nicht, diese „wirtschaftsbezogenen Gedankengänge ${ }^{\text {“308 }}$ von in der Regel gut bepfründeten Klerikern mit „mittelalterlichem Wirtschaftsdenken“ gleichzusetzen. ${ }^{309}$

Aber man darf wohl zweifeln, ob derartige Auffassungen vor allem bei den Laien großen Widerhall gefunden haben. Daneben gab es sicherlich auf breiter Front, auch bei Klerikern, ein Verständnis von Wucher, das weitgehend dem heutigen entsprach; unter den geschilderten Voraussetzungen fällt es nur schwer, explizite Äußerungen dieses Inhalts ausfindig zu machen. ${ }^{310}$ Denn für jeden, der dringend Kredit braucht, war und ist

krass irrigen Interpretation dieser Urkunde in der Literatur der 1970er Jahre (Inge-Maren PETERS) s. Hans-Jörg GILOMEN, Wucher und Wirtschaft im Mittelalter, in: HZ 250, 1990, S. 265-301, S. 277, Anm. 39. Das Verfahren wurde durch den Lübecker Rat mit formaler Begründung (ein päpstliches Gerichtsstand-Privileg für die Stadt und ihre Bürger nicht beachtet) abgewehrt, siehe ebd. Nr. 431, 439 und 444.

${ }^{307}$ Etwa Raymond DE RoOvER. La pensée économique des scolastiques. doctrines et méthodes, Montréal u. Paris 1971.

${ }^{308}$ Francesca ScHINZINGER, Ansätze ökonomischen Denkens von der Antike bis zur Reformationszeit (Erträge der Forschung 68), Darmstadt 1977, S. 62.

${ }^{3(x)}$ Etwa Diana WOOD. Medieval Economic Thought. Cambridge 2002. Mit dieser kritischen Anmerkung zur Titelwahl soll natürlich nicht behauptet werden, dass die Autorin nicht wusste, dass ihr Thema wenig mit dem zu tun hat, was wirtschaftlich tätige Laien über „Wirtschaft" gedacht haben mögen; schließlich hat sie bereits auf S. I ihres Buches selbst dargelegt, dass und inwiefern ,strictly speaking. .Medieval Economic Thought' is a misnomer". Auch findet man etwa in der Einleitung zum Kapitel .The just price and the just wage" (S. 132) die treffende Bemerkung: „In scholastic literature prices tended to overshadow wages because scholastics were not usually wage-earners". Andererseits schloss selbstverständlich eine noch so gute Pfründe nicht grundsätzlich die Fähigkeit aus, zentrale Elemente der sozioökonomischen Realität zutreffend zu beschreiben; das gilt z. B. für den Hl. Antoninus, Erzbischof von Florenz im 15. Jh., einen Dominikaner (über ihn etwa DE ROOVER, Scolastiques, wie Anm. 307, S. 28f.). der sehr wohl wusste, was dem „gerechten Lohn“ vor allem im Wege stand: Die unzureichende Verhandlungsmacht der Arbeiter (WOOD a.a.O. S. 152). Aber natürlich hatte auch dieser alles andere als weltfremde Theologe (den sogar DE ROOVER in einem Alterswerk als "großen Wirtschaftsdenker des Mittelalters“ bezeichnet hat), nichts über die Ursachen dieser Verhältnisse zu sagen, geschweige denn darüber, wie man sie hätte ändern können.

${ }^{310}$ Zwei Belege aus dem England des ausgehenden 13. Jh.s bei WoOD (wie Anm. 309), S. 172: In einem Wucherprozess vor dem "Canterbury consistory court" hat I292 ein Zeuge die Bemerkung fallen lassen, dass der Angeklagte, ,took less than the archbishop takes from his debtors". Ebenderselbe Erzbischof hatte 1279 einem Abt vorgeworfen, er habe von einem armen Mann ,,more than 100 per cent of usury, which even civil law forbids" genommen; hier schimmert also - kaum sehr genaue - Kenntnis des römischen Rechts durch, vgl. unten mit Anm. 313. Sichtbar wird der Gesichtspunkt natürlich immer dann. wenn die seit dem späten 12. Jh. belegte Konzessionierung von berufsmäßigen Geldverleihern, jüdischen wie christlichen, mit Maximalzinsvorschriften verbunden wurde. In die Privilegien scheinen diese aber erst im 15. Jh. Eingang gefunden zu haben, s. dazu für die sog. „Lombarden“ in Brügge und überhaupt in den Niederlanden und in Nordwesteuropa Raymond DE ROOVER, 
klar, dass die Chance, ein zinsloses Darlehen zu bekommen, anderswo als im engsten Kreis der Verwandten und Freunde sehr gering ist. Wenn sich bei den Zinsen die Frage des „ob“ oder „ob nicht“ gar nicht erst stellt, ist die Frage nach ihrer Höhe fundamental. Das galt natürlich besonders dann, wenn unter vormodernen Wirtschaftsbedingungen von der Möglichkeit, überhaupt (und natürlich nur gegen ein Zinsversprechen) ein Darlehen zu bekommen, kurzfristig die physische Existenz des Kreditbedürftigen abhängen konnte, mittelfristig aber durch überhöhte Zinsen die Möglichkeit, auch wirtschaftlich zu überleben, in Frage gestellt war; ${ }^{3 / 1}$ es gibt ein eindrucksvolles Zeugnis dafür, dass dieser Zusammenhang bereits in der Karolingerzeit von aufmerksamen Beobachtern der wirtschaftlichen Realität klar erkannt worden ist. ${ }^{312}$ Im spätantiken römischen Recht bestand der Kern der Kredit-Normen in der Festlegung von Höchstzinssätzen von $6 \%$, äußerstenfalls 12 oder $12 \frac{1}{2} \%$ pro Jahr. ${ }^{3.3}$ Von diesen Regeln des „Kaiserrechts" wird man auch im spätmittelalterlichen Norddeutschland gewusst haben; mindestens bei den formal besser gebildeten Angehörigen einer bedeutenden laikalen Institution wie des Lübecker Rats darf man

Money, Banking and Credit in Mediaeval Bruges. Italian Merchant-Bankers, Lombards and Money-Changers. A Study in the Origins of Banking (The Mediaeval Academy of America, Publication 51), Cambridge. Massachusetts, 1948, S. 104f. Aus den Brigger Stadtrechnungen kann der Autor einen Höchstzins von $43 \frac{1}{3} \%$ bereits für 1306 nachweisen. Bei GiLOMEN, Wucher (wie Anm. 306), der sich in diesem Aufsatz eingehend vor allem mit dem "lombardischen und jüdischen Wucher" (S. 269) befasst hat, gibt es leider keine systematische Diskussion dieses Themas; immerhin findet man S. 277 in anderem Zusammenhang den Hinweis, dass 1270 „der Bischof von Minden den in seiner Stadt lebenden Juden das Geschäft mit Zinsdarlehen (erlaubte), ... aber unter Hinweis auf das vom [4. Lateran-]Konzil [von 1215] erlassene Verbot von schwerem und maßlosem Wucher einen Höchstzinssatz fest(setzte)*.

${ }^{311}$ Dem an solchen Dingen interessierten Zeitungsleser begegnen diese Zusammenhänge auch heute noch recht oft in Berichten aus der Dritten Welt, und zwar nicht nur aus den allerärmsten Ländern.

${ }^{312}$ Siehe die lebendige Darstellung der einschlägigen Erörterungen auf der Pariser Reformsynode von 829 bei Horst FuHRMANN, Der "schnöde Gewinn“ oder das Zinsverbot im Mittelalter, in: DERS., Überall ist Mittelalter. Von der Gegenwart einer vergangenen Zeit (Beck'sche Reihe 1473), München 2003 (zuerst 1996), S. 123-149, hier S. 126f. Die Analyse ist den Zeitgenossen vielleicht dadurch erleichtert worden, dass es hier nicht um Geldkredit ging, sondern um Getreidedarlehen zu Zeiten der Hungersnot, die mit der drei- oder vierfachen Menge zurückgezahlt werden mussten. Vgl. dazu auch Harald SiEMS, Handel und Wucher im Spiegel frühmittelalterlicher Rechtsquellen (Monumenta Germaniae Historica, Schriften 35), Hannover 1992, S. 801-804 (die Interpretation aus wirtschaftsgeschichtlicher Sicht teilweise fragwürdig).

${ }^{313}$ FuHRMANN a.a.O. S. 124. P. LANDAU, ,Zins", in: Handwörterbuch zur deutschen Rechtsgeschichte Bd. 5, Berlin 1998, Sp. 1707-1713, hier Sp. 1709. SiEMS a.a.O. S. 602 bespricht eine Kaiserkonstitution von 386, nach der die legitima centesima, der gesetzliche [Höchst-]Zins, drei Siliquen pro Solidus, d. h. 12,5\%, betrug. Bei SCHINZINGER, Ansätze (wie Anm. 307) folgt auf den Abschnitt "Das römische Recht" (S. 38-43) gleich das Kapitel „Die Zeit der Kirchenväter" (S. 44-58), ohne dass irgendwo die Höchstzinsvorschriften des römischen Rechts erwähnt würden. 
solche Kenntnisse sicherlich voraussetzen. ${ }^{314}$ Ein derartiges Verständnis von „Wucher" war ja die Voraussetzung dafür, dass seit dem früheren 16. Jahrhundert im Reich und seinen Territorien das grundsätzliche Verbot des Zinsnehmens beseitigt werden und durch Gebote ersetzt werden konnte, bestimmte maßvolle Zinssätze nicht zu überschreiten. ${ }^{315}$ Aber mit etwas Glück kann man sogar im Lübecker Quellenmaterial Indizien dafür finden, dass diese Sicht selbst einem Seelsorger des frühen 14. Jahrhunderts nicht nur geläufig, sondern auch plausibel gewesen sein dürfte. Denn als am 18. Oktober 1331 eine wohlhabende alleinstehende Dame namens Alheid van Wittenborch, sehr wahrscheinlich eine Verwandte "unserer" Wittenborch, ihr Testament errichtete, ${ }^{316}$ da stellte sich ihr die Gewissensfrage, wie künftig mit den redditus für je $64 \mathrm{ml}$. verfahren werden sollte, die sie schon lange von zwei Verwandten auf Grund eines „Darlehensvertrags“ bezogen hatte. ${ }^{317}$ An einer ,pragmatischen“ Lösung des Problems, die sowohl Alheids Bedürnissen wie, allerdings erst im Falle ihres Todes, den Forderungen der Kirche gerecht wurde, war auch ihr Beichtvater beteiligt: Ihre Kapitalien sollten künftig (wohl wie bisher) mit je 4 $\mathrm{ml} .=6.25 \%$ verzinst werden; das war in den 1320er Jahren noch der normale Zinssatz für Ewigrenten gewesen. ${ }^{318}$ Aber die Renten sollten künftig als Leibrenten gelten; Alheid hat damit sowohl auf die an sich fällige höhere Verzinsung wie auf die Rückzahlung der Kapitalien verzichtet. Die bisher gezahlten und künftig noch zu zahlenden Zinsen konn-

\footnotetext{
${ }^{31+}$ Nachweise für Kenntnis des „Kaiserrechts“ in Lübeck seit dem Ende des 13. Jh.s etwa bei vON BRANDT, Knochenhaueraufstände (wie Anm. 140), S. 155 mit Anm. 28.

${ }^{315}$ LANDAU a.a.O. Sp. 1710. Vgl. auch H.-W. STRÄTZ, „Wucher“, in: Handwörterbuch zur deutschen Rechtsgeschichte Bd. 5, Berlin 1998, Sp. 1538f. Für die Reichsebene ausfuhrlich Fritz BLAICH, Die Wirtschaftspolitik des Reichstags im Heiligen Römischen Reich. Ein Beitrag zur Problemgeschichte wirtschaftlichen Gestaltens (Schriften zum Vergleich von Wirtschaftsordnungen 16). Stuttgart 1970. S. 159-165.

${ }^{316}$ Reg. Test. (wie Anm. 93) 1, Nr. 111 (S. 66). Der 2. Testamentsvollstrecker Herman van Wittenborch darf mit Herrn Johans Vater identifiziert werden; die beiden anderen laikalen Testamentsvollstrecker, Lubert Drugehorn und Marquard van Wittenborch, kennen wir als dessen Geschäftspartner. Alheid war aber keinesfalls identisch mit der Alheid Lurley, Hermans angeblicher Schwester (siehe oben Anm. 84), mit der Mollwo S. III und XX sie hat gleichsetzen wollen, was noch VON BRANDT a.a.O. referiert hat.

${ }^{317}$ Die Schuldner waren der 1. Testamentsvollstrecker, ein Priester, und Herman Wittenborch. Von einer Bindung der Renten an ein Immobiliarobjekt ist keine Rede, und nach den ganzen Umständen hat es das hier eben so wenig gegeben wie bei der Rente, die Herman Wittenborch den Nonnen-Töchtern des Herrn Alvin Grope gezahlt hat (oben mit Anm. 118-120) und bei einem verzinslichen Kredit, der 1376 einem Hamburger Goldschmiedemeister gewährt wurde (unten mit Anm. 352). Es handelte sich bei den Darlehen, die Alheid ihren Verwandten gewährt hatte, wohl um denselben Typ von nicht an die komplizierten Regeln des „offiziellen“ Rentenmarkts gebundener Kreditaufnahme und Geldanlage unter Verwandten, die uns bereits bei den $80 \mathrm{ml}$. begegnet ist, für die sich Herman Wittenborch 1333 seinen Schwägerinnen im Kloster verpflichtet hatte.

${ }^{318}$ VON BRANDT, Rentenmarkt (wie Anm. 100), S. $19 \mathrm{f}$.
} 
ten seitdem als ratenweise Rückzahlung von unverzinslich gewährten Darlehen betrachtet werden.

Beim so verstandenen Wucher handelt es sich darum, dass für kurz- bis mittelfristige Darlehen Zinsen in einer Höhe verlangt wurden, die sich dem Satz näherte, den zwei Gruppen von öffentlich konzessionierten Geldverleihern fordern durften: Die Pfandleiher jüdischen oder christlichen Bekenntnisses; diese waren bekanntlich die Kawertschen oder so genannten Lombarden, die ebenso bekanntlich von den italienischen Merchant bankers sorgfältig zu unterscheiden sind. ${ }^{319}$ In Lübeck und ebenso in Hamburg hat es aber ja im Spätmittelalter nie konzessionierte Pfandleiher gegeben, und es war daher von vornherein zu vermuten, dass der eine oder andere Bürger diese Lücke gefüllt hat. Johan Wittenborch ist offenbar einer dieser Bürger gewesen. So weit es sich in seinem „Rechenbuch“ erkennen lässt, hat er solche Geschäfte vor allem in den Jahren 1345/46 gemacht, also in den ersten Anfängen seiner selbständigen Geschäftstätigkeit. Die Transaktionen erscheinen natürlich auch im „Handlungsbuch“ in maskierter Form. Aber die Masken sitzen nicht so fest, dass sie der heutige Wirtschaftshistoriker nicht abreißen könnte, vorausgesetzt, er kennt sich in den Lübecker Währungsverhältnissen der Zeit einigermaßen aus.

Ich komme zu den Fällen: Folio „, $8^{“,}$, das erste Blatt, auf dem Johan Forderungen aus seiner kaufmännischen Geschäftstätigkeit verbucht hat, ${ }^{320}$ ist auf der Vorderseite fast ganz reinen Finanztransaktionen in einem einzigen Geschäftstyp vorbehalten: Johan hat jemandem einen bestimmten Betrag an golde gegeben, $100 \mathrm{ml}$., $85 \mathrm{ml}$., $30 \mathrm{ml}$., $20 \mathrm{ml}$. Die Empfänger sollten zu vereinbarter Zeit, offenbar nach einigen Monaten, dieselben Beträge an (lubeschen) sulveren penningen wiedergeben. ${ }^{321}$ Am Kopf der Rückseite steht noch ein letzter Vertreter des Typs: ${ }^{322}$ Für 20 aurei Lubicenses sollten 10 lib. den. an sulveren $d$., zu lesen 10 punt penninge an sulveren penningen, ${ }^{323}$ zurückgezahlt werden; das sind 10 mal 20 Schilling Silbermünze für 20 mal 10 Schilling in Gold. An dem ersten Geschäft war

\footnotetext{
${ }^{319}$ Immer noch grundlegend: DE ROOVER, Bruges, wie Anm. 310; dort auch zur Sache.

${ }^{320}$ Folio ,7“", Handlungsbuch (wie Anm. 55) S. 12, Nr. Il 1-6, enthält nur Aufzeichnungen über Rentenbesitz und über eine geringwertige Gefälligkeits-kumpenighe, die Johan mit seinem Handlungsgehilfen Bertolt eingegangen ist.

${ }^{321}$ Handlungsbuch (wie Anm. 55) S. 13, Nr. Il 7-10. Für den letzten Fall gibt es als Sicherung einen Eintrag im Schuldbuch, Handlungsbuch (wie Anm. 55) S. 80, Nr. V 36. Da reicht die Laufzeit vom 25. Juli bis zum 6. Dezember 1346.

${ }^{322}$ Handlungsbuch (wie Anm. 55) S. 13, Nr. II 13.

${ }^{323}$ Die Verwendung von lateinischen Kürzungen für deutsche Wörter in einem deutschen Text ist mir auch noch in den ersten Jahren des 16. Jh.s gelegentlich in den geschäftlichen Aufzeichnungen eines Lübecker Bürgermeisters (Johan Hertze, FEHLıNG Nr. 571) begegnet, besonders die ,tenetur"-Kürzung für „schuldich“. Wir kennen von dieser Praxis heute nur noch den Gebrauch des ,et"-Zeichens für „und".
} 
der ältere Kollege Albrecht Wullenpunt ${ }^{324}$ mit $30 \mathrm{ml}$. beteiligt. Johan war also nicht der einzige Lübecker Kaufmann, der diese - damals ganz neue - Geschäftsart „gepflegt" hat, und er wird sie wohl auch nicht erfunden haben. Dahinter steckt Folgendes: ${ }^{325}$ Seit 1342 hat die Stadt Gulden nach Florentiner Vorbild prägen lassen. Ihr Nennwert wurde vom Rat mit 10 Schilling lübisch festgesetzt; ein Gulden und 120 silberne Hohlpfennige sollten also gleichwertig sein. Tatsächlich waren die Gulden aber in Silbergeld deutlich weniger wert, anfangs wohl höchstens $9 \frac{1}{2}$ Schilling, später noch weniger. Da der Rat offenbar nicht bereit war, den Nennwert der Gulden entsprechend herabzusetzen, zahlte in Lübeck jedermann nach Möglichkeit mit Gulden; die silbernen Pfennige wurden zurückgehalten und für andere Zwecke verwendet, beispielsweise für Zahlungen nach Hamburg oder Wismar. So entstand ganz ohne Planung, nur durch die Wirkung des sog. Gresham'schen Gesetzes, eine stadtlübische Goldwährung, in der nur die Gulden die Edelmetallbasis darstellten, ${ }^{326} 1,6$ Stück für eine in 16 Schillinge geteilte ml. 1346 dürfte der Wert eines florenus Lubicensis allerhöchstens bei etwa 9 Schilling Silbergeld gelegen haben. Wer unter diesen Umständen für jeden Gulden 10 Schilling Silbermünze zurückgeben musste, der zahlte 1/9 mehr, als eigentlich gerechtfertigt war. Wenn wir annehmen, dass die Darlehen im Durchschnitt ein halbes Jahr gelaufen sind, dann mussten die Kreditnehmer, auf ein ganzes Jahr umgerechnet, $2 / 9$ oder $22 \%$ mehr zurückzahlen, als sie empfangen hatten ${ }^{327}$ verglichen mit einem Rentenmarktzins von damals meist (wieder) 6,25\% in einer „Krisenzeit“ ${ }^{4328}$ ein ,stolzer" Satz. Falls der Guldenkurs niedriger

\footnotetext{
${ }^{324}$ Er begegnet auch sonst öfter in Johans Unfeld, vorher aber schon, 1333, als einer der Vormünder der Töchter des Herrn Alvin Grope, in einem Geschäft mit Johans Vater Herman: Handlungsbuch (wie Anm. 55) S. 3, Nr. I 13 (vgl. dazu oben mit Anm. 119).

${ }^{325}$ Das folgende nach STEFKE, „Goldwährung" (wie Anm. 150), passim, bes. S. 50-57

${ }^{326}$ Unter dem Ausdruck „Gresham’sches Gesetz" versteht man die Regel „Schlechtes Geld vertreibt gutes Geld". In Geldsystemen, deren Grundlage der Stoffwert des Stückgeldes ist. bedeutet das „Gesetz“: Wenn nebeneinander zwei Geldsorten existieren, deren Stoffwert bei gleichem Nennwert verschieden ist, dann wird je länger je mehr nur noch die nach ihrem Stoffwert geringerwertige Sorte zum Nennwert für Zahlungen verwendet.

${ }^{327}$ Diese Verhältnisse sind bereits anhand des oben Anm. 321 genannten Beispiels, bei dem die Laufzeit des Darlehens - vom 25. Juli bis zum 6. Dezember 1346 - genau bekannt ist. ausführlich dargestellt bei STEFKE a.a.O., S. 37. Da die Laufzeit dieses Kredits nur ,gut vier Monate" (genau: vier Monate und 13 Tage) betrug, errechnet sich hier ein noch höherer Zinssatz von ,annähernd $30 \%$ ".

${ }^{328}$ VON BRANDT, Rentenmarkt (wie oben Anm. 100), S. 20. Hier erscheinen, an den Zinssatzverhältnissen gemessen, die Jahre 1344 und 1345 als Kernjahre der ,große[n] Krisenzeit des 5. Jahrzehntes“. Ausführlicher hat der Verf. diese „Krise“ als 1340 einsetzende ..langandauernde Epoche des Niederganges" auf S. 15f. dargestellt. Hieran anknüpfend, hat HansJoachim WENNER, Handelskonjunkturen und Rentenmarkt am Beispiel der Stadt Hamburg um die Mitte des 14. Jahrhunderts (Beiträge zur Geschichte Hamburgs 9), Hamburg 1972 , S. 97-99, „die wirtschaftliche Depression 1341-45“ dargestellt. In beiden Städten handelt es
} 
war, ist der Zinssatz noch höher gewesen. Bemerkenswert ist übrigens die Vielfalt, in der die verschiedenen Formen der Kreditsicherung hier auftreten: Geschäftsabschluss in Gegenwart von genannten Zeugen; Bürgschaft; Eintragung im Niederstadtbuch; Übergabe von „,verfolgten“ Pfändern mit dem Versprechen, einen etwaigen Minderertrag bei deren Verkauf nachzuschießen, alles vor Zeugen. Dieser spezielle Geschäftstyp ist dann aber sehr bald aus dem Handlungsbuch verschwunden. Es folgen noch vier Einträge, die auf Forderungen - dreimal $20 \mathrm{ml}$. und $60 \mathrm{ml}$. - an sulveren penningen lauten, aber nicht mehr erkennen lassen, wie die Forderungen entstanden sind; ${ }^{329}$ die Vermutung liegt nahe, dass es sich um denselben Geschäftstyp gehandelt hat, der jetzt aber besser verhüllt worden ist. Danach gibt es nichts Derartiges mehr. Hat sich irgendeine verbietende Instanz eingeschaltet, die nötigenfalls auf die Rechnungsbücher der Kaufleute als Beweismittel hätte zugreifen können ? Vielleicht ist es doch kein bloßer Zufall, dass praktisch gleichzeitig, am 5. Juli 1346, der Bischof von Lübeck ein Mandat gegen die „wucherische“ Betätigung in Stadt und Diözese erlassen hat. ${ }^{330}$ Zwar hat der Bischof seine Initiative damit begründet, ,dass viele Kleriker und Laien Wuchergeschäfte treiben“, ,als wäre es erlaubt“, 331 also offen; genau das hätte der junge Johan Wittenborch aber ja gerade nicht getan. Aber möglicherweise ist der Bischof und sein geistliches Umfeld den „Schäfchen" schneller und leichter auf die Spur gekommen als der moderne Historiker, der die Vorgänge nicht Tag für Tag beobachten kann, sondern sie aus dem Trümmerfeld ihrer „Überreste“ mühsam rekonstruieren muss. Sobald diese Eintragungen als das erkannt sind, was sie sind, überteuerte Darlehen, über die wir fast alles wissen, was man von derartigen Krediten sonst nicht erfährt, stellen sich weitere Fragen: So wäre es gewiss nicht ohne Interesse, sich einmal näher mit den Nehmern solcher Kredite zu befassen, die ja bei den dokumentierten Beträgen keine richtig armen Leute gewesen sein können. Bei derartigen Zinssätzen kann es sich wohl nur um Konsumkredite gehandelt haben; zumindest mit normalen Warengeschäften wären derartige

sich zunächst um ungewöhnlich niedrige Umsätze auf den lokalen Märkten für neubegründete Hausrenten. Von einer ,großen Krise des Welthandels, den der von England ausgehende Zusammenbruch des Florentiner Bankhauses der Peruzzi 1343 einleitete und der auch in Lübeck viele Konkurse zur Folge hatte". ist dagegen bei KOPPE u. KOPPE, Frankfurt-Händler (wie Anm. 79), S. 135, die Rede; man vermisst jeglichen Literaturhinweis. Endlich ist bei STEFKE a.a.O., S. 53f., beschrieben, wie sich der europäische Vorgang des Verfalls des Goldwerts $1344 / 45$ in Norddeutschland dargestellt hat. Eingehendere Studien über diese Zeit wären gewiss erwünscht.

${ }^{329}$ Handlungsbuch (wie Anm. 55) S. 13f., Nr. II 12, 14-16.

${ }^{330}$ Schleswig-Holsteinische Regesten und Urkunden 4. Nr. 250 (S. 164f.).

${ }^{331}$ quasi licite usuras exerceant. 
Sätze sicherlich nicht zu verdienen gewesen. ${ }^{332}$ Und: Woher kam die plötzliche Nachfrage nach so teuren Krediten? Wo blieb sie, seitdem - gewiss nicht nur bei Johan Wittenborch - diese Kreditform in Lübeck nicht mehr angeboten wurde? Vielleicht war es ja wirklich nur eine neue For m; dann hälte es derartige Kredite vorher wie nachher immer so zahlreich gegeben, nur in anderer Form? Bei der einfachsten und im Spätmittelalter wohl auch häufigsten Form wäre die Verzinsung bereits im Schuldbetrag enthalten; wenn der geschickt gewählt wurde, ließ sich ohne Kenntnis der Vereinbarung zwischen den Geschäftsbeteiligten nicht einmal begründet vermuten, dass Zinsen verlangt und gewährt worden sind. In diesem $\mathrm{Zu}$ sammenhang kann man mit Rörig auf die zahlreichen glatten Schuldsummen im Niederstadtbuch verweisen. Davon sind vermutlich viele auf Darlehensgewährung zurückzuführen; über die Konditionen lässt sich aber nur in Ausnahmefällen etwas sagen. ${ }^{33}$

Wo Johan Wittenborch ausdrücklich notierte, dass er Darlehen gewährt hatte, ist von Zinsen nichts gesagt. In diesen Fällen gibt es auch keine Indizien dafür, dass er welche verlangt hat. Aber natürlich ist daraus nicht zu folgern, dass wir es hier immer mit zinslosen Gefälligkeitskrediten zu tun haben. Einen verlässlichen Beleg für das Gegenteil liefert eine Transaktion, die Herr Johan am 15. August 1353 mit seinem Kollegen Hermen Blomenrot abgeschlossen hat. ${ }^{334}$ Sie erscheint auf den ersten Blick gar nicht als Gewährung eines Darlehens, sondern als ein Warentermingeschäft: Herr Johan hat, so notierte er sich, von Herrn Hermen $25 \mathrm{Ge}$ wichtsmark $^{335}$ "lötiges Silber lübischen Zeichens“, das hochhaltige Standardsilber des Lübecker Geschäftsverkehrs, gekauft für 3,25 ml. oder 52 Schilling [in Gold] pro Mark; „die soll er nächste Lichtmess [am 2. Februar 1354] bezahlen". Nach den Umständen muss man annehmen, dass bitalen hier als ,liefern“ zu deuten ist. Dass hier etwas nicht stimmt, merkt man erst, wenn man sich nach weiteren Preisen für dies Silber umsieht: Es

\footnotetext{
${ }^{332}$ Schon gar nicht in einer ,große|n| Krisenzeit" (s. oben mit Anm. 328). Zum Grundsätzlichen vgl. etwa GILOMEN. Wucher (wie Anm. 306), S. 292-294.

${ }^{333} \mathrm{Vgl}$. die oben mit Anm. 119, 305 und 321 behandelten Fälle. Über Darlehen im Niederstadtbuch hat Rörig 1931 gehandelt: Fritz RÖRIG, Das Lübecker Niederstadtbuch des 14. Jahrhunderts. Seine rechtliche Funktion, sich wandelnde Zwecksetzung und wirtschaftsgeschichtliche Bedeutung, in: Ehrengabe dem Deutschen Juristentage überreicht vom Verein für Lübeckische Geschichte und Altertumskunde. Lübeck 1931, S. 35-54. hier 49-51. Allerdings hatte Rörig nur den ersten erhaltenen. bis 1363 reichenden Band des Niederstadtbuchs gründlich durchgearbeitet; seine Aussagen werden anhand des zweiten, jetzl gedruckt vorliegenden Bandes (s. Anm. 289) zu überprüfen und zu ergänzen sein.

${ }^{334}$ Handlungsbuch (wie Anm. 55) S. 22, Nr. II 100. Siehe dazu bereits STEFKE, „Goldwährung" (wie Anm. 150) S. 37f,; auf die Person des Schuldners ist hier aber noch nicht eingegangen.
}

${ }^{335}$ Je $233.85 \mathrm{~g}$, siehe STEFKE a.a.O. S. 68-70. 
kostete im Herbst 1353 und Frühjahr 1354 in Lübeck, wenn man bar bezahlte, 60 1/2 und $60 \% \frac{2}{3}$ Schilling in Gold. ${ }^{336}$ Das hätte auch Herr Herman zahlen müssen, wenn er das Silber Anfang Februar hätte kaufen wollen, um es Herrn Johan zu übergeben; möglicherweise hat er sich die Mühe aber gar nicht machen müssen, weil Herr Johan mit dem Gegenwert in auro zufrieden war. Aus der Differenz zwischen den beiden Preisen ergibt sich ein Zinssatz von fast $35 \%$ pro Jahr. Man fragt sich, wieso ein Ratmann genötigt war, sich Geld zu solchen Wucherzinsen zu leihen. Die Antwort ist, dass er, ${ }^{337}$ von 1336 bis zu seinem Tod 1359 im Rat, ${ }^{338} 1353$ wohl schon ein ziemlich alter Mann war, der kein seinen Ansprüchen genügendes regelmäßiges Einkommen besaß. ${ }^{339}$ Möglicherweise war er in den 1350er Jahren auch nicht mehr völlig Herr seiner geistigen Kräfte; jedenfalls ist er nach 1350 nicht mehr als Testamentszeuge eingesetzt worden, ${ }^{340}$ obwohl ihn seine Schwiegersöhne Herr Herman van Dulmen 1350 und Herr Bertram Vorrad 1351 noch als einen ihrer Testamentsvollstrecker benannt haben. Seinen erwachsenen Söhnen Tideke und Johan galt er offenbar als ein Verschwender; er wurde von ihnen wohl auch finanziell kurz gehalten. Die Söhne haben sich in ihren Testamenten darüber Gedanken gemacht, wie der Vater nach ihrem Ableben versorgt werden könnte. 1353 waren ihm etwa $50 \mathrm{ml}$. jährlich zugedacht, ${ }^{341} 1355$ und 1357 nur noch $30 \mathrm{ml}$. jährlich. ${ }^{342}$ Beide Beträge waren gewiss nicht viel für einen alten Ratmann, der vielleicht jahrzehntelang auf großem Fuß gelebt hatte. Gegen diese Behandlung hat er sich offenbar gewehrt, indem er bei akutem Geldmangel Kredit aufnahm, wo und zu welchen Bedingungen er ihn kriegen konnte. Er war also sicherlich ein problematischer Schuldner.

\footnotetext{
${ }^{336}$ Handlungsbuch (wie Anm. 55) S. 22, Nr. II 103 und S. 26, Nr. II 127.

${ }^{337}$ LUTTERBECK Nr. 27 (S. 204f.); besonders zu beachten ist Anm. 1110. Siehe neuerdings auch KOPPE u. KOPPE. Frankfurt-Händler (wie Anm. 79), besonders S. 130-139 (mit teilweise anderer Deutung der Daten als der im folgenden vertretenen).

${ }^{338}$ Nach FEHLING S. 33 wäre er ..wahrscheinlich, mit Rücksicht auf sein Alter, 1354 aus dem Rate ausgetreten". Die Angabe ist von KOPPE u. KOPPE a.a.O. S. 138 übernommen worden, aber mit anderer Begründung. Bei LUTTERBECK a.a.O. ist die Sache nicht einmal erwähnt, geschweige diskutiert, was sicherlich damit zu tun hat, dass er S. 35f. (mit Herman Blomenrot als einem von zwei Beispielen) ausführlich (aber für mich nicht überzeugend) dargelegt hat, dass es ein förmliches Ausscheiden aus dem Rat „aus Alters- oder Gesundheitsgründen" nicht gegeben habe.

${ }^{339}$ Nach KOPPE u. KOPPE a.a.O. S. 138 hat er zu Beginn der 1350er Jahre durch den Anfall von Häusern, aus denen er bisher Renten bezogen hatte, arbeitsloses Einkommen von $112 \mathrm{ml}$. jährlich eingebüßt.

${ }^{34 \prime \prime}$ Reg. Test. (wie Anm. 93) 2, S. 349 (Personenregister). Bis 1350 ist er insgesamt $16 \mathrm{mal}$ belegt, in diesem Jahr noch zweimal (Reg. Test. (wie Anm. 93) 1, S. 225, dgl.).

${ }_{341}$ Reg. Test. (wie Anm. 93) 2, Nr. 501 (S. 55f.; Tideke).

${ }^{342}$ Ebd. Nr. 553 (S. 85: Tideman) und Nr. 634 (S. 128; Johan).
} 
Herrn Johan Wittenborch hat das anscheinend nicht gestört; ${ }^{343}$ die hohen Zinsen waren ihm wichtiger. Darin stand er offenbar nicht allein. Denn Herr Herman hatte schon Anfang Juli $1353100 \mathrm{ml}$. bis Weihnachten bei Herrn Bernard Paal ${ }^{344}$ aufnehmen können, und am 11. November hat er auch dem Johan Metelere, einem künftigen Ratmann, ${ }^{34.5} 25$ Mark des bcwussten Lübecker Silbers zum nächsten Lichtmesstag versprochen. ${ }^{346}$ Es gibt keinen Grund zu bezweifeln, dass auch hier Wucherzinsen bezahlt worden sind; nur lässt es sich nicht beweisen, weil die Daten aus dem Niederstadtbuch stammen.

Nicht zu erörtern ist hier der Fall des Herman Klensowe, der 1358 nach Juni 21 in die Schuldknechtschaft gehen musste. ${ }^{347}$ Denn dies ist offensichtlich nicht wegen der Forderung geschehen, die Herr Johan und sein Mitgläubiger Johan Wickede geltend machten. Denen hat vielmehr der Schuldner noch in letzter Minute sein Wohnhaus verpfändet, ${ }^{348}$ „damit [so hat es sich Herr Johan notiert] ich meines Geldes sicher bin". Darf man danach vermuten, dass Herman die beiden noch für die menschlichsten unter seinen Gläubigern gehalten hat?

Man fragt sich nach diesen Zeugnissen, wie Johan Wittenborch mit diesem Aspekt seiner geschäftlichen Tätigkeit gegenüber seinem Beichtvater umgegangen sein mag. Da auf eine solche Frage natürlich keine Antwort möglich ist, stellt sich sogleich die weitere Frage, ob sich vielleicht andere Zeugnisse für die Art seines „praktischen" Christentums finden lassen. Im „Handlungsbuch“ gibt es dazu nichts. Allenfalls ist zu erwähnen, dass er sich einmal einem „kleinbürgerlichen“ Schuldner gegenüber gnädig gezeigt hat: 1356 hatte ihm ,Albertus, ein Schreiber, der auch ein Krämer ist", alle seine Ware und sein Hausgerät für eine Schuld von $10 \mathrm{ml}$. 5 Schilling verpfändet; der Betrag war halb zu Ostern und halb zu Pfingsten (1357) fällig. ${ }^{349}$ Der Schuldner konnte offenbar nicht rechtzeitig zahlen, fand aber zwei Bürger, die sich bereit erklärten, für Zahlung bis Mitsommer selbstschuldnerisch zu bürgen; dabei wurde die Schuld-

\footnotetext{
${ }^{343}$ Ein unsicherer Schuldner war er damals wohl nicht; jedenfalls hat Herr Johan auf jede besondere Sicherung seines Darlehns verzichtet. Herr Herman hat nach LUTTERBECK S. 205 gerade 1354 drei Häuser verkauft; ob diese Verkäufe wirklich so dramatisch zu deuten sind, wie es bei KOPPE u. KOPPE a.a.O. S. 138f. geschehen ist?

344 Über ihn oben mit Anm. 259.

${ }^{345}$ LUTTERBECK Nr. 148 (S. 299f.), im Rat 1358-1373.

${ }^{346}$ KOPPE u. KOPPE a.a.O. S. $138 \mathrm{f}$. Die beiden Silbertransaktionen sind von den Autoren übrigens ohne Einschränkung als Warengeschäfte gedeutet worden; das mit Johan Wittenborch ist S. 134 geradezu als „Nachweis“ dafür gewertet worden, dass Herman Blomenrod mit Silber gehandelt hat.

${ }^{347}$ Handlungsbuch (wie Anm. 55) S. 35, Nr. II 216 mit Anm. 286.

${ }^{348}$ Ebd. S. 82, Nr. V 55.

${ }^{349}$ Ebd. S. 34, Nr. II 204.
} 
summe nicht erhöht, jedenfalls nicht von Herrn Johann. ${ }^{350}$ Die Zahlung ist dann tatsächlich erfolgt, nach dem Vermerk persolvit zu urteilen, durch den Schuldner selbst. Die beiden Bürgen, Arnolt Buc und Brant van Stockem, scheinen im „Handlungsbuch" sonst nicht vorzukommen.

Was ,nichts“ konkret heißt, kann man etwa ermessen, wenn man sich das „Handlungsbuch" seines vielleicht nur zehn, allerhöchstens etwa zwanzig Jahre jüngeren Hamburger Standesgenossen ansieht, des Ratmanns Frederik oder Vicke van Geldersen. Es ist in seiner Struktur dem Wittenborch-Buch recht ähnlich, reicht aber von der 2. Hälfte der 1360er Jahre bis zum Tode des Inhabers im Jahre 1391. ${ }^{35 !}$ Dort findet man zwar einige Zeugnisse dafür, dass Herr Frederik auch verzinsliche Darlehen gewährt hat. Aber mehr als $10 \%$ jährlich hat er nie verlangt. Für wucherischen Geldverleih im oben definierten Sinn ist nirgends auch nur das mindeste Indiz zu sehen. Dafür gibt es aber ein Zeugnis für die Gewährung eines nicht ganz kleinen Darlehens, $60 \mathrm{ml}$., zu dem gewöhnlichen $6 \frac{2}{3} \%$-Zinssatz des Hamburger Hausrentenmarkts an einen Handwerker, einen Meister des Goldschmiedeamts, der offenbar kein Grundeigentum besaß und deshalb auf den Hausrentenmarkt nicht gehen konnte. ${ }^{352}$ Und wir finden erhebliche Unterstützungsleistungen für einen in Not geratenen Bruder. ${ }^{353}$ Wir beobachten hier nicht etwa einen Wohltäter der Menschheit in Kaufmannsverkleidung. So musste der Goldschmied sechs andere Handwerksmeister überreden, für ihn myt ener sameden hant zu bürgen; und die Aufwendungen für seinen Bruder hat sich Herr Frederik durchaus

\footnotetext{
${ }^{350}$ Ebd. S. 33, Nr. II 196.

${ }^{351}$ Oben mit Anm. 63. Das Buch ist darüber hinaus auch noch von Nachkommen benutzt worden. aber nicht mehr als ,richtiges" Handlungsbuch.

${ }^{352}$ A.a.O. S. 100. Nr. I 621, 1376 Sept. 29. Die Laufzeit des Kredits betrug ein Jahr; die vereinbarten Zinsen sind tyns genannt. Alle - hier nicht auszubreitenden - Umstände sind in diesem Fall so genau bekannt, dass man mit an Sicherheit grenzender Wahrscheinlichkeit sagen kann: Hier liegt ganz gewiss eine ,mittelalterliche Rente ... ohne sachenrechtliche Radizierung" vor, auch wenn diese nach Winfried TRUSEN (in ZRGG 98, 1981, S. 362) "nicht denkbar (ist), weil sie in einer solchen Form gegen das kanonische Wucherverbot verstoßen hätte"; dies Geschäft wurde nicht nur vom Mitglied eines großstädtischen Rats gemacht und mit allen Details in sein "Rechenbuch" eingetragen. es wurde auch in aller Öffentlichkeit - mit sechs Bürgen und drei Handlungszeugen - abgeschlossen. Eine Eintragung in eines der Beurkundungsbücher „seines“ Rats hätte Herr Frederik aber wohl nicht in Betracht gezogen. Auf ähnliche Kredite im Lübeck der 1330er Jahre war bereits oben mit Anm. 119 und 317 hinzuweisen; in einem Fall verschweigt die Stadtbuch-Eintragung, dass Zinsen gezahlt wurden, in den beiden anderen Fällen hat es vermutlich gar keine Beurkundung in einem Stadtbuch gegeben.

${ }^{35.3}$ Darüber zusammenfassend NIRRNhEIM a.a.O. S. XVII. Die wichtigste Quellenstelle steht in der Edition auf S. $112 \mathrm{f}$., Nr. 1728 . Zum Ausgleich hat sich Herr Frederik 1380 ein Haus seines Bruders uibertragen lassen, ihn und seine Familie aber anscheinend gegen eine geringe Rente von $2 \mathrm{ml}$. jährlich weiter darin wohnen lassen. Jedenfalls haben nach dem Tod des Bruders und seiner Frau im Jahre 1389 deren Kinder dort gewohnt; sie sollten die Rente (die für einen frommen Zweck gestiftet war) bezahlen: Ebd. S. 121, Nr. II 27 mit Anm. 14.
} 
erstatten lassen, so weit das möglich war. Aber er zeigte in seinem praktischen Verhalten anscheinend den Sinn für das Maß, das Johan Wittenborch nur in der Feder geführt hat. Wenn es den „maßhaltenden Kaufmann" wirklich gegeben hat, dann war das gewiss ein Kaufmann, der nicht alle Grundsätze mitmenschlichen Anstands über Bord warf, sobald ein Extraprofit winkte. Und wenn man fragt, welcher der beiden Hansekaufleute aus den Jahrzehnten zwischen 1345 und 1391, über deren Person überhaupt ein einigermaßen begründetes Urteil möglich ist, ${ }^{354}$ diesem Anspruch genügt haben könnte, dann fällt die Entscheidung nicht schwer. Johan Wittenborchs "Gewinnstreben" hat offenbar wenig Hemmungen gekannt.

Auch sonst hat er dem Geld nachgestellt, wo immer es sich blicken ließ. Besonders deutlich zeigt sich das in der Präzision und Ausführlichkeit, mit der er, 1355 nach Bastian, einen Erbanspruch dokumentiert hat. ${ }^{355}$ Es handelte sich um zwei Renten von zusammen $9 \mathrm{ml}$. jährlich, die von den Kindern von Herrn Arnold Bardewich, also Herrn Johans Frau und seinem Schwager Arnold Bardewich, sowie den Kindern aus der Ehe einer Schwester des Herrn Arnold mit dem 1340 gestorbenen Bürgermeister her Hinric Plessecowe de olde ${ }^{356}$ als nächsten Erben würden beansprucht werden können, wenn eine - vermutlich schon ältere - Nonne im Johanniskloster $^{357}$ einmal sterben sollte; wenn man bedenkt, dass der Betrag min-

${ }^{35+}$ Das „Buch” der Rostocker Tolner (siehe oben mit Anm. 62) enthält so gut wie nichts, was ein Bild von den Personen vermittelt. Ausführliche Testamente lassen zwar gelegentlich individuelle Charaktere erkennen, was Einstellung und Verhalten gegenüber Mitmenschen angeht; dafür erfahren wir dort aber meist wenig oder nichts über die Testatoren als Kaufleute.

${ }^{355}$ Handlungsbuch (wie Anm. 55) S. 34f., Nr. II 213. dazu Bastian 1, S. 266 u. 271. Die Eintragung nimmt eine ganze Seite, „Fol. 28a“, ein (der Seitenwechsel hinter Nr. 212 ist im Druck versehentlich nicht kenntlich gemacht).

${ }^{356}$ LUTTERBECK Nr. 184 (S. 337-339), im Rat seit 1301, Bürgermeister ,bereits 1324". Als seine 2. Frau ist hier Gertrud. Tochter des Herrn Albrecht van Bardewich. genannt; über das Ehepaar siehe bereits oben Anm. 182. Aus dieser Ehe sind sechs Kinder aufgeführt, darunter Herr Arnold Pleskow, der 1359-1363 dem Rat angehört hat: LUTTERBECK Nr. 181 (S. 333 f.).

${ }^{357}$ Telse, die Tochter der Frau Heleke Keysers, auf deren Verfügungen die beiden Renten zurückgehen. Die erste Rente hatte ursprünglich Frau Helekes Sohn Johan, Dominikaner im Burgkloster, gehört; er war zum Zeitpunkı der Aufzeichnung schon tot. Nach KOPPMANN in Chroniken Lübeck 2, S. 291 war Helemburg, die zweite Schwester des Herrn Arnold Bardewich, mit einem Herman Keyser verheiratet. Helenburg, die Witwe des Lübecker Bürgers Herman Keyser, und ihre Söhne Johan und Rodinger erscheinen 1343 als Verkäufer von Landgut auf Poel: WiegandT. Plescows (wie Anm. 182), S. 166,3 und 172,3. Diesen Herman Keyser wird man wohl kaum identifizieren dürfen mit dem gleichnamigen Bruder des Herrn Johan Keyser, der von 129l bis 1311 im Rat belegt ist: LUTTERBECK Nr. 57 (S. 222f.); denn der gehörte ja zur Generation des Vaters der drei Geschwister Bardewich. Auch MolLwo S. 96 hat Heleke Keysers als Schwester des Herrn Arnold Bardewich bezeichnet; bei LUTTERBECK S. 198f. ist eine Heleke als Tochter bzw. Schwester der Ratmannen Albrecht und Arnold Bardewich erwähnt, allerdings ohne irgendeine Angabe darüber, was aus ihr geworden ist. 
destens durch vier zu teilen sein würde, handelte es sich um ziemlich bescheidene Aussichten. Herrn Johans Aufzeichnung stellt ein Muster an praktischer Genealogie dar; es muss ihn einige Zeit gekostet haben, alle Daten zusammenzutragen. ${ }^{358}$

Auf der Suche nach weiteren Zeugnissen für Johan Wittenborchs Religiosität stößt man auf die beiläufige Erwähnung eines Ritts nach Aachen, ${ }^{359}$ der gewiss eine Pilgerfahrt gewesen ist, im Jahre $1356 .{ }^{360}$ Sonst bleibt nur noch sein (letztes) Testament, das er am 14. März 1362 errichtet hat, ${ }^{361}$ sicherlich in dem Wissen, dass er in Kürze zur Ausübung eines mit Lebensgefahr verbundenen militärischen Kommandos ausrücken würde. Wenn man bedenkt, dass der Testator ein durchaus wohlhabender, in der Stadt schon von Amts wegen allgemein bekannter Mann war, der gewiss wusste, dass sein Tun und Lassen auch nach seinem Tod überall beachtet werden würde, dann überrascht auf das Höchste, wie spärlich alles außer der eigenen Frau und den eigenen Kindern bedacht ist. Für kirchliche und wohltätige Zwecke hat Herr Johan ganze $40 \mathrm{ml}$. ausgesetzt: $10 \mathrm{ml}$. für die Marienkirche, wo er unter dem lapis funeralis seines Vaters begraben werden wollte; das ist wohl eher als der übliche Kaufpreis für die Grabstelle zu werten, nicht als wirkliche Spende, $10 \mathrm{ml}$. für die Jakobikirche, wo er ja, wie erwähnt, mehrere Jahre lang Provisor gewesen war, es vielleicht sogar immer noch gewesen ist, und $20 \mathrm{ml}$. zu den communes elemosine zum Heil seiner Seele; wir wüssten nicht, was genau darunter verstanden wurde, ${ }^{362}$ wenn nicht in einem anderen Lübecker Testament der Zeit - es handelt sich um denselben Betrag - ausdrücklich gesagt wäre, das Geld sei „unter die Armen zu verteilen“. ${ }^{36.3}$ Das Erstaunen über die

\footnotetext{
${ }^{358}$ Als einschlägige Dokumente sind erwähnt denkebreve (siehe dazu oben Anm. 257), die sich bei her Hermen Wickede und her Bernolt [!] Oldenborc to thughe befanden, und ein Testament der Frau Heleke Keysers, das offenbar nicht erhalten geblieben ist (es findet sich weder in Reg. Test. (wie Anm. 93) 1 u. 2, noch ist es erwähnt im „Index der Testatoren“ bei NoODT, Religion und Familie (wie Anm. 160).

${ }^{359}$ Handlungsbuch (wie Anm. 55) S. 28, Nr. II 152. Nach Mollwo S. XI wäre er danach nach Brügge weitergereist; diese Annahme beruht auf einem Missverständnis.

${ }^{360}$ In diesem Jahr wurde zum zweitenmal die große, seit 1349 in ,einem strengen siebenjährigen Turnus" stattfindende Aachener „Heil(ig)tumsfahrt" veranstaltet, siehe Mark MERSIOWSKY, Aspekte adligen Lebens um 1400. Frühe westfälische und rheinische Adelsrechnungen im Vergleich, in: Vestigia Monasteriensia. Westfalen - Rheinland - Niederlande. Hg. von Ellen WidDER, Mark MERSIOWSKY u. Peter JOHANEK (Studien zur Regionalgeschichte 5), Bielefeld 1995, S. 263-304, hier S. 283 mit Anm. 131 u. 132.

${ }^{361}$ Handlungsbuch (wie Anm. 55) S. 89f., Nr. VI 3; Reg. Test. (wie Anm. 93) 2, Nr. 925 (S. 294).

${ }^{362}$ Das Wort „elemosina“, niederdeutsch ,almisse“, kann jede Art von Gabe zum Seelenheil des Gebers oder eines vom Geber Begünstigten bedeuten.

${ }^{363}$ Reg. Test. (wie Anm. 93) 2, Nr. 977 (S. 321, 1363 März 31), Ratmann Bernard Paal. Vgl. auch noch Reg. Test. (wie Anm. 93) 1, Nr. 405 (S. 208f., von 1350), § 24: ,sollen die Armen eine Spende (elemosinam communem que dicitur eyn spende) erhalten". Johan Wit-
} 
Geringfügigkeit dieser Vermächtnisse ad pias causas und die Gleichgültigkeit gegenüber den Details der Maßnahmen für das Seelenheil des Testators wäre noch größer, wenn man nicht bei der Musterung der „Nachbarschaft" von Herrn Johans Testament auf ein Stück stieße, in dem die größeren Legate eines anderen Ratmanns, des Herrn Bernard Paal, ${ }^{364}$ fast ebenso aussehen. ${ }^{365}$ Immerhin kommt hier noch eine Reihe von Bagatellvermächtnissen im Gesamtvolumen von etwa $75 \mathrm{ml}$. hinzu. Die lenken allerdings auch die Aufmerksamkeit darauf, dass Johan Wittenborch nicht einen entfernten Verwandten, nicht einen Handlungsdiener, nicht eine Magd mit der kleinsten Gabe bedacht hat. Andererseits hat es aber nach den Untersuchungen von Birgit Noodt während des langen Zeitraums vom späten 13. Jahrhundert bis zur Wende zum 15. jederzeit in nicht ganz geringer Zahl sogar Testamente von Lübecker Bürgern gegeben, auch von hochgestellten und reichen, in denen überhaupt nichts ad pias causas vermacht wurde. ${ }^{366}$ Ein derartiges Testament ist das des uns wohlbekannten

tenborch hat 1358 selbst von Geld gesprochen, dat papperibus [!], armen luden, to armissen horet: Handlungsbuch (wie Anm. 55) S. 39. Nr. II 256.

${ }^{36+}$ Über ihn oben mit Anm. 259.

365 Wie oben Anm. 363. - Dass der Ratmann Johan Pleskow (über ihn oben mit Anm. 278 und öfter) in seinem Testament von 1362 nur $54 \mathrm{ml}$. ,an geistliche Institutionen vermachte“, „obwohl er als Klosterprovisor sicher der Kirche zugetan war" [!?], hat WIEGANDT, Plescows (wie Anm. 182), S. 155f., als verlässlichen Anhalt für eine erheblich ,.verschlechtert(e) ... Vermögenslage" gewertet.

${ }^{36}$ NOODT, Religion und Familie (wie Anm. 160), S. 179 mit Anm. 238 im Kapitel „Das Pestjahr 1350": "Immerhin $1 /$ Männer und drei Frauen erachteten es nicht als notwendig, einen Teil ihres letzten Willens frommen Gaben zu widmen". Nach S. 177 in Verbindung mit dem Säulendiagramm auf S. 590 zu urteilen, beziehen sich diese Zahlen wohl auf 123 Testamente aus dem Jahr 1350 (oder 126 nach S. 197 ?); als ,die Erben in diesen 14 Stücken“ werden Verwandte, hauptsächlich nahe, genannt. Eine Behandlung des Gesichtspunkts für den Zeitraum 1351-1366 (S. 191-206) sucht man vergeblich. Doch findet man auf S. 209 die Angabe, dass die „Rate“ der Lübecker Testamente, in denen sich ,kein Hinweis auf eine Donation um Gottes willen“ befindet, „,von 1350 bis zum Ende des Untersuchungszeitraums [im Jahr 1400] ... relativ konstant (bleibt)“; Anm. 357 (S. 462) erfährt man dann die folgenden Prozentwerte: $135011 \%, 1351-136616 \%, 1368-137514 \%$ und 1376-1400 $15 \%$. Für das „Pestjahr 1367“ gilt nach S. 209. dass von „, 246 nummerisch [!?] ausgewerteten“ Testamenten 32, also $13 \%$, keine Vermächtnisse für fromme Zwecke enthalten. Hier erfährt man dann auch, dass der Antejl der Testamente ohne ,jeglichen religiösen Bezug“ von den Jahrzehnten um 1300 (bis 1325) bis zum Zeitraum 1326-1349 von $25 \%$ auf $17 \%$ gesunken ist; das könne allerdings ,,in Wandlungen der Urkundenform begründet sein". nämlich dem Aufkommen der Praxis, über einen etwaigen Vermögensrest zugunsten des eigenen Seelenheils zu verfügen. Mit diesem Hinweis bekommt man auch einen interessanten Einblick in die qualitativen Grundlagen der NOODT"schen „Statistik“ (nach S. 3 betrug, auf den gesamten Untersuchungszeitraum bezogen, der Anteil der Testamente, in denen „konkrete religiöse Verfügungen getroffen wurden", nur „etwa 2/3“). Auf S. 214 werden drei oberschichtliche Testatoren des Jahrs 1367 vorgeführt, die sich ,ausgesprochen zurückhaltend gegenüber den kirchlich gebotenen Verpflichtungen“ [?] ,präsentiert“ hätten. Von ihnen war der Ratmann Bernard van Cosvelde offenbar sparsam, aber bigott (er wollte u. a. zwei Lohnpilger auf die Reise schicken), während seine Witwe ausschließlich an ihre Kinder gedacht hat. Vom Drit- 
Herrn Bertram Vorrad vom 26. Juni $1351 .^{367}$ Er hat zwar $50 \mathrm{ml}$. vergeben, das waren aber nicht seine Legate, sondern die seiner verstorbenen Ehefrau Telse, und sie sollten bezahlt werden mit Geld, das der Schwiegervater seiner Tochter noch schuldete. Wenn wir lesen, dass der Schwiegervater der uns ebenfalls schon bekannte Herr Herman Blomenrot war, können wir uns vorstellen, wie groß die Chance war, dass diese Vermächtnisse jemals ausgezahlt werden würden. Nur einem einzigen Außenstehenden hat Herr Bertram etwas vermacht, ganz gewiss keinem Bedürftigen: seinem Namensvetter, dem Lübecker Bischof Herrn Bertram (Cremon) seinen besseren vergoldeten Becher. ${ }^{368}$ Alles übrige Gut vermachte dieser bemerkenswerte Ratmann seinen Kindern zu gleichen Teilen. Bei denen hat er mit seiner Abneigung gegen Zahlungen für das eigene Seelenheil möglicherweise Schule gemacht. Denn auch sein Sohn Tideman, der 1384 ebenfalls in den Rat gewählt wurde, aber bereits im Jahr darauf gestorben ist, ${ }^{369}$ hat, als er 1367 sein erstes Testament machte, nichts für

ten erfährt man nur, dass er in seinem Testament ,dem jenseitigen Element keinen Anteil (eingeräumt)" habe. Aus dem Zeitraum 1368-1375 werden auf S. 221 mit Anm. 414 (S. 464) nur ein Ratmann und ,drei den Ratsfamilien angehörige Männer" namhaft gemacht, in deren Testamenten ,alle kirchlichen Stätten, Kulte [!?] und Rituale vollständig übergangen werden“. Für den Schlusszeitraum 1376-1400 hat die Autorin dann auf S. 234 dargestellt. dass und inwiefern sich ein Ratmann und zwei Männer, die erst 1402 bzw. 1408 in den Rat gekommen sind, „allen kirchlichen Belangen gegenüber äußerst reserviert“ gezeigt haben. Besonders interessant ist Herman Vorste, im Rat 1384-1406 (LUTTERBECK Nr. 270, S. 408-410), weil von ihm eine ganze, von 1379 bis 1406 reichende Folge von Testamenten erhalten geblieben ist, die mit unbedeutenden Variationen alle dasselbe Bild zeigen: LUTTERBECK a.a.O., dem ich diese Informationen verdanke, hat es in dem Satz zusammengefasst: Vorste ,..setzt in einigen seiner sechs Testamente zwischen 5 und $10 \mathrm{~m}$.d. [= ml.] für die Armen und 1385 je 3 m.d. für das Katharinenkloster und das Burgkloster aus“. Die hier mühsam aus einem Bereich von 70 Druckseiten zusammengeklaubten Daten hätten gewiss, nebst vielen weiteren, eine systematische Zusammenstellung an einer Stelle verdient gehabt. die dann die Grundlage für eine ausführliche Diskussion der Sachverhalte hätte bieten können. Beides lag aber offenbar außerhalb des Interesses der Autorin. Zu den zitierten globalen Werten siehe bereits Hildegund HÖLZEL, .... pro salute anime mee ... ordino testamentum meum ...". Studien zur Lübecker Kirchengeschichte im 14. Jahrhundert, in: ZVLGA 70, 1990, S. 27-59, hier S. 28f.: „von den 1019 Testamenten, die zwischen 1278 und 1363 errichtet wurden, (enthalten) nur $265(=$ ca. $26 \%$ ) keine Legate ad pias causas. Zieht man ... diejenigen Testamente ab, die eine Verfügung über ,alles übrige Gut zum Seelenheil des Erblassers enthalten, bzw. die die Auszahlung der Legate an die Empfänger an die Bedingung knüpfen, für sein Seelenheil zu sorgen, so bleiben lediglich 169 Testamente $(=\mathrm{ca}$. $17 \%$ ). in denen die Sorge um das eigene Seelenheil keinen Ausdruck findet. Die meisten dieser 169 Erblasser wandten ihr gesamtes Vermögen ihrer Familie zu oder bestimmten einen Universalerben.".

${ }^{367}$ Reg. Test. (wie Anm. 93) 2, Nr. 449 (S. 29).

${ }^{368}$ Damit war er der einzige Laie, der nach den erhaltenen Testamenten des Zeitraums 1351-1363 dem Bischof überhaupt etwas vermacht hat; alle anderen Legate stammen von Priestern.

${ }^{369}$ LUUTTERBECK Nr. 267 (S. 406f.). 
fromme Zwecke vorgesehen. ${ }^{370} 1378$ hat er sich dann freilich eines anderen besonnen. ${ }^{371}$ Ein weiterer alter Bekannter unter denen, die nach Ausweis ihrer Testamente nichts für fromme Zwecke übrig hatten, ist der Ratmann Johan Meteler, im Rat 1358-1373; er hatte 1353 zu den Kreditgebern von Herrn Herman Blomenrot gchört. ${ }^{372} 1373$ hat er gewiss angemessen für seine Familie gesorgt, aber auch seiner Magd Abele $50 \mathrm{ml}$. vermacht. ${ }^{373}$ Irgendjemand muss dann doch nach seinem Tode etwas für Herrn Johans Seelenheil gestiftet haben; denn man findet seinen Namen im Memorienbuch der Marienkirche. ${ }^{374}$

Damit kommen wir auf einen Zusammenhang, der auch für die Interpretation von Johan Wittenborchs Testament bedeutsam ist: Für das kirchlich gebotene und sozialgruppenspezifisch übliche Handeln zwischen Tod und Bestattung eines Familienmitglieds und die gängigen Formen des rituellen Totengedenkens brauchte ein Angehöriger der städtischen Oberschicht in Lübeck und anderswo im Spätmittelalter sicherlich keine testamentarische Vorsorge zu treffen; er konnte sich gewiss darauf verlassen, dass seine Hinterbliebenen alles Nötige schon in die Wege leiten würden. Wenn sich in einem Testament zu diesem Bereich nichts findet, darf man also unterstellen, dass der Testator oder die Testatorin das Übliche erwartete und damit einverstanden war. Erklärungsbedürftig ist es vielmehr, wenn ein Testament umfangreiche Vorschriften für die Gestaltung des Bereichs enthält; dann darf man vermuten, dass sich die testierende Person durch ein besonders großes Maß an formaler, extrovertierter Kirchlichkeit oder durch ausgeprägtes, über den Tod hinausreichendes Prestigedenken oder durch beides ausgezeichnet hat. Bei Herrn Johan Wittenborch war davon offenbar nichts gegeben.

5. Herrn Johan Wittenborchs Amtsethos: Der „Kirchenstiefvater" von St. Jakobi und seine Hinterbliebenen

Ich wende mich der Frage nach dem Amtsethos von Herrn Johan Wittenborch zu. Am 15. August 1358 hat er an verschiedenen leeren Stellen seines „Handlungsbuchs" drei Verfügungen niedergeschrieben, die offenbar Nachträge zu seinem damaligen Testament sein sollten; deshalb hat er wohl jedes Mal hervorgehoben, dass er dit sulven screven habe; ${ }^{375}$ ab Seite

\footnotetext{
${ }^{377}$ NoOdT, Religion und Familie (wie Anm. 160), S. 214 mit Anm. 388

${ }^{371}$ LUTTERBECK S. 407.

${ }^{372}$ Siehe oben mil Anm. 346.

${ }^{37.3}$ NOODT, Religion und Familie (wie Anm. 160) S. 221; von seinen Legaten ist nur das für die Magd erwähnt.

${ }^{374}$ LUTTERBECK S. $300 \mathrm{mit}$ Anm. 2106.
} 


\section{"7a“ der Handschrift stammt ja alles von Johans Hand. ${ }^{376}$ Anlass waren Ereignisse, die er - mit vielen anderen - für den Beginn eines zweiten Pestzugs in Lübeck gehalten hat; er schrieb, nu dit sterwent hir bigunt. ${ }^{377}$}

${ }^{375}$ Die früheste ausdrückliche Lübecker Erwähnung von Vermächtnissen auf den Todesfall, die jemand eigenhändig in seinem liber computationis niedergeschrieben hat, findet sich in einem Testament von 1387: Carl Wilhelm PAULI, Das Erbrecht der Blutsfreunde und die Testamente nach Lübischem Rechte. Größtentheils aus ungedruckten Quellen (DERS., Abhandlungen aus dem Lübischen Rechte. Größtentheils nach ungedruckten Quellen, 3), Lübeck 1841, S. 225.

${ }^{376}$ MOLLwo S. XXXVII: ,entstammt völlig der Feder von Johann Wittenborg“. Vgl. Franz BASTIAN, Ebbe und Flut handelsgeschichtlicher Leistung in Bayern, in: Zeitschrift für Bayerische Landesgeschichte 9, 1936, S. 376-411, hier S. 396: „Der ganze spätere Text des Lübecker Wittenborgbuches scheint tatsächlich vom Chef herzurühren“. Ich selbst habe nur an einer Stelle Bedenken, mich diesen Urteilen anzuschließen, bei Handlungsbuch (wie Anm. 55) S. $26 \mathrm{f}$., Nr. II I 28 (wo übrigens am Ende eine Betragsangabe, vielleicht 86 cuur., ausgelassen ist) und, von derselben „Feder“, 129, 1. Satz (im Zusatz, von Herrn Johans vertrauter Hand, muss es statt „9 m.“ $/ \mathrm{m}$. heißen).

${ }^{377}$ Vgl. IBS, Pest (wie Anm. 176), S. 97, zur „monatliche|n] Verteilung der Testamente“ in Lübeck; danach kam der Verf., der das Wittenborch-Buch nicht benutzt hat, zur Feststellung eines ,,sommerlichen Höhepunkt[s] der Seuche“. In der graphischen Darstellung dieser Verteilung auf S. 98 tritt aber der August so deutlich als erster Monat mit stark erhöhter Zahl (20) der Testamente hervor, dass Johan Wittenborchs tagesgenaue Angabe nicht nur unsere Kenntnisse präzisiert, sondern auch den Wert einer fast quantitativen Betrachtung der Testamentserrichtungen (vgl. dazu oben mit Anm. 176 u. 255) für die genaue Datierung wenn nicht von Pestverläufen, so wenigstens der stadtbürgerlichen Reaktionen auf Anzeichen beginnender Pest unterstreicht, und zwar noch über das von IBS vermutete Maß hinaus; von den 20 Testamenten des August (Reg. Test. (wie Anm. 93) 2, S. 152-163, Nr. 677-696) sind nämlich nur vier vor dem 14. (!) des Monats errichtet worden. Danach sind die Testamentszahlen der nächsten beiden Monate (18 im September, 19 im Oktober; im November dann nur noch 12) wohl sogar schon als Indizien für einen Rückgang der Pestfurcht zu werten. Dass es im Spätsommer 1358 in Lübeck keinen Pestverlauf gegeben hat, der mit denen von 1350 und 1367 irgend vergleichbar wäre, ergibt sich auch daraus, dass in Lübeck 1358 nur ein einziges Ratsmitglied gestorben ist, dieses noch dazu außerhalb der Zeit, in der man nach den bisher zusammengestellten Daten einen Pesttoten am ehesten erwarten durfte, am 19. November (Bürgermeister Hinrik Pleskow, im Rat seit 1348; vgl. über ihn oben Anm. 278). Sein Todestag war nach der „Oldenborgschen Ratslinie“ der Elisabethtag (LUTTERBECK S. 453, Nr. 332); ich weiß nicht, weshalb bei LUTTERBECK S. 339 „31. 8.“ steht, und weshalb WIEGANDT, Plescows (wie Anm. 182), S. 68, behauptet hat, ,sein genaues Todesdatum (sei) unbekannt". NOODT, Religion und Familie (wie Anm. 160), S. 191 (vgl. auch S. 248), hat die genannten Zahlenverhältnisse ebenfalls dargestellt, mochte aber ohne Auseinandersetzung mit IBS ( dessen Arbeit sie übersehen hat) an ,einen zweiten Pestausbruch im Jahr 1358 in Lübeck“ nicht glauben; zur Begründung führte sie an, dass der Anteil derer, die „krank“ ihr Testament machten, 1358 „unter dem Durchschnitt der gesamten Periode“ 1351-1366 gelegen habe; tatsächlich liegt der Wert im Bereich des Durchschnitts, und zwar auch, wie hinzuzufügen ist, in den drei pestverdächtigen Monaten (vermutlich hatte sich inzwischen auch bei vielen anderen Lübeckern die Einsicht durchgesetzt, dass man letztwillige Verfügungen besser macht, bevor man krank wird). Die Wittenborch-Nachrichten hat NOODT nicht beachtet, obwohl die hier an dritter Stelle zu besprechende Stelle in anderem Zusammenhang bei ihr zitiert ist: S. 38 mit Anm. 246 (S. 422). In der erneuten Behandlung des Themas bei Birgit NOODT, Lübecker Material zur demographischen Wirkung der Pest im 14. Jahrhundert, in: Das Gedächtnis der Hansestadt Lübeck. Festschrift für Antjekathrin Graßmann zum 65. Geburtstag, hg. von Rolf HAMMEL-KIESOW u. Michael HUNDT, Lübeck 2005, S. 55-65, 
Wir dürfen gewiss unterstellen, dass Herr Johan, der das „,große Sterben“ von 1350 überlebt hatte und damals auch keine nahen Verwandten verloren zu haben scheint, hier alles bisher Ungeregelte aufgezeichnet hat, was er für den Fall eines schnellen Todes unbedingt geregelt haben wollte. In der mil Abstand ausführlichsten Verfügung geht es darum, dass seine Tochter Greteke im St.-Johannis-Kloster für ihr ganzes Leben verlässlich mit einer Rente von $10 \mathrm{ml}$. jährlich versorgt werden soll. ${ }^{37 x}$ Das Thema begegnet erneut in Herrn Johans Testament von 1362; es ist hier ohne Interesse. ${ }^{379}$ Die zweite Verfügung ist sehr kurz: Im Fall seines Todes sollen seine „Vormünder" der Stadt $160 \mathrm{ml}$. zuwenden; dar hebben se recht to ${ }^{380}$ Herr Johan hatte also damals einen nicht unbedeutenden Betrag an städtischem Geld in seinem Besitz, das ohne diese Verfügung in seinem Nachlass untergegangen wäre, mindestens zunächst, weil es darüber offenbar keine früheren Aufzeichnungen gab. Das klingt sehr bedenklich; aber da es dazu wirklich nichts zu geben scheint, jedenfalls nicht im „Handlungsbuch“, muss die Sache auf sich beruhen bleiben.

Mit der dritten Verfügung ${ }^{381}$ kommen wir an den Kern unserer Frage. Diese Aufzeichnung enthüllt zunächst ein Chaos in Herrn Johans Aufzeichnungen über die finanzielle Seite seiner Tätigkeit als Kirchenprovisor der Jakobikirche und Verwalter einer weiteren, damit höchstwahrscheinlich verbundenen Kasse; diese Aufzeichnungen stehen offenbar alle in seinem „Handlungsbuch“, und eine Bemerkung am Schluss der Verfügung lässt ahnen, dass die Sache auch damit noch nicht ausgestanden war: „Ich ... will, dass meine Vormünder bezahlen sollen, wie es hier in diesem Buch steht, nämlich meine Schulden, was zu St. Jakob gehört und was ich bei mir habe, das armen Leuten zu Almissen gehört, außer dem, das da abbezahlt [!?] ist, wie es hier in diesem Buch vorne geschrieben steht".

Macht man sich daran aufzusuchen, was vorn steht, dann kommt das Folgende zutage: 1352, wohl im Frühjahr, haben sich Herr Johan Woltvogel, der uns schon mehrfach, auch als Provisor der Jakobikirche, in Verbindung mit Johan Wittenborch begegnet ist, ${ }^{382}$ und dieser $250 \mathrm{ml}$. „von St. Jacobs Gelde“ geliehen und damit einen Wechsel bezahlt, mit

hier S. 61 u. 65, kann ich nichts belangvoll Neues entdecken. Bei IBS a.a.O. S. 97 gibt es außer den Lübecker Testamentsdaten zu 1358 auch Nachrichten aus Hamburg, dem Stift Fischbeck und der „Region um Braunschweig“, zu 1357 eine Nachricht aus Magdeburg und zu 1359 Testamentsdaten aus Stralsund. Sollte es sich überall nur um den „Schatten des Verdachtes, die Pest könne erneut ... hereinbrechen". gehandelt haben ?

${ }^{378}$ Handlungsbuch (wie Anm. 55) S. 43f., Nr. II 291. Hier auch der Verweis auf $\min$ testament.

${ }^{379}$ Siehe dazu aber noch unten Anm. 409.

${ }^{380}$ Handlungsbuch (wie Anm. 55) S. 43, Nr. II 290.

${ }^{381}$ Handlungsbuch (wie Anm. 55) S. 39, Nr. II 256.

${ }^{382}$ Oben mit Anm. 228 u. 252. 
dessen Valuta Tuche gekauft wurden. Als dies ins „Handlungsbuch“ übertragen wurde, standen die 48 Popersche lakene schon, ,in Herrn Johan Woltvogels Haus“. „Wenn die Tuche verkauft werden, soll man die $250 \mathrm{ml}$. wieder zu St. Jakobs Geld legen“, heißt es abschließend. ${ }^{383}$ Der Gesamterlös, von dem noch die - nicht überlieferten - Transaktionskosten abzuziehen wären, betrug nicht mehr als $276 \mathrm{ml}^{384}$ Davon sind, so weit wir es erkennen können, zu einem unbekannten Zeitpunkt tatsächlich ganze $15,25 \mathrm{ml}$. von den beiden Herren „wieder in St. Jakobs Kiste“ gelegt worden. ${ }^{385}$ Von wem die Initiative zu dieser Art der Kapitalbeschaffung ausgegangen ist, lässt sich nicht mit Bestimmtheit sagen. Denn an dem Geschäft waren beide Herren zu gleichen Teilen beteiligt. ${ }^{386}$ Für Johan Wittenborch als Initiator wäre immerhin anzuführen, dass auch die Anregung, Tuche nicht in Lübeck zu kaufen, sondern sie selbst aus Flandern zu importieren, von ihm stammen könnte. Möglicherweise hat Johan Woltvogel das nämlich vor 1352 nicht getan. Denn 135 I vor dem 2. Februar ist er zusammen mit seinem Bruder Albrecht Herrn Johan Wittenborch $26,5 \mathrm{ml}$. für zwei Brügger Laken schuldig geworden; ${ }^{387}$ Albrecht dürfte ein Wantschneider gewesen sein. ${ }^{388}$ Es zeugt nicht von großer Kapitalkraft. dass der verhältnismäßig kleine Betrag erst am 3. Februar des nächsten Jahres bezahlt werden sollte; aber vielleicht gilt das nur für den Bruder, und der Ratmann ist hier bloß für diesen selbstschuldnerisch mit eingetreten. ${ }^{389}$

Nicht viel später sind weitere $155 \mathrm{ml}$. „von St. Jakobs Gelde“ von den beiden Herren ausgeliehen worden; damit wurden etwa 2/3 eines neuen Wechsels finanziert, dessen Valuta in Brügge ähnlich angelegt worden ist. Davon hatte Johan Wittenborch $12 \mathrm{ml}$. im Auftrag eines alten Geschäfts-

\footnotetext{
${ }^{383}$ Handlungsbuch (wie Anm. 55) S. 22, Nr. II 105.

${ }^{384}$ Zur Berechnung s. unten Anm. 386.

${ }^{385}$ Handlungsbuch (wie Anm. 55) S. 23, Nr. II 109. In der 1. Zeile ist statt ,300“ zu lesen 250; das letzte Wort der letzten Zeile ist heben, nicht „hebben“ (Vermeidung von Doppelkonsonanten ist ein charakteristisches Merkmal von Herrn Johans Orthographie).

${ }^{386}$ Nach der eben zitierten Buchung könnte man auf den ersten Blick denken, von den 48 Tuchen hätten Wittenborch nur drei gehört. Aber aus Handlungsbuch (wie Anm. 55) S. 23, Nr. II 107, der Eintragung, die den Fortgang des Geschäfts dokumentiert, ergibt sich dann eindeutig, dass Wittenborchs Anteil an einem Packen von $48+3$ Stück $24+3$ betragen hat. Damals waren alle 5I Laken en bloc dem Willeken Bust (so zu lesen statt „Busc", s. oben Anm. 289) zum Stückpreis von 11 1/2 Verding verkauft; da der Verding nichts weiter als ein Viertel der ma $=0,5 \mathrm{ml}$. war, macht das für 48 Stück $276 \mathrm{ml}$. Das war also alles andere als ein hochprofitables Geschäft, zumal die Bezahlung erst zu Michaelis erfolgen sollte.

${ }^{387}$ Handlungsbuch (wie Anm. 55) S. 20, Nr. 1184.

${ }^{388}$ Handlungsbuch (wie Anm. 55) S. 19, Nr. Il 77.

${ }^{389}$ Ein weiterer, leider undatierter Borgkauf der Brüder, vier Brügger Tuche für $56 \mathrm{ml}$., ist ebd. S. 19. Nr. II 76 dokumentiert: das Geschäft ist jedenfalls vor dem Frühjahr 1353 abgeschlossen worden. In der 1. Zeile des Drucks ist hinter mihi dominus einzufügen.
} 
freunds empfangen, des Albrecht Wullenpund; ${ }^{390}$ sie waren für das Begräbnis seiner Frau bestimmt. 11/15 dieses Wechsels haben $170 \mathrm{ml}$. und 4 Schilling Maklerhonorar gekostet. ${ }^{391}$ Dafür wurden 32 Laken aus Poperingen gekauft, von denen 9 je 11 Verdinge brachten, insgesamt also 49,5 $\mathrm{ml}$.; nach diesem Verkauf wanderten $50 \mathrm{ml}$. zurück in de kisten sunte Jacoppes. Für die anderen 23 Tuche bekamen die Herren nur $10 \%$ ding pro Stück, zusammen also $120,75 \mathrm{ml}^{392}$ Der Gesamterlös betrug damit 170,25 ml., auf den Schilling genau so viel, wie der Wechsel gekostet hatte; die - nicht verbuchten - weiteren Spesen, die hiervon noch abzuziehen waren, machten das Ganze vollends zu einem klaren Verlustgeschäft. ${ }^{393}$

So weit die hier ausgewertete Dokumentation reicht, sind von $405 \mathrm{ml}$, die aus der Jakobikasse genommen worden waren, in zwei Raten 65,25 ml. zurückgegeben worden. $339,75 \mathrm{ml}$. standen also noch aus. Über die Entwicklung in der nächsten Zeit - wohl bis zu Herrn Johan Woltvogels Tod, am 25. April $1354^{394}$ - findet man im „Handlungsbuch" nichts. ${ }^{395}$ Dann hat Wittenborch - in räumlicher Nachbarschaft zu den besprochenen Buchungen - seine eigenen Schulden bei der Jakobikirche mit $388 \mathrm{ml} .10$ Schilling beziffert, wovon er $12,5 \mathrm{ml}$. zurückbezahlt hatte. ${ }^{396}$ Zur Erklärung des „Zuwachses“ wird man zunächst eine Eintragung von 1354 heranziehen, in der ic Wittenborch festhielt, dass er pauperibus $45 \mathrm{ml}$. und 14

\footnotetext{
${ }^{390}$ Erwähnt oben mit Anm. 119 u. 324: s. im übrigen MoLLwo S. 99 (Personenverzeichnis).

3.1) Handlungsbuch (wie Anm. 55) S. 22f., Nr. Il 106.

${ }^{392}$ Ebd. S. 23. Nr. II 108. In der 2. Zeile ist Poperse zu lesen, in der 3. weder leget; dahinter ist das Komma zu streichen.

${ }^{343}$ Nach MoLLwo S. LXXI mit Anm. 6 wären ,etwa $5 \%$ Gewinn“ erzielt worden. Er hat seine Rechnung nicht offengelegt; auch dieser Wert setzt aber jedenfalls voraus, dass der Verding richtig mit 8 Schilling lübisch veranschlagt ist, obwohl es eine ausdrückliche ÄuBerung über die „marca argenti“ zu $2 \mathrm{ml}$. und ilıre Teilung bei MOLLwo nicht gibt. BASTIAN hat 1, S. 222, Anm. 68 Mollwos Angabe unter der irrigen Voraussetzung zu korrigieren versucht, dass es sich beim „Ferting" um „1/4 Mark Feinsilber“ gehandelt hat.

${ }^{394}$ LUTTERBECK S. 441.

${ }^{395}$ In diese Zeit, aber offenbar nicht in diesen Zusammenhang gehören die Aufzeichnungen Handlungsbuch (wie Anm. 55) S. 24f., Nr. II 118/119. Hier ist, abgesehen von zwei Zeilen „Federprobe" ganz zum Schluss, die ganze Seite mit einer einzigen „Feder" (also abschriftlich) gefüllt worden mit Notizen über den finanziellen Ertrag des Verzapfens von 1] Fässern importierten Weins und über verschiedene Ausgaben, die Wittenborch aus dem Erlös bestritten hat; der „Berichtszeitraum“ reicht vom Ende eines Jahres bis zum Anfang des nächsten, das spätestens 1.354 gewesen sein muss, da Herr Johan Woltvogel noch als lebend erwähnt ist (er und ein gewisser Gise van Munster waren bei diesem Geschäft Wittenborchs Partner). Unter diesen Ausgaben (von denen mehrere doppelt notiert sind) erscheinen auch vier Zahlungen zugunsten der Jakobikirche, zusammen 46,25 $\mathrm{ml}$. in Gold. Mit dem Geschäft hatten diese Zahlungen aber wohl nur das eine zu tun, dass sie der Einfachheit halber aus dem größten Barbestand bestritten worden sind, den Wittenborch damals in der Hand hatte.

${ }^{396}$ Handlungsbuch (wie Anm. 55) S. 23, Nr. II 112
} 
Lübecker Gulden sculdich sei, zusammen also $53,75 \mathrm{ml}$. in Gold, ${ }^{397}$ das Stichwort kennen wir ja schon aus Herrn Johans „Bekenntnis" von 1358. Hierzu gibt es, in drei „Schüben“, Vermerke über Abzahlungsvorgänge im Wert von $15 \mathrm{ml}$. 2 Schilling 9 Pfennig; ${ }^{398}$ dadurch wurde diese Schuld auf $38 \mathrm{ml}$. 9 Schilling 3 Pfennig vermindert. Auch danach wird die Höhe des Gesamtbetrags - es bleiben ja immer noch $350 \mathrm{ml}$. und 9 Pfennige - aber nur verständlich, wenn man eine nicht ausdrücklich belegte Hilfsannahme einführt: ${ }^{399}$ Es muss unterstellt werden, dass der Kollege Woltvogel vor seinem Tod den größten Teil seiner Schulden bei St. Jakobi getilgt hat, und zwar durch Zahlung an Wittenborch; der kann dann allerdings nur einen kleinen Teil des empfangenen Geldes in die Kirchenkiste zurückgelegt haben. Denn eine weitere Buchung lautet: ${ }^{400}$ „Ich Wittenborch bin schuldig St. Jakob $348 \mathrm{ml}$. 10 Schilling. Als Herr Johan Woltvogel starb, da blieb er schuldig St. Jakob $41 \frac{1}{2} \mathrm{ml}$; davon hat sein Sohn $12 \frac{1}{2} \mathrm{ml}$. bezahlt, das ist in St. Jakobs Kiste gekommen“. Aufzeichnungen über weitere Rückzahlungen, sei es von Wittenborch, sei es von Woltvogels Sohn, sind im „Handlungsbuch" nicht zu finden. Albrecht Woltvogel, Herrn Johans Sohn, ${ }^{401}$ hatte 1356 noch recht engen Kontakt zu Wittenborch. Er war damals in Flandern und hat dort gemeinsam mit einem gewissen Lubbrecht Knop mit der Valuta eines Wechsels, den Herr Johan Wittenborch in Lübeck gekauft hatte, für diesen Brügger Laken erworben. ${ }^{402}$ Mit einem Denkelbrief vom 22. Mai hatte er Herrn Johan Witten-

${ }^{397}$ Ebd. S. 25, Nr. II 125. Die ersten beiden Zeilen sind Abschrift der Eintragung Nr. II 121, die dadurch sicherlich ersetzt werden sollte. Die letzten drei Worte der 5. Zeile und alles Weitere behandeln einen anderen Sachverhalt, der eine eigene Artikel-Nummer hätte bekommen müssen.

${ }^{398}$ Hier kommt dann auch das 2 . Stichwort von 1358 , to almissen, gleich zweimal vor. Wo die Rückzahlung lateinisch notient ist, heißt es immer persolvit; gemeint ist offensichtlich ,persolvi" = hebe ic bitalet .

${ }^{399}$ Ich halte es nicht für wahrscheinlich, dass Wittenborch in der Zwischenzeit noch weitere größere Beträge aus der Kirchenkasse entliehen hat, ohne darüber Aufzeichnungen zu machen. Aus seinen Notizen kennen wir nur noch eine weitere Anleihe, die er sich ut sunte Jacoppes budele genehmigt hat, 24 lübische Gulden (=15 ml. in Gold) im Jahre 1356: Handlungsbuch (wie Anm. 55) S. 29, Nr. II 156; ,sunde“ ist natürlich Druckfehler. Die kurze Eintragung ist (waagerecht) gestrichen, und ich sehe keine Indizien dafür, dass der Betrag nicht bald zurückgezahlt worden ist. Überdies hat Herr Johan im gleichen Jahr der Jakobikasse 26 lübische Gulden geliehen: Handlungsbuch (wie Anm. 55) S. 28, Nr. II 149; statt "do" ist to zu lesen. Zwischen den beiden Eintragungen gibt es aber keine enge zeitliche Nähe; sie stammen nicht von derselben „Feder".

${ }^{4(1)}$ Ebd. S. 23, Nr. Il 113.

${ }^{401}$ Er trug denselben Taufnamen wie sein Großvater und der Bruder seines Vaters (LUTTERBECK S. 441). Im „Handlungsbuch“ lassen sich Onkel und Neffe ohne genauere Untersuchung meist nicht sicher scheiden, so dass bereits MOLLwo S. 99 die beiden in einem Registereintrag zusammengefasst hat.

+102 Handlungsbuch (wie Anm. 55) S. 33, Nr. II 198. 
borch, seinem Onkel Albrecht Woltvogel und dem Johan Meteler ${ }^{403}$ für die Zeit seiner Abwesenheit umfassende Handlungsvollmacht erteilt. ${ }^{404}$ Aber in dem Testament, das er krank am 27. Oktober 1360 gemacht hat, ${ }^{405}$ sind weder Beziehungen zur Jakobikirche noch zu Johan Wittenborch erkennbar. $^{406}$

Wittenborchs Schuld hat am 15. August 1358 also weiterhin fast 350 ml. betragen. ${ }^{407}$ Von dieser Sachlage müsste eigentlich auch noch der uns nicht bekannte - Lübecker Ratmann Kenntnis bekommen haben, der 1354 vom Rat zum Nachfolger von Herrn Johan Woltvogel als zweiter Provisor der Jakobikirche bestimmt worden ist. Oder muss man etwa damit rechnen, dass ein solcher nachbenannter, nicht geschäftsführender Provisor gar nicht in die finanziellen Verhältnisse seines Aufgabengebiets eingeweiht $\mathrm{zu}$ werden brauchte? ${ }^{408}$ Auch nach dem „Sterben“ von 1358 hat Herr Johan Wittenborch allem Anschein nach von seinen Schulden bei der Jakobikasse nichts abgetragen, ${ }^{409}$ und da wir beobachten konnten, wie wenig er bis 1358 geneigt gewesen war, von dem Geld der Kirche irgendetwas zu seinen Lebzeiten aus den Händen zu lassen, so werden wir kaum anzunehmen haben, dass sich daran bis 1362 irgendetwas geändert haben könnte. Allein daraus, dass in seinem Testament vom März 1362 nicht einmal andeutungsweise von finanziellen Verpflichtungen gegenüber der Jakobikirche die Rede ist, werden wir gewiss nicht schließen müssen, dass er seine Schulden zwischen Ende 1358 und Anfang 1362 bezahlt hat. Andererseits würde ich daraus aber auch nicht folgern wollen, dass Herr

\footnotetext{
403 Über ihn oben mit Anm. 345f. u. 372-374.

${ }^{404}$ Handlungsbuch (wie Anm. 55) S. 92, Nr. VI 6.

${ }^{4115}$ Reg. Test. (wie Anm. 93) 2, Nr. 847 (S. 247f.).

${ }^{4(k 6}$ Auch der Onkel kommt nicht vor. Johan Metler, jetzt Ratmann, steht aber unter den drei Testamentsvollstreckern an erster Stelle.

${ }^{407}$ Zum Vergleich: Die Summe aller 165 Spenden für die Jakobikirche, die in den erhaltenen Testamenten des Zeitraums 1350-1366 dokumentiert sind, beträgt $528 \mathrm{ml}$.: NOODT, Religion und Familie (wie Anm. 160), S. 180 u. 192.

${ }^{408}$ Dass es gar keinen Nachfolger gegeben hat, wird man kaum annehmen wollen, auch nicht deshalb, weil Herr Johan Woltvogel, als er 1350 zum ersten Mal als Jakobi-Provisor auftrat, ohne einen Kollegen tätig war (s. schon oben Anm. 254).

${ }^{409}$ Alle drei Eintragungen sind zwar in derselben Weise wie andere, normale Geschäftsbuchungen in ihrer Umgebung gestrichen, mit sauberen Kreuz- und Querstrichen. Dies ist die Form, die auch im Niederstadtbuch ,zur Löschung eines Schulden-Eintrags“ angewandt wurde; angehende Notare haben offenbar diese Form des „,cancellare oder delere“ schulmäßig gelernt: Jürgen REETZ, Über das Lübecker Niederstadtbuch, in: ZVLGA 35, 1955, S. 34-56, hier S. 51 mit Anm. 116. Im vorliegenden Fall bedeutet die Löschung aber wohl kaum, dass die vorgesehenen Zahlungen geleistet worden sind, sondern nur, dass die Eintragungen nicht mehr als Zusätze zum Testament gelten sollten, nachdem Herr Johan auch das "Sterben" von 1358 unbeschadet überstanden hatte. Mindestens für die Verfügung zugunsten seiner Tochter im Johanniskloster lässt sich das beweisen; denn noch dreieinhalb Jahre später waren für sie erst $6 \mathrm{ml}$. Rente sichergestellt, wie wir aus des Vaters Testament vom 14. März 1362 erfahren: Handlungsbuch (wie Anm. 55) S. 89, Nr. VI 3.
} 
Johan, als er 1362 sein Testament errichtete, beschlossen hatte, das Geld der Kirche überhaupt nicht mehr zurückzugeben. Aber es war wohl nach zehn Jahren nicht mehr leicht, es zu tun, ohne Aufsehen zu erregen; die Sache muss ja um so delikater geworden sein, je länger sie unerledigt gelegen hatte. Ein "öffentliches" Testament war keinesfalls der richtige Platz, so etwas zu regeln. Der Anschein wird allerdings schon 1363 wie heute gegen ihn gezeugt haben.

Gegen die Annahme, dass Wittenborch seinen Verpflichtungen vor März 1362 oder überhaupt zu seinen Lebzeiten nachgekommen sein könnte, spricht auch, dass seine Witwe mit ihren Provisoren und Kindern zu einem unbekannten Zeitpunkt vor Ratsdeputierten auf eine Rente von 18 ml. - mit einem Kapitalwert von 360 ml.? - verzichtet hat. ${ }^{4 i \prime \prime}$ Da kein Grund besteht, sich den Bürgermeister Johan Wittenborch und seine Familie am Anfang der 1360er Jahre als besonders reiche Leute vorzustellen, ${ }^{411}$ dürfte diese Verminderung des zinsbringenden Vermögens für die Witwe mit ihren sechs Kindern einen fühlbaren Verlust dargestellt haben. Aber ins Bodenlose sind sie dadurch ganz gewiss nicht gefallen. Dass sie in Lübeck weiterhin gute Freunde hatten, auch solche, die für uns zu Herrn Johans Lebzeiten noch gar nicht sichtbar geworden waren, zeigt ein Vorgang vom 3. April 1364. Damals wurde durch Eintragung ins Niederstadtbuch beurkundet, ${ }^{412}$ dass Elizabeth, die Witwe des Herrn Johan Wittenborch, durch ihre Vormünder und auch für ihre Kinder von Herrn Segebode Krispin ${ }^{413}$ die Hälfte einer Rente von $35 \mathrm{ml}$. im Dorf Groß-Sarau

\footnotetext{
${ }^{+10}$ Handlungsbuch (wie Anm. 55) S. 73, Anm. 4 zu Nr. IV 25. Vgl. Mollwo S. VIII.

11 Es würde sehr viel Platz kosten, diese Auffassung detailliert zu begründen, ohne dass einigermaßen genaue Ergebnisse zu erwarten wären: Der Umfang des Geschäftskapitals lässt sich überhaupt nicht ermitteln, für den Rentenbesitz wäre nur ein Höchstwert anzugeben. der deutlich niedriger wäre als der Betrag, den sein Vater gegen Ende seines Lebens wirklich hatte (oben mit Anm. 114), und nur der Hausbesitz lässt sich im Anschluss an Herrn Johans Testament von 1362 zwar bestimmen (vier Häuser als Fahrhabe, von denen er ein kleines noch kurz vor seinem Tod veräußert hat, und das Wohnhaus), aber nicht bewerten. Mit Sicherheit sind aber die Vorstellungen falsch, die MoLLwo erweckt hat, als er von ,gewaltige[r] Ausdehnung“ des Geschäfts sprach (S. III), Herrn Johan ,im Besitz eines bedeutenden Vermögens, das er in Immobilien anlegte", sah (S. VIII) und die immer wieder nachgeschriebene Zahl von $6776 \mathrm{ml}$. nannte. die sein ,Umsatz“auf Kredit ,in den Jahren 1357 und 1358 " betragen habe (S. LXIX).

${ }^{412}$ UB. Stadt Lüb. 4, Nr. 92 (S.91). Bloßer Hinweis auf den Druckort (der Inhalt nicht einmal angedeutet): Handlungsbuch (wie Anm. 55) S. 86, Nr. V 84. Neuerer Druck: NStB 1363-1399 (wie Anm. 289), S. 26, 3 (S. 47f.).

${ }^{413}$ LUTTERBECK Nr. 83 (S. 248-250): Im Rat 1349-1388; seine Schwester (nicht Tochter, wie bei LUTTERBECK S. 425 versehentlich angegeben) Alheid war mit Herrn Wedeke van Warendorpe verheiratet, in dessen Testament vom 4. Oktober 1350 (Reg. Test. (wie Anm. 93) 1. Nr. 406, S. 209f.) Herr Segebode unter den Testamentsvollstreckern an 3. Stelle erscheint, vor Herrn Johan Wittenborch. Durch diese Heirat ist Herr Segebode ebenfalls zu einem Mitglied der oben mit Anm. 190-210 behandelten Warendorp-Sippschaft und damit auch zu
} 
gekauft habe. Da es sich um einen Zehnprozenter handelte, kann man davon ausgehen, dass der Verkauf eine Gefälligkeit dargestellt hat. Die Eintragung ist durch die drei anwesenden Vormünder veranlasst worden; der erste war dominus Seghebodo predictus. Der zweite Provisor war Brun Warendorp. Sohn des Herrn Godschalk, der Bürgermeister und „Kriegsheld" des 2. Waldemarskriegs, ${ }^{414}$ der als Vertrauter der Witwe erstmals schon am 21. September 1363 sichtbar geworden war; denn als erster der drei damaligen Provisoren des „verstorbenen Herrn Johan Wittenborch“415 vertrat er tatsächlich ja die Interessen von Herrn Johans Hinterbliebenen. 1367 treffen wir ihn unter den Testamentsvollstreckern der Witwe an erster Stelle an. ${ }^{416}$ Ihr dritter Provisor war 1364 Herrn Johans alter Geschäftsfreund Johan Laurencii, der im „Handlungsbuch“ erstmals 1351 mit der Namensform Henneke Laurencius belegt ist ${ }^{417}$ und 1363 ebenfalls zu den Provisoren des verstorbenen Herrn Johan gehört hatte. Auch ihn hat die Witwe 1367 erneut bemüht; in Telses Testament ist er gleich hinter Herrn Brun und noch vor ihrem Bruder Arnold Bardewich aufgeführt. Von den drei Provisoren des Jahres 1364 hat keiner zu den sechs (!) Männern gehört, die Herr Johan selbst 1362 als seine Testamentsvollstrecker benannt hatte. ${ }^{418}$

Abschließend sei hier noch ausdrücklich festgestellt: Es gibt nirgends auch nur das kleinste Indiz dafür, dass die beiden ratsherrlichen Darlehensnehmer des Jahres 1352 jemals erwogen hätten, der Jakobikirche das Geld zu vergüten, ${ }^{419}$ sei es auch nur mit dem auf dem Lübecker Rentenmarkt seit den späten 1340er Jahren wieder meist üblichen Fünf-ProzentSatz; ${ }^{420}$ hätten sie sich anders verhalten, dann hätten sie ja auch, wenigstens in der Sicht mancher Moraltheologen der Zeit, eine Sünde begangen. $^{421}$

einem Verwandten der Familie Wittenborch geworden. Diese Verwandtschaft war allerdings eine sehr entfernte, und zwar wohl nicht erst für unsere Begriffe: Weder in Herrn Johans Testament von 1362 noch in dem seiner Witwe von 1367 kommt Herr Segebode vor.

${ }^{414}$ Näheres über seine Karriere von der Wahl in den Rat 1366 bis zu seinem frühen Tod in Schonen 1369 siehe unten mit Anm. 588-593.

+15 Siehe oben Anm. 289.

${ }^{416}$ Handlungsbuch (wie Anm. 55) S. 90f., Nr. VI 4.

${ }^{417}$ Ebd. S. 20. Nr. II 85.

${ }^{418}$ Handlungsbuch (wie Anm. 55) S. 90, Nr. VI 3.

${ }^{419}$ Daran könnte denken, wer bei CORDES, Gesellschaftshandel (wie Anm. 72), S. 213, Anm. 32 den folgenden Satz liest: „Das Engagement für St. Jacobi hat Hermann seinem Sohn Johann vererbt, der später das Geld der Gemeinde verwaltet und in Widerlegungen und Sendegutgeschäften anlegt (Mollwo 1901. S. 22f. Nr. 105 u. 106)“".

${ }^{420}$ VON BRANDT, Rentenmarkt (wie Anm. 100), S. 20, und PETERS, Sterben (wie Anm. 176), S. 56, für 1350-1358.

${ }^{421}$ Nach Odd LANGHOLM, The legacy of scholasticism in economic thought. Antecedents of choice and power, Cambridge 1998, S. 68, hat sich im Rahmen einer breiteren Diskussion 
6. Herrn Johan Wittenborchs Verfehlungen und die Herrschaftslegitimation des Lübecker oligarchischen Ratsregiments. Die Verwaltung der Kirchenvermögen als Konfliktfeld zwischen Bürgeropposition und Rat

Modern gesprochen, muss man wohl konstatieren, dass Herr Johan Wittenborch schwere Untreue ${ }^{422}$ bzw. Unterschlagung ${ }^{423} \mathrm{im} \mathrm{Amt}^{424}$ begangen hat, obwohl sich nicht beweisen lässt, dass er irgendwann beschlossen hat, das eigenmächtig geliehene Geld nie mehr zurückzugeben ${ }^{425}$. Auch wenn es alle diese Rechtsbegriffe damals noch nicht gegeben hat, ${ }^{426}$ darf man doch annehmen, dass damaliges Rechtsempfinden dem heutigen näher gestanden hat, als man nach der Verschiedenheit der Deliktsterminologie denken würde. ${ }^{427}$ Und so ist es wohl auch erlaubt zu unterstellen, dass die überwältigende Mehrzahl der Menschen schon im 14. Jahrhundert wenig geneigt war, Nachsicht gegenüber einem Politiker zu üben, der nicht nur in seinem Amt versagt hatte, sondern auch einen großen Betrag an anvertrautem Geld seinem Geschäftskapital einverleibt hatte. Ich meine, dieser Befund reicht aus verständlich zu machen, wieso der Lübecker Rat einen solchen Mann aus dem Wege räumen wollte, ohne einer breiten Öffent-

über die Frage, ob sündige. wer Zinsen bezahle. im frühen 14. Jh. ein Theologe namens Durand von Saint-Pourçain dahin ausgesprochen. dass ein Kaufmann ,sins if he has enough on which to live adequately from other sources and. motivated solely by avarice. borrows money at usury in the hope of investing it profitably and thus accumulating superfluous wealth"; dieser Analyse habe im 15. Jh. der oben bereits erwähnte Hl. Antoninus von Florenz. zugestimmt.

${ }^{422}$ Zur Geschichte des Delikts St. Chr. SAAR, „Untreue“, Handwörterbuch zur deutschen Rechtsgeschichte Bd. 5, Berlin 1998, Sp. 546-550.

${ }^{423}$ K. LIEBERWIRTH, „Unterschlagung", ebd. Sp. 522-526.

${ }^{124}$ DERS., „Amtsvergehen (Amtsverbrechen)“, ebd. Bd. 1, Berlin 1971, Sp. 157f. Der Artikel ist praktisch unverändert auch in die „2., völlig überarbeitete und erweiterte Auflage“ des „Handwörterbuchs" eingegangen: Rolf LIEBERWIRTH, „Amtsvergehen, Amtsverbrechen", [Bd. 1], Berlin 2004 ff., Sp. 221-223 (1. Lieferung).

${ }^{425}$ Mindestens der moderne „Untreue“-Begriff setzt dies auch gar nicht voraus. So wurde Ende 2000 in Frankfurt am Main ein Polizeibeamter, der für die Gerichtskasse Geld entgegenzunehmen zu hatte, ,wegen Verwahrungsbruchs und Untreue“ zu einem Jahr Haft verurteilt, weil er ,in mindestens 25 Fällen ihm anvertrautes Geld in einer Höhe von mehr als 24000 Mark bis zu eineinhalb Jahre lang nicht abgeliefert hatte". Das Gericht nahm an, er habe das Geld verwendet, „um jeweils finanzielle Löcher zu stopfen“, statt es „unverzüglich weiter zu leiten": Frankfurter Rundschau vom 5.12.2000. S. 26.

${ }^{426}$ Dementsprechend ist die Literatur zur Geschichte des mittelalterlichen Strafrechts auch für unser Thema wenig ergiebig, so weit sie sich vor allem mit der Vorgeschichte moderner Straftatbestände befasst.

${ }^{427}$ So hat etwa schon Wilhelm EBEL, Der Bürgereid als Geltungsgrund und Gestaltungsprinzip des deutschen mittelalterlichen Stadtrechts, Weimar 1958, S. 153 mit Anm. 58, darauf hingewiesen, dass von den „todeswürdigen Straftatbestände[n]“ „besonders der Diebstahlsbegriff ... eine kasuistische Erweiterung durch Einbeziehung ... verschiedener Unterschlagungstatbestände" erfahren hat, und es wird unten mit Anm. 494 eine Kontroverse von 1420/2 I dazustellen sein, der m. E. zum modernen Untreuetatbestand nur der Begriff fehlt. 
lichkeit zu erklären, warum. Schließlich waren derartige Vorkommnisse ja geeignet, das Vertrauen der Bürger in den Rat und damit dessen Herrschaftslegitimation zu erschüttern.

Denn so autoritär und oligarchisch die Herrschaft des sich selbst ergänzenden Lübecker Rats im 14. Jahrhundert auch erscheinen mag: ${ }^{428}$ Das Lübecker politische System der Zeit war bekanntlich nur nach seinem äußerlichen Erscheinungsbild ,in ruhigen Verhältnissen“ eindeutig so beschaffen. In wichtigen Fragen hat der Rat des Spätmittelalters und der frühen Neuzeit den Bürgern so gut wie nie die beratende, Einvernehmen anstrebende Mitwirkung an seinen Entscheidungen versagt; ob man dahinter nur vernünftige Einsicht des Rats in die Grundbedingungen seiner Herrschaft zu sehen hat, oder ob es einen - auch vom Rat nicht bestrittenen - Rechtsanspruch der Bürger auf Mitwirkung gab, kann und muss hier dahingestellt bleiben. ${ }^{429}$ Grundsätzlich hat es sich bei der Herrschaft

${ }^{228}$ Vor engstem, borniertestem Geschlechtertum bewahrte ihn wohl vor allem die Regel, dass Vater nicht mit Sohn und Bruder nicht mit Bruder gleichzeitig im Rat sitzen durften (EBEL. Lübisches Recht, wie Anm. 91, S. 229). Damit blieb auch mehr Platz für reiche Einwanderer und Aufsteiger aus der Stadt. die berücksichtigt werden konnten, wenn sie erkennen ließen, dass sie sich in das politische System nahtlos einfügen würden. Diese "offene Stelle" ist daher auch von den Sympathisanten dieses Systems immer wieder hervorgehoben und ausführlich behandelt worden. So hat noch Erich HOFFMANN, Hoch- und Spätmittelalter (wie Anm. 70) im Anschluss an die Behandlung des Zeitraums 1403-1416 die „Frage des „Patriziats““ diskutiert und dabei (S. 261) den Begriff der „Oligarchie“ auf den von der Bürgeropposition monierten speziellen Missstand eingegrenzt, dass die wesentlichen Entscheidungen nicht vom ganzen Rat getroffen wurden, sondern von fünf oder sechs Leuten aus dem Rat.

${ }^{429}$ Dies Wissen reicht weit ins 19. Jh. zurück. Als „klassische“ Darstellung des Themas galt lange C. WEHRMANN, Die obrigkeitliche Stellung des Raths in Lübeck, in: HGBll. Jg. 1884 (1885), S. 5I-73, hier S. 60): „Freiwillig musste der Gehorsam geleistet werden, ihn wider den Willen der Bürger zu erzwingen, wäre auf die Dauer unmöglich gewesen“. Eine ausführliche Darstellung des Gegenstands für die Jh.e vom 14. bis zum 17. findet man bei Jürgen ASCH. Rat und Bürgerschaft in Lübeck 1598-1669. Die verfassungsrechtlichen Auseinandersetzungen im 17. Jahrhundert und ihre sozialen Hintergründe (Veröffentlichungen zur Geschichte der Hansestadt Lübeck 17), Lübeck 1961, S. 45-54. Der Verfasser hat geradezu von einem „Mitentscheidungsrecht" der „Gemeinde" gesprochen und eingehend die Bereiche - neue Steuern, Krieg, wichtige Bündnisse - besprochen, für die es regelmäßig galt. Dabei hat ASCH aber wohl nicht an einen formellen Rechtsanspruch gedacht. Zum Ratsregiment und seinen Grenzen jetzt grundlegend EBEL, Lübisches Recht (wie Anm. 91), besonders S. 291 ff. (das wörtliche Zitat im Text S. 304). Die Ansicht, dass die Bürger einen Rechtsanspruch auf Berücksichtigung ihrer Vorstellungen und Forderungen in wichtigen Sachen gehabt hätten, der durch die Vorsteher der Handwerksämter und der "Meinheit" (magistri officiorum mechanicorum ac universitatis) ausgeubt worden sei, hat neuerdings mit großer Beredsamkeit vertreten Ernst PITZ, Bürgereinung und Städteeinung. Studien zur Verfassungsgeschichte der Hansestädte und der deutschen Hanse (Quellen und Darstellungen zur hansischen Geschichte N.F. 52). Köln usw. 2001, S. 65-76 (im Kapitel „Autonome Gemeinde und vollmächtiger Rat (") und DERS., Verfassungsgeschichtliche Forschungen, in: Konzeptionelle Ansätze der Hanse-Historiographie, hg. von Eckhard MÜLLER-MERTENS u. Heidelore BÖCKER (Hansische Studien 14), Trier 2003, S. 141-154, besonders S. 143-152. PITZ 
des „lübischen“ Rats um illegitime Herrschaft gehandelt. „Das Regiment des Rates (ruhte), genau genommen, auf usurpierter Macht, die, von wirtschaftlichen und sozialen Faktoren getragen und von den Bürgern hingenommen, nur so lange einen vom Rat zielbewusst gepflegten Rechtscharakter besaß, als sie nicht gewaltsam in Frage gestellt wurde".430 Den nachdenklicheren Mitgliedern des Rats muss immer klar gewesen sein, dass diese Herrschaft, die anders als vergleichbare moderne Herrschaften über so gut wie keine eigenen ständigen Mittel gewaltsamer Machtausübung verfügt hat, auf die Zustimmung der waffenfähigen Bürgerschaft angewiesen war. Diese Zustimmung und die darauf gegründete Bereitschaft der Herrschaftsunterworfenen, dem Rat „Gehorsam“ zu erweisen, beruhte natürlich auf der Überzeugung der Bürger, dass der Rat nur tat, was dem Wohl der Bürger nützte. Die Spannung zwischen unbedingtem Herrschaftsanspruch des Rats und bedingter Gehorsamsbereitschaft der Bürger wird wohl nirgendwo so deutlich wie im folgenden Satz aus dem Artikel-Grundbestand der ältesten, vor 1350/51 niedergeschriebenen Lübecker Bursprake: ${ }^{431}$ „Wir danken allen unseren Bürgern, dass sie uns horsam unde bequeme gewesen sind, und wenn diese Herren viel Gutes getan haben, das unseren Bürgern nützlich gewesen ist, das haben sie gern getan“. Dies wurde den Bürgern Jahr für Jahr verlesen, am 22. Februar,

stützt sich dafür auf Texte von 1340, die an der römischen Kurie in einem Rechtsstreit zwischen dem Hamburger Rat und dem Hamburger Domkapitel von den Ratsvertretern verwendet werden sollten. Eine seit langem bekannte, relativ knappe Version erscheint als urkundenförmiges Zeugnis des Lübecker Rats für das Bestehen solcher Verhältnisse in Hamburg (Druck und Übersetzung a.a.O. S. 144f.); am Ende des Kontextes steht ein Satz, den man dahin deuten kann. dass derartige Verhältnisse auch in Lübeck und den benachbarten Städten geherrscht haben. Ob dieser Text, der auch nach PITz` Ansicht Hamburger „Empfängerdiktat“ ist, als Basis für so bestimmte Aussagen über die politische „Verfassung" der Stadt Lübeck ausreicht? Zwar hat auch EBEL a.a.O. S. 293 den Text als grundsätzlich zutreffende Beschreibung der „Praxis“ „in den lübischen Städten“ akzeptiert und nur Übertreibung "gefälligkeitshalber" angenommen. wo ein "Zwang zum consensus" behauptet wird. Allerdings hat sich erst ein paar Jahre nach dem Erscheinen von EBEl.S Werk herausgestellt. dass der Text wahrscheinlich im Prozess nicht vorgelegt und vielleicht auch gar nicht vom Lübecker Rat besiegelt worden ist: Rat und Domkapitel von Hamburg um die Mitte des 14. Jahrhunderts. Teil 2. Das Prozess-Schriftgut aus den Streitigkeiten des Hamburger Rates und einzelner Bürger mit dem Domkapitel 1336 bis 1356. Bearbeitet von Jürgen REETZ (Veröffentlichungen aus dem Staatsarchiv der Freien und Hansestadt Hamburg 9,2), Hamburg 1975, S. 155, Anm. 12 zu S. 146.

${ }^{430)}$ EBEL a.a.O. S. 305.

${ }^{431}$ UB. Stadt Lüb. 6, Nr. 783. hier S. 760, 3. Absatz. Zur Datierung der hier erst zu „vor 1421 "gedruckten Handschrift (,wohl aus den 1340er Jahren. jedenfalls vor 1350/51") s. Gustav KORLÉN, Zur Datierung der ältesten Lübecker Bursprake, in ZVLGA 39, 1959. S. 117-121. Für Inhalt und Wortlaut des Satzes bietet diese Datierung natürlich nur einen Terminus ad quem. In speziellerem Zusammenhang bin ich auf diesen Text auch schon früher ganz kurz eingegangen: STEFKE, „Goldwährung“ (wie Anm. 150), S. 58. 
dem letzten Tag des Rats-Geschäftsjahrs. ${ }^{432}$ Der Text stellt wohl gleichzeitig den ältesten ausdrücklichen Beleg dafür dar, dass der Lübecker Rat von den Bürgern „Gehorsam“ erwartet hat. ${ }^{433}$ Wie die Bürgerschaft in

${ }^{432}$ Anschließend wurde den Bürgern noch mitgeteilt, durch welche drei seiner Mitglieder der Rat jetzt für das neue Geschäftsjahr umgesetzt werden würde: zum Verfahren, vor allem nach diesem Text. Friedrich BRUNS, Der Lübecker Rat. Zusammensetzung, Ergänzung und Geschäftsführung von den Anfängen bis ins 19. Jahrhundert, in: ZVLGA 32, 1951, S. 1-69. hier S. 29 mit Anm. 85.

${ }^{433}$ EBEL, Lübisches Recht (wie Anm. 91), S. 287 hat die zitierte Formulierung, ohne auf die Zeitstellung der Bursprake oder auf sonstige Details einzugehen, bloB als ,verschleiert[e]" Version des Gebots, „dem Rate gehorsam zu sein“, gewertet. Das hat sicherlich damit zu tun, dass er seit seinem Buch über den Bürgereid (oben Anm. 427) ohne zeitliche Differenzierung die Ansicht vertreten hat, das Versprechen von "Treue und [!] Gehorsam gegenüber dem Rat" hätten einen zentralen Inhalt des Bürgereids dargestellt. Dass ihm dabei nicht ganz wohl war, zeigen besonders seine Ausführungen Bürgereid S. 37f.: Das Nebeneinander von Treue und Gehorsam berge „von Haus aus etwas Verschiedenes, ja Widerspruchsvolles in sich“, es gebe „einige wenige Eide, die lediglich die Treupflicht enthalten“. weshalb aber „nicht gesagt werden (könne), dass die Ireue, als das ältere und ursprünglichere, schon der Zeit unentwickelter Ratsherrschaft angehörige Element des Bürgerschwurs, in jedem Eid und immer vorkäme, der Gehorsam hingegen nur als jüngerer Zusatz neben ihr". Anders ausgedrückt: EBEL, der sein Thema systematisch angegangen ist, hat es mindestens für sehr gut möglich gehalten, dass eine entwicklungsgeschichtliche Betrachtung des Forderungspaars zu der Einsicht führen könnte, die Gehorsamsforderung sei ein ,jüngerer Zusatz“ aus einer Zeit „entwickelter Ratsherrschaft". So weit ich sehe, steht eine derartige Studie bis heute aus, überlokal wie speziell für Lübeck. Nach den Quellen zu urteilen, stammt das früheste Indiz dafür, dass es in einem Lübecker Bürgereid eine Selbstverpflichtung zum Gehorsam gegen den Rat gegeben hat, erst aus einem Bericht über die Verhandlungen zwischen Rat und Bürgern, die Ende 1403 stattgefunden haben. Damals soll ein Vertreter der Handwerksmeister, nachdem deren Gleichstellung mit den übrigen Bürgern durch Abschaffung von diskriminierenden besonderen Eiden erreicht war, erklärt haben, die Handwerksämter wollten dem Rate allike gerne truwe, holt und horsam sein (Chron. Lüb. (wie Anm. 231) 2, S. 384). Ob damit nur der abgeschaffte besondere Eid oder auch der allgemeine Bürgereid zitiert ist. lässt sich nicht sagen, da weder der eine noch der andere im Wortlaut überliefert ist (dass es sich um die „übliche Verpflichtung" gehandelt hat, wie Wilfried EHBRECHT, Bürgertum und Obrigkeit in den hansischen Städten des Spätmittelalters, in: Die Stadt am Ausgang des Mittelalters. Hg. von Wilhelm RAUSCH (Beiträge zur Geschichte der Städte Mitteleuropas 3), Linz/Donau 1974. S. 275-294, hier S. 278 mit Anm. 36 meinte, geht aus dem Bericht nicht hervor). Auch ist ungewiss, seit wann die Verpflichtung zum Gehorsam wenigstens in einem Eid der Handwerker enthalten gewesen ist. In dem ältesten überlieferten, wahrscheinlich 1380 situationsbezogen entstandenen Text steht nichts davon: UB. Stadt Lüb. 4, Nr. 447 (S. 494, 2. Text; ich datiere mit VON BRANDT, Knochenhaueraufstände, wie Anm. 140, S. 188 mit Anm. 43). Wenn ich nichts Entscheidendes übersehen habe, ist der Wortlaut eines „normalen“ besonderen Eids der Amtsmeister mit Gehorsamsverpflichtung (truwe und holt und horsam wesen) erst in dem Schiedsspruch vom 15. Juni 1416 enthalten, der die Voraussetzungen für die friedliche Wiederherstellung des, ,alten" Ratsregiments formuliert hat (UB. Stadt Lüb. 5. Nr. 583, S. 641-653, hier S. 644f.; HR I, 6, Nr. 270, S. 240, herausgelöst aus ebd. Nr. 268, § 5, S. 235); dieser Wortlaut muss natürlich nicht erst damals entstanden sein. Vermutlich ist die Selbstverpflichtung spätestens 1416 auch zum Bestandteil des allgemeinen Bürgereids geworden, da an anderer Stelle desselben Schiedsspruchs die Verhinderung von unhorsam als zentrales Ziel jährlich wiederholter Selbstverwillkürung aller Bürger im Schosseid genannt ist (UB. Stadt Lüb. 5, S. 645; HR I, 6. S. 235, § 8; vgl. EBEL, Lübisches Recht, S. 249 und 302). 
Lübeck zusammengesetzt war, reichte notfalls auch die Unterstützung der Kaufleute, wenn im Laufe eines Konflikts, der sich allmählich auf eine gewaltsame Auseinandersetzung zu bewegte, klar wurde, dass die Kaufmannschaft (im weitesten Sinn des Begriffs) geschlossen auf der Seite des Rats stehen würde. ${ }^{434}$ So haben sich die Verhältnisse 1380 entwickelt. ${ }^{435}$

${ }^{4.34}$ Die große Mehrzahl der selbständigen Fernkaufleute mit Bürgerrecht und eigenem Haushalt kann gewiss als die in jeder Beziehung verlässliche Personenbasis der Ratsherrschaft angesehen werden. Für diese Gruppe dürfte auch gelten. was VON BRANDT, Knochenhaueraufstände (wie Anm. 140), S. 135, vermutet hat: ,dass die Kaufmannschaft sich nach allem, was wir wissen, sehr viel stärker als eine (sozial, rechtlich und wirtschaftlich) einheitliche Schicht fühlte. als das für die Gesamtheit der [Handwerks-] Ämter anzunehmen ist". Allerdings war der Personenkreis mit wahrscheinlich nicht mehr als etwa 500 Männern (dazu unten mit Anm. 522) nicht allzu groß, wenn man ihn mit den ,etwa 4500 erwachsenen. männlichen Haushaltungsvorstände|n]" vergleicht, mit denen VON BRANDT a.a.O. S. 127 mit Anm. 15 für das späte 14. Jh. gerechnet hat. Wenn es um militärisches Droh- und Kampfpotential ging, mag dieser Kreis mindestens noch einmal so viele gut gerüstete Kämpfer aus waffenfähigen Söhnen und sonstigen männlichen Abhängigen in Haus und Geschäft haben aufbieten können. Andererseits ist aber mit diesen etwa 500 Fernkaufleuten, die ihr Geschäft hauptsächlich vom Lübecker Kontor aus getrieben haben, der Kreis der in Lübeck beheimateten Kaufleute keineswegs erschöpft. Denn VON BRANDT a.a.O. S. 128 wollte unter den .,rund 2500 Kaufleuten, die die Lübecker Pfundzollquellen von 1368 nennen“, „,bei vorsichtigster Kalkulation“ „mindestens 1200-1300“ Lübecker erkennen. Dann hätte es damals allermindestens 700-800 „Gelegenheitshändler“ und „Kaufgesellen“ gegeben. Die werden in einer Konfliktsituation gewiss nicht alle bedingungslos für die Sache des Rats, der Großkaufleute und ihres Anhangs zu den Waffen gegriffen haben. Diese Gruppe war nicht nur in Lübeck zahlreich; Wilhelm KOPPE, Das Stockholmer Testament eines deutschen Kaufgesellen. Mit Bemerkungen über die hansische Kaufmannschaft, in: ZVLGA 34, 1954, S. 37-44. hier S. 37, hat allein schon die Kaufgesellen, ,die im 13. und 14. Jh. zwischen den Städten an der deutschen Küste und Schweden Handel getrieben haben“, mit „einigen Hunderten“" veranschlagt. Allerdings werden die meisten von ihnen in ,ihrer" Stadt vom Frühjahr bis zum Herbst nicht zuhaus gewesen sein. Wie die Kräfteverhältnisse bei Konflikten in den Städten waren, wenn es auf gewaltsame Auseinandersetzung hinauslief, das hing also auch davon ab, zu welcher Jahreszeit der Streit stattfand. In Lübeck gab es weiterhin nach VON BRANDT a.a.O. S. 129f. „knapp 400“ Männer des „Mittelstands“, die als Einzelhändler. Schiffer, Brauer usw. tätig waren. Dass davon „mindestens zwei Drittel“ „dem Kautmannsstand ... nahe" gestanden haben, besagt natürlich nicht, dass sie ohne weiteres zur Klientel der Fernkaufleute gerechnet werden müssen. Bei den sog. „Verlehnten“, formal selbständigen Arbeitern, die in der Stadt und im Hafen hauptsächlich Hilfsdienste, insbesondere Transporte, für die Kaufleute leisteten (VON BRANDT a.a.O. S. 131 mit Anm. 31), mag das anders ausgesehen haben. Ihre Zahl hat VON BRANDT a.a.O. S. 134 mit ,mindestens 500“ angesetzt. Sieht man einmal von Lohnabhängigen außerhalb der Handwerksämter ab. über deren Menge sich so gut wie nichts sagen lässt, dann stehen dem bisher behandelten, sicherlich nur sehr begrenzt homogenen Personenkreis von etwa 210()$-2200$ beruflich selbständigen Männern des Handels im weitesten Sinn etwa 1350 Handwerksmeister gegenüber (VON BRANDT a.a.O. S. 130-134); sie hätten im Fall eines zu Gewaltanwendung hindrängenden politischen Streits vermutlich noch annähernd eben so viele - allerdings nur mangelhaft bewaffnete - Knechte aufbieten können. Wenn es in Lübeck im ausgehenden 14. Jh. in einem inneren Konflikt zwischen dem Rat und den Ämtern einmal zu allgemeiner Mobilisierung aller Waffenfühigen gekommen wäre, dann wären die Kräfte zahlenmäßig ziemlich ausgeglichen gewesen, wenn es dem Rat gelang. alle Männer des Handels in dem hier vertretenen weiten Sinn für seine Sache auf den Plan zu bringen. Praktisch wären die - überwiegend wohl besser gerüsteten - 
Aber der Rat, der durch seine Personen ja nur einen kleinen Teil der Kaufleute an sich gebunden hat, konnte sich durchaus nicht darauf verlassen, dass ein Konflikt immer so verlaufen würde.

Die ersten einigermaßen deutlich fassbaren und zuverlässig dokumentierten Auseinandersetzungen zwischen dem Lübecker Rat und einer Bürgeropposition haben Ende 1374 stattgefunden. ${ }^{436}$ Es hat sich zwar nicht um reine „Handwerkerunruhen" gehandelt. Der organisierte und - wie Ehbrecht gezeigt hat, in der Zeit nicht als illegitim angesehene - Widerstand gegen den Rat $^{437}$ könnte aber in den Handwerksämtern entstanden sein. Der weitere Verlauf zeigt, dass es auch in Lübeck nicht empfehlenswert war, sich ohne Not, und bevor sich der Rat versichert hatte, dass alle Kaufleute wirklich hinter ihm stehen würden, auf einen scharfen Konflikt mit den Handwerkern einzulassen, der sich zu einem uplop entwickeln ${ }^{438}$ und mit einem Waffengang enden konnte. Die in ihren Ämtern organisierten Handwerksmeister erscheinen als die Speerspitze der Opposition. Diese wird überhaupt erst durch eine von den Ämtern am 3. Dezember eingereichte, original überlieferte Petition sichtbar. ${ }^{439}$ Aber für das, was die

Ratsanhänger sehr wahrscheinlich überlegen gewesen.

${ }^{435}$ In der Wertung der erzählenden Quellen und damit auch in der Chronologie folge ich den überzeugenden Darlegungen von vON BRANDT a.a.O. S. 181-190 (anders EHBRECHT. Bürgertum und Obrigkeit, wie Anm. 433, S. 277 mit Anm. 26). Es war sicherlich die Lehre von 1380. die Hinrik Paternostermaker und seine Freunde veranlasst hat, 1384 ihr Glück mit der geheimen Planung eines Putsches zu versuchen und dabei nicht einmal das Bündnis mit Angehörigen des holsteinischen Adels zu scheuen.

${ }^{4.36} \mathrm{Vgl}$. VON BRANDT ebd. S. 179-181. Die Analyse ist (nur) hier aber erstaunlich mangelhaft, angefangen bei der Bereitschaft, die Datierung der Vorgänge auf 1376 durch Detmar wieder ernsthaft in Betracht zu ziehen, obwohl der zu 1376 ein Tagesdatum mitgeteilt hat, das keinesfalls zu diesem Jahr gehören kann, s. unten mit Anm. 442. Die frühere Datierung "1374" hat ohne weiteres schon zwei Jahre nach dem Erscheinen des Aufsatzes AsCH, Rat und Bürgerschaft (wie Anm. 429), S. 47 mit Anm. 54 wieder vertreten. Dasselbe hat dann, ausführlich argumentierend, ein gutes Dutzend Jahre später EHBRECHT. Bürgertum und Obrigkeit (wie Anm. 433). S. 28I f. getan. Auch HofFMANN, Hoch- und Spätmittelalter (wie Anm. 70), S. 243f., der EHBRECHTS Aufsatz nicht zitiert hat, ist stillschweigend zu „1374" zurückgekehrt.

${ }^{437}$ EHBRECHT a.a.O. S. 276f. Im Grundsatz hat dies aber auch schon Wilhelm EBEL nicht anders gesehen, wie seine oben mit Anm. 430 wörtlich zitierte Äußerung zu den Grundlagen der Ratsherrschaft zeigt.

${ }^{438}$ EBEL, Lübisches Recht (wie Anm. 91), S. 249. hat den Beschluss des Hansetages vom Sommer 1417, der erstmals uplop maken ... jegen den rad generell und „überall“ mit der Todesstrafe bedroht hat, umfassend interpretiert als "die Gemeinde gegen den Rat zusammenrufen und Aufruhr [!] stiften"; die Quellenangabe dazu muss lauten HR I, 6. Nr. 397, § 106 (S. 385) bzw. (,Statuten") Nr. 398. § I (S. 388; auch hier ist sicherlich die Todesstrafe gemeint, obwohl sie nicht ausdrücklich erwähnt wird).

${ }^{4.39}$ UB. Stadt Lüb. 4. S. 357, Anm. 1 zu Nr. 326; gut lesbare Abbildung der Handschrift bei vON BRANDT a.a.O., Abb. 2 vor S. 177. der den Text S. 180f. auch interpretiert. allerdings völlig verkannt hat, dass sich hinter ,bittender, fast demütiger Form“ eine ausgesprochen drohende Haltung nur notdürftig verbirgt; sie wird deutlich in dem Hinweis auf die schon 
Ämter vor allem verlangt haben, machten sie vollkommen überzeugend das Interesse der „Ämter und der ganzen Meinheit“ geltend. Sie verlangten, de groten nyen matten rückgängig zu machen. Bei dieser finanzpolitischen Maßnahme handelte es sich um eine fühlbare Erhöhung der Abgabe vom Mahlen des Getreides; da die „Matte“ als prozentualer Anteil am Mahlgut erhoben wurde, hatte sie eine kopfsteuerähnliche Wirkung. Die Erhöhung traf alle Bürger, die einen eigenen Haushalt und eine Familie hatten, und zwar umso stärker, je geringer das Einkommen und je größer die Zahl der Angehörigen ohne eigenes Einkommen waren. Davon war gewiss nicht nur die große Masse der Handwerksmeister betroffen, sondern auch ein erheblicher Teil der Kaufleute, die ja beileibe nicht alle "Großkaufleute“ waren. Erst an zweiter Stelle forderten die menen ammete, „das Geld, das ihr von den Ämtern nehmt", mit Ausnahme des „rechten Schoss“ abzuschaffen; denn die neringhe, die Konjunktur, sei schlecht. Nach Detmar hat es sich bei dem „Geld", offenbar einer Sondersteuer, um eine Mark lübisch pro Meister gehandelt. ${ }^{440}$ Nur aus Detmars Bericht kennen wir den Fortgang der Ereignisse: ${ }^{441}$ Am 8. Dezember $^{442}$ versammelte sich die „Meinheit“" (nur von ihr ist noch die Rede) im Katharinenkloster der Franziskaner zu erfolgreichen Verhandlungen mit den Bürgermeistern; bereits am 10. bekam die Opposition die Nachricht, dass der Rat ihre Forderungen bewilligt hatte. Wir dürfen mit großer Bestimmtheit vermuten, dass zu der opponierenden „Meinheit“" auch ein groBer Teil der Kaufmannschaft gehört hat. Deshalb erscheint es auch nicht

erwiesene und künftige militärische Leistungsbereitschaft der Ämter und in dem Verlangen nach sofortiger Antwort. EHBRECHT, Bürgertum und Obrigkeit (wie Anm. 433), S. 282 mit Anm. 123, ist in dieser Frage vON BRANDT gefolgt. Das Missverständnis kann bis zu WEHRMANN, Rat (wie Anm. 429), S. 59f. zurückverfolgt werden. den dieselben Formulierungen zu dem Satz inspiriert haben: „In dem Gehorsam gegen den Rat fand der Gemeinsinn seinen natürlichen Ausdruck".

${ }^{+41)}$ Chron. Lüb. 1 (wie Anm. 231), S. 557, § 776 (überarbeitete Fassung) und Chron. Lüb. 2 (wie Anm. 231), S. 254, § 776 (ursprüngliche Fassung, in der sog. Rufus-Chronik). Ob Detmar dies Geld zu Recht „Vorschoss“ genannt hat. muss dahingestellt bleiben. J. HARTWIG, Der Lübecker Schoss bis zur Reformationszeit (Staats- und socialwissenschaftliche Forschungen, hg. von Gustav Schmoller, Bd. 26, 1 = Heft 100), Leipzig 1903, S. 104 mit Anm. 4 und S. 114 hat die Angabe nicht in Frage gestellt; ich würde sie lieber als den einzigen inhaltlichen „Beitrag" werten. den der Mönch seiner offenbar hochkompetenten, aber keine Jahreszahlen nennenden schriftlichen Vorlage über die Vorgänge von 1374/75 hinzugefïigt hat. - Dass die neuen Ahgahen ,die Be[zieher] kleinerer Finkommen ungleich härter" getroffen hätten, sah bereits EHBRECHT, Bürgertum und Obrigkeit (wie Anm. 433), S. 279.

${ }^{441}$ Chron. Lüb. I (wie Anm. 231), S. 557, $\$ 777$ und Chron. Lüb. 2 (wie Anm. 231), S. 254, $\S 777$.

42 Die Tagesangabe bei Detmar, ,am Tage Mariae Empfängnis, einem Freitag“, stellt sicher, dass seine eigene Jahresangabe „1376" falsch und „1374" richtig ist, siehe KoPPMANN ebd. S. 557, Anm. 4. Vgl. dazu bereits oben mit Anm. 436. 
weiter auffällig, dass zu einem Fest der Versöhnung mit dem „ganzen Rat", das am nächsten 22. Juni stattfand, nicht die Älterleute der Handwerksämter eingeladen haben, sondern ,die Hauptleute der Meinheit". ${ }^{443}$ Der Rat hatte sich mit seinem unüberlegten Versuch, die große Mehrheit der Bürger mit zusätzlichen Abgaben zu belasten und damit die wirklich Reichen zu schonen, ${ }^{44}$ eine gründliche Niederlage zugezogen. ${ }^{445}$ Sein schnelles Nachgeben hat ihn wohl davor bewahrt, sich bereits damals mit Fragen nach der Seriosität seines Ausgabeverhaltens und mit Forderungen nach Einschränkungen seiner „Vollmacht“ auseinandersetzen zu müssen. Eine Erleichterung der allgemeinen Steuerlast ist 1374 offenbar nicht gefordert worden, und es hat sie anscheinend auch nicht gegeben. ${ }^{446}$

${ }^{+43}$ Chron. Lüb. 1 (wie Anm. 231), S. 560, $\$ 786$ und Chron. Lüb. 2 (wie Anm. 231), S. 255, $\$ 786, \mathrm{zu}, 1377^{\circ}$.

${ }^{244}$ Auffallenderweise scheint in der einschlägigen Lübeck-Literatur noch nie erörtert worden zu sein, unter welchen Umständen ein Rat, dem jedes politische Gespür in sulchen Dingen abgegangen sein muss, beschlossen haben mag, die Erhöhung der städtischen Einnahmen mit diesen Mitteln anzustreben. Das will nicht zu dem Ruf hohen politischen Geschicks passen, den der Lübecker Rat der Zeit um 1370 im allgemeinen genießt. Dabei ist allerdings zu beachten, dass dieser Ruf so gut wie ausschließlich auf der Untersuchung und Würdigung seiner Leistungen auf dem Gebiet der "Außen"- und Hansepolitik beruht (siehe dazu etwa die glänzende Studie von Ahasver v. BRANDT, Der Stralsunder Friede. Verhandlungsablauf und Vertragswerk 1369-1376. Eine diplomatische Studie, in: HGBll. 88, 1970, S. 123-147). Wenn diese nun von einer sehr kleinen Gruppe aus dem Rat getragen wurde (wie sich bereits für das Jahrzehnt seit dem Ausgang der 1350er Jahre zeigen lässt, s. dazu unten mit Anm. 546ff.), dann stellt sich natürlich die Frage, ob nicht für andere Sachgebiete, etwa die Finanzpolitik, Entsprechendes gegolten haben könnte; solche kleinen Gruppen müssen sich ja nicht immer durch besondere Kompetenz ausgezeichnet haben. Man muss allerdings gleich hinzufügen, dass diese Frage weitgehend .,akademisch“ ist, weil die Quellenlage es kaum jemals erlaubt. andere Felder der Lübecker Ratspolitik so (relativ) genau zu crfassen wie die "große" und hansische Politik.

45 Allenfalls könnte man schon hier mit Rhyman A. ROTZ. The Lubeck Uprising of 1408 and the Decline of the Hanseatic League. in: Proceedings of the American Philosophical Society 121, 1977, S. 1-45, hier S. 37, von einer „taxpayers' revolt“ sprechen, wenn man im Auge behält. dass es sich 1374 ,nur“ um die große Mehrzahl der Steuer- und Abgabenpflichtigen gehandelt hat. In Lübeck waren bekanntlich alle Bürger mit Ausnahme der allerärmsten Steuerzahler, vor dem 16. Jh. auch die Ratmannen (HARTwIG, Schoss, wie Anm. 440, S. 58), wenn auch, wie alle reichen Leute, mit Zahlungsmodalitäten, die die Frage nach ihrer Steuerehrlichkeit zugleich aufwerfen und die Beantwortung unmöglich machen.

${ }^{446}$ Nach einer Aufzeichnung von 1376 betrug damals "das rechte Schoss", die tallia, vier Pfennige von der ma, also 1/96: UB. Stadt Lüb. 4, Nr. 326 (S. 357); vgl. dazu HARTwIG a.a.O. S. 105 und 112. Dass hier nur der Ertrag von acht Handwerksämtern verzeichnet ist, berechtigt natürlich nicht zu der Aussage. „die Schoßleistungen der Ämter zeigten ... auch 1376 noch eine ungewöhnliche Höhe" (VON BRANDT, Knochenhaueraufstände, wie Anm. 140, Anm. 10 zu S. 180, übernommen von EHBRECHT, Bürgertum und Obrigkeit, wie Anm. 433, S. 282; noch vergröbert HOFFMANN, Hoch- und Spätmittelalter, wie Anm. 70. S. 244: „war nachweislich der Schoss des Jahres 1376 wieder für die Mitglieder der Handwerksämter besonders hoch angesetzt"). Tatsächlich haben die ca. 582 Meister, um die es hier geht, im Durchschnitt $0,83 \mathrm{ml}$. bezahlt. also weniger als das, was 1374 zusätzlich zum ,rechten Schoss" verlangt worden war, und es gibt (schon in Ermanglung einschlägiger Quellen) 
Wie damals, so war Streit natürlich immer vor allem dann zu erwarten, wenn die materiellen Interessen zahlreicher Bürger berührt waren. Die Auseinandersetzungen der Jahre 1403 bis 1408, über die wir ungewöhnlich gut, und zwar auch durch Schriftstücke der damaligen Opposition, informiert sind, ${ }^{447}$ zeigen dies deutlich. Darüber hinaus wird hier auch über allen Zweifel klar, dass die Erregung besonders stark und breit wurde, wenn Forderungen des Rats nach vergrößerten Leistungen der Bürger bei diesen auf den Verdacht trafen, dass der erhöhte Finanzbedarf der Stadt dadurch zustande gekommen war, dass Mitglieder des Rats öffentliche Mittel verschwendet oder sich gar an ihnen persönlich bereichert hatten. Dieser Kern verschwindet zwar manchmal fast in der Masse der Detailbeschwerden und Einzelforderungen, von denen vermutlich manche überhaupt nur formuliert worden sind, um - im Rahmen einer ,Ermattungsstrategie“ der Opposition - den Rat zu einer Zersplitterung seiner Abwehrkräfte zu zwingen. Aber wo man Anlass hatte, sich auf die wesentlichen, auch Außenstehende überzeugenden Punkte zu konzentrieren, da wird schnell deutlich, dass der Verdacht, Angehörige des Ratsregiments könnten ihre amtlichen Positionen zu privater Bereicherung missbraucht haben, einen Schwerpunkt der Vorwürfe gegen das Amtsgebaren des ,,alten" Rats dargestellt hat. Es verwundert daher nicht, dass der Rat mit „schwerem Geschütz“ geantwortet und 1407 das erklärte Misstrauen der Bürger gegen die Sauberkeit seiner Finanzverwaltung als ruchlosen Angriff auf den guten Ruf der Stadt zu diskreditieren versucht hat; er verlangte, die Bürger müssten sodanen unloven schlichtweg fallen lassen. ${ }^{448}$

keinerlei Anlass zu vermuten, dass für die übrigen Schosspflichtigen (über deren Steuerleistung wir nicht das Geringste wissen) ein niedrigerer Satz gegolten hat.

477 Jedoch gibt es bis heute keine angemessene, ausführliche Darstellung der Vorgänge. Erich HofFMAnN. Hoch- und Spätmittelalter (wie Anm. 70), S. 819 zu S. 248, hat gewiss recht, dass man ,immer noch die klarste Darstellung der Fakten der Auseinandersetzung“ finde bei C. WeHRmanN, Der Aufstand in Lübeck bis zur Rückkehr des Alten Raths 1408-1416, in: HGBll. 1878 (1879), S. 101-156. Allerdings handelt es sich zugleich um eine Parteischrift für den Alten Rat, aus der man keinen Satz unüberprüft übernehmen darf; vgl. dazu bereits Reinhard BARTH. Argumentation und Selbstverständnis der Bürgeropposition in städtischen Auseinandersetzungen des Spätmittelalters. Lübeck 1403-1408 - Braunschweig 1374-1376 - Mainz 1444-1446 - Köln 1396-1400 (Kollektive Einstellungen und sozialer Wandel im Spätmittelalter 3), Köln. Wien 1974, S. 27; hier S. 28f. auch das Nötige zu dem. was PITL, Schrift- und Aktenwesen (wie Anm. 243), S. 291-298, zur Deutung der Vorgänge beigesteuert hat. Wie BARTH, so konzentriert sich auch ROTZ, Uprising (wie Anm. 445), auf sein - am Titel allerdings nicht erkennbares - Spezialthema. die prosopographische Untersuchung der an den Auseinandersetzungen Beteiligten. Nichts Neues brachte natürlich auch Ernst DAENELL, Die Blütezeit der deutschen Hanse. Hansische Geschichte von der zweiten Hälfte des XIV. bis zum letzten Viertel des XV. Jahrhunderts. Bd. 1-2. Berlin 1905-1906, 3. Auflage [Reprint] mit einem Vorwort von Horst WERNICKE, Berlin, New York 2001, der die Geschichte Lübecks zwischen 1403 und 1418 in Band 1 im Bereich der Seiten 163-193 mitbehandelt hat (nicht in 2, 157-197, wie bei HOFFMANN a.a.O. angegeben). 
Besonders klar wird das weiter in einem Text, den der „neue“" Rat, wohl 1409, nach Dänemark geschickt hat, um das Handeln der Bürgeropposition gegen den ,,alten“ Rat und dessen Mitglieder zu rechtfertigen. ${ }^{449} \mathrm{Be}$ reits die Überschrift stellt die materiellen Aspekte des Schadens in den Vordergrund, den die Lübecker van deme regimente des rades crlitten haben. Der Verdacht, dass es Unterschleif gegeben hatte, wurde zu drei Bereichen geäußert und mit Indizien belegt: ${ }^{450}$ Bei Münze und Wechsel, beim Schossertrag und bei der Kämmerei. Auch die Höhe der jährlichen Gesamteinnahmen sei etwa $5000 \mathrm{ml}$. höher gewesen als angegeben. In die Kritik sind auch die als „Gotteshäuser“ bezeichneten Spitäler, Heiligengeist und St. Jürgen, einbezogen worden. Die Untersuchungen ergaben: „Die Spitäler sind so nachlässig verwaltet worden, dass ihnen ihr Geld und Gut verloren gegangen ist, und die Bürger können keinerlei Informationen darüber bekommen, wo es geblieben ist" ${ }^{451}$ Die Forderung der Bürger,

${ }^{48}$ Chron. Lüb. 2 (wie Anm. 231), S. 412, Nr. 13, 11 am Ende; eine glättende Nacherzählung, die die Schärfe der Auseinandersetzung nicht mehr erkennen lässt, bei WEHRMANN, Aufstand (wie Anm. 447), S. 108. Auch DAENELL a.a.O. 1, S. 163f., hat von dieser Passage gerade so viel wörtlich zitiert, dass der Leser nicht auf den Gedanken kommen kann, es könnte hier um das Vertrauen in die Finanzverwaltung des Rates gegangen sein. In dieser Quelle gibt es auch den ersten Beleg für die Aussage, dass Lübeck en hovet is der hensestede. Es handelt sich um eine Ratsformulierung; die Aussage gehört hier zu dem Bemühen des Rats, die Merkmale seiner bisherigen Herrschaftsform zum konstituierenden Bestandteil des Ansehens der Stadt zu erklären. Wenn man Abwandlungen dieser Formel wenig später in Texten findet, als deren Urheber andere erscheinen. etwa der Hildesheimer Rat oder die Älterleute des Brügger Kontors (WEHRMANN a.a.O. S. 117 u. 122), dann darf man dahinter gewiss die unermüdlichen Propagandisten des Alten Rats als Inspiratoren suchen. - Misstrauen gegenüber der Uneigennützigkeit einer städtischen Finanzverwaltung, die sich für die Bürger als völlig undurchschaubar darstellte, war natürlich nicht auf Lübeck oder Norddeutschland beschränkı. So sieht Valentin GROEBNER, Ungestalten. Die visuelle Kultur der Gewalt im Mittelalter, München. Wien 2003. S. 48, neben dem ..Vorwurf der Manipulation althergebrachter Gesetze" den Vorwurf "der Unterschlagung und Misswirtschaft in den (ebenfalls geheimen) städtischen Finanzen im Zentrum der meisten städtischen Aufstände und Unruhen im Mittelalter". Das eröffnete unter Umständen Angehörigen der Führungsschicht die Möglichkeit, Missliebige in den eigenen Reihen dadurch auszuschalten, dass man ihnen zu Unrecht oder mit zweifelhaftem Recht einschlägige Verfehlungen vorwarf. So hat Gerhard FouqueT, Die Affäre Niklas Muffel. Die Hinrichtung eines Nürnberger Patriziers im Jahre 1469, in: VSWG 83, 1996. S. 459-500, den von ihm untersuchten Fall bewertet; auf S. 464f. hat der Verfasser weitere oberdeutsche Fälle des späten 15. Jh.s zusammengestellt, die er ähnlich zu beurteilen geneigt ist. Einen weiteren Fall dieser Art, in dem der Beschuldigte mit einer Geldstrafe und dem Ausscheiden aus allen Ämtern davonkam, hat kürzlich Matthias STEInBrink, Ulrich Meltinger. Ein Basler Kaufmann am Ende des 15. Jahrhunderts (VSWG Beihefte 197), Stuttgart 2007, in Verbindung mit der Edition von Meltingers „Geschäftsbuch" behandelt.

449 UB. Stadt Lüb. 5, Nr. 188, S. 183-186.

${ }^{450}$ Mehr war nicht möglich, weil es, so weit wir wissen, niemals und nirgends Untersuchungen zum Amtsgebaren der Inhaber der Ratsämter gegeben hat. - Das Folgende nach ebd. S. $185 \mathrm{f}$.

${ }^{+51}$ In der Wiedergabe dieses Schriftstücks durch WEHRMANN a.a.O. S. 114 kommt nicht nur 
Rechnungslegung nicht nur von den beiden Spitälern, sondern auch van allen kerken zu erhalten, war bereits 1407 erhoben und vom Rat zugestanden worden. ${ }^{452}$ Aus den überlieferten Quellen wird nicht ersichtlich, warum wir später von den Pfarrkirchen und vom Johanniskloster nichts mehr hören. Wir werden aber wohl kaum e silentio folgern dürfen, dass die dortigen Verhältnisse untersucht worden sind, aber nicht zu Beanstandungen Anlass gegeben haben.

Die eben referierte Diskussion aus dem ersten Jahrzehnt des 15. Jahrhunderts macht deutlich, dass nur ausgeprägt formalistisches Denken zu dem Einfall führen konnte, bei der Darstellung der spätmittelalterlichen Lübecker Ratsverwaltung ,bedürf[t]en die Ratsmannen, die zu Provisoren der geistlichen Institute bestellt waren“, „keiner weiteren Erwähnung“, weil sie „,nur eine Kontrolle über nichtstädtische Verwaltungen (führten) ${ }^{\text {“. }}{ }^{453}$ Die Wirtschaftsverwaltung der Lübecker Hospitäler, die, wie eben erwähnt, den „Gotteshäusern“ zugerechnet wurden. der vier Pfarrkirchen und auch des St. Johannis-Frauenklosters war integraler Bestandteil der Ratsverwaltung. Sie erfolgte ebenso durch ein vom Rat ernanntes Kollegium von je zwei Ratmannen wie jedes andere Ratsamt. ${ }^{454}$ Und da zu den

all dies nicht vor; die Besprechung des Textes beginnt auch mit dem Satz: „Ungetreue Verwaltung wird darin dem alten Rath nicht vorgeworfen, nur politische Fehler werden ihm zur Last gelegt“. Rotz, Uprising (wie Anm. 445), S. 12 mit Anm. 36, hat dem Text (der hier irrig zu 1407 gestellt ist) immerhin entnommen, dass der Rat die genannten Bereiche „mismanaged“ hatte. Dass es u. a. um den Vorwurf der „Veruntreuung städtischer Gelder“" geht, hat auch Gudrun GLEBA. Die Gemeinde als alternatives Ordnungsmodell. Zur sozialen und politischen Differenzierung des Gemeindebegrifts in den innerstädtischen Auseinandersetzungen des 14. und 15. Jahrhunderts. Mainz, Magdeburg, München, Luibeck (Dissertationen zur mittelalterlichen Geschichte 7), Köln, Wien 1989, S. 234f., gesehen. - Wenn wirklich richtig ist, dass die Geldeinkommensverhältnisse der Spitäler am Ende ihrer Verwaltung durch Angehörige des ,alten" Rats undurchschaubar waren, dann müsste das Rentebuch des Heiligengeisthauses, das am 25. Januar 1411 in einer Niederstadtbucheintragung erwähnt wird (UB. Stadt Lüb. 5, Nr. 350, S. 379), als Produkt einer Reformmaßnahme des ,neuen“ Rats gedeutet werden. Dann würde es allerdings verwundern, dass sich eine so ratsnahe Einrichtung gleichzeitig des zu Unterschleif geradezu einladenden Instituts der Treuhänderschaft bedienen musste, um die Erwerbung einer städtischen Hausrente im Oberstadtbuch beurkundet zu bekommen.

${ }^{452}$ Chron. Lüb. 2 (wie Anm. 231), S. 410, Nr. 12, 13, und S. 413, Nr. 13, 15.

${ }^{453}$ PITZ, Schrift- und Aktenwesen (wie Anm. 243), S. 321. Es bedarf kaum der Erwähnung, dass der Autor die für das Thema bis heute grundlegenden scharfsinnigen und gründlichen Untersuchungen von Wilhelm SUHR, Dic Lübecker Kirche im Mittelalter. Ihre Verfassung und ihr Verhältnis zur Stadt (Veröffentlichungen zur Geschichte der Hansestadt Lübeck 13), Lübeck 1938, S. 80-110, nicht gelesen hatte. Die folgende Darstellung beruht auf SUHRS Ausführungen, wenn nichts Anderes angegeben ist.

${ }^{454}$ EBEL. Lübisches Recht (wie Anm. 91), S. 238. hat geradezu von „Ratsämter[n] für die Stadtkirchen und die Hospitäler" gesprochen. Bei Wolf-Dieter HAUSCHILD, Kirchengeschichte Lübecks. Christentum und Bürgertum in neun Jahrhunderten, Lübeck 1981, sind die Ratsprovisoren der vier Pfarrkirchen nur (S. 86) unter dem Gesichtspunkt „Eingriffe des Rats in das Kirchenwesen" ganz kurz behandelt worden. - Zum Thema vgl. auch ganz allgemein 
Merkmalen der Lübecker Ratsherrschaft auch ihr Zentralismus gehört hat, waren die in den Kirchspielen eingesessenen Bürger weder an der Bestimmung der Provisoren der Pfarrkirchen beteiligt, noch waren sie berechtigt, deren Arbeit zu kontrollieren. ${ }^{455}$ Die ratsherrlichen Provisoren mussten nicht einmal unbedingt Mitglieder der Pfarrgemeinde sein, in der sie über alle Angelegenheiten zu entscheiden hatten, die nicht spezifische geistliche Aufgabe des Pfarrers und der übrigen Priester an der Kirche waren. Die Kirchspiele konnten überdies im Bedarfsfall wohl mehr, als nach der Quellenlage heute noch erkennbar ist, auch zu Einheiten intensiver Kontrolle der Stadtregionen durch den Rat gemacht werden. ${ }^{456}$ Das alles war den Lübecker Bürgern natürlich zur Genüge bekannt. Und deshalb konnte das Ratsregiment nicht nur von der Zentrale her und ihren „Fachressorts“ seine Legitimation einbüßen, sondern ebenso von den Kirchspielen aus.

Dies sind die allgemeinen, strukturellen Merkmale. Der Beschäftigung mit Herrn Johan Wittenborch als - spätestens seit 1354 geschäftsführendem - Provisor der Jakobikirche verdanken wir nun einen Einblick in die Funktionsweise des Systems der Kirchenverwaltung durch Ratsprovisoren: Im zentralen Bereich des Umgangs mit den baren Mitteln der „Got-

Arnd ReITEMEIER, Pfarrkirchen in der Stadt des späten Mittelalters: Politik. Wirtschaft und Verwaltung (VSWG Beihefte 177), Stuttgart 2005. Allerdings geht es in der gründlichen Studie, einer Kieler Habilitationsschrift, in erster Linie um die Auswertung von Rechnungen, besonders der der beiden Pfarrkirchen von Wesel am Niederrhein aus dem 15. und frühen 16. Jh. Lübeck ist nur ganz beiläufig mitberücksichtigt, und nicht zu den hier interessierenden Themen.

${ }^{455}$ Auf die begrenzte Sonderstellung der Aegidienkirche (SUHR a.a.O. S. 91 f.) ist hier nicht einzugehen.

${ }^{45 h}$ Dafür gibt es anscheinend nur einen einzigen Beleg (UB. Stadt Lüb. 4, Nr. 623, S. 695f.): In einem offenbar formal unbeglaubigten Schriftstück vom 2. April 1395 haben Herr Hinrich Westhof, im Rat 1372-1408/1415 und Bürgermeister seit 1392 (LUTTERBECK Nr. 290, S. 429-431), und Herr Brun Warendorp (Wilhelms Sohn), im Rat 1367-1408/1411 (LUTTERBECK Nr. 278, S. 415-417) festgehalten oder festhalten lassen. dass sie als vormundere des kerspels to sunte Peter (also nicht nur der Pfarrkirche und ihrer Fabrik !) mit Erlaubnis des Rats in fünf Straßen je zwei genannte erlike lude als hovetlude eingesetzt haben. WEHRMANN, Rath (wie Anm. 429) S. 56, hat dies ohne weiteres dem Bereich ,,militärische Organisation" zugeordnet (er schrieb offenkundig - der ganze Aufsatz ist beleglos aus dem Gedächtnis und sprach daher von „1396“ und ,zwei Bürgermeister[n]“), und man darf wohl die Vermutung hinzufügen. dass es damals ebenso wenig um Widerstand gegen einen Versuch ging, dic Stadt von außen zu erobern, wie im April 1408, als die bürgerliche Opposition die Stadt in vier Teile geteilt hatte und up islick verendel hovetlude gesat hatte, um sicherzustellen, ,dass kein Auflauf in der Stadt werde"; anschließend haben die Bürger vom Rat für diese Hauptleute ,vier Banner" verlangt (Chron. Lüb. 2 (wie Anm. 231), S. 425). Das Ganze war offenbar als Konkurrenz zu den vier Kirchspielen in der Hand des Rats gemeint, und es überrascht nicht, dass dagegen besonders Herr Hinrick Westhoff gesprochen hat: „Die Stadt", d. h. der Rat, würde ..davon entrechtet". Der Text von 1.395 ist auch erwähnt bei SUHR a.a.O., S. 99 f., der daraus schloss, dass die Aufgabe der Kirchspiels„Vormünder" „die Aufrechterhaltung der Ordnung im Kirchspiel“" gewesen sei, und bei LUTTERBECK S. 47, der sich mit einer ganz kurzen Inhaltsangabe begnügt hat. 
teshäuser" war es ausgesprochen missbrauchsanfällig. ${ }^{457}$ Die Mängel des Systems, die von der Bürgeropposition des frühen 15. Jahrhunderts kritisiert worden sind, ließen sich hier bereits ein halbes Jahrhundert früher beobachten. Offensichtlich hat der Rat nicht das Geringste dafür getan, eigennützigem Handeln der Provisoren vorzubeugen. So weit unsere fragmentarische Kenntnis der Personen reicht, die diese Stellungen im 14. Jahrhundert bekleidet haben, ${ }^{458}$ war es, schon seit dem Beginn des Jahrhunderts, die Regel, dass die Ratmannen, denen einmal ein Amt übertragen war, es sehr lange behielten. Die sieben Amtsjahre, die sich für Herrn Johan aus seinen eigenen Aufzeichnungen nachweisen lassen, sind da nicht als ein besonders langer Zeitraum anzusehen. ${ }^{45}$ Dass die Kollegialität der Ämterbesetzung keinen wirksamen Schutz vor Unterschleif bot, wenn die Kollegen sich einig waren, die Kirchenmittel zu ihrem persönlichen Vorteil zu verwenden, zeigt sich am Zusammenwirken von Wittenborch und Woltvogel. Darüber hinaus dürfte es für den geschäftsführenden Provisor aber auch keinen Zwang gegeben haben, seinen Kollegen so an der Verwaltung des Amts zu beteiligen, dass dieser überhaupt eine Kontrollmöglichkeit besessen hätte. Endlich scheinen die Provisoren, die in ihrem unmittelbaren Tätigkeitsbereich niemandem rechenschaftspflichtig waren, auch nicht zu regelmäßiger Rechenschaftslegung vor dem Rat verpflichtet gewesen zu sein. Dass nicht ratsangehörige Zeitgenossen schon in den 1360er Jahren dies System für mangelhaft gehalten haben, lässt sich nur vermuten. Gut vier Jahrzehnte später gab es jedenfalls, wie erwähnt,

\footnotetext{
${ }^{457}$ In der beeindruckenden Masse von publizierten und ungedruckten Quellen, die SUHR a.a.O. sorgfăltig durchgearbeitet hat, fehlt das Wittenborchsche „Handlungsbuch“. Aus MOLLwOS Einleitung ist ja auch nicht ersichtlich, dass SUHR dort etwas für sein Thema Belangvolles hätte finden können.

${ }^{458}$ Besonders schlecht ist die Quellenlage für die Pfarrkirchen. Am besten sind wir informiert über das Johanniskloster und das Heiligengeistspital. Denn diese beiden „Gotteshäuser" haben auch noch während des 14. Jh.s viel Landgut erworben, und in den Urkunden, mit denen der Besitz übertragen wurde, war es üblich, die Provisoren als die Rechtsvertreter der beiden Institutionen namentlich zu nennen, mindestens in den Zeugenlisten. Es gibt nur einen Überblick über die Ratmannen, die im 14. Jh. Provisorenstellen (und überhaupt Ratsämter da ist die Lage nicht viel besser) bekleidet haben, bei LUTTERBECK S. 44-48; die Form alphabetisch, der jeweilige Kollege nicht erwähnt (so auch in den Ratmannen-Artikeln) - ist auffällig mangelhaft.

${ }^{459}$ Das älteste mir bekannte Beispiel sind die Herren Alvin Grope und Herman Mornewech als Provisoren oder procuratores des Johannisklosters. Als solche werden sie erstmals 1310 und 1311 genannt (UB. Stadt Lüb. 2, Nr. 255, S. 219, und Nr. 282, S. 241 f.; vgl. LUTTERBECK S. 264 mit Anm. 1734 und S. 310 mit Anm. 2204). Zuletzt kommen sie 1321 in einer Urkunde des Herzogs Erich I. von Sachsen-Lauenburg für das Kloster vor (UB. Stadt Lüb. 2, Nr. 415, S. 366); unter den fünf cives Lubicenses der Zeugenliste stehen Hermannus Mornewech, Alvinus Grope an 1. und 2. Stelle. gewiss, weil sie immer noch die Ratsprovisoren des Klosters waren. Noch länger hat vier Jahrzehnte später das gleich zu besprechende Gespann Herman van Wickede und Bertram Vorrad am Heiligengeistspital amtiert.
} 
einiges Misstrauen. Was man damals für veränderungsbedürftig hielt, zeigen die Neuerungen, die der ,neue" Rat seit 1408 in der Verwaltung der Kirchenfabriken vorgenommen hat; wir kennen sie dank eines „Rechnungsbuche[s] der St. Petri-Kirche", von dem Auszüge aus den Jahren 1411-1414 gedruckt vorliegen: ${ }^{460}$ Der Kreis der Provisoren, dessen Zusammensetzung öfters geändert wurde, ist durch Bürger auf mindestens vier erweitert worden, es fanden in kürzeren Abständen Abrechnungen statt, und es gab eine institutionalisierte, allerdings anscheinend nicht sehr detaillierte Buchführung.

Dass die Mängel des alten Systems ${ }^{461}$ immer wieder die Sicherheit des Geldvermögens der so verwalteten geistlichen Institute bedroht haben müssen, zeigt ein zweiter Fall aus den frühen 1360er Jahren. Ein paar Monate, bevor der „Fall Wittenborch“ frühestens zum Fall geworden sein kann, scheint man im Lübecker Rat auf eine vergleichbare Problemlage oder wenigstens auf Ansätze dazu beim hier schon oft erwähnten, damals ältesten Bürgermeister Herman van Wickede in seiner Funktion als langjährigem Provisor des Heiligengeistspitals ${ }^{462}$ gestoßen zu sein. Denn nach dem 10. April und vor dem 1. Mai 1362 wurde, doch wohl auf Veranlassung des Rats, folgendes im Niederstadtbuch eingetragen: ${ }^{463}$ „Herr Herman van Wickede hat bekannt, dass er dem Heiligengeisthaus in Lübeck $500 \mathrm{ml}$. schuldet. Dafür hat er dem Haus aufgelassen $28 \mathrm{ml}$. jährlicher Rente von jenen 30 m Rente, die er im Dorf Mechow hat, jede m für $20 \mathrm{~m}$ zurückzukaufen, wie es die diese Rente behandelnde Urkunde näher ausweist, die dem Herrn Bertram Vorraad ${ }^{464}$ vom genannten Herrn Herman übergeben worden ist". Die beiden Herren hatten das Provisorenamt seit 1350 gemeinsam bekleidet; ${ }^{465}$ aus dem letzten Detail darf man vielleicht

${ }^{460}$ UB. Stadt Lüb. 6, Nr. 798 (S. 779f.); dazu SUHR, Lübecker Kirche (wie Anm. 453), S. 91 mit Anm. 579f. Ich finde die Rechnung bei ReITEMEIER, Pfarrkirchen (wie Anm. 454), nicht erwähnt.

${ }^{461} \mathrm{Ob}$ es seit 1416 in vollem Umfang wiederhergestellt worden ist, lässt sich beim derzeitigen Forschungsstand nicht sagen.

${ }_{462}$ Über ihn besonders oben mit Anm. 266. Nach LUTTERBECK S. 432 war er ,seit 1350 Vorsteher des HI.-Geist-Hospitals", dafür in Anm. 3508 zahlreiche (nicht alle möglichen) Belege, die insgesamt dicht genug sind, dass man annehmen darf, Herr Herman habe das Amt bis 1364 Sept. 2 (UB. Stadt Lüb., Bd. 3, Nr. 501, S. 531) ohne Unterbrechung bekleidet.

${ }^{46.3}$ Druck: Mecklenburgisches Urkundenbuch 15, Nr. 902.5 (S. 177), erwähnt bei LUTTERBECK S. 433 (vgl. S. 137, unter .Vermögenslage und Ratsmitgliedschaft").

tht Über ihn besonders oben mit Anm. 267 u. 286. Nach LUTTERBECK S. 403 ,seit 1333 Vorsteher des Hl.-Geist-Hospitals", dafür in Anm. 3214 zahlreiche Belege, zuletzt UB. Stadt Lüb. 4, Nr. 261 (S. 279) von 1375 Aug. 1, für deren Interpretation seit 1350 dasselbe gilt. was zu Herman van Wickede gesagt ist; bis dahin ist die Belegfolge allerdings so dünn, dass man nicht ohne Bedenken behaupten wird. Herr Bertram habe das Amt mehr als vier Jahrzehnte lang ununterbrochen bekleidet.

${ }^{46.5}$ Dabei erscheint Bertram Vorrad immer an 2. Stelle, auch dann noch, als er selbst eben- 
schließen, dass jetzt die Geschäftsführung, die bisher Herr Herman in der Hand gehabt hatte, an Herrn Bertram übertragen worden ist. Etwa anderthalb Jahre später (und nach Herrn Johan Wittenborchs Tod) könnten sich die Verhältnisse am Heiligengeistspital so weit geklärt haben, dass Herr Herman wieder über seine Rente verfügen durfte, obwohl er bis dahin seinen Verpflichtungen noch nicht einmal buchhaltungstechnisch nachgekommen war. Denn unter dem Datum des 22. November 1363 liest man im Niederstadtbuch folgendes ${ }^{466}$ : „Herr Herman van Wickede schuldet dem Heiligengeisthaus $500 \mathrm{ml}$., über die er Herrn Bertram Vorraad für das genannte Haus Rechnung legen wird ${ }^{6467}$. Mehr geben die veröffentlichten Quellen für diesen Fall nicht her. ${ }^{468}$ Insbesondere fehlt jedes Indiz dafür, dass Herr Herman im Gefolge dieser kleinen Affäre (die außerhalb des Rats sicherlich nicht bekannt geworden ist), irgendwelchen Einschränkungen seiner amtlichen Tätigkeit unterworfen worden wäre.

Aber es scheint doch, dass damals eine maßgebende Gruppe im Lübecker Rat durch diese beiden Vorkommnisse beunruhigt war. Es könnte sogar sein, dass damals eine systematische Suche nach Sachverhalten angestellt worden ist, die man als unrechtmäßige oder übermäßige Selbstbereicherung im städtischen Dienst werten konnte. Denn es hat noch einen weiteren Fall gegeben, in dem von einem Angehörigen des Ratsregiments ein großer Betrag an den Rat abgetreten worden ist; ${ }^{469}$ nach den ganzen Umständen ist das sicherlich nicht aus freien Stücken geschehen. Es handelte sich um eine Rente von jährlich $30 \mathrm{ml}$, für $480 \mathrm{ml}$. zurückzukaufen, die am 29. September 1362 beim Kieler Rat erworben worden war. Die Verzichtleistung fand am 19. September 1363 statt, also zwei Tage, bevor Herrn Johan Wittenborchs Tod erstmals aktenkundig geworden ist. In diesem 3. Fall ging es aber nicht um ein Mitglied des Rats, sondern um einen hochqualifizierten Bediensteten, den derzeitigen 2. Protonotar Meister Martin van Golnowe. Er war im Begriff, den Lübecker Dienst zu verlassen, in den er 1350 als ,einfacher" Ratsschreiber eingetreten war. Aller-

falls Bürgermeister und vielleicht (oder doch nicht ?) geschäftsführender Provisor war. Diese Konstellation ist zuletzt zum 2. September 1364 belegt.

${ }^{466}$ NStB 1363-1399 (wie Anm. 289) T. 1, S. 18, 2.

${ }^{467}$ Die obige Deutung geht zugunsten von Herrn Herman davon aus, dass es sich hier um dieselben $500 \mathrm{ml}$. gehandelt hat, um die es 1362 gegangen ist, nicht etwa um weitere $500 \mathrm{ml}$. deren Verbleib ungeklärt war. Beweisen lässt sich diese Annahme nicht, weil wir nicht wissen, wann und unter welchen Umständen der Niederstadtbucheintrag von 1362 ,getilgt". d. h. für erledigt erklärt worden ist.

${ }^{468}$ Zwischen Herrn Hermans letzter Erwähnung als Provisor des Heiligengeisthauses am 2. September 1364 und der nächsten namentlichen Nennung von Inhabern dieses Amts, der Bürgermeister Jacob Pleskow und Bertram Vorrad, am 31. Mai 1369 (UB. Stadt Lüb. 3. Nr. 685) liegt Herrn Hermans Todestag.

${ }^{469}$ UB. Stadt Lüb. 3, Nr. 477 (S. 507-510). 
dings beschränkten sich seine Erwerbsquellen schon seit langem nicht mehr auf die Möglichkeiten, die der Lübecker Dienst bot. Bereits 1353 war er, dank päpstlicher Provision, auch bepfründetes Mitglied und Scholaster im Schweriner Domkapitel geworden. Seit dem 3. September 1361 besaß er außerdem die Pfründe eines Pfarrers von St. Marien in Wismar; darauf hat er allerdings schon einige Jahre vor seinem Tod, am 11. August 1366, „freiwilligen Verzicht“ geleistet. ${ }^{470}$ Das Lob, das ihm der Rat aussprach. er habe „das Notarsamt ehrbar und lobenswert ausgeübt“, darf man sicherlich nicht als Beleg dafür deuten, dass der Rat wirklich keine Einwände gegen seine Amtsführung gehabt hat. ${ }^{471}$ Dies Lob war offenbar Bestandteil einer ausgehandelten „Trennung im beiderseitigen Einvernehmen", wie wir sie so zahlreich in unserer wirtschaftlichen Gegenwart beobachten können; dazu gehört auch gewiss des Notars Versicherung, der Rat habe ihn stets angemessen versorgt, so dass er sich gut stehe und zufrieden sei. Hätte sich Meister Martin dieser Lösung verweigert, dann hätte man ihn wahrscheinlich auch seines Amtes entsetzt, dann aber wohl auf eine für ihn noch schmerzvollere und vielleicht auch weniger das Decorum wahrende Weise. Wir wissen nicht, welchen Hintergrund dieser Enteignungsvorgang gehabt hat: die Auflassung der Rente vor Bischof Bertram, die mit einem von diesem besiegelten Notariatsinstrument beurkundet wurde, ist von fünf Ratsmitgliedern entgegengenommen worden, an deren Spitze übrigens die Bürgermeister Herman van Wickede und Bertram Vorrat gestanden haben. Der unerlaubte Einsatz von städtischen Mitteln für private Zwecke kann mit der Enteignung kaum geahndet worden sein; denn Ratsnotare haben nach unserer Kenntnis keinen unkontrollierten Zugang zu öffentlichen Kassen gehabt. Noch weniger kommt Kon-

\footnotetext{
${ }^{470)}$ Über ihn zuletzt Margit KaLUZA-BAUMRUKER. Das Schweriner Domkapitel (1171-1400) (Mitteldeutsche Forschungen 96), Köln, Wien 1987, besonders S. 224, Nr. 68; alle wesentlichen Belege aber auch schon bei REETZ, Niederstadtbuch (wie Anm. 409), S. 53 mit Anm. 129. Danach sind die Angaben über seinen Pfründenbesitz bei Klaus WRIEDT, Das gelehrte Personal in der Verwaltung und Diplomatie der Hansestädte, in: HGBll. 96, 1978, S. 15-37, hier S. 25, zu berichtigen. Diese Angaben beruhen auf der insoweit ungenauen älteren Lübeck-Literatur: Karl KoPPMANN, Die lübische Stadeschronik und ihre Ableitungen, in: HGBII. 1897 (1898), S. 147-202, hier S. 176f., Friedrich BRUNS. Die Lübecker Stadtschreiber von 1350 - 1500, in: HGBll. Jg. 1903 (1904), S. 43-102, hier S. 46 (nach KoppMANN a.a.O.), A.C. HøJBERG ChrISTENSEN, Studier over Lybacks Kancellisprog fra c. $1300-$ 1470. København 1918, S. 60 (mit dem Nachweis, dass die Nachricht über den genauen Zeitpunkt seines Ausscheidens aus dem Lübecker Dienst, die Abgabe des Niederstadtbuchs am 14. Oktober 1363, gedruckt Mecklenburgisches Urkundenbuch 15, Nr. 9206. und neuerdings Niederstadtbuch 1363-99. S. 14, 4, nicht von ihm selbst stammt, sondern von seinem bisherigen Kollegen Gerhard Rademyn). Friedrich BRUNS, Die Lübecker Syndiker und Ratssekretäre bis zur Verfassungsänderung von 1851, in: ZVLGA Bd. 29, 1, 1937. S. 91-168. hier S. 124 (nach BRUNS und HøJBERG; CHRISTENSEN a.a.O.).

${ }^{471}$ Wie Jürgen REETZ a.a.O. angenommen hat.
} 
fiskation eines beim Schoss verschwiegenen Vermögensobjekts ${ }^{472}$ in Frage, denn Meister Martin war nicht schosspflichtig, sogar aus doppeltem Grund: Als Weltgeistlicher und als Ratsdiener. ${ }^{473}$ Aber wenn wir nicht annehmen wollen, dass hier einfach ein unbeliebter, als geldgierig verrufencr Kleriker zugunsten der Ratskasse ausgeplündert worden ist, muss er das Geld auf eine Weise erworben haben, die aus der Sicht des Rats nicht zu billigen war. ${ }^{474}$

Neben den strukturellen Mängeln der Verwaltung von Mitteln für kirchliche und wohltätige Zwecke durch so gut wie gar nicht kontrollierte Zweier-Ausschüsse des Rats ist noch ein zweiter Sachverhalt hervorzuheben, der Missbrauch von Stiftungsmitteln für andere Zwecke als die vorgesehenen geradezu provoziert haben muss: Dass in einer Stadt wie Lübeck, in der es sehr viel privaten Reichtum und daher auch viele Stiftungskapitalien gab, öfters größere Beträge „,herumgelegen“ haben müssen, weil sie auf Jahre hinaus für den Stiftungszweck nicht eingesetzt werden konnten. Der häufigste Fall dürften Stiftungen für die Gründung von Altarbenefizien gewesen sein, die der Genehmigung durch die kirchlichen Oberen bedurfte. Aber damit waren die Möglichkeiten durchaus nicht erschöpft. Ein gut dokumentiertes Beispiel aus den hier besonders interessierenden Jahren sei vorgeführt: Am 24. Juni 1363 wandte sich das Schweriner Domkapitel an den Lübecker Rat mit der Bitte, ihm das Geld auszuzahlen, das der frühere Schweriner Domherr und Thesaurar Detmar Schulop für den Dombau vermacht hatte; es sei beim Rat deponiert. ${ }^{475}$ Meister Detmar war bereits Ende 1349 oder Anfang 1350 gestorben. ${ }^{476}$ Die Sache lag damit so weit zurück, dass die Schweriner ihre späte Meldung für begründungsbedürftig hielten: Sie hätten erst jetzt zu bauen begonnen und wären nun allerdings fortiter dabei. Dass es sich um einen Betrag handelte, der in so langer Zeit beachtliche Zinsen hätte bringen können, erfahren wir erst aus der Quittung vom 28. Juni 1363 über einen Teilbetrag von $100 \mathrm{ml} . .^{477} 271 \mathrm{ml}$. Die prompte Zahlung hat sich also auf

\footnotetext{
172 Darüber HaRtwig. Schoss (wie Anm. 440), S. 181.

${ }^{\$ 73}$ Ebd. S. 54 u. 58-64.

${ }^{474}$ Sicherlich bestand die Problematik nicht darin, dass der Protonotar das Geld auswärts zu $6.25 \%$ angelegt hatte. Denn die Möglichkeit, außerhalb der Stadt eine etwas bessere Verzinsung zu bekommen als die derzeit in Lübeck üblichen $5 \%$, wurde von vielen Lübeckern genutzt (vgl. dazu bereits oben mit Anm. 114 u. 115 über Herman Wittenborch), natürlich auch von Mitgliedern des Rats. Bekannt ist das etwa von Herrn Jacob Pleskow, einem der führenden .,Außenpolitiker” der Stadt seit 1363/64: WIEGANDT, Plescows (wie Anm. 182), S. 217 u. 246-253.

${ }^{475}$ UB. Stadt Lüb. 3, Nr. 466 (S. 494 f.).

476 Über ihn zuletzt KALUZA-BAUMRUKER, Schweriner Domkapitel (wie Anm. 470), besonders S. 266, Nr. 153.

${ }^{477}$ UB. Stadt Lüb. 3, Nr. 467 (S. 495).
} 
eine Rate beschränkt; das war 1363 kaum im Sinne der Empfangsberechtigten. Hat etwa der Lübecker Rat selbst auch gern mit fremdem - und sicherlich unverzinstem - Geld gearbeitet? Der Gedanke ist kaum von der Hand zu weisen, wenn man liest, dass es noch fast drei weitere Jahre gedauert hat, bis die Testamentsvollstrecker des Magisters über den Empfang einer letzten Rate von $60 \mathrm{ml}$. Quittung erteilen konnten. ${ }^{478}$

\section{7. „Großzügiger" Umgang mit fremden und öffentlichen Mitteln in der Sicht der Zeit}

Eine solche Beobachtung bestärkt den Verdacht, dass es der Rat mit gröBerer Gelassenheit als die Bürger angesehen haben könnte, wenn einzelne Mitglieder öffentliche Gelder mehr oder minder lange Zeit dazu verwandten, Engpässe ihrer privaten Liquidität zu überbrücken oder einfach ihr Geschäftskapital konkurrenzlos billig zu vermehren. Aus dem Lübecker Rat gibt es dazu keine ausdrücklichen Äußerungen. Oder soll man es als Äußerung werten, dass sich erst seit 1665 ein neues Mitglied eidlich verpflichten musste, das gemeine Gut getreulich zu verwalten ${ }^{979}$ Die zwei Fälle derartiger Verfehlungen, die Friedrich Bruns dargestellt hat, deuten in dieselbe Richtung. Hier ist nur der erste, von 1384, zu besprechen: ${ }^{480}$ Hinrik Schonenberch, von 1376 bis Anfang 1384 im Rat und am 20. Januar dieses Jahres gestorben, ${ }^{481}$ soll kurz vor seinem Tode zahlungsunfähig geworden sein; es ,kam damit zugleich die peinliche Begleiterscheinung zutage, dass er der Pfundgeldkasse 125 Mark entnommen hatte, zu deren Wiedererstattung er genötigt wurde, dem Rat sein Wohnhaus zu verpfänden, und dass er außerdem der Ratsweinkellerverwaltung 83 Mark schuldig blieb“. ${ }^{482}$ Soweit man in diesen Fall hineinschauen kann, bietet er

\footnotetext{
${ }^{478}$ Ebd. Nr. 561 (S. 595) von 1366 Juni 3.

${ }^{479}$ Über die Amtseide der Ratmannen/Senatoren von 1294 bis 1848 siehe BRUNS, Rat (wie Anm. 432), S. 20 f., 29 und 31.

${ }^{480}$ Ebd. S. 62.

${ }^{4 R !}$ LUTTERBECK Nr. 206 (S. 365f.). Die im folgenden darzustellenden Sachverhalte sind hier ebenso wenig wie im systematischen Teil des Buches auch nur angedeutet. Die näheren Angaben über diesen Ratmann bei FEHLING Nr. 410 (S. 46) bestehen überhaupt nur aus einer Zeile über sein Wohnhaus.

${ }^{482}$ Die von BRUNS nicht genannte Quelle findet sich. jetzt gedruckt, wo man sie vermuten durfte: NStB 1363-1399 (wie Anm. 289). S. 533f., 1384 Jan. 1-6, Nr. 7 (S. 536). Es fällt auf, dass dies vor Ratsdeputierten verhandelt worden ist, die zu Herrn Hinrik geschickt worden waren; war er, der noch am 1. Januar vor dem Rat zugunsten des Propstes in Bücken ein Schuldbekenntnis über ein Darlehen von $160 \mathrm{ml}$. abgegeben hatte (ebd. Nr. 5), ganz plötzlich schwer krank geworden ? Oder hatte ihn der Rat etwa gefangengesetzt ? Nach den ganzen Umständen halte ich es für gut möglich, dass sich seine Zahlungsunfähigkeit erst herausgestellt hat, als ihm seine Schulden bei zwei Ratsämtern vorgehalten wurden.
} 
gegenüber den Fällen Johan Wittenborch ${ }^{483}$ und Herman van Wickede nichts Neues. Ob Herr Hinrik in den zwei Wochen, die er nach dem 6. Januar 1384 noch zu leben hatte, wirklich ,zur Amtsniederlegung genötigt" worden ist, wie Bruns angenommen hat, ist ganz ungewiss. In den zwei Eintragungen des Niederstadtbuchs, die ihn nach seinem Tod noch erwähnen, wird er weiterhin ,dominus“ genannt. ${ }^{484}$ Auch hat man ihm, anders als Johan Wittenborch, die Eintragung in die Totenliste des Lübecker Rats, die so genannte „Oldenborchsche Ratslinie“, nicht verweigert. ${ }^{485}$ Der zweite Fall, der des Dr. jur. Johann Nikolaus Sibeth, im Senat 1783-1795, ${ }^{486}$ hat sich mehr als 400 Jahre später ereignet und ist deshalb hier nicht zu erörtern; man kann aber diesen Fall, in dem ein bankrotter Senator, der gleich in mehrere Amtskassen gegriffen hatte, von Senat und „Bürgerschaft" wie ein Wohltäter der Vaterstadt behandelt worden ist, ${ }^{487}$ jedem zum Studium empfehlen, der sich ein realistisches Bild von den politischen Strukturen der Reichsstadt Lüheck gegen Ende des Ançien Régime machen möchte. ${ }^{488}$

Auch in anderen Städten lübischen Rechts scheint es um das einschlägige Wissen nicht besser bestellt zu sein. Wilhelm Ebel $^{489}$ hat für das späte 13. und 14. Jahrhundert generell vom ,noch schwach entwickelten Begriff des öffentlichen Vermögens" gesprochen, als einziges Beispiel für Missbrauchsfälle, die „durchaus als Unrecht empfunden“ wurden, aber nur das jahrzehntelange Treiben des Stralsunder Bürgermeisters Bertram Wulflam, seiner drei Söhne und des mit ihnen ver-

\footnotetext{
${ }^{483}$ Wenn man behaupten wollte, Herr Hinrik wäre hingerichtet worden, wäre das ebenso wenig widerlegbar wie bei Herrn Johan Wittenborch; der Unterschied bestünde allein darin, dass bei Hinrik Schonenberch keine Chronik dies behauptet.

${ }^{484}$ NStB 1363-1399 (wie Anm. 289), S. 538, 1384 Febr. 16, Nr. I (S. 540), und S. 650, 1388 Febr. 23, Nr. 4 (S. 628). Beide Eintragungen lassen erkennen. dass der Ratmann noch Vermögenswerte hinterlassen hat.

${ }^{485}$ LUTTERBECK S. 455 , Nr. 369.

${ }^{486}$ FEHLING Nr. 931 (S. 151).

${ }^{487}$ BRUNS a.a.O. S. 63 f. Er konnte den angerichteten Schaden nicht selbst erstatten und brauchte es auch nicht. Darüber hinaus „,beantragte der Senat, Dr. Sibeth jährlich 1500 Mark zum Unterhalt auszusetzen, was auch die Bürgerschaft einstimmig genehmigte“. Der Betrag entsprach etwa dem, den damals drei Handwerkerfamilien für ihren Lebensunterhalt zur Verfügung hatten.

${ }^{488}$ Vgl. Franklin KopitzSCH. Das 18. Jahrhundert: Vielseitigkeit und Leben. in: Lübeckische Geschichte, hg. von Antjekathrin GrassmanN, 3. verbesserte und ergänzte Auflage Lübeck 1997. S. 491-527, hier S. 499: „Die enge Zusammenarbeit von Ratsherren und Bürgern wurde zu einem Faktor der politischen Stabilität". Im folgenden Jahr wurde den Soldaten der Garnison die Hälfte einer 1795 gewährten Teuerungszulage, „im wesentlichen ein Roggenbrot pro Woche“, entzogen, was bei ihnen Unruhen hervorrief; diese wurden ,mit Hilfe der Bürgergarde ... niedergeschlagen“ (ebd. S. 502).

${ }^{489}$ Zum folgenden EBEL, Lübisches Recht (wie Anm. 91), S. $306 \mathrm{f}$.
} 
schwägerten Bürgermeisters Albert Gildehusen angeführt. ${ }^{490}$ Allerdings ist es hier nicht nur um den eigennützigen Umgang mit städtischem Geld gegangen. Auch kamen Kritik und Widerstand von einer Bürgeropposition, deren Kern dem Rat angehört hat. ${ }^{49 \mid}$ Für unser Themenfeld wirklich einschlägig ist nur ein Wismarer Ratsstatut von 1360: „Ein Ratmann, der vom Rat zu einem Amt gesetzt wird, das die Stadt angeht, es sei, welches es sei, die [!] sollen das Geld ihres Amtes niemandem in der Welt leihen oder überlassen, bei [Geldstrafe von] drei Mark Silber ... Es sei denn, dass die Kämmerer für städtische Zwecke Geld brauchen; denen dürfen sie leihen ohne Strafe, oder einer dem anderen für die Zwecke der städtischen Ämter, mit Wissen der Bürgermeister". ${ }^{492}$ Die ausführliche, fast umständliche Formulierung lässt vermuten, dass dahinter ein konkreter Fall steckt, der im Rat zu lebhafter Diskussion geführt hat; offensichtlich war hier wirklich erst Rechtsbewusstsein zu schaffen. Selbst das anscheinend Selbstverständliche wurde detailliert geregelt: Die Norm sollte nicht verhindern, dass sich städtische Ämter untereinander aushalfen; aber dies durfte doch nicht so völlig ohne jede Kontrolle geschehen, dass es dabei zu eigennützigem Zusammenwirken zwischen einzelnen Ratmannen oder kleinen Ratmannengruppen hätte kommen können. Wir dürfen wohl auch unterstellen, dass mit dem Ausdruck ,niemandem in der Welt" der jeweilige Amtsinhaber außerhalb seiner amtlichen Tätigkeit mitgemeint war. Und doch war das Handeln gegen eine derart wichtige Norm nur mit einer Geldstrafe mittlerer Höhe bedroht! $!^{493}$ Allerdings: Dass „Ausleihen“ und „Behalten“ zwei verschiedene Dinge waren, das wird hier offenbar als selbstverständlich vorausgesetzt, und daher erfahren wir auch aus Wismar nicht, wie ein hansestädtischer Rat solches

\footnotetext{
${ }^{490}$ Darüber in neuerer Zeit ausführlicher Konrad FRITZE, Entstehung, Aufstieg und Blüte der Hansestadt Stralsund, in: Geschichte der Stadt Stralsund. Hg. von Herbert EwE (Veröffentlichungen des Stadtarchivs Stralsund 10), Weimar 1984, S.9-102, hier besonders S. 68-76 („Der Kampf um die Reform der Stadtverfassung am Ausgang des 14. Jahrhunderts"). Die hier nicht genannte ältere Spezialliteratur findet man in der (auch S. 34. Anm. 86 und öfter zitierten) Dissertation von Hans KOEPPEN, Führende Stralsunder Ratsfamilien vom Ausgang des 13. bis zum Beginn des 16. Jahrhunderts (Greifswalder Abhandlungen zur Geschichte des Mittelalters 10), Greifswald 1938.

${ }^{+91}$ Ihre Namen sind wenigstens zum Teil überliefert. Dagegen scheint es keinerlei Nachrichten über die Ratsmitglieder zu geben, auf die sich die beiden Bürgermeister Wulflam und Gildehusen gestützt haben müssen.

${ }^{492}$ Mecklenburgisches Urkundenbuch 14, Nr. 8791, I (S. 652). Den Hinweis auf diese Willkür verdanke ich ebenfalls EBEL a.a.O. S. 307; seiner Deutung, es ginge hier um Kreditgewährung ,,auf Zins“, und die Kämmerer dürften ,solche Geschäfte ... zum Nutzen der Stadt" machen, kann ich allerdings nicht folgen.

${ }^{493}$ Die zweite Willkür dieses Tages, ebd. S. 652f., hat die Zahl der Erwachsenen, die ein Kind außerhalb der Stadt „zu Kloster“ begleiten durften, auf 16 begrenzt; Zuwiderhandlung wurde mit zehn Mark Silber Strafe bedroht.
} 
„Behalten“ bald nach der Mitte des 14. Jahrhunderts beurteilt und nötigenfalls bestraft hätte.

Ob es erlaubt sei, zeitweilig fremde Mittel ohne ausdrückliche Erlaubnis der Eigentümer zu nutzen, darüber hat noch sechs Jahrzehnte später im doch wohl ziemlich einheitlichen - Milieu der hansischen Kaufmannschaft durchaus keine Einigkeit geherrscht. Das zeigt eine Debatte, die 1420/21 nicht ohne Schärfe zwischen den Vertretern des Brügger Kontors und dem Lübecker Rat geführt worden ist. ${ }^{494}$ Hier wurde einmal mit vertauschten Rollen diskutiert: Die Lübecker, die bei mindestens zwei Hansetagen vollen Rückhalt fanden, hatten den Älterleuten vorgeworfen, was heute „Untreue“ heißen würde: Dass sie vom Ertrag des Pfundzolls „einigen ihrer Freunde“ Darlehen gewährt hatten, damit „,die guten Leute in ihren Nöten das Geld eine Zeitlang hätten verwenden können“; mit der Klausel, die Empfänger müssten das Geld zurückgeben, wenn die Lübecker es nicht länger entbehren wollten, glaubten die Brügger alles Nötige getan zu haben. Dagegen beharrten die Städte darauf, der Kaufmann habe das Pfundgeld, das er für die Städte uppe loven bei sich gehabt habe, gegen solchen loven den Städten zu ihrem großen Schaden entzogen (entfernet); er sei nicht berechtigt gewesen, das zu verleihen, was seines nicht gewesen sei.

Übrigens war im norddeutschen Spätmittelalter das Phänomen, dass einzelne Angehörige von genossenschaftlich organisierten Institutionen mit anvertrauten Mitteln zum eigenen Nutzen leichtfertig, um nicht zu sagen skrupellos umgegangen sind, nicht auf die Räte der Hansestädte und auf kaufmännische Kreise beschränkt. Zu einer gründlichen Auseinandersetzung mit allen Aspekten des Themas sah sich 1392 das Kapitel des Kanonikerstifts Bützow in der Diözese Schwerin veranlasst. In einem am 10. Dezember beschlossenen Statut ${ }^{495}$ wurde es allen gegenwärtigen und zukünftigen Angehörigen des Stifts untersagt, Gelder der Kirche, die als Kapitalien für die Feier des liturgischen Gedächtnisses von Stiftern und die damit verbundenen Distributionen bestimmt waren, für eigene Zwecke an sich zu nehmen bzw. sie sich gewissermaßen als Darlehen zu gewähren, und zwar auch dann, wenn jemand dafür seine Kurie zum Pfand setzen und Rente (annuos redditus) bezahlen wolle - dies zu tun war also offenbar bisher nicht üblich gewesen. Derzeit ausstehende Beträge sollten in den nächsten Jahren allmählich abgetragen, bis dahin aber verzinst werden. Dem Statut künftig Zuwiderhandelnde sollten ipso facto der Exkommunikation verfallen. Von einer Bestrafung der bisherigen Darlehens-

\footnotetext{
${ }^{494}$ Das folgende nach HR I, 7, Nr. 180 (S. 89f.), Nr. 181 (S. 90f.), Nr. 186 (S. 94-96) und Nr. 355, $\$ 10$ (S. 205).

${ }^{495}$ Mecklenburgisches Urkundenbuch Bd. 22, Nr. 12462 (S. 198f.).
} 
Nehmer ist keine Rede. Allerdings gibt es auch hier nicht die leiseste Andeutung des Verdachts, dass in diesem Personenkreis jemals jemand vorgehabt haben könnte, das eigenmächtig geliehene Geld überhaupt nicht zurückzuzahlen.

\section{Die Hinrichtung von diskreditierten Ratmannen durch den Rat als Technik der Herrschaftssicherung?}

In der Diskussion um den Tod des Bürgermeisters Johan Wittenborch ist der Gedanke nicht neu, dass es dem Lübecker Rat weniger darum gegangen sein mag, tatsächliches Fehlverhalten zu bestrafen, sondern eher darum, den Schaden für das Ansehen des Rats wieder wettzumachen, der durch Herrn Johans Tun und Lassen entstanden sein soll. Die Vorstellung findet sich bereits bei Wilhelm Mantels, der allerdings zunächst nur an das Ansehen bei den verbündeten Seestädten gedacht hat: „Der Rat hat des Bürgermeisters Tod, der [!?] Lübecks Vorortstellung auf Jahre lang gründlich compromittirte, ${ }^{496}$ entschieden gewollt“ ${ }^{497}$ Einfacher ausgedrückt: Johan Wittenborch wäre als "Sündenbock“ oder „Bauernopfer" ums Leben gebracht worden. Das hat Mantels ein Dutzend Zeilen weiter noch näher ausgeführt: „Der Rat (habe) in seiner Majorität begriffen ..., es sei nötig, der Gerechtigkeit ein Opfer zu bringen [das heißt, die Gerechtigkeit zu opfern! G. S.], um sein altes Ansehen unangetastet zu wahren“. Demselben Gedanken hat Fritz Rörig 1943 eine zeitgemäß knappere Formulierung gegeben: Der Bürgermeister habe ,sein Haupt auf dem Marktplatz lassen (müssen), weil er den Glauben an die Führerqualität des Rates gefährdet hatte““.98 Aber schon 1926 hatte Rörig Mantels` Überlegungen viel weiter ausgesponnen und dabei auch die Wirkung des Misserfolgs auf die Stimmung der Lübecker Bürger ins Spiel gebracht: ${ }^{499}$ Als der Lübecker „,militärische[n] Führung“ des Krieges „der Erfolg versagt blieb, da hat Lübeck seinen Bürgermeister, der den Oberbefehl führte, ... hinrichten lassen. Nur so allein [!] glaubte der Rat sein Ansehen vor den Verbün-

\footnotetext{
${ }^{4 \% 6}$ Vgl. MANTELS, Schiffshauptleute (wie Anm. 11), S. 196: „Ein Hauptnachteil, den Wittenborgs Niederlage nach sich zog, schlimmer als der erlittene Verlust selber, war die Lockerung des seit 1361 sichtlich erstarkten Städtebundes und in Folge davon die Zaghaftigkeit und Unentschlossenheit der wendischen Städte."

${ }^{497}$ Ebd. S. 191; nach dem Zusammenhang muss sich „der“ auf „Bürgermeister" beziehen, nicht auf „Tod". Es handelt sich um einen reinen Schluss „ex eventu“; unsere jüngsten und, genau besehen, einzigen Informationen darüber, was der Lübecker Rat gewolit hat, nämlich über den Fall allein entscheiden, stammen vom Lübecker Hansetag vom 24. Juni 1363, s. oben mit Anm. 40-47.

${ }^{498}$ Fritz RÖRIG, Lübeck, in: HGBII. 67/68, 1942/43, S. 25-50, hier S. 46.

${ }^{499}$ Fritz RÖRIG, Geschichte Lübecks im Mittelalter, in: Geschichte der freien und Hansestadt Lübeck, Hg. von Fritz ENDRES, Lübeck 1926, S. 28-56, hier S. 39.
} 
deten, seine Autorität gegenüber der eigenen städtischen Bevölkerung wiederherstellen zu können. Nur der Erfolg schien den Genuss des überragenden Ansehens, das durch die Zugehörigkeit zum Rate bedingt war, zu rechtfertigen; wem er versagt blieb, den gab die eigene Genossenschaft preis, um die Würde der Institution zu retten“. 1944 hat Rörig dann auch diese Spekulation in den Rang einer allgemeinen, keines Hinweises auf empirisch Erforschtes bedürftigen Einsicht über ein zentrales Strukturmerkmal der hansestädtischen Ratsherrschaft in den ,früheren und kraftvollsten Jahrhunderte[n] der Hanse“ erhoben: ${ }^{500}$ „Wer von den Gliedern des Rates in den ihnen gestellten Aufgaben versagte, oder wem Verfehlungen nachgewiesen werden konnten, büßte dafür mit Gut und Freiheit, sogar mit dem Leben. Dann gab der Rat selbst den Ratsgenossen preis, um das Ansehen und die Autorität der Institution, des Rates, zu wahren“.

Auch wenn ich nicht sagen kann, an was für „Verfehlungen“ - von Johan Wittenborch oder wem auch immer - Rörig hier gedacht haben mag, passt doch dieser Satz nicht schlecht zum „Fall Wittenborch“, wie er sich beim jetzt erreichten Wissensstand darstellt, wenn man zum Einzelfall zurückkehrt und außerdem „Versagen oder Verfehlungen“ durch „Versagen und Verfehlungen“ ersetzt. Denn wer sich im hansischen Beobachtungsfeld nach weiteren Fällen von ratsherrlichem „Versagen“ umsieht, der wird sich schwer tun, Beispiele aus Friedenszeiten ausfindig zu machen. Dabei kann man ohne Bedenken davon ausgehen, das so etwas damals nicht weniger häufig vorkam als heute. In unseren Quellen findet sich aber nichts davon. Vermutlich liegt das daran, dass nicht erst wir über Vorgänge im Innern von hansestädtischen Ratsgremien des Spätmittelalters überhaupt sehr wenig wissen, von den - vergleichsweise sehr seltenen - Fällen abgesehen, in denen das Verhalten von einzelnen Ratmannen oder Ratmannengruppen zum Gegenstand von Erörterungen in der Bürger-Öffentlichkeit geworden ist. Da ging es dann aber in der Regel um den Vorwurf von Verfehlungen. ${ }^{501}$ Ähnlich sieht es auch im militärischen Bereich aus. Vielerörtert sind die Vorgänge von 1427/28, nach den ersten Misserfolgen, die die Städte an der Seite der Holsteiner Grafen im Krieg um Schleswig erlitten hatten. Damals kam es bekanntlich in Lübeck, Hamburg und Wismar zu innerstädtischen Auseinandersetzungen, mit Ratmannen-Hinrichtungen in Wismar und Hamburg; ${ }^{.02}$ in Lübeck ist es den Freunden des

${ }^{500}$ Fritz RörIG, Volk, Raum und politische Ordnung in der deutschen Hanse. Festvortrag ... am 27. Januar 1944 (Preußische Akademie der Wissenschaften, Vorträge und Schriften 19). Berlin 1944, S. 16f. Der Bezug auf den .Fall Wittenborch“ ist fortgelassen.

${ }^{501}$ So im Stralsunder Fall des Bertram Wulflam und seiner Clique, s. oben mit Anm. $490 \mathrm{f}$.

${ }^{502}$ Dazu noch immer am ausführlichsten E. DAENELL, Die Hansestädte und der Krieg um Schleswig, in: ZGesSHG 32, 1902, S. 271-450, hier S. 331-338; vgl. auch DAENELL. Blütezeit (wie Anm. 447) 1, S. 226-237. 
beschuldigten Bürgermeisters Tideman Steen gelungen, die Entscheidung so lange hinauszuzögern, bis die erste „Volkswut" verrauscht war. ${ }^{503}$ Diese Ereignisse haben inzwischen den Weg ins Internet und zu „Wikipedia“ gefunden. In zeitlicher Nähe zum „Fall Wittenborch“ gibt es nur den „Fall“" des Rostocker Ratmanns Frederik Suderland, ${ }^{504}$ der 1365/66 das den Städten von den Königen Magnus und Håkon verpfändete Öland als Hauptmann der Burg Borgholm hatte bewahren sollen, ${ }^{505}$ es aber ohne Gegenleistung an Håkon (der damals schon König Waldemars Schwiegersohn war !) zurückgegeben hatte. Auf dem Rostocker Hansetag vom 16. Dezember 1366 hat der Rostocker Rat die Städte gefragt, ob deswegen Herr Frederik oder die Rostocker verantwortlich zu machen seien. Die Antwort wurde an die Räte zurückgezogen $;^{506}$ durch einen Brief des Lübecker Rats vom 21. Dezember ist dann die Stadt Rostock für haftbar erklärt worden. ${ }^{507}$ Die nächste Nachricht datiert vom 12. März $1367 ;^{508}$ damals haben die Lübecker auf die - nicht erhaltenen - Verwendungsbriefe dreier westfälischer Herren für Suderland geantwortet, sie seien an seiner Gefangensetzung, Fesselung und Tötung in Rat und Tat nie beteiligt gewesen; was die Rostocker gegen ihn gehabt hätten, wüssten sie nicht. Erst aus dieser genauen Beschreibung der Maßnahmen des Rostocker Rats gegen sein Mitglied erfahren wir (und haben anscheinend auch die Beschwerdeführer erfahren), dass Herr Frederik Anfang März nicht mehr am Leben war. Da weitere Einzelheiten des Rostocker „Falles“ offenbar nicht bekannt sind, kann man nicht einmal begründete Vermutungen darüber anstellen, was sich der Rostocker Rat von Herrn Frederiks Tod versprochen haben mag. Daher trägt dieser „Fall“ trotz der dem ersten Anschein nach gemeinsamen Züge ${ }^{5(0)}$ nicht das Geringste zu einem besseren Verständnis des Lübecker „Falls Wittenborch" bei. ${ }^{510}$

${ }^{50.3}$ Über Tideman Steen sehr detailliert MANTELS, Schiffshauptleute (wie Anm. 11), S. 207-227.

${ }_{5(4)}$ Dazu SCHÄFER, Hansestädte (wie Anm. 9). S. 412 mit Anm. 2, und etwas ausführlicher, aber ohne Belegangaben, Adolph HoFMEISTER. Rostocks Anteil an den Kämpfen der Hansa gegen Waldemar IV. von Dänemark, in: Beiträge zur Geschichte der Stadt Rostock 1. 4, 1895, S. 1-20, hier S. 15-17.

${ }^{505}$ Zum Hintergrund siehe SCHÄFER a.a.O., S. 592-597: „Borgholm (Oeland) im Besitz der Städte (1362-1366)".

${ }^{506}$ HR I, I, Nr. 388, \$9 (S. 348).

${ }^{507}$ Ebd. Nr. 394 (S. 352).

${ }^{508}$ Ebd. Nr. 395 (S. 352 f.).

${ }^{509} \mathrm{Vgl}$. etwa Walter FREYNHAGEN, Die Wehrmachtsverhältnisse der Stadt Rostock im Mittelalter, in: Mecklenburgische Jahrbücher 95, 1931, S. 1-120, hier S. 43: Suderland musste, „wie auch wenige Jahre vorher der Lübecker Ratsherr und Oberbefehlshaber Johann Wittenborg, den Verlust der Feste Borgholm mit dem Tode sühnen“.

510 Bereits MANTELS, Schiffshauptleute (wie Anm. 11), S. 192, Anm. 1, nannte den „Fall“ Suderland „ein für das Verfahren gegen Wittenborg lehrreiches Beispiel“, ohne etwas über 
Zusammenfassend kann man, in freiem Anschluss an Wilhelm Ebel, ${ }^{511}$ wohl sagen: Wie Räte sich einzelnen Mitgliedern gegenüber verhalten haben, denen politisch-militärisches Versagen vorgeworfen wurde, das hing offenbar in erster Linie davon $a b$, wie die Bürgerschaften auf die Vorkommnisse reagiert, und in welchem Maße sie politischen Druck auf den betreffenden Rat ausgeübt haben. In Lebensgefahr dürften die umstrittenen Ratsmitglieder vor allem dann geraten sein, wenn der Verdacht des „Verrats“ im Raum stand. Auch das war natürlich ein politischer Vorwurf.

Wie die „Volksstimmung“ 1362/63 in Lübeck ausgesehen hat, darüber ist uns rein gar nichts Glaubwürdiges überliefert. Trotzdem haben Historiker versucht, davon ein Bild zu malen. Dies Bild ist wesentlich bestimmt durch die, wie oben gezeigt, sehr schwach fundierte Annahme, Herr Johan Wittenborch sei öffentlich hingerichtet worden. Diese Annahme hat zu Spekulationen über die politischen Voraussetzungen geführt, unter denen das geschehen sein soll. So hat sich Dietrich Schäfer ${ }^{5 / 2}$ die Sache nicht ohne „hochgehende Bewegungen" in der Lübecker Bürgerschaft vorstellen können. Ohne im Dunkeln zu lassen, dass er reine Mutmaßungen vortrug, beschrieb Schäfer eine Art „vorrevolutionäre Situation“: „Es muss eine Zeit gewesen sein, in der die heftigsten Leidenschaften wogten und der empörte Sinn der Bürger ein Opfer forderte". Tatsächlich hat sich Schäfer aber wohl durch die Verhältnisse von 1427/28 zu dieser Sicht inspirieren lassen; Mantels hatte ja schon die „Fälle“ Johan Wittenborch und Tideman Steen zusammengestellt. Nun hätte es zwar in Lübeck, wenn man allein auf einschlägige Quellennachrichten abstellen wollte, vor den Ereignissen der Jahre 1374 bis $1384^{513}$ niemals auch nur den Versuch von heftigen innerstädtischen Auseinandersetzungen gegeben, in denen die bisherige Ratspolitik von Teilen der Bürgerschaft in Frage gestellt worden

den Inhalt der Lehre zu sagen. Die beiden Fälle sind auch in neuerer Zeit öfters zusammengestellt worden, ohne dass dadurch das Verständnis für das Gemeinsame der beiden „Fälle“ wesentlich gefördert worden wäre. So meinte Klaus FRIEDLAND, Die Hanse (Urban-Taschenbücher 409), Stuttgart usw. 1991, S. 162f., es sei in diesen Fällen und in einem weiteren Fall „verurteilt und hingerichtet“ worden, weil die Ratsmitglieder „eigenwillig oder grob leichtfertig über das gemeine Gut verfügt“" hätten. Dagegen hat, eher beiläufig, Wilhelm EBEL, Lübisches Recht (wie Anm. 91), S. 361, diese und weitere Ratsherren-Hinrichtungen ebenso einfach wie plausibel als „politisch motivierte“ angesprochen: dies Urteil ist ihm sicherlich um so leichter gefallen. als er früher hatte überzeugend darstellen können, wie freigiebig das städtische Willkür-Strafrecht des Spätmittelalters mit der Androhung (und zuweilen auch Ausführung) der Todesstrafe hantiert hat: EBEL, Bürgereid (wie Anm. 427), S. 151-155.

5II Siehe die vorige Anmerkung.

512 SCHÄFER, Hansestädte (wie Anm. 9) S. 360.

513 VON BRANDT, Knochenhaueraufstände (wie Anm. 140), S. 179-190, und, teilweise anders, oben mit Anm. 435-446. 
wäre. Das wird man aber ungern behaupten wollen. So kann ich mir insbesondere die Situation kaum als völlig friedliche vorstellen, in der am Ende des 13. Jahrhunderts der Lübecker Rat zu dem verzweifelten Mittel seine Zuflucht nehmen musste, eine stadtherrliche Ratswahlordnung zu erfinden, um den Ausschluss eines großen Personenkreises, besonders aller Handwerker, vom Rat zu legitimieren. ${ }^{514}$ Die Regel, dass sehr wohl sein kann, was nicht in den ,actis“ ist, könnte auch für 1362/63 gelten; ein deutliches Indiz würde reichen. Aber Lübeck und die Lübecker selbst waren ja durch die unmittelbaren Folgen von Herrn Johans militärischem Misserfolg nur relativ wenig betroffen, und wenn man dazu neigt, seine öffentliche Hinrichtung für eine außerhalb der Stadt erfundene Mär zu halten, dann gibt es in den Quellen nur die - allerdings erhebliche Summe der Kriegskosten ${ }^{515}$ als Indiz dafür, dass sich damals in der Stadt öffentliche Kritik an der bisherigen Dänemark-Politik oder wenigstens an ihren führenden Vertretern im Rat lauthals bemerkbar gemacht haben könnte. Quellenmäßig nachweisbar ist aber nur, dass Anfang 1363 in Lübeck eine aggressiv antidänische Stimmung geherrscht hat. ${ }^{516}$ Da dies für den ganzen Zeitraum zwischen 1360 und 1369/70 gegolten haben dürfte (es war sicherlich die unabdingbare Voraussetzung für die Dänemarkpolitik des Rats und seiner Verbündeten), ist diese Information für die Erklärung von Johan Wittenborchs Tod ohne jeden Wert.

Dass oligarchische Räte dem laxen Umgang von Angehörigen des Ratsregiments mit anvertrauten Mitteln relativ tolerant begegnet sind, ist öfters beobachtet worden, nicht nur in Lübeck. Dass Johan Wittenborch härter behandelt worden ist, erklärt sich zur Genüge daraus, dass in seiner Person

\footnotetext{
${ }^{514}$ Andeutungen in dieser Richtung, nach einem Hinweis von W. SUHR, bereits bei VON BRANDT a.a.O. S. 185, Anm. 34. Nicht weiterführend Bernhard AM ENDE, Studien zur Verfassungsgeschichte Lübecks im 12. und 13. Jahrhundert (Veröffentlichungen zur Geschichte der Hansestadt Lübeck Reihe B, 2), Lübeck 1975, S. 89 mit Anm. 7 (S. 119).

${ }^{515}$ Die Kosten der Lübecker Kriegführung, einschließlich einiger Gesandtschaftskosten, sind auf dem Wismarer Hansetag vom 25. Juli 1363 mit etwas mehr als $37000 \mathrm{ml}$. beziffert worden: HR I, 1, Nr. 299, §5 (S. 241). In den Verhandlungen mit König Håkon von Norwegen, die Ende Juni/Anfang Juli 1370, also erst nach dem 2. Waldemarskrieg, in Bohus stattfanden, wurden zu den "Ausgaben im Krieg“" von (rund) $38000 \mathrm{ml}$. noch (rund) 40000 ml. ,aus der Befreiung der Gefangenen" angeführt: HR I, 2, Nr. 1, § 6 (S. 3), dazu SCHÄFER, Hansestädte (wie Anm. 9), S. 314 u. 355 (,wohl reichlich hoch“ berechnet; der Betrag schließt aber vermutlich neben den Lösegeldern auch nachträgliche Soldzahlungen, Entschädigung für verlorene Pferde und Waffen u. ä. ein). Diese Ausgaben haben sich allerdings über einen längeren Zeitraum verteilt, und die Bedeutung des Themas „Lösung der Kriegsgefangenen“ für die Lübecker „Volksstimmung“ wird man überhaupt nicht zu hoch einschätzen dürfen. Denn unter den Gefangenen hat es wahrscheinlich nur wenige Lübecker Bürger gegeben, siehe dazu oben mit Anm. 172.

${ }^{516}$ HR I, 1, Nr. 293 (Bericht über die Verhandlungen in Dänemark seit dem 7. Mai 1363), § 20 (S. 228). Es handelt sich um König Waldemars Beschwerden; was die Lübecker darauf geantwortet haben, ist leider nicht überliefert.
} 
zwei Formen der Fehlleistung im Amt zusammengekommen sind: Das Versagen bei der Erfüllung einer wichtigen politisch-militärischen Aufgabe und der eigennützige Umgang mit anvertrautem Geld, der angesichts des langen Zeitraums, um den es sich gehandelt hat, der Unterschlagung des Geldes mindestens sehr nahe gekommen ist. In einem solchen seltenen Einzelfall konnte es sich auch einmal gegen ein Ratsmitglied auswirken, dass der Bereich der mit der Todesstrafe bedrohten Handlungen im Statutarrecht der spätmittelalterlichen Städte erheblich ausgeweitet worden ist. ${ }^{517}$ Was die Form seiner Bestrafung angeht, sollte man eher davon ausgehen, dass öffentliches Aufsehen möglichst vermieden worden ist. Auch nehme ich nicht an, dass der Lübecker Rat bei dieser Gelegenheit ausgerechnet das getan hat, was er so lange zu vermeiden bemüht gewesen war: Einer breiten Öffentlichkeit darzulegen, was Herrn Johan außer dem Misserfolg im Öresund noch vorgeworfen wurde. Auch der Lübecker Rat hat sicherlich die Möglichkeit gekannt, die uns ausdrücklich aus dem Deutschen Orden überliefert ist: Jemanden zu bestrafen, ohne den Grund über den Kreis hinaus bekannt werden zu lassen, der ihn bereits kannte. ${ }^{518}$ Die Abschreckungswirkung wäre dann auf die Personen eingeschränkt gewesen, um die es in einem solchen Zusammenhang nur gehen konnte: Die übrigen Mitglieder des Lübecker Rats; nur die konnten in ihrer Zeit ja auch davon erfahren, dass Wittenborchs Name nicht in die von den Stadtschreibern geführte Totenliste des Rats gekommen ist. ${ }^{514}$ Dass 1363 so verfahren worden ist, dafür spricht auch, dass sich der Rat öffentlich nie von seinem Mitglied Johan Wittenborch distanziert zu haben scheint. Jedenfalls ist bisher kein im Verantwortungsbereich des Lübecker Rats nach Herrn Johans Rückkehr vom dänischen Kriegsschauplatz entstandenes Schriftstück bekannt geworden, in dem ihm der Herren-Titel verweigert worden wäre, weder zu seinen Lebzeiten noch nach seinem Tode. ${ }^{520}$

\footnotetext{
${ }^{517}$ Siche oben Anm. 510 am Ende.

${ }^{518}$ Vgl. Kurt ForstreutER, Der Deutsche Orden am Mittelmeer (Quellen und Studien zur Geschichte des Deutschen Ordens 2), Bonn 1967, S. 263 (1339). Die Visitatoren der mediterranen Niederlassungen sollten ,das Verbrechen (crimen), das ihnen berichtel worden war, geheim halten", allerdings auch die Namen der Schuldigen nicht bekannt werden lassen. FORSTREUTER hat „solche geheimen Vergehen“ auf „eine lockere Lebensführung“ deuten wollen.

${ }^{519}$ Wenn er dort wirklich bewusst ausgelassen wurde. Die Totenliste ist bekanntlich für diese Zeit nur abschriftlich erhalten, in der sogenannten Oldenborchschen Ratslinie, in der es nach der Meinung von Friedrich BRUNS, Die älteren lübischen Ratslinien, in: ZVLGA 27.1, 1933, S. 31-99, hier S. 39f., neben den ,zweifellos absichtlich ubergangen[en]“ Namen (zu diesen zählte er Johan Wittenborch) auch „versehentlicherweise ausgelassen[e]" gibt.

${ }^{520} \mathrm{Vgl}$. dazu bereits oben Anm. 44.
} 


\section{Johan Wittenborch - ein typischer Lübecker Kaufmann und Ratmann seiner Zeit?}

Die nähere Beschäftigung mit Herrn Johans Art, seine Geschäfte zu betreiben und seine Ämter auszuüben, hat gezeigt, dass er sich in beiden Tätigkeitsbereichen jedenfalls nicht untypisch verhalten hat. Die Untersuchung von Johan Wittenborchs problematischen Finanztransaktionen ließ erkennen: In beiden Kategorien, wucherische Darlehensgewährung und Aneignung von öffentlichem Gut. hat er nicht nur nachweislich Mitwirkende gehabt, die ebenso wie er Kaufmann bzw. Kaufmann und Mitglied des Lübecker Rats waren. Hier handelte es sich um Geschäftsfreunde bzw. einen Geschäftsfreund, der zugleich Herrn Johans Kollege in einem kollegial besetzten Ratsamt war. Darüber hinaus ließ sich für die zweite Kategorie wahrscheinlich machen und für die erste mindestens plausibel vermuten, dass auch andere Angehörige der Personengruppen, zu denen Johan Wittenborch gehört hat, die aber nicht zu seinem persönlichen und amtlichen Umfeld gehört haben, ${ }^{521}$ sich nicht anders als er verhalten haben. Diese Personengruppen haben in dem Zeitraum, in dem wir Johan Wittenborch besser als jeden anderen Lübecker seiner Zeit beobachten können, eine ziemliche Größe gehabt: Rolf Hammel-Kiesow hat für einen wenig späteren Zeitpunkt die Zahl der gleichzeitig in Lübeck als Bürger mit eigenem Haushalt lebenden ,hauptberuflichen Kaufleute (Fernhändler)“ auf „höchstens 500" geschätzt und damit eine von Ahasver von Brandt genannte erheblich höhere Zahl von mindestens 700 bis 800 plausibel auf das Wahrscheinliche reduziert; ${ }^{522}$ für einen Zeitraum von etwa 15 Jahren, von 1345 bis 1359/60, in den das ,große Sterben“ fiel, darf man gewiss unbedenklich von etwa 800 Personen ausgehen. Dem Rat haben in der Zeit zwischen 1350 und 1362 fast fünfzig Männer angehört. ${ }^{523}$ Daran gemessen, ist die Zahl der Personen, die in Johan Wittenborchs „Handlungsbuch" vorkommen, unserer Hauptquelle für ihn und seinen Kreis, doch sehr gering; sie wird noch geringer, wenn man die abzieht, die so selten vorkommen, dass man sie kaum zu diesem „Kreis“ rechnen kann.

\footnotetext{
${ }^{521}$ Genauer gesagt, für uns nicht in diesem Umfeld sichtbal werden. Die Einschränkung gilt natürlich vor allem für den amtlichen Bereich, da für das 14. Jh. die Besetzung der Ratsämter noch überwiegend nur sehr fragmentarisch dokumentiert ist.

${ }^{522}$ HAMMEL. Hauseigentum (wie Anm. 94). S. 135-137, zu VON BRANDT. Knochenhaueraufstände (wie Anm. 140), S. 127-129; nicht enthalten sind in diesen Zahlen, ,eine erhebliche Zahl von unbedeutenden ,Gelegenheitshändlern“", wie sie in den Lübecker Pfundzollisten von 1368 sichtbar würden, und die „Kaufgesellen“ (die Formulierungen von VON BRANDT). Siehe dazu oben Anm. 434.

52.3 Ausgezählt nach LUTTERBECK S. $177 \mathrm{f}$.
} 
Damit ist die aus sozialgeschichtlicher Sicht zentrale Frage, ob und wie weit er und seine Verhaltensweisen als repräsentativ für diese Personengruppen gelten können, schon halb beantwortet: Zumindest für einen Teil davon kann Repräsentativität konstatiert werden. Aber wie groß dieser Teil gewesen ist, lässt sich auch nach dem Wittenborch-Material nicht sagen. Das heißt nicht etwa, dass dies Material mangelhaft wäre und die intensive Beschäftigung nicht lohnen würde. Es ist vielmehr das mit groBem Abstand beste, was wir haben. Und das Material ist im Laufe der folgenden Jahrhunderte nicht etwa erheblich besser geworden, im Gegenteil: In dem Maße, in dem die Formen der kaufmännischen Buchführung technisch an Qualität gewonnen haben, verschwinden aus den Geschäftsbüchern die individuellen Züge, die gegebenenfalls auch gravierendes Fehlverhalten des Kaufmanns erkennen lassen. Das gilt schon ein gutes halbes Jahrhundert später; man braucht sich nur zu fragen, was man über Hildebrand Veckinchusen und sein Umfeld wüsste, wenn nur seine Geschäftsbücher überliefert wären, ${ }^{524}$ nicht auch seine Korrespondenz. ${ }^{525}$ Und mit den Veckinchusen-Büchern ist ja noch durchaus nicht der Gipfel der Formalisierung der Buchhaltung erreicht! Letztendlich handelt es sich aber ohnehin um Sachverhalte, über deren Verbreitung auch im gegenwärtigen „statistischen Zeitalter" allenfalls anonym durchgeführte Befragungen der Wirtschaftssubjekte einigermaßen zuverlässige quantitative Aussagen ermöglichen würden. Mir persönlich reicht das, was für Johan Wittenborch und sein engeres Umfeld ermittelt werden konnte, völlig aus als Basis für die Aussage, dass derartige Verhaltensweisen in der Lübecker Kaufmannschaft, auch bei den kaufmännisch tätigen Ratsmitgliedern, um die Mitte des 14. Jahrhunderts weit verbreitet gewesen sein dürften. Ich leugne nicht, dass dieses Urteil ein Werturteil ist, zu dem man leichter kommt, wenn man im Gewinnstreben nicht die Quelle allen Fortschritts in der menschlichen Gesellschaft sieht.

10. Herr Johan Wittenborch als Provisor der Jakobikirche in der geschichtswissenschaftlichen Literatur des 20. Jahrhunderts

Wer der Untersuchung bis hierher gefolgt ist, mag jetzt fragen, wie sich die eigenartige Form, in der zwei Provisoren einer Lübecker Pfarrkirche

\footnotetext{
524 Davon bisher nur gedruckt: Michail P. LESNIKOV, Die Handelsbücher des hansischen Kaufmannes Veckinchusen (Forschungen zur mittelalterlichen Geschichte 19), Berlin 1973. Auf den - von Walter STARK bearbeiteten - Rest warte sicherlich nicht nur ich mit Spannung.

${ }^{525}$ Hildebrand Veckinchusen. Briefwechsel eines deutschen Kaufmanns im 15. Jahrhundert. $\mathrm{Hg}$. und eingeleitet von Wilhelm STIEDA, Leipzig 1921.
} 
mit den ihnen anvertrauten Mitteln der Kirchenfabrik umgegangen sind, so lange dem Blick einer im 20. Jahrhundert doch recht dichten hansischen Spätmittelalterforschung hat entziehen können. Die Antwort muss lauten: Tatsächlich ist das gar nicht der Fall gewesen. Die einschlägigen Stellen sind vermutlich von allen Autoren gesehen und verstanden worden, dic sich, mit den nötigen Vorkenntnissen ausgestattet, überhaupt die Mühe gemacht haben, den ganzen Text des „Handlungsbuchs“ zu lesen. Allerdings fehlte bisher eine umfassende Analyse aller Nachrichten. Aber zum Inhalt dieser Eintragungen haben sich schon vor langer Zeit zwei Forscher geäußert. Als erster hat das bereits 1906 der Wirtschaftshistoriker Friedrich Keutgen (1861-1936) ${ }^{526}$ getan. Keutgen wirkte damals in Jena; seit 1910 hat er am Hamburger Historischen Seminar die Mittelalterliche Geschichte vertreten. Zumindest in den Jahren vor dem Ersten Weltkrieg kann man ihn wohl sogar zum engeren Kreis der Hanseforscher rechnen. In seinem großen Aufsatz über hansische Handelsgesellschaften ${ }^{527}$ hat er beiläufig von der „Zwangsanleihe" gesprochen, die „Wittenborg und Herr Johann Woltvogel bei der St. Jakobs-Kasse, die sie verwalteten", gemacht hätten, um einen Tuchkauf zu finanzieren; auch „die Rückzahlung dieses Darlehens schein[e] ... nicht so ganz glatt von statten gegangen zu sein" ".28 Keutgen warf auch schon die Frage auf: „Sollte übrigens dieser Eingriff in eine öffentliche Kasse nicht bei Wittenborgs Prozess mitgespielt haben?“; dabei hat er die zentrale Stelle von 1358 hier gar nicht zitiert. ${ }^{529}$ Das Thema ist dann ein paar Jahrzehnte später von Franz Bastian wieder aufgegriffen worden. ${ }^{530}$ Er hat sich zunächst über Herrn Johans Eigenkapitalbasis ausgesprochen, die er, wahrscheinlich zu Recht, für mangelhaft hielt. Deshalb habe Herr Johan beim Einkaufen Kredit in Anspruch nehmen müssen, ,auch zusammen mit seinen Gesellschaftern“; dabei „,mussten [auch] direkt oder indirekt von Wittenborg verwaltete Amtskassen ,herhalten“". Bastian fährt dann fort: „Seine mit Mitteln des St. Jakob-

\footnotetext{
${ }^{526}$ Über ihn etwa Peter BOROWSKY, Geschichtswissenschaft an der Hamburger Universität 1933 bis 1945, in: Eckart KRAUSE, Ludwig HUBER, Holger FISCHER (Hg.), Hochschulalltag im „Dritten Reich“. Die Hamburger Universität 1933-1945, Teil II: Philosophische Fakultät, Rechts- und Staatswissenschaftliche Fakultät (Hamburger Beiträge zur Wissenschaftsgeschichte 3, II), Berlin. Hamburg 1991, S. 537-588, hier S. 538 mit Anm. 3 (u. a. Nachrufe) und öfter. Keutgen stammte, wie Bastian, aus Bremen.

${ }^{527}$ Dazu jetzt CORDES. Gesellschaftshandel (wie Anm. 72), S. 32-37 und öfter.

${ }^{528}$ F. KEUTGEN, Hansische Handelsgesellschaften, vornehmlich des 14. Jahrhunderts, in: VSWG 4, 1906, S. 278-324, 461-514, 567-632, hier S. 605f.

${ }^{529}$ Erwähnt sind nur die Stellen aus dem Bereich Handlungsbuch (wie Anm. 55) S. $22 \mathrm{f}$., Nr. II 105, 107-109, 112, 113 und 119 (S. 24; m. E. nicht einschlägig, s. dazu oben Anm. 395). Die Tatsache, dass Nr. II 106 nicht zitiert ist, zeigt zur Genïge, dass KEUTGEN das Thema nicht abschließend hat behandeln wollen.

${ }^{530}$ Das folgende nach BASTIAN 1, S. 219.
} 
Klosters [!] im Jahre 1352 begonnenen Operationen sind bereits in der Literatur herausgestellt, wenn vielleicht auch zu weitgehend zur Erklärung seines tragischen Endes ausgewertet worden". Irgendeinen Hinweis auf die hier gemeinte Literatur hat der Verfasser nicht gegeben; er hat wohl aus dem Gedächtnis zitiert. Gemeint sein kann aber nur die eben besprochene Stelle bei Keutgen. Bastians geringes Interesse an ostelbisch-norddeutschen Lokalverhältnissen kommt wieder einmal darin zum Ausdruck, dass er sich nicht die Mühe gemacht hat herauszufinden, ob St. Jakob wirklich auch in Lübeck, wie in Regensburg, der Patron eines Klosters war. Für seine Neigung, über Lübecker Verhältnisse dennoch sehr bestimmte Aussagen zu machen, ${ }^{5,1}$ ist es bezeichnend, dass er sich einerseits an Keutgens Äußerung zum Wittenborch-Prozess gar nicht genau erinnerte (Keutgen hatte ja nur eine Frage aufgeworfen !), sich aber andererseits zu einer ablehnenden Stellungnahme ohne Angabe von Gründen befugt hielt. Auf die zentrale Niederschrift von 1358 und die beiden anderen gleichzeitig entstandenen „eigenhändigen“ Eintragungen ist Bastian erst an späterer Stelle eingegangen. Hier interessierte ihn aber vor allem die buchführungstechnische Seite, die „Separatstellung anormaler Vorwürfe“. 532

Bei Gelehrten, die ihr wissenschaftliches Lebenswerk zur Gänze oder größtenteils der Erforschung der hansischen und Lübecker Geschichte gewidmet haben, womöglich auch in Lübeck und Umgebung ansässig und berufstätig gewesen sind, findet man allerdings keine ausdrücklichen Zeugnisse dafür, dass sie Keutgens und Bastians Äußerungen zur Kenntnis genommen oder gar selbst entdeckt haben, was es mit Herrn Johan Wittenborchs einschlägigen Aufzeichnungen auf sich hat. Dennoch ist es nicht sehr wahrscheinlich, dass sie alle all das einfach übersehen haben. Das gilt zu allererst für den „Sekretär der Handelskammer in Lübeck“ „Dr. Carl Mollwo“. ${ }^{533}$ Der hat zwar, als er unter dem Gesichtspunkt „lateinisch und deutsch“ Herrn Johans ,letztwillige Verfügungen, die er 1358 in sein Handlungsbuch eintrug", besprach, die Eintragung nicht erwähnt, in der es um die Jakobikirche geht. ${ }^{534}$ Und ebenso wenig hat er darauf hingewiesen, als er zutreffend feststellte: „Zur Kirche S. Jacobi scheint Johann Wittenborg in näherem Verhältnis, möglicherweise als Vorsteher, gestanden zu haben“. ${ }^{535}$ Dafür wird dann diese Stelle, jedoch ohne jeden Hinweis auf

\footnotetext{
${ }^{531}$ Dazu bereits oben Anm. 79.

${ }^{532}$ BASTIAN 1, S. 270. Vgl. zu den Geschäften „mit Geldern der S. Jakobskasse“ auch noch S. 227 u. 273 f. sowie 2, S. VII.

${ }^{533}$ So die Herausgebernennung auf dem Titelblatt der Edition.

${ }_{534}$ Mollwo S. XL mit Anm. 2.

${ }^{535}$ Ebd. S. XLI.
} 
ihren Inhalt, zum Beleg dafür zitiert, dass „eine private Aufzeichnung eines Kaufmanns“ „auch diejenigen verpflichtete, die seinen Nachlass zu ordnen hatten“. ${ }^{536}$ Und alle drei Eintragungen sind aufgeführt am Ende der Anmerkung, mit der Mollwo seine Aussage belegt hat, dass ,eine Reihe von Bemerkungen“ im „Buch“ „mit seiner Bestimmung als Handlungsbuch gar nichts zu thun haben“. ${ }^{537}$ Man könnte fast auf den Gedanken kommen, Mollwo habe den Lesern seiner „Einleitung“ sagen wollen: „Schlagt doch nach, dann werdet ihr schon entdecken, was ich nicht aussprechen kann", sähe es nicht an zwei weiteren Stellen so aus, als hätte er sich, bewusst oder unbewusst, geradezu Mühe gegeben, die Sache zu kaschieren. ${ }^{538}$ Verwunderlich wäre das nicht. Auf was für Reaktionen beim spätwilhelminischen Lübecker Wirtschafts- und Bildungsbürgertum sich jemand gefasst machen musste, der ihre Kreise öffentlich der Lächerlichkeit oder der Verachtung preisgab, hat bekanntlich der Senatorensohn Thomas Mann nach dem Erscheinen seiner „Buddenbrooks“ erlebt. ${ }^{539}$ Das hätte er sich denken können, ging es doch hier vor allem um die Verwandten aus der zweiten Hälfte des 19. Jahrhunderts, also um Leute, die man noch persönlich kannte. Allerdings brauchte sich ein zunehmend erfolgreicher Schriftsteller in München, der dort auch familiär neue Wurzeln geschlagen hatte, darüber nicht allzu sehr zu grämen. Aber die Lübecker städtische Oberschicht des zweiten deutschen Kaiserreichs dürfte auch noch die entsprechende Schicht des Spätmittelalters mit ihren politischen Institutionen $\mathrm{zu}$ ihren unmittelbaren Vorfahren gerechnet haben. ${ }^{540}$ Der

\footnotetext{
${ }^{536}$ Ebd. S. XLIII mit Anm. I.

${ }^{537}$ Ebd. S. XLI mit Anm. 2.

${ }^{538} \mathrm{Im}$ Kapitel „Gesellschaften und Sendeve“, auf S. LXIII mit Anm. 5, hat er, in einem äußerst speziellen Zusammenhang, auch die Buchungen Handlungsbuch (wie Anm. 55) Nr. „II.105-107" erörtert, also den Bereich, in dem die beiden großen Anleihen bei der Kasse der Jakobikirche dokumentiert sind. Und ausgerechnet hier heißt es: „Das Kapital der Sozietät geben Joh. Wittenborg und Joh. Woltvogel her". Auch hier musste man schon die Stellen nachschlagen, um zu sehen, dass es sich erst einmal um ein „Hernehmen“ gehandelt hat. Und im Kapitel "Makler, Handelsmarken, Spesen" hat MolLwo, als er (S. LXXIV mit Anm. 4) über ,Geldmakler“ sprach, die Buchung Handlungsbuch (wie Anm. 55) II 106 in diesen Zusammenhang gezogen mit dem Satz: „Als Wittenborg einmal eine größere Summe brauchte, wandte er sich an einen solchen Makler, der ihm diese auch aus der Kirchenkasse der St. Jacobikirche besorgte". So schwer es auch fallt, muss man doch wohl glauben, dass MoLLwo wirklich nicht gesehen hat, dass das in dieser Buchung erwähnte Maklerhonorar für die Vermittlung eines in Flandern zahlbaren Wechsels gezahlt worden ist (ein zweiter derartiger Fall: Handlungsbuch (wie Anm. 55) S. 37, Nr. II 236). Denn als er (S. LXVIII) den ,geringen damaligen Wechselverkehr" (S. LXVII) behandelte, wusste er offenbar nicht, dass es in Lübeck in den $1350 \mathrm{er}$ Jahren Wechselmakler gegeben hat.

${ }^{5.39} \mathrm{Vgl}$. nur Gerhard AHRENS, Von der Franzosenzeit bis zum Ersten Weltkrieg 1806-1914: Anpassung an Forderungen der neuen Zeit. In: Lübeckische Geschichte, hg. von Antjekathrin GRASSMANN, 3. verbesserte u. ergänzte Auflage Lübeck 1997, S. 529-675, hier S. 672-674.

${ }^{540}$ Hartmut BoOCKMANN hat, zuerst 1983, in seinem Essay über „Spätmittelalterliche deut-
} 
junge Angestellte einer zentralen Einrichtung der Lübecker „Wirtschaft", der sich mit diesem Gegenstand befasst hatte, war da in einer weniger komfortablen Lage: Nach seiner Darstellung erhielt „das Bild Wittenborgs ... tiefe Schatten" bereits durch den Vorwurf, er hätte ein hansisches Handelsverbot missachtet, ${ }^{541}$ wie hätte Mollwo öffentlich sagen dürfen, ohne seine „bürgerliche Existenz" zu gefährden, dieser Lübecker Bürgermeister habe Unterschlagung im Amt begangen! Hier bestanden offenbar Hürden, die in der Regel gar nicht wirklich aufgestellt werden mussten, weil sie bereits in der Vorstellung der literarisch Tätigen vorhanden waren und wirksam geworden sind. ${ }^{542}$ Solche Hürden, die erst sichtbar wurden, wenn jemand sich anstellig gemacht hatte, sie zu überspringen, gab es damals natürlich nicht nur in Lübeck. Sie sind freilich wohl nirgends gut und breit dokumentiert. Aus Lübeck kenne ich nur, was Ahasver von Brandt 1952 in einem archivgeschichtlichen Aufsatz mitgeteilt hat, ${ }^{543}$ und was dann 1988 von Gerhard Ahrens einer größeren Öffentlichkeit zur Kenntnis gebracht worden ist: ${ }^{544}$ Dass der Senat in der zweiten Hälfte der 1870 er Jahre und 1890 Forschern die Benutzung von Akten des Lübecker Archivs aus

sche Stadt-Tyrannen“, in: DERS., Wege ins Mittelalter. Historische Aufsätze. Hg. von Dieter Neitzert, Uwe ISrael und Ernst Schubert, München 2000, S. 37-54, hier S. 53, darauf hingewiesen, dass die Art. wie die deutsche Stadtgeschichte des Spätmittelalters in Deutschland meist wahrgenommen werde, damit zusammenhänge, dass das Thema im 19. Jh. als eine „die Ziele damaliger bürgerlicher Politik vermeintlich legitimierende Vergangenheit" wiederentdeckt worden sei; ,die Bürger des 19. Jh.s" hätten geglaubt, ,in einer kontinuierlichen Verbindung mit dem spätmittelalterlichen Stadtbürgertum zu stehen “. Das ist eine Feststellung, die sicherlich auch für die Hansestädte zutrifft. Weniger zustimmungsfähig scheint mir allerdings BOOCKMANNS weitere Aussage. diese Bürger hätten gemeint „die bürgerliche Freiheit und die demokratische Verfassung, welche sie selber erstrebten, in den spätmittelalterlichen Städten vorgebildet zu finden“. Wenigstens dicjenigen hansestädtischen Bürger des späteren 19. Jh.s, die mir bei der Arbeit an dieser Studie als Erforscher der Lübecker Geschichte begegnet sind, haben sicherlich gewusst, dass sie es mit einem ausgesprochen autoritären oligarchischen Regiment zu tun hatten, und ich habe nirgends den Eindruck gewonnen, dass sie dieses Regiment mit Abneigung betrachtet haben. Ich erspare es mir, auch noch von den nachfolgenden Generationen zu reden, bis hin zu dem Deutschnationalen, späteren Nationalsozialisten Fritz RöRIG und seinen großenteils hochbegabten Schülern, von denen ,nicht wenige“ „überzeugte und schwärmerische Nationalsozialisten“ gewesen sind: NoODT, Rörig (wie Anm. 77) S. 178. Dass es auch damals rühmliche Ausnahmen gegeben hat, wie den Hamburger Archivar Hans NIRRNHEIM (siehe Joist GrollE und Ina LORENZ. Der Ausschluss der jüdischen Mitglieder aus dem Verein für Hamburgische Geschichte. Ein lange beschwiegenes Kapitel der NS-Zeit (Mit biographischem Anhang), in: ZVHG 93, 2007, S. 1-145, hier S. 4ff. passim; über ihn auch noch unten mit Anm. 545), soll nicht verkannt werden.

${ }^{5+1}$ Moll.wo S. XVII.

${ }^{542}$ Heute beschreibt man Derartiges meist mit dem Bild der "Schere im Kopf“.

${ }^{543}$ Ahasver VON BRANDT, Das Lübecker Archiv in den letzten hundert Jahren. Wandlungen, Bestände, Aufgaben, in: ZVLGA 33, 1952, S. 33-80, hier S. 70. Der zu 1890 genannte „Direktor des Archivs, Th. Behn“ ist gemäß S. 39f. identisch mit dem Senator und langjährigen Bürgermeister Heinrich Theodor Behn (FEHLING Nr. 998).

${ }^{544}$ AHRENS, Franzosenzeit (wie Anm. 539), S. 664 (S. 863 die Literatur dazu). 
der ersten Hälfte des 19. Jahrhunderts verwehrt hat, weil er befürchtete, die Resultate würden das politische Handeln seiner Vorgänger in dem schlechten Licht zeigen, das es nach dem Wissen der Entscheider durchaus verdient hatte. Im ersten Fall war in die Entscheidungsfindung auch der Hamburger Senat einbezogen gewesen. Aus Hamburg hatte kurz zuvor der ehemalige Direktor des Hamburger Staatsarchivs Heinrich Reincke in seinem 1947 gesprochenen, 1951 gedruckten Nachruf auf seinen Vorgänger Hans Nirnheim berichtet und damit für die Nachwelt festgehalten, dass man als wissenschaftlicher Bediensteter der Freien und Hansestadt vor dem Ersten Weltkrieg nicht öffentlich sagen durfte, „dass es jemals eine Zeit gegeben habe, da Hamburg keine freie Reichsstadt war, noch, dass sein Rat je an mittelalterlichen Urkundenfälschungen beteiligt gewesen sein könnte“. Reincke schloss seine Bemerkungen mit dem Ausruf „Da war freilich schlecht Geschichte schreiben!“. 545

\section{1. „Parteien“ im Rat? Die Protagonisten der Lübecker „Außen“- und Hansepolitik von 1358 bis zur Kölner Konföderation von 1367}

Abschließend soll gefragt werden, welche weiteren Änderungen am bisherigen Bild der Lübecker Politik zu Ende der 1350er Jahre und in den 1360er Jahren im Gefolge der Neubearbeitung des „Falles Wittenborch“ vorzunehmen sind. Mantels hatte die Vermutung in die Diskussion gebracht, die Entscheidung des Rats, Herrn Johan Wittenborch hinrichten zu lassen, sei keine einmütige gewesen; nur eine Mehrheit im Rat habe das beschlossen; es müsse dort zwei sich bekämpfende Gruppen („Parteien“) gegeben haben. Als Mantels' Zeitgenosse, der Lübecker Senator und zweite Vorsitzende des Hansischen Geschichtsvereins Wilhelm Brehmer (1828-1905), ${ }^{546}$ einen weiteren Lübecker Bürgermeister dieser Zeit, Herrn Jacob Pleskow, zum Gegenstand einer biographischen Darstellung gemacht hatte, da war ihm aufgefallen, dass sein „Held“, der 1352 in den Rat gewählt worden war, ${ }^{547}$,,an keinem Hansetage und an keiner Gesandtschaft" beteiligt gewesen ist, die den Krieg von 1362 vorbereitet hatten, aber „mit dem Beginn des folgenden Jahres plötzlich in den Mittelpunkt

${ }^{545}$ Heinrich REINCKE, Hans Nirrnheim (1865 bis 1945), in: DERS., Forschungen und Skizzen zur hamburgischen Geschichte (Veröffentlichungen aus dem Staatsarchiv der Hansestadt Hamburg 3), Hamburg 1951, S. 277-300, hier S. 293f. NIRRNHEIMS Buch über den Bürgermeister Hinrich Murmester (1908) ,musste ... auf amtlichen Befehl aus dem Buchhandel zurückgezogen werden, weil die offizielle Geschichtslegende unserer Stadt [derartige Aussagen nicht] vertragen konnte“. Über NIRRNHElM siehe auch oben Anm. 540 am Ende.

546 Über ihn zuletzt Antjekathrin GRASSMANN, Biographisches Lexikon für SchleswigHolstein und Lübeck Bd. 11, Neumünster 2000, S. 65-67.

${ }^{547}$ LUTTERBECK Nr. 186 (S. 340-343); gestorben 1381. 
des politischen Lebens eintritt" ${ }^{548}$ Zur Erklärung griff Brehmer Mantels” „Parteien“-These auf; „die bis dahin massgebende“ Partei habe Herrn Jacob „nicht zu ihren Anhängern“ gezählt. Das ist eine sehr vorsichtige Formulierung; im Ergebnis läuft sie aber doch auf die Behauptung hinaus, Gegner des Bürgermeisters Johan Wittenborch ${ }^{549}$ hätten nach seinem Tod im Rat die Mehrheit gestellt und, mindestens in der Dänemark-Politik, das Ruder allein in die Hand genommen. Von alternativen Lösungen für strittige Sachfragen hat Brehmer allerdings nichts zu sagen gewusst, und es würde auch schwer fallen, eine inhaltliche Veränderung der Lübecker Politik, besonders gegenüber König Waldemars Dänemark, seit 1363 zu entdecken.

Zwar ist zweifellos richtig, was Brehmer über die ungleichgewichtige Verteilung der Zeugnisse für Herrn Jacob Pleskows Teilnahme an der „großen Politik“ gesagt hat. Aber was besagt das? Soweit es um die Zeit vor dem 6. November 1362 geht, braucht nur an unsere Bemühungen erinnert zu werden, ein einigermaßen deutliches Bild von Herrn Johan Wittenborch als Politiker zu entwerfen. Derselbe Rezess vom 6. Dezember 1358, dem wir entnehmen konnten, dass Herr Johan schon vor der Aufnahme unter die Bürgermeister im Frühjahr 1359 an der hansischen Politik des Lübecker Rats beteiligt gewesen ist, nennt außerdem noch den Bürgermeister Herman van Wickede und den alterfahrenen Ratmann Bertram Vorrad. Dieselbe Dreiergruppe hat Lübeck dann 1360 und 1361 beim Abschluss der Verträge mit Herzog Erich dem Jüngeren von Sachsen-Lauenburg vertreten. Im Herbst 1361 traten dann, nach den drei einschlägigen Quellennachrichten zu urteilen, Herr Herman und Herr Bertram in den Hintergrund, und neben dem Bürgermeister Johan Wittenborch sind neu aufgetreten je zweimal (jedoch innerhalb von nur etwa zwei Monaten und in einheitlichem Sachzusammenhang) die Ratmannen Johan Pleskow und Bernard Oldenborch ${ }^{550}$ und einmal der Ratmann Segebode Crispin. In sechs „Vorfällen“ aus den drei Jahren zwischen Ende 1358 und Ende 1361 begegnen uns also zwei Bürgermeister und fünf „einfache“ Ratmannen, ${ }^{551}$ von diesen einer dreimal und zwei zweimal. In diesem Bereich ist damit gerade ein Viertel von den 28 oder 29 Bürgermeistern und Ratmannen belegt, die im Zeitraum 1358 bis 1361 dem Rat angehört haben. ${ }^{552}$ Die

\footnotetext{
${ }^{548}$ Wilhelm BREHMER, Der Lübecker Bürgermeister Jacob Plescow, in: HGBll. Jg. 1882 (1883), S. 49-66, hier S. 55.

${ }^{549}$ So ausdruicklich KOPPE u. KOPPE. Frankfurt-Händler (wie Anm. 79), S. 128, über die Herren Johan Perceval und Jacob Plescowe.

${ }^{550}$ Der aber als führender Lübecker Hansepolitiker durchaus nicht „,neu" war; mit FlandernSchwerpunkt ist er bereits 1358 und 1360 belegt: LUTTERBECK S. 319 mit Anm. 2301.

551 Johan Wittenborch ist doppelt gezählt.

${ }^{552}$ Ausgezählt nach LUTTERBECK S. 177 f.: 27. dazu ein zweites Mal Johan Wittenborch und
} 
sechs „Vorfälle“ enthalten 17 namentliche Erwähnungen von Ratsmitgliedern. Davon entfallen aber schon acht auf die beiden Bürgermeister. Bürgermeister hatten bei wichtigen Gelegenheiten eine stark überproportionale Erwähnungschance, weil in Zweierdelegationen in der Regel ein Mitglied Bürgermeister war und Dreierdelegationen oft aus zwei Bürgermeistern und einem „einfachen“ Ratmann bestanden. In „unserem“ Zusammenhang wird man aus den wenigen Belegen allenfalls folgern dürfen, dass die anderen beiden Bürgermeister des Zeitraums, Tideman Warendorp. Bürgermeister seit 1356, und Herman Gallin, Bürgermeister seit 1360, in diesem Bereich wahrscheinlich keine Rolle gespielt haben; das ist oben schon geschehen. ${ }^{553}$ Dagegen wäre es ein typischer (unzulässiger) Schluss e silentio, einen „einfachen“ Ratmann wie Jacob Pleskow schon deshalb für politisch einflusslos oder oppositionell (oder beides) zu erklären, weil er im extrem lückenhaft überlieferten Datenmaterial nicht erwähnt ist.

Wie sich die personellen Verhältnisse im Lübecker Rat nach der Rückkehr von Herrn Johan Wittenborch aus Dänemark dargestellt haben, wenn es um Beratungen mit den anderen Seestädten ging, und zwar nicht nur über Fragen der Dänemark-Politik, ist ebenfalls schon dargelegt worden: ${ }^{554}$ Von den drei übrig gebliebenen Bürgermeistern tauchen zwei in diesem Bereich weiterhin nicht auf; der dritte war nur dann zur Mitwirkung fähig, wenn die Hansetage in Lübeck stattfanden. Andererseits war aber offenbar auch keiner der drei so geschwächt, dass mit seinem baldigen Tod gerechnet werden konnte, oder dass er bereit gewesen wäre, seine Position für einen jüngeren Mann zu räumen. Auch war anscheinend zunächst nicht klar, ob wenigstens Johan Wittenborchs Stelle als dauerhaft vakant anzusehen war. So begegnet uns die erste Lübecker Delegation zu einem auswärtigen Hansetag des Jahres 1362, deren Zusammensetzung wir kennen, die zum Rostocker Tag vom 6. November, als eine Gesandtschaft, die nur aus drei „einfachen“ Ratmannen besteht. Davon sind uns zwei schon als Teilnehmer an den gegen Dänemark gerichteten Aktivitäten der Jahre 1360 und 1361 bekannt: Herr Bertram Vorrad und Herr Johan Pleskow. Nur der dritte, Herr Johan Pertzeval, im Rat seit $1352,{ }^{555}$ ist uns in diesem

Herman Gallin, die in diesen Jahren Bürgermeister geworden sind. Davon ist mit an Sicherheit grenzender Wahrscheinlichkeit wieder abzuziehen der Bürgermeister Nikolaus Schoneke, der nach LUTTERBECK S. 35 fünf Jahre vor seinem Tod im Jahre 1362, also 1357, zuletzt als Ratsmitglied erwähnt wird; ich finde seine letzten Nennungen in UB. Stadt Lüb. 3, Nr. 269, von 1356 Dezember 21, hier S. 266, und vorher in dem langen Schriftsatz ebd. Nr. 273 von „1357. Nach Jan. 10“, hier S. 274 zu 1356 Mai 5.

553 Oben mit Anm. 284 u. 285

554 Oben mit Anm. 286 - 288.

${ }^{55.5}$ LUTTERBECK Nr. 180 (S. 331-333), gestorben 1399. 
Zusammenhang vorher noch nicht begegnet. Allerdings hatte auch er schon vor 1362 an den hansischen Aktivitäten des Lübecker Rats teilgenommen, wenn auch auf einem Gebiet, das hier sonst nicht untersucht wird: 1361 ist Johan Pertzeval zusammen mit dem Wisbyer Ratmann Hinrik van Vlanderen in Nowgorod gewesen, wo die Verhältnisse des deutschen Kaufmanns zu regeln waren ${ }^{536}$.

Auch die weitere Entwicklung können wir dann in allen ihren Einzelheiten verfolgen. Denn für die knapp zwei Jahre vom November 1362 bis zum September 1364 sind uns erstmals, vor allem dank der Lübecker Rezesshandschrift aus dem frühen 15. Jahrhundert, der so genannten „Ledraborger", alle Hanserezesse eines längeren Zeitraums erhalten geblieben. Bei der Versammlung, die am 1. Januar 1363 in Stralsund begonnen hat, ${ }^{557}$ war Herr Bertram nicht dabei. Zu Johan Pleskow und Johan Pertzeval hatte sich Herr Jacob Pleskow gesellt. Dessen erster für uns erkennbarer Auftritt auf einem Hansetag sieht also ganz und gar nicht so aus, als übernähme mit ihm eine oppositionelle Gruppe im Lübecker Rat die „Macht“; eher könnte man den Eindruck gewinnen, hier wäre zwei bereits bewährten Männern ein dritter zum Versuch beigegeben worden. Ebenso stellt es sich auch am 5. Februar in Rostock dar: ${ }^{558}$ Zusammen mit Herrn Johan Pleskow und Herrn Bernard Oldenborch, der uns aus dem Herbst 1361 vertraut ist, tritt Jacob Pleskow zum zweiten Mal auf. Zum dritten Mal treffen wir ihn auf dem Wismarer Hansetag vom 17. März ${ }^{559}$ an, wieder mit zwei Erfahrenen, Bertram Vorrad und Johan Pleskow. Herr Bertram war damals vielleicht schon zum Bürgermeister erhoben. Irgendwann in den ersten Monaten des Jahres 1363, nach dem 11. Januar und vor dem 29. April, muss der Lübecker Rat beschlossen haben, dass der „Fall Wittenborch" einen Stand erreicht hatte, der es erlaubte, Wittenborchs Bürgermeisterstelle neu zu besetzen, und zwar - ein wahrhaft umwälzender Akt - mit dem Mann, der damals, nächst dem Bürgermeister Herman van Wickede, am längsten dem Rat angehört hatte, und den wir als Mitwirkenden an der Lübecker ,großen Politik“ beobachten konnten, seitdem - am 6. Dezember 1358 - solche Beobachtungen überhaupt möglich ge-

\footnotetext{
${ }^{556}$ Darüber zusammenfassend KOPPMANN in HR I, 3, S. 17f., der hier die Interpretation der zentralen Quellen nachgeholt hat. Diese sind bereits HR I, 1, Nr. 376 (Rezess des Lübecker Hansetags vom 24. Juni 1366), \$26, S. 336 mit Anm. 1, und Nr. 385 (S. 344 f.) zusammengestellt (s. dazu noch HR I, 8, S. 553). Vgl. KOPPE u. KOPPE, Frankfurt-Händler (wie Anm. 79), S. 128 mit Anm. 477. LUTTERBECK hat S. 332 mit Anm. 2442 die Quellenstücke zwar zitiert, ihren Inhalt aber mit „I366 Pläne für eine Gesandtschaft nach Nowgorod" unrichtig wiedergegeben.

${ }^{557}$ HR I, 1, Nr. 280, Namen der Ratssendeboten S. $210 \mathrm{f}$.

${ }^{558}$ Ebd. Nr. 287, S. 217.

${ }^{559}$ Ebd. Nr. 291, S. 222.
} 
worden waren, Bertram Vorrad. ${ }^{560}$ Auf die Teilnahme an den nächsten beiden Reisen, nach Wismar zur Hansetagung am 23. April ${ }^{561}$ und nach Dänemark zu den Verhandlungen mit den Dänen, die am 7. Mai begonnen haben, ${ }^{562}$ hat Herr Bertram wieder verzichtet. $\mathrm{Zu}$ Hause blieb aber auch Herr Jacob Pleskow; stattdessen hat sich die bewährte „Troika“ Johan Pleskow, Johan Pertzeval und Bernard Oldenborch auf den Weg gemacht. Auf dem Hansetag, der am 24. Juni 1363 in Lübeck begann, treffen wir dann fast alle Lübecker Ratsmitglieder beieinander an, die wir bisher in unterschiedlichen Kombinationen als auswärtige Vertreter der Stadt registrieren konnten. ${ }^{563}$ Es fehlte nur Johan Pleskow, den man auch in der Folgezeit öfters bei Hansetagen vermisst, und hinzu traten der nicht mehr reisefähige Bürgermeister Herman van Wickede und Herr Segebode Crispin, dem wir bereits, wahrscheinlich Ende 1361, als Partner von Herrn Johan Wittenborch, auf einer diplomatischen Reise nach Hamburg begegnet waren. ${ }^{564}$ Ende Juli und im September ${ }^{565}$ waren dann erstmals mit Johan Pertzeval und Jacob Pleskow neben Bernard Oldenborch die „Neulinge" in einer Dreiergesandtschaft in der Mehrheit. Auf die Reise zum Greifswalder Tag am 1. November ${ }^{566}$ nahmen die beiden dann noch jemanden mit, der überhaupt erst 1356 in den Rat gekommen war: Dethard Sachtelevend. ${ }^{567}$ Dies ist allerdings wahrscheinlich nur deshalb geschehen, weil er als neuer Hauptmann für Borgholm ${ }^{568}$ vorgesehen war; dort ist er offenbar bis März 1365 als Chef der städtischen Militärverwaltung von Öland tätig gewesen. Über deren finanzielle Seite hat er auf dem Stralsunder Hansetag vom 27. März 1365 abgerechnet; das machte ihn jedoch nicht zum Lübecker Gesandten. ${ }^{569}$ Auf dem Rostocker Hansetag vom 5. Oktober 1365 erscheint er aber wieder, an 3. Stelle, als Lübecker Ratssendebote; allerdings hat auch hier das Thema „Borgholm“ auf der Ta-

\footnotetext{
${ }^{560)}$ Über ihn vor allem oben mit Anm. 267 u. 286.

${ }^{561}$ HR I, 1, Nr. 292, S. 223.

$\$ 62$ Ebd. Nr. 293, S. 225.

${ }^{56.3}$ Ebd. Nr. 296. S. 232f. Für die Lübecker Teilnehmer - Herman van Wickede und Bertram Vorrad als Bürgermeister. Segebode Crispin. Johan Pertzevale, Jacob Pleskowe und Bernard Oldenborch als „einfache“ Ratmannen - ist die Liste der Rostocker Handschrift zugrunde zu legen, die mit der Liste in der original überlieferten Urkunde HR I, 1, Nr. 297 (S. 238f.) übereinstimmt. In der Ledraborger Handschrift fehlt. offenbar infolge eines Abschreibfehlers, Bernard Oldenborch. Er fehlt auch bei POECK, Ratssendboten (wie Anm. 225). S. 122.

${ }^{564}$ Siehe oben Anm. 281.

565 HR I, I, Nr. 299 u. 300, Namen S. 240 u. 245-247.

566 Ebd. Nr. 305, Namen S. 254.

${ }^{567}$ LUTTERBECK Nr. 199 (S. 355 f.). Er ist bereits am 13. Juli 1367 gestorben.

${ }^{568}$ Zum folgenden grundlegend SCHÄFER, Hansestädte (wie Anm. 9), S. 593-596. Sicherlich danach, aber ungenau, auch ein Satz bei FEHLING S. 39.

${ }^{569} \mathrm{Vgl}$. SCHÄFER a.a.O. S. 596.
} 
gesordnung gestanden. ${ }^{570}$ Man kann ihn doch wohl noch nicht zu den jüngeren Leuten rechnen, durch die der Kreis der Hansespezialisten des Lübecker Rats in der Folgezeit wiederholt erweitert worden ist. Den Greifswalder Termin am 19. November $1363^{571}$ haben Johan Pertzeval und Jacob Pleskow ausnahmsweise allein wahrgenommen. Dagegen war am 6. Januar 1364 in Stralsund wieder Bernard Oldenborch dabei. ${ }^{572}$ Wer Lübeck auf den vier (!) weiteren Stralsunder Tagen zwischen dem 1. Februar und dem 24. März vertreten hat, wissen wir nicht, weil die Rezes$\mathrm{se}^{573}$ keine Teilnehmernamen enthalten. Am 14. April in Rostock war Lübeck nur durch den Ratsnotar Gerard Rademyn vertreten. ${ }^{574}$ Erst für den Lübecker Tag am 25. Mai 1364 gibt es wieder eine umfassende Liste der Lübecker Teilnehmer, sieben an der Zahl, darunter kein neuer Name. ${ }^{575}$ Trotzdem gibt es etwas Neues zu berichten: Der Rat ist es offenbar leid geworden, noch länger darauf zu warten, dass eine weitere Bürgermeisterstelle durch den Tod eines der beiden in hansischen Dingen völlig untätigen älteren Bürgermeister frei werden würde, und hat einen der „Aktivisten" der letzten anderthalb Jahre zum fünften Bürgermeister gewählt, Herrn Jacob Pleskow. ${ }^{576} \mathrm{Da}$ er vor Herman van Wickede und Bertram

${ }^{570}$ HR I, I, Nr. 374, hier S. 324 und $§ 7$ (S. 325). Nach LUTTERBECK S. 355 mit Anm. 2722 wäre Herr Dethard außerdem „1365 mit der Einnahme des Pfundzolls betraut" worden. Von den angeführten Quellenstellen muss HR I, 1, Nr. „359“ durch einen Übertragungsfehler hierher gekommen sein. und mit ebd. Nr. 376, dem Rezess der Lübecker Versammlung vom 24. Juni 1366, kann hier eigentlich nur der lange $\$ 25$ (S. 334-336) gemeint sein, in dem Herr Dethard wiederholt erwähnt ist; hier geht es aber wieder um die Berechnung der Kosten von Borgholm sowie der sonstigen Ausgaben, die 1364-1366 im Zusammenhang mit dem Krieg gegen den König von Dänemark entstanden sind, und ihre Umlegung auf die einzelnen Städte.

${ }^{571}$ HR I, 1, Nr. 307, S. 258f.

572 Ebd. Nr. 310, S. $263 \mathrm{f}$.

${ }^{573}$ Ebd. Nr. 313-316 (S. 269-273).

${ }^{574}$ Ebd. Nr. 321, hier S. 275.

${ }^{575}$ Ebd. Nr. 325, hier S. 280f. Maßgebend ist wieder die Rostocker Handschrift; in der Ledraborger Handschrift und bei POECK, Ratssendboten (wie Anm. 225), S. 122 ist Johan Pleskow ausgelassen.

${ }^{576}$ Die Angabe, Herr Jacob Pleskow sei bereits 1363 als Bürgermeister belegt, bei LuTTERBECK S. 341 und KOPPE u. KOPPE, Frankfurt-Händler (wie Anm. 79), S. 128 mit Anm. 480, beruft sich auf die Erwähnung des „Bürgermeisters“ Jacob Pleskow als Ratszeuge für ein Testament vom 8. Oktober 1363. Diese Nachricht ist aber nicht nur problematisch (siehe dazu bereits die Anmerkung zu Reg. Test. (wie Anm. 93) 2, Nr. 1006, auf S. 336), sondern nachweislich unverwertbar; denn Herr Jacob ist noch am 6. Januar 1364 hinter Johan Pertzeval aufgeführt: HR I, 1. Nr. 310, hier S. 263 (die von WIEGANDT, Plescows, wie Anm. 182, S. 229, Anm. 807, im gleichen Sinne herangezogene, in Avignon am 27. (nicht „17.“) Februar 1365 ausgestellte Kardinalsurkunde UB. Stadt Lüb. 3, Nr. 514, hier S. 543, bietet schon deshalb nichts Genaueres, weil in ihrer Liste der burgenses Lubicenses Bürgermeister, Ratmannen und ein „einfacher" Bürger durcheinandergewürfelt sind). Mit der Wiederherstellung des traditionellen Datums (FEHLING S. 38: „1364 ward er Bürgermeister") erledigen sich auch die Behauptungen von LUTTERBECK S. 57, Jacob Pleskow habe erst als Bürgermeister 
Vorrad aufgeführt ist, hat er sicherlich auch den Tag geleitet, ${ }^{577}$ und wir dürfen davon ausgehen, dass er seitdem der führende Mann im Lübecker Rat gewesen ist, wenigstens in Fragen der ,großen Politik“. So weit es den Lübecker Beitrag angeht, war Herr Jacob also jetzt in erster Linie verantwortlich für die „Zaghaftigkeit und Unentschlossenheit der wendischen Städte“, dafür, dass sie ,sich von einem Waffenstillstand zum andern (schleppen)", „es nur zu halben Demonstrationen gegen Dänemark (bringen)“ und ,endlich 1365 einen faulen Frieden (schließen) ${ }^{\text {“. }}{ }^{578}$ Offenbar in der Absicht, Herrn Jacob die Planung dieser nicht gerade „schneidigen“ Politik zu erleichtern, wurde auch Johan Pertzeval ein Jahr später zum Bürgermeister erhoben; in der Liste der Lübecker Teilnehmer am Lübecker Hansetag vom 28. Mai 1365 erscheint er unter den Bürgermeistern hinter Jacob Pleskow an 2. Stelle. ${ }^{579}$ Seitdem hat es in Lübeck gleichzeitig sechs Bürgermeister gegeben, ${ }^{580}$ wenn auch nur für kurze Zeit. Denn 1366

an „Hanse- und Städtetagen“ teilgenommen, und von KOPPE u. KOPPE a.a.O., er sei ,an ... Statt" von Johan Wittenborch Bürgermeister geworden.

${ }^{577} \mathrm{Zu}$ weit gegangen ist sehr wahrscheinlich BREHMER, Jacob Plescow (wie Anm. 548), S. 56, als er aus dem Sachverhalt schloss. Herr Jacob sei ,sofort mit dem Vorsitze im Rathe betraut" worden. In der Frage, was die Reihenfolge bedeutet, in der im 14. Jh. mehrere Bürgermeister in einem städtischen oder ratsnahen Schriftstück aufgeführt sind (natürlich immer alle vor den ,einfachen" Ratmannen), bedarf allerdings das meiste noch der Klärung; guten Gewissens kann man aber behaupten, dass die Reihung vor allem etwas mit der Verteilung der Aufgaben des Amts auf die verschiedenen Personen zum jeweiligen Zeitpunkt zu tun hat. Anciennität, das Prinzip, nach dem die Namen der „einfachen" Ratmannen geordnet wurden, scheint hier in der Regel keine Rolle gespielt zu haben. S. aber noch unten Anm. 580 am Ende.

${ }^{578}$ Alle wörtlichen Zitate aus MANTELS, Schiffshauptleute (wie Anm. 11), S. 196.

${ }^{579}$ HR I, I, Nr. 361, hier S. 312. LUTTERBECK S. 332, der in dieser Frage die ältere Literatur zu korrigieren hatte (FEHLING S. 38: „1363 zum Bürgermeister gewählt“), hat diese Stelle übersehen und gibt daher „1366“ als Jahr des ersten Bürgermeisterbelegs an. Ihm folgen KOPPE u. KOPPE, Frankfurt-Händler (wie Anm. 79), S. 128 mit Anm. 481; übrigens enthält das Buch ausführliche Angaben über die persönlichen und wirtschaftlichen Verhältnisse des aus Braunschweig stammenden Johan Pertzeval. Angesichts überbordender „Pleskowmanie“ (s. oben Anm. 278) verdient es ausdrücklich erwähnt zu werden, dass Johan Pertzeval, der ebenso wie Jacob Pleskow 1352 in den Lübecker Rat gekommen ist, weder zu Herrn Jacob noch zu irgendeinem anderen Lübecker Pleskow verwandtschaftliche oder geschäftliche Verbindungen gehabt zu haben scheint; bei WIEGANDT, Plescows (wie Anm. 182) kommt Johan Pertzeval nach Ausweis des Personenregisters nicht ein einziges Mal vor.

${ }^{580}$ Der Sachverhalt ist bei LUTTERBECK S. 55 erwähnt; statt , 1366" ist dort jetzt ,.1365/66“" zu lesen. Ebd. sind nur zwei weitere Fälle aus dem 14. Jh. nachgewiesen, in denen es gleichzeitig mehr als vier (nämlich fünf) Bürgermeister gegeben hat, zu 1328 (UB. Stadt Lüb. 2. Nr. 495, hier S. 445) und zu 1373 (hierzu Näheres unten Anm. 582). Tatsächlich hat es noch ein weiteres Mal. nämlich von 1393 bis 1396. fünf gleichzeitig amtierende Bürgermeister gegeben, als zu Johan Pertzeval, Gerard van Attendorn, Thomas Murkerke und Hinrik Westhof noch Johan Nyebur hinzugetreten war. Alle fünf sind zusammen aufgeführt HR I, 4, Nr. 156, hier S. 127, und Nr. 192, hier S. 166. Dieser jüngste Fall ist auch bei BRUNS, Rat (wie Anm. 432), S. 33 (dem LUTTERBECK a.a.O. folgt) nicht erwähnt. An beiden zitierten Stellen scheinen übrigens die ersten beiden Namen (die der worthaltenden Bürger- 
haben die beiden alten Bürgermeister Herman Gallin und Tideman Warendorp - man ist fast versucht zu sagen, endlich - das Zeitliche gesegnet, Gallin irgendwann nach dem 6. Januar, ${ }^{581}$ Warendorp am 23. Mai; damit waren hier die „,normalen Verhältnisse“ wiederhergestellt. ${ }^{582}$ Herr Johan Pertzeval hat bald nach seiner Erhebung zum Bürgermeister die Reisetätigkeit eingestellt; ${ }^{583}$ er bildete seitdem gewissermaßen das ortsfeste Element in der hansischen Politik des Lübecker Rats. ${ }^{584}$ Als seinen reisenden „Ersatzmann" darf man wohl Herrn Simon Swerting, im Rat 1363-1388, ${ }^{585}$ ansehen. Er ist als Ratssendebote erstmals am 18. Juni 1364 und erneut am 27. März 1365 belegt, beide Male zusammen mit Herrn Johan Pertzeval in Stralsund. ${ }^{586}$ Herr Simon ist dann auch, vermutlich erst Anfang 1371,

meister ?) und die letzten drei in sich nach Anciennität im Bürgermeisteramt geordnet zu sein.

${ }^{581}$ Siehe oben mit Anm. 285.

$5 \times 2$ Weshalb der Lübecker Rat dann einige Jahre später noch einmal einen fünften Bürgermeister gewählt hat (vgl. LUTTERBECK S. 55), nämlich spätestens im Frühjahr 1373 den Ratmann Hartman Pepersack (erster Beleg: Rezess des Lübecker Hansetags vom I. Mai. HR I, 2, Nr. 53, hier S. 65. aufgeführt zwischen Jacob Pleskow und Bertram Vorrad. 2. Beleg UB. Stadt Lüb. 4. Nr. 198. 1373 Mai 21, hier S. 197), der 1369-1385 im Rat gesessen hat (LUTTERBECK Nr. 179. S. 329-331), ist nicht nach dem Muster der Jahre 1363-1366 zu erklären (vgl. auch noch unten mit Anm. 594). Denn Herr Hartman hat in der Hansepolitik des Rats anscheinend nie eine größere Rolle gespielt. Er hat keinen einzigen auswärtigen Hansetag besucht, und selbst auf den Lübecker Hansetagen kann er erst seit dem Herbst 1378 als „Ersatz" für den alten Bertram Vorrad gelten, der im Sommer 1379 gestorben ist. Dieser hat dann allerdings keinen ..Nachfolger" bekommen; erst 1382. nach Jacob Pleskows Tod. wurde erneut jemand (Gerard van Attendorn) zum Bürgermeister erhoben. An erster Stelle im Verzeichnis der Lübecker Vertreter auf einem Hansetag in Lübeck erscheint Herr Hartmann erstmals im Sommer 1382: HR 1, 2, Nr. 248, hier S. 298. Dass dieser Bürgermeister nicht zu seinem Satz passt, die ..Bürgermeister Lübecks seit der Mitte des 14. Jh.s“ seien „vor der Wahl zum Bürgermeister als Sendbote in hanseaticis tätig" gewesen. hat auch POECK, Ratssendboten (wie Anm. 225) wenigstens anmerkungsweise (S. 131, Anm. 102) eingeräumt. Hartman Pepersack als Ratmann und Bürgermeister ist auch von KOPPE u. KOPPE. Frankfurt-Händler (wie Anm. 79) besprochen worden. Mag man es allenfalls noch für vertretbar halten, dass (S. 162) seine Aufnahme in den Rat auf die "Wertschätzung“ zurückgeführt wird. die sein älterer Bruder Bernard Pepersack, im Rat 1358-1366 (LUTTERBECK Nr. 178, S. 329) dort genossen hat, so kann man das Argument nicht mehr ernstnehmen, wenn es auch die Erhebung zum Bürgermeister erklären soll. Auch Herrn Hartmans eingehendere Behandlung an anderer Stelle (S. 248-252) bringt dazu nichts Plausibles. Ich kann mir nur vorstellen, dass er zu Beginn der 1370er Jahre als besonders tüchtiger Vertreter eines Qualifikationsbereichs (oder cines wichtigen Interessentenkreises?) gegolten hat, der unter den bisherigen Bürgermeistern schlecht repräsentiert war.

${ }^{583}$ Auf einem auswärtigen Hansetag ist er zulet $/ t$ am 5. Oktober 1365 in Rostock belegt: HR 1, 1, Nr. 374, hier S. 324.

${ }^{58+}$ Die auffällige Veränderung seines Verhaltens ist bereits den Daten zu entnehmen, die LUTTERBECK S. $331 \mathrm{f}$. zusammengestellt hat.

${ }^{585}$ LUTTERBECK Nr. 240 (S. 385-388).

${ }^{586}$ HR I, 1, Nr. 326 (S. 285) und Nr. 356 (S. 307). Für weitere Belege reicht der Hinweis auf LUTTERBECK S. 386. 
Bürgermeister geworden, ${ }^{587}$ nachdem der drei Jahre nach ihm, vielleicht schon wegen seiner militärischen Qualitäten, in den Rat aufgenommene und am 22. Februar 1368 zum Bürgermeister ,beförderte“ Brun Warendorp, Herrn Gottschalks Sohn, bereits am 21. August 1369 in Schonen gestorben war. ${ }^{588}$ Wir kennen Herrn Brun schon als einen engen Vertrauten von Herrn Johan Wittenborchs Witwe. ${ }^{589}$ Als Ratssendeboten trifft man ihn erstmals am 16. Dezember 1366 in Rostock an ${ }^{590}$ Danach kommt er aber mehr als ein Jahr lang nie als Lübecker Teilnehmer an einem Hansetag vor, auch nicht auf dem Lübecker vom 2. Februar $1368 ; ;^{591}$ auch ihn darf man wohl nicht als den typischen „Nachwuchs“-Hansepolitiker werten. Doch treffen wir ihn dann wenig später, am 27. Februar 1368 in Grevesmühlen und am 15. März in Rostock, als offenbar „frischgebackenen“ Bürgermeister an, verzeichnet gleich hinter Herrn Jacob Pleskow und vor ,einfachen" Ratmannen, die früher als er in den Rat gekommen waren. ${ }^{592}$ Herrn Bruns „Beförderung“ erfolgte gerade rechtzeitig, bevor am 15. März seine Ernennung zum ersten der drei Lübecker Hauptleute für den Krieg gegen Dänemark bekannt gemacht wurde. ${ }^{593}$ Dabei war die Bürgermeisterposition bereits am 29. Januar 1367 durch den Tod des alten, aber wenigstens bei Hansetagen in Lübeck immer noch tätigen Herrn Herman van Wickede frei geworden. Man sieht, seit es zwei jüngere, sehr

\footnotetext{
${ }^{587}$ Nach FEHLING S. 40 „1370 zum Bürgermeister gewählt"; nach LUTTERBECK S. 386 mit Anm. 3035 „bereits 1369“ Bürgermeister, unter Berufung auf eine Urkunde vom 28. September eines nicht genannten Jahres (UB. Stadt Lüb. 3, Nr. 734, = HR I, 3, Nr. 306), deren Datierung ganz ungewiss ist (der jüngste Druck, in Dipl. Dan. 3, 8, Nr. 487, S. 550f., nennt "|1370-81]" nach den Amts- und Lebensdaten der beiden hier genannten Bürgermeister, die natürlich von FEHLING bezogen wurden). Sicherer Terminus post quem ist jedenfalls der 21 . Oktober 1369, denn im Rezess des damaligen Stralsunder Hansetags steht Herrn Simons Name noch hinter dem des ,ewigen“ „einfachen“ Ratmanns Segebode Crispin: HR 1, I. Nr. 510, hier S. 467. Am 11. Juni 1370 wird Herr Simon als erster der beiden Richteherren erwähnt (UB. Stadt Lüb. 3, Nr. 721, S. 793). Da dies sicherlich kein Nebenamt für einen Bürgermeister war (nur LUTTERBECK S. 58 hält so etwas ohne weiteres für möglich) und kein Grund zu erkennen ist, weshalb Herr Simon das Amt vor Schluss des Amtsjahrs am 22. Februar 1371 hätte abgeben sollen, so liegt die Vermutung nahe, dass er an diesem Tage bei der Ratsumsetzung Bürgermeister geworden ist. Gut zwei Monate später war er es jedenfalls; im Rezess des Lübecker Hansetags vom 1. Mai 1371 erscheint er unter den vier Bürgermeistern als zweiter: HR I, 2, Nr. 9, hier S. 18.

${ }^{588} \mathrm{Er}$ ist ausführlich. auch in Abgrenzung gegen seinen Namensvetter, Herrn Brun, Wilhelms Sohn, bchandelt worden von MANTELS, Schiffshauptleute (wie Anm. 11), S. 194-207.

LUTTERBECK Nr. 277 (S. $414 \mathrm{f}$.)

${ }^{589}$ Siehe oben mit Anm. 414-416.

${ }^{590}$ HR 1, 1, Nr. 388, hier S. 346.

${ }^{591}$ Ebd. Nr. 427, hier S. 386.

${ }^{592}$ Ebd. Nr. 436, hier S. 394, und Nr. 440A, hier S. 398. LuTterbeck S. 414 mil Anm. 3332 nennt als ersten (?) Beleg für Herrn Bruns Bürgermeisterstatus eine Urkunde, die erst am 12. November 1368 ausgestellt worden ist.

${ }^{593}$ HR I, I. Nr. 440A, \$3 (S. 398).
} 
belastbare Bürgermeister neben dem anscheinend immer noch unermüdlichen Herrn Bertram Vorrad gab, hat sich der Lübecker Rat mit der Besetzung der 4. Stelle durchaus Zeit gelassen. ${ }^{594}$ Die anderen beiden Lübecker Hauptleute waren Johan Schepenstede, im Rat 1350-1388, der auf dem Rostocker Tag vom 15. März 1368 auch zum ersten Mal als Lübecker Vertreter auf einem Hansetag erscheint, ${ }^{595}$ und Gerard van Attendorn, der, erst im Vorjahr in den Rat aufgenommen, ihm bis zu seinem Tode im Jahre 1396 angehört hat, seit 1382 als Bürgermeister. ${ }^{596}$ Bei Herrn Gerd wird besonders schnell deutlich, wie eng damals Kriegsplanung und militärisches Kommando zusammengehangen haben. Denn er hatte Jacob Pleskow bereits auf den Rostocker Tag vom 6. Oktober 1367 begleitet, auf dem nicht nur die abschließenden Verhandlungen mit den niederländischen und preußischen Städten in Köln, sondern auch schon der Krieg gegen Dänemark vorbereitet worden sind, ${ }^{597}$ und dieselben beiden Herren hatten Lübeck dann bei den Verhandlungen in Köln vertreten, deren Hauptergebnis die „Kölner Konföderation“ vom 19. November 1367 gewesen ist. ${ }^{598}$

Gewiss ist die Karriere des Herrn Jacob Pleskow bemerkenswert schnell verlaufen. Wer aus der Stellung eines „einfachen“ Ratmanns, der zu Herrn Johan Wittenborchs Zeiten vielleicht nicht in den kleinen Kreis derer einbezogen war, von denen die Lübecker Hansepolitik der Zeit ausgeführt und doch wohl auch formuliert wurde, zu einem der wichtigsten Ratsmitglieder in diesem Bereich und zum Bürgermeister in weniger als zwei Jahren emporstieg, der hatte schon einen großen Schritt zurückgelegt. Aber der wurde getan im Zusammenwirken mit den, wie gesagt, wenigen Ratsmitgliedern, die hier bereits vor 1362/63 tätig gewesen waren. Und die hauptsächliche Voraussetzung für diese Karriere, der die des Herrn Johan Pertzeval mit geringer Verzögerung gefolgt ist, war doch, dass schon zu Johan Wittenborchs Zeit zwei Bürgermeister in diesem Bereich überhaupt nicht tätig gewesen sind, während der dritte, der nach Herrn Johans Ausscheiden übrig blieb, nicht mehr reisen konnte oder mochte, und der, durch den die vierte Stelle wieder gefüllt wurde, ebenfalls ein

\footnotetext{
${ }^{594}$ Damit wird es noch rätselhafter, wieso 1373 der anscheinend vorher kaum hervorgetretene Hartman Pepersack zum überzähligen Bürgermeister gewählt worden ist, siehe oben Anm. 582.

${ }^{595}$ LUTTERBECK Nr. 204 (S. 360-363).

${ }^{596}$ LUTTERBECK Nr. 12 (S. 192f.).

${ }^{597}$ HR I, I, Nr. 411 (S. 370-372).

${ }^{598}$ Ebd. Nr. 413 (S. 373-376). Neuester Druck, in dem die von Koppmann als „Abschrift“ bezeichnete Lübecker Handschrift L im Anschluss an HøJBERG CHRISTENSEN, Kancellisprog (wie Anm. 470), S. 62, als Ausfertigung (Zerter) charakterisiert ist: Dipl. Dan. III, 8, Nr. 92 (S. 93-101).
} 
alter Herr war. Allenfalls drei Ratmannen, die ohne das Auftreten von Jacob Pleskow und Johan Pertzeval vielleicht eine größere Rolle gespielt und die Chance gehabt hätten, Bürgermeister zu werden, mögen sich verdrängt und durch weniger Erfahrene überholt gefühlt haben: Herr Johan Pleskow, Herr Bernard Oldenborch und Herr Segebode Crispin. Sie sind aber immerhin nicht aus dem Betätigungsfeld hinausgedrängt, sondern nur von der Spitze weggedrängt worden. Übrigens sind die beiden Erstgenannten schon 1367 gestorben. Herr Segebode hat zwar zwischen Juni 1363 und Juni 1366 nur an den Lübecker Hansetagen teilgenommen, wurde aber seit Dezember 1366 oft auch (wieder?) zu auswärtigen Versammlungen herangezogen. ${ }^{599}$ Er allein könnte sich um 1370 erneut übergangen gefühlt haben. Alles in allem genommen kann man sagen: Personell hat in Lübeck zwischen 1360-1362 und 1367/68, von der Ausschaltung der einen Person Johan Wittenborch abgesehen, ebenso Kontinuität geherrscht wie inhaltlich, wenn es um die Grundlinien der Politik gegenüber dem König von Dänemark ging. ${ }^{600}$ Dass es hier allenfalls Differenzen über Fragen der Taktik geben konnte, dafür hat ja offenbar schon König Waldemar gesorgt. Man urteilt in diesem Punkt wohl nicht (nur) „ex eventu“, wenn man zwischen 1362/63 und 1367/68 beim Lübecker Rat die feste Entschlossenheit erkennt, sich nicht noch einmal auf einen Krieg gegen Dänemark in einer zu schmalen Koalition und mit unzuverlässigen fürstlichen Bundesgenossen einzulassen, aber sogleich zuzugreifen, sobald sich eine solide Chance für erfolgreiche Kriegführung bot.

\section{Register der Personen- und Ortsnamen}

Zahlen ohne Zusatz bezeichnen die Druckseiten. Wenn ein Name sowohl im Text wie in einer dazugehörigen Anmerkung vorkommt, wird nur die Druckseite ausgeworfen. Wenn ein Name lediglich in einer Anmerkung erscheint, wird nur diese, mit vorangestelltem „A.“, genannt. Personen, für die kein Orts- oder Ländername angegeben ist, sind sicher oder sehr wahrscheinlich Lübecker. „NN“ steht für. unbekannte Taufnamen. Ratmannen und Bürgermeister sind als „Rm.“ und „Bm.“ bezeichnet. Bei Mitgliedern des Lübecker Rats sind die Amtsjahre angegeben, bei Bürgermeistern mit dem genauen Datum ihrer ersten Erwähnung, wenn es hier ergänzt oder neu festgestellt worden ist. Als Ortsnamen sind auch von Ortsnamen abgeleitete Adjektive gewertet.

\footnotetext{
${ }^{599}$ Siehe die Übersicht bei LUTTERBECK S. 248.

${ }^{600}$ Zur Geschichte der städtischen Dänemark-Politik 1361-1370 nach Dietrich SCHÄFER, Hansestädte (wie Anm. 9) an ausführlichsten GöTZE, Greifswald (wie Anm. 9).
} 
Nicht berücksichtigt sind „Wittenborch, Johan“, Namen von wissenschaftlichen Autoren des 19. bis 21. Jahrhunderts, Namen in Buch- und Aufsatztiteln, „Lübeck“ und die Orte von hansischen Versammlungen.

A

A, Everhard van der 28, A. 124.

Aachen 38, 80.

Abele, Magd d. Rm. Johan Meteler 83.

Albertus, Schreiber u. Krämer 77.

Allen, Gerard van A. 289.

Anklam A. 42, 44f., A. 210.

Antoninus, Hl., Dominikaner, A. 309, A. 421.

Atendorn, Gerard van, Rm. 1367-1396, Bm. 1382 52, A. 580, A. 582, 134.

Avignon (vgl. „Rom“) A. 576.

B

Bayern 21, A. 77.

Bardewich, Albrecht van, Rm. 1291-1310 A. 182, 44. A. 357; „Albert“ (lies „Arnold“) A. 201; Arnold, Rm. 1327-1350 A. 56, 36, 43f., 46. 79; Arnold, sein Sohn A. 56, 43-47, 79, 91; Elisabeth, Tochter des Rm. Arnold, s. Wittenborch, Elisabeth; Gertrud, Schwester des Rm. Arnold, verheiratet mit Bm. Hinrik Pleskow A. 182, 79; Heleke, Schwester d. Rm. Arnold, s. Keysers, Heleke; NN, Ehefrau d. Rm. Arnold, Schwester (?) d. Bm. Herman Warendorp senior 46f.

[Bardewich ?], Agnete, nahe Verwandte der Kinder d. Rm. Arnold Bardewich 44.

Basel A. 448.

Behn, Heinrich Theodor, Senator 1858-1901, wiederholt Bm. A. 543.

Bischop der Kölner, 1357 Weinlieferant A. 250.

Blomenrot, Herman, Rm. 1336-1359 75-77, 82f., A. 372; Johan u. Tideke, seine Söhne 76; Telse, Tochter d. Rm. Herman, s. Telse Vorrad.

Bohus, Burg A. 515.

Bocwolde, Sifrid van, Knappe A. 272.

Borgholm, Burg auf Öland 115, $129 \mathrm{f}$.

Brant, Sebastian, Humanist 66.

Braunschweig A. 377, A. 579.

Bremen 6, 9, 21, A. 277, A. 526.

Brügge A. 278, A. 310, 86, 88, A. 448, 112.

Bücken, Stift A. 482.

Buc, Arnolt 78.

Bulowe (Bülow), Herr Johan [Ritter] A. 117. 
Bu(z)st, Willeke A. 289, A. 386.

Bützow, Stift $112 \mathrm{f}$.

$\mathrm{C}$ : siehe $\mathrm{K}, \mathrm{C}$

D

Dänemark (s. auch Waldemar Atterdag, König von D.) 8f., $57 \mathrm{f}$., A. $275 \mathrm{f}$., $62,101,117,126$, A. 570, 131, $134 \mathrm{f}$.

Dannenberg, Schloss 52.

Detlef, witte, Ausreiter A. 241.

Detmar, Franziskaner, Chronist 10, A. 36, 51, A. 233, A. 269, A. 436, 98 f.

Dömitz, Schloss 51-53, 55.

Drugehorn, Lubert A. 316.

Dulmen, Herman van, Rm. 1350 A. 176, 76; Rodolf van u. seine Kinder 27; Margareta, Witwe des Rodolf, s. Margareta Grope.

Dunker. Tiderik, Herman Dunkers Sohn, Knappe 54.

Durand von St. Pourçain, Theologe A. 421.

E

England 37f., A. 328.

Erich, Herzog von Sachsen-Lauenburg, „I.“ A. 264, A. 459; „II.“ 51, 54. 57-60, 126; ,IV.“ A. 275.

F, V

Falk, Bo, zu Vallø, dänischer Adliger, Chronist ? A. 15.

Veckinchusen, Hildebrand 120.

Fischbek, Stift A. 377.

Flandern 19-21, A. 127, 35-38, 50, 86, 88, A. 538, A. 550.

Vlanderen, Hinrik van, Wisbyer Rm. 128.

Florenz 73, A. 328.

Volme(n)ste(y)n. Hinrik, Socius d. Herman Wittenborch u. seiner Witwe A. 136.

Vorrad, Bertram, Rm. 1332-1379, Bm. 1363 April 29 50, 54, 58f., 63, 76, 82, A. 459, 105-107, 126-131, A. 582, 134; Telse, seine Frau, geb. Blomenrot 82; Tideman, Rm. 1384-1385 82f.

Vorste, Herman, Rm. 1384-1406 A. 366.

Frankfurt/M. A. 79.

Frankreich 37.

Freiburg/Br. 21.

Vrese, Godeke, verheiratet mit Alheid Wittenborch A. 105.

Vundengudes, Elisabeth, Schwester von Herman Warendorp A. 209. 
G

Gallin, Herman, Rm. 1351-1366 nach Jan. 6, Bm. 1360 April 9 A. 272, 62f., A. 552, 127, 132.

Geldersen, Frederik (Vicke) van, Hamburger Rm. 18 f., $78 \mathrm{f}$. Gildehusen, Albert, Stralsunder Rm. u. Bm. 110f., A. 501.

Golnowe, Martin van, Schweriner Domherr, Ratsnotar 106f.

Grabowe, Nicolaus A. 127.

Greifswald A. 60.

Grope, Alvin (Alf ?), Rm. 1301-1325 24-29, 32-34, A. 459; Alvin, sein Sohn A. 88, 25-28, 33 f.; „Alwin“, angeblicher Vater der Margarete Grope-Wittenborch A. 85; ,Alwin u. Nicolaus“, angeblich ihre Brüder 34; Goswin, Dominikaner A. 88, 33; Hille, Frau (Witwe) d. Rm. Alvin, u. ihre Kinder 27, A. 127; Hinrik, Sohn d. Rm. Alvin A. 88, 27; Hinrik, Bruder d. Margarete Grope-Wittenborch A. 88, 27f., 33, A. 135; Margareta, 1332 Frau, 1333 Witwe d. Alvin (junior) 27: Margareta s. Wittenborch, Margareta, Mutter d. Bm. Johan Wittenborch; Tideman A. 90; Werner, Rm. 1275 25, 28; NN, Töchter d. Rm. Alvin. Nonnen 29, 32f., A. 317, A. 324; NN, Frau d. Rm. Werner A. 127; NN, Tochter d. Rm. Werner, A. 89, 28; NN, Schwester d. Margareta Grope-Wittenborch 33. Groß-Saarau, Dorf 90.

$\mathrm{H}$

Håkon, König von Norwegen 8, 60f., 115, A. 515.

Hamburg 18, A. 219, 60, 72f., 78f., A. 377, A. 429, 114, 121, A. 540, 125, 129.

Heinrich, Graf von Holstein $7 \mathrm{f}$.

Helsingborg, Burg am Öresund 8, 14.

Hemeling, Johan d. J., Bremer Rm., Bm. u. Chronist, s. Rinesberch.

Hereke, Peter van Rm. 138732.

Hertze, Johan, Rm. 1484-1510, Bm. 1498 A. 323.

Hildesheim A. 448.

Hoykendorp, Kopeke A. 84.

Holstein 7, A. 435, 114.

Holt, Johan A. 84.

Hvitfeldt, Arild, dänischer Adliger, Geschichtsschreiber A. 25.

I, Y, J

Italien 72.

Jena 121.

Jütland 8 . 
$\mathrm{K}, \mathrm{C}$

Kampen (Niederlande) 5.

Canterbury A. 310.

Karl IV., Kaiser 52.

Keyser(s), verschiedene A. 357.

Keysers, Heleke, Schwester d. Rm. Arnold Bardewich A. $357 \mathrm{f}$.

Kerkhove, Gozwin vamme A. 172.

Kiel 5, 14, 20, A. 454, 106.

Klensowe, Herman 77.

Clingenberch, Johan (Henneke), Sohn d. Rm. Wedeke A. 127; Wedeke, Rm. 1344-1350, u. seine Kinder A. 127, 37; Wedeke, ,avunkulus“ d. Margarete Grope-Wittenborch, wahrscheinlich identisch mit dem Rm. Wedeke A. 127.

Knop, Lubbrecht 88.

Köln A. 250, 134.

Kolberg A. 64.

Korner, Herman, Dominikaner, Chronist 4-6, 10-12.

Cosfelde. Bernard van, Rm. 1351-1367, u. seine Witwe A. 366.

Cremon, Bertram. Bischof von Lübeck 82, 107; Herr Herman [Priester ?] A. 164.

Crispin, Alheid, Schwester d. Rm. Segebode, s. Alheid Warendorp, Frau d. Rm. Wedeke; Segebode, Rm. 1349-1388 A. 281, 90f., 126, 129, 135. Christopher, Sohn von König Waldemar Atterdag A. 18.

L

Lange. Arnold A. 172.

Laurencii (Laurencius), Johan (Henneke) A. 289, 91.

Luchow, Hinrik, Ausreitervogt 54.

Lüchow, Schloss 52 .

Lüneburg A. 209.

Lurley, Alheid A. 316.

M

Magdeburg A. 377.

Magnus, König von Schweden 8, 60f., 115.

Mann. Thomas, Schriftsteller 123.

Mechow, Dorf 105.

Meltinger, Ulrich, Basler Kaufmann A. 448.

Meteler, Johan, Rm. 1358-1373 77. 83, 89.

Minden, Bischof von A. 310.

Mornewech, Herman. Rm. 1308-1338. Bm. 1314 A. 459. 
Mowe, NN, Ausreiter A. 241.

München A. 77, 123.

Muffel, Niklas, Nürnberger Patrizier A. 448.

Munster, Gise van A. 395.

Murkerke, Thomas, Rm.1365-1401, Bm. „1386“ (Fehling), 1387 Okt. 9 (HR I, 3, S. 371), „1389“ (Lutterbeck) A. 580.

Murmester, Hinrich, Hamburger Bm. A. 545.

$\mathrm{N}$

Nyebur, Johan, Rm. 1386-1399, Bm. 1393 A. 580.

Niederlande 37, A. 310.

Norwegen s. Håkon.

Nowgorod 128.

Nürnberg A. 448.

$\mathrm{O}$

Öland $115,129$.

Öresund 5, A. 37, 118.

Oldenborch. Bernard. Rm. 1352-1367 56, 61, A. 358, 126, 128-130, 135.

$P$

Paal, Bernard, Rm. 1349-1363 56, 77, A. 363, 81.

Paris A. 312.

Paternostermaker, Hinrik A. 435.

Pepersack, Bernard, Rm. 1358-1366 A. 582; Hartman, Rm. 1369-1385, Bm. 1373 Mai 1 A. 582, A. 594.

Pertzeval, Johan Rm. 1352-1399, Bm. 1365 Mai 28 54, A. 549, 127-132, $134 \mathrm{f}$.

Peruzzi, Florentiner Bankhaus A. 328.

Pleskow, verschiedene Ratmannen d. 2. Hälfte d. 14. Jh. A. 278, A. 579; Arnold, Rm. 1359-1363 A. 278, A. 356; Bernard, Rm. 1344-1367 A. 278; Gertrud, Frau d. Bm. Hinrik, s. Gertrud Bardewich; Hinrik der Alte, Rm. 1301-1340, Bm. 1324 A. 182, A. 186, A. 278, 79; Hinrik d. J., Rm. 1348-1358 Nov. 19, Bm. 1357 April 16 A. 278, A. 377; Jacob, Rm. 1352-1381, Bm. 1364 Mai 25 A. 262, A. 278, A. 287, A. 468, A. 474, 125-131, A. 582, 133-135; Johan, Rm. 1348-1367 A. 225, 61 , A. 365 , 126-129, A. 575, 135; Jordan, Rm. 1389-1425, Bm. 1401 A. 278.

Poperinge(n), Stadt in Flandern $86 \mathrm{f}$.

Premzslaw, Arnold, 2. Ehemann d. Margarete Grope-Wittenborch ? A. 138. 
Preußen 37.

$\mathbf{R}$

Rademyn, Gerard, Ratsnotar A. 470, 130.

Regensburg $21 \mathrm{f}$., 122.

Rinesberch, Gert, Bremer Kleriker, Chronist 6, 9.

Rint, Herman, lauenburgischer Knappe u. Vogt 54.

Rom (römisches Recht) A. 142, 70f.; (4. Laterankonzil) A. 310; (Kurie, vgl. Avignon) A. 429.

Rostock A. 43f., 14, 18f., 52, 115.

Runtinger, Kaufleute in Regensburg 22.

S, Z

Sachsen-Lauenburg s. Erich.

Sachtelevend, Dethard, Rm. 1356-1367 $129 \mathrm{f}$.

Zagense, Marquard van, in Vorpommern 1350 (wahrscheinlich identisch mit dem Folgenden) 45.

Sagentze, Marquard van, $1363 \mathrm{Rm}$. in Anklam, "swagerus" d. Bm. Johan Wittenborch A. 42, A. 64, $44 \mathrm{f}$.

Schene, Herbort, Bremer Kleriker, Chronist, s. Rinesberch.

Schepenstede, Johan, Rm. 1350-1388 A. 176, 134.

Schiphorst, Eghard, Ratsmarschall A. 272.

Schleswig, Herzogtum 114.

Schoneke, Nicolaus, Rm. 1328-1356/62, Bm. 1343 A. 552.

Schonen A. 154, A. 271.

Schonenberch, Hinrik, Rm. 1376-1384 109f.

Schulop, Detmar, Schweriner Domherr 108f.

Schweden (s. auch Magnus) A. 271, A. 434.

Schwerin, Bistum 107-109, 112; Grafschaft A. 84.

Sibeth, Dr. Johann Nikolaus, Senator 1783-1795 110.

Smale, Elisabeth, verheiratet mit Everhard van der A 28, A. 124; Everhard (= Everhard van der A ?) A. 124; Gertrud 28; Johan 28.

Sorø, dänisches Kloster A. 25.

Stade A. 306.

Steen, Tideman, Rm. 1408-1427, Bm. 1427 15, 115 f.

Stockem, Brant van 78.

Stortebeker, Johan, Danziger Schiffer A. 5.

„Störtebeker, Klaus“, Seeräuber (legendär) 4-6.

Stralsund 5, 14, A. 60, A. 377, 110f., A. 501.

Suderland, Frederik, Rostocker Rm. 115.

Swarte, Everhard, Rm. 1352-1367 56. 
Swerting, Simon, Rm. 1363-1388, Bm. 1371 Mai 1 52, $132 \mathrm{f}$.

T

Tolner, Rostocker Kaufmanns- und Ratsfamilie 18, A. 354.

Trier, Kirchenprovinz A. 303.

V: s. F, V

W

Waldemar Atterdag, König von Dänemark 4f., 7f., A. 26, A. 36, 58-62, 115, A. $515 \mathrm{f} ., 126,135$.

Warendorp allgemein A. 208, A. 210; aus Vorpommern (Anklam ?) A. 200, A. 208, 47f., A. 413; Alheid, Frau d. Rm. Wedeke A. 413; Brun, Rm. 1289-1341, Bm. 1314 A. 202; Brun (nicht identifizierbar) 37, 41; Brun, Sohn d. Rm. Gotschalk, Rm. 1366-1369, Bm. 1368 Febr. 27 A. 11, 48, A. 172, A. 289, 91, 133; Brun, Sohn d. Wilhelm, Rm. 1367-1408/11 A. 172, A. 456; Elisabeth, Schwester d. Bm. Herman senior, u. ihre Kinder 46; Elisabeth, Tochter d. Rm. Wedeke A. 209; Gotschalk A. 119; Herman senior, Rm. 1309-1333, Bm. 1322 46f., A. 212 (seine 4 Söhne); Herman, Sohn d. Bm. Herman senior, Bruder d. Rm. Wedeke 36, 45, 47-49; Herman minor, Rm. 1334-1350 A. 162; Herman van, Neubürger 1344 A. 200; Herman, Sohn d. Rm. Herman minor A. 209; Herman, 1362 Testamentsvollstrecker d. Bm. Johan Wittenborch A. 209; Herman, Bruder der Elisabeth Vundengudes A. 209; Lutbert, Bruder d. Bm. Herman senior, Neubürger 1331 47: Lutbert, verschiedene 47; Reinfried van A. 202; Tideman van, Neubürger 1337 (identisch mit dem Rm. Tideman ?) A. 206; Tideman, Rm. 1340-1366, Bm. 1356 45, 47, A. 219, 62f., 127, 132; Wedeke, Sohn d. Bm. Herman senior, Rm. 1343-1350 36, 43, 45-49, A. 413; NN, Schwester (?) d. Bm. Herman senior, s. Bardewich, NN, Frau d. Rm. Arnold Bardewich. Weger, Tiderik A. 59.

Wensin, Adelsfamilie A. 306.

Wesel A. 454.

Wes(se)ler, Johan, Rm. 1351-1367 53, A. 262; Marquard (s. auch Wittenborch) A. 164.

Westfalen A. 204, 115.

Westhof, Hinrik, Rm. 1372-1408/15, Bm. 1392 A. 456, A. 580.

Wickede, Herman van, Rm. 1327-1367, Bm. 1351 50, A. 225, 58f., 62f., A. 358, A. 459, 105-107, 110, 126, 128f., 133; Johan 77.

Wismar 14, 18, 52, 73, 107, $111 \mathrm{f} ., 114$.

Wittenborch, verschiedene A. 84; Alheid, errichtet 1331 Testament A. 84, 
A. 119, 71f.; Alheid (Taleke), Tochter d. Bm. Johan A. 105; Bertolt, kaufmännischer Mitarbeiter d. Bm. Johan A. 59, A. 84, A. 154, A. 156. A. 320; Elisabeth (Telse), Frau d. Bm. Johan (u. ihre Kinder) 36, 38, 46, 48f., 64, 79, 90f., 133; Greteke, Tochter d. Bm. Johan im Johanniskloster 85, A. 409; Herman, Vater d. Bm. Johan 16, 20, 23, A. 96, 29-32, 34f., 39, A. 316f., A. 324, 80, A. 411, A. 419, A. 474; Hinrik, Rm. u. Bm. 1253-1271 A. 81; Hinrik, Rm. u. Bm. 1301-1321 A. 81; Johan, Rm. 1350-1363, Bm. 1359 Mai 25 passim; Johan, Sohn d. Hinrik A. 136; Margarete, geb. Grope, Mutter d. Bm. Johan 17, 23-25, 27-37, 39 f., 43; Marquard van (s. auch Wesler) A. 316; Nicolaus, Domherr, $\uparrow 1489$ A. 35.

Wittenburg, Stadt A. 84.

Witzekendorp, Hinrik, Hamburger Rm. A. 219.

Woltvogel, Albrecht, Bruder d. Rm. Johan 86, A. 401, 89; Albrecht, Sohn d. Rm. Johan 88f.; Johan, Rm. 1338-1354 51, 55, 85-89, 104, 121, A. 538.

Wulflam, Bertram (u. seine 3 Söhne), Stralsunder Rm. u. Bm. 110f., A. 501 .

Wullenpunt, Albert (Albrecht) u. seine Frau A. 119, 73, 87; Henneke, verheiratet mit NN Grope, Tochter d. Rm. Werner A. 89, 28; Johan (identisch mit Henneke ?) 27.

\section{Z: s. S, Z}

\section{Stellenregister zu Mollwos „Handlungsbuch“-Edition}

Die ausgeworfenen Zahlen beziehen sich auf die Anmerkungen. Ein * hinter einer Anmerkungsnummer bedeutet, dass an dieser Stelle eine Ergänzung oder Berichtigung des Quellenwortlauts mitgeteilt oder vorgeschlagen wird.

Teil I, Nr. 1-87 (S. 1-11): „Handlungsbuch“ bis 1345:

1-43: 112. 2: 90*. 4: 84. 6: 112. 7: 136. 8: 136. 9: 114. 12: 114. 13: 119*, 324. 15: 113. 16: 116. 17: 84. 21: 114. 24: 116. 25: 113, 137. 26-28:

114. 28: 115. 29: 116. 30: 163. 31: 114. 32:116. 33: 116. 35: 112, 116. 37: 116. 41a: 164. 42: 117. 44: 105. 46: 125. 47: 127. 49: 127. 52: 136. 53: 125*, 138. 55-56: 136. 58: 121. 59: 136. 60: 124. 61: 136. 63: 136. 64: 164. 65: 136. 67: 136*. 68: 126, 127, 135.69: 126, 135. 72: 109.73: 110. 82-87: 143, 146. 82: 146. 83-87: 144. 84: 127, 149. 85: 149. 86-87: 171 .

Teil II, Nr. 1-351 (S. 12-65): „Handlungsbuch“ 1345-1359 (1360):

1-6: 320. 1-2: 148. 7-16: 167. 7-10: 321. 12: 329. 13: 322. 14-16: 329. 
17-20: 167. 50: 127, 154. 51: 127, 153, 154. 56-61: 154. 69: 251. 70: 294. 76: 389*. 77: 388. 78: 183. 79-82: 253. 84: 387. 85: 417. 89: 181 . 90: 185. $91: 105.100: 334$. 103: 336. 105-107: 538. 105: 251, 383, 419, 529. 106: 391, 419, 529, 538. 107: 386*, 529. 108: 392*, 529. 109: 385*, 529. 110: 154.111:241. 112: 396, 529. 113: 400, 529.114: 158*, 232. 115: 238. 116: 238, 239. 117: 181. 118-119: 156, 395. 119: 529. 121: 397. 125: 397*, 398. 126: 196. 127: 336. 128-129: 376*. 130: 241. 134: 156. 149: 399*. 152: 359. 156: 399*. 161: 250. 181: 57. 196: 350. 198: 402. 204: 349. 213: 355. 214: 250. 216: 347. 236: 538. 238: 185. 242: 127. 256: 363, 381, 409, 529. 262: 105. 290: 380, 409. 291: 378, 409. 336-338: 59. 349-351: 59.

„Federproben“, in der Handschrift über Teil I u. Teil II verstreut: 56, 253, 292-295, 395.

Teil IIa, Nr. 1-4 (S. 54): Im „Handlungsbuch“ überlieferter Zettel:

1: 194. 2: 193.

Lederumschlag des Buchs, Beschriftung:

MolLWO S. XXXIV, Anm. 1: 112. Handlungsbuch Teil IIb (S. 54): 295.

Teil III, Nr. 1-3 (S. 66 f.), Beilage „Briefe“:

2: 64. 3: 187.

Teil IV, Nr. 1-35 (S. 68-75), Beilage „Oberstadtbucheintragungen“:

8: 104*. 9: 108. 10: 110. 13-14: 148. 19: 105. 25: 410. 26: 39. 27: 39, 289.

Teil V, Nr. 1-84 (S. 76-86), Beilage „Auszüge aus dem Niederstadtbuch“" 13: 119. 27: 112. 34: 136. 36: 321. 38: 154. 55: 348. 60-71a: 59. 74: 127. 76: 209. 79: 127. 83: 289. 84: 412.

Teil VI, Nr. 1-8 (S. 87-93), Beilage "Testamente [und Litterae memoriales]":

3 (Testament des [Bm.] Johan Wittenborch von 1362): 107, 127 f., 129*, 198, 209, 361, 409, 418. 4: 195, 290, 416. 6-8: 257. 6: 404. 7: 59. 